Portland State University

PDXScholar

Fall 11-21-2014

\title{
Teachers Teaching Teachers: A Sustainable and Inexpensive Professional Development Program to Improve Instruction
}

Carol L. Campbell

Portland State University

Follow this and additional works at: https://pdxscholar.library.pdx.edu/open_access_etds

Part of the Educational Leadership Commons, and the Teacher Education and Professional Development Commons

Let us know how access to this document benefits you.

Recommended Citation

Campbell, Carol L., "Teachers Teaching Teachers: A Sustainable and Inexpensive Professional Development Program to Improve Instruction" (2014). Dissertations and Theses. Paper 2072. https://doi.org/10.15760/etd.2071

This Dissertation is brought to you for free and open access. It has been accepted for inclusion in Dissertations and Theses by an authorized administrator of PDXScholar. Please contact us if we can make this document more accessible: pdxscholar@pdx.edu. 
Teachers Teaching Teachers: A Sustainable and Inexpensive Professional Development Program to Improve Instruction

by

Carol L. Campbell

A dissertation submitted in partial fulfillment of the requirements for the degree of

\section{Doctor of Education}

in

Educational Leadership: Administration

Dissertation Committee:

Thomas Chenoweth, Chair

Dannelle Stevens

Deborah Peterson

Renjeng Su

Portland State University

2014 
(C) 2014 Carol L. Campbell 


\begin{abstract}
School districts face tremendous budget challenges and, as a result, professional development has been "trimmed" from many school budgets (Habegger \& Hodanbosi, 2011). School administrators responsible for planning professional development face a daunting task and often focus on PowerPoints, district mandated training, one-shot presentations, and workshops that are delivered by expensive experts. These types of activities lack teacher collaboration, time for sharing of ideas and opportunity for reflection and analysis (Torff \& Byrnes, 2011, Coggins, Zuckerman \& Mckelvey, 2010). The problem addressed in this study is that teacher professional development is usually planned by school administrators who are provided little support or training. This study used the problem-based learning approach designed by Bridges and Hallinger (1995) to determine the usefulness of a handbook for principals to use as they plan professional development. The handbook was developed, field tested and revised using Borg and Gall's (2003) research and development cycle. This qualitative study included surveys, observations, interviews and workshops to determine the usefulness of the handbook. The study consisted of preliminary field testing and product revision followed by the main field testing. The main field test was a workshop for K-12 school and district level administrators on how to use the handbook in planning meaningful, ongoing teacher professional development. The data collected in this study determined that the handbook, Teachers Teaching Teachers: Designing Successful Teacher Professional Development
\end{abstract}


on a Shoestring Budget, is a useful tool for school administrators responsible for planning teacher professional development. 


\section{Acknowledgements}

I would like to recognize all of the teachers, colleagues and students who have inspired me during the past 30 years. Thanks to my advisor, Dr. Tom Chenoweth, who stuck with me for the past 8 years, always positive and gently but firmly pushing me to finish. Thanks to my good friend and mentor, Linda Christensen, who is an amazing teacher and colleague. Thanks to my partner and best friend, Vicki Peterson. Without her support, love and motivational speeches, I would never have finished this project. 
Table of Contents

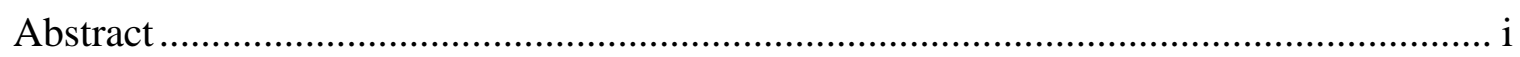

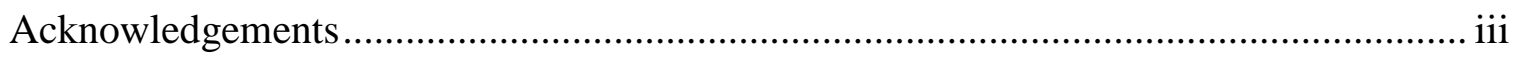

List of Tables .................................................................................................. vii

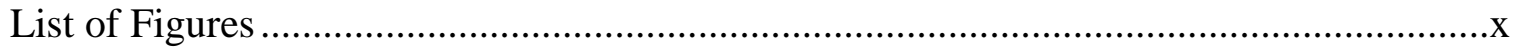

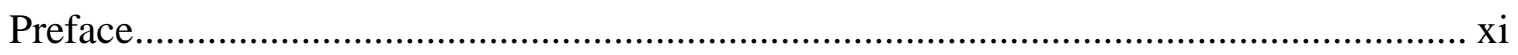

\section{CHAPTER}

I Problem Statement and Significance ...............................................................

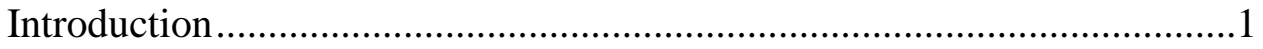

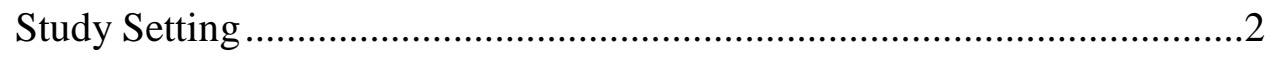

Statement of the Problem..................................................................4

Context: Demographics ............................................................

Purpose and Significance of the Study ..............................................

Research Methodology .............................................................. 10

Step 1: Research and Information Collecting ...............................12

Step 2: Planning Objectives, Learning Activities, and

Small-Scale Testing................................................................12

Step 3: Develop Preliminary Form of the Product ..........................12

Step 4: Preliminary Field Testing................................................12

Step 5: Main Product Revision.................................................13

Step 6: Main Field Testing .........................................................13

Step 7: Operational Product Revision ...........................................13

Steps 8, 9, and 10: Operational Field Testing, Final Product

Revision and Dissemination and Implementation......................13

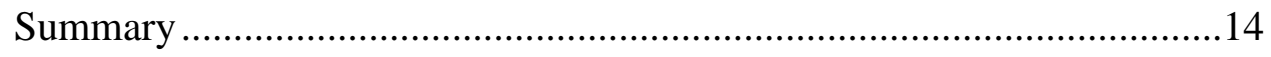

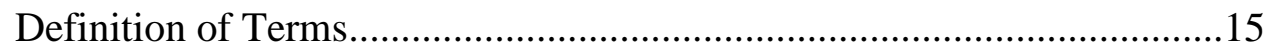




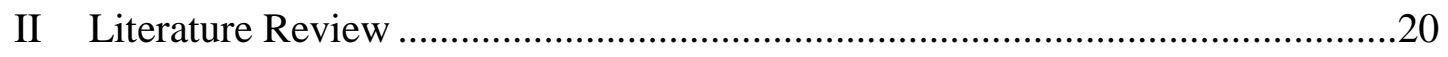

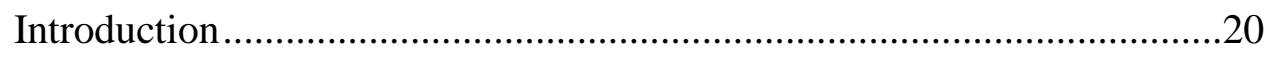

Leadership to Promote Collaboration ...................................................25

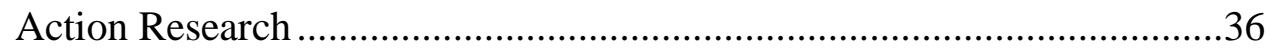

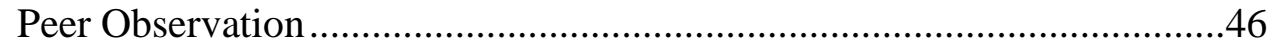

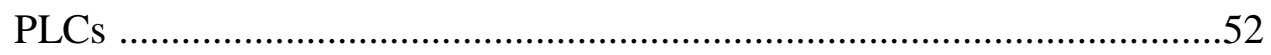

Preliminary Small-Scale Research and Testing ..................................57

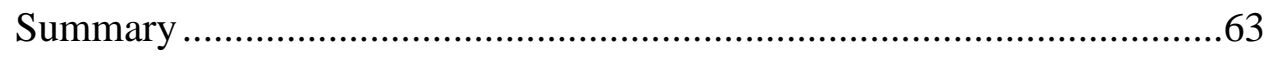

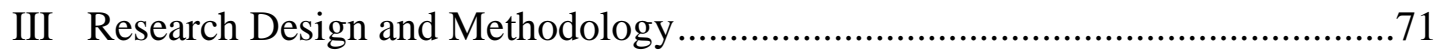

Introduction ............................................................................... 71

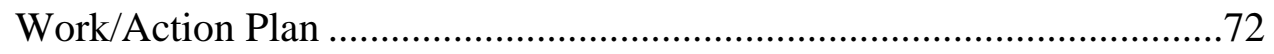

Restatement of the Problem ................................................................ 75

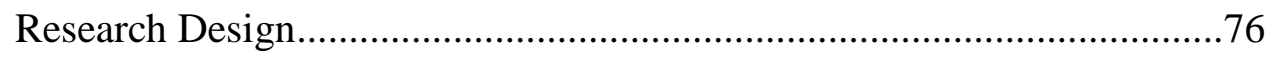

Research and Information Collecting.........................................77

Planning Objectives, Learning Activities, and Small-Scale

Testing .............................................................................. 78

Development of the Preliminary Form of the Project ......................84

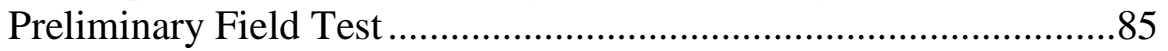

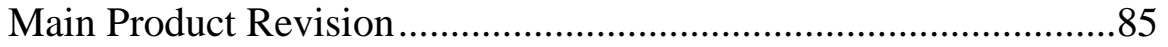

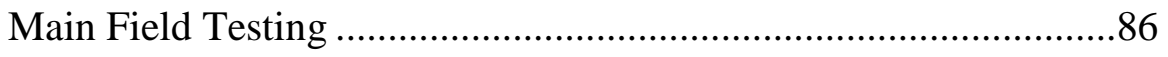

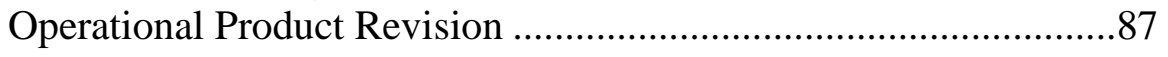

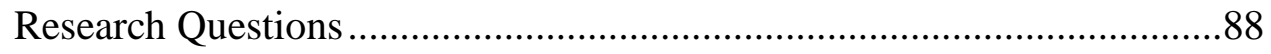

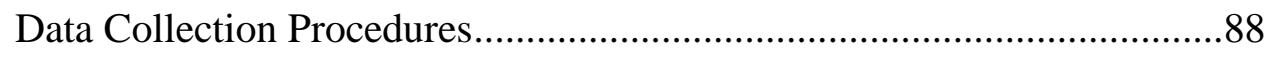

Data Analysis/Interpretation Strategies ............................................90

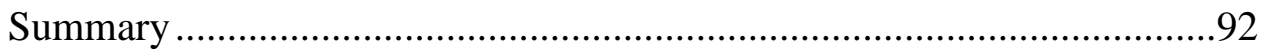




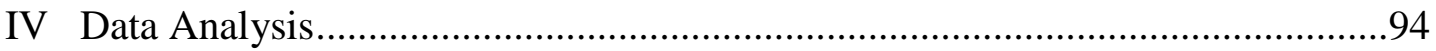

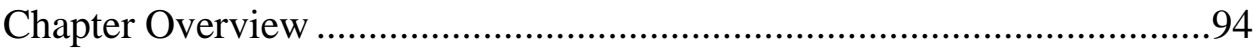

Review of Research Questions and Goals of the Study.............................95

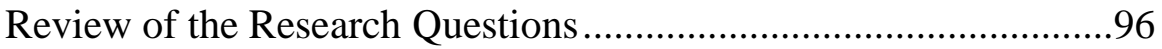

Review of Research Goals ...........................................................97

Development and Implementation (Field Testing) of the Problem

Based Learning Project ......................................................................97

Step 1: Research and Information Collecting ……………................97

Step 2: Planning Objectives, Learning Activities, and Small-Scale Testing .................................................................104

Step 3: Develop Preliminary Form of the Product ...........................106

Steps 4 and 5: Preliminary Field Testing and Main Product

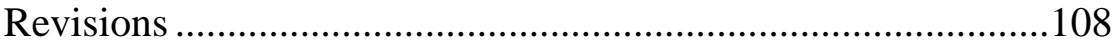

Step 6: Main Field Testing …………………………………......118

Step 7: Operational Product Revisions.............................................144

Field Testing Issues and Challenges ......................................................148

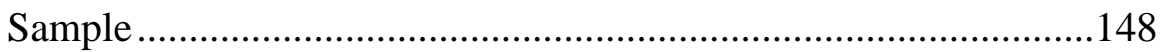

Post-Workshop Survey Results .....................................................148

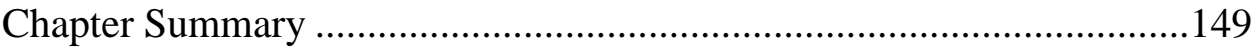

V Conclusions, Speculations, and Recommendations for Leadership ..................150

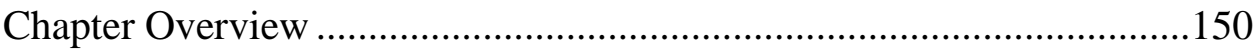

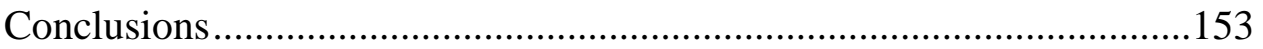

Preliminary Field Testing ................................................................153

Suggestions for Future Research, Development, and Use of the Project.

Recommendations for Leadership .........................................................163

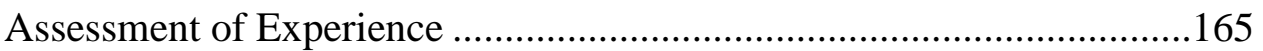




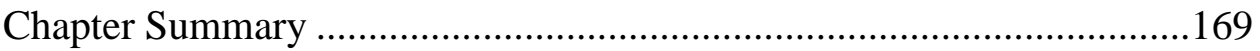

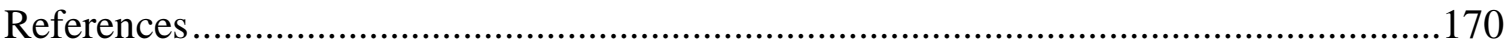

\section{Appendices}

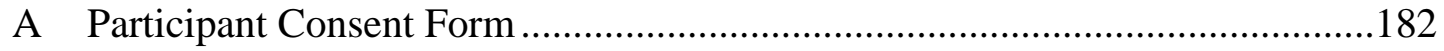

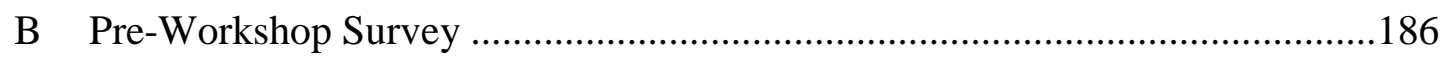

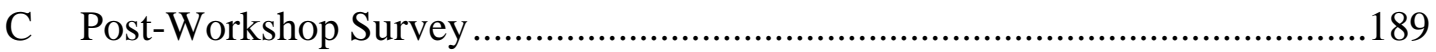

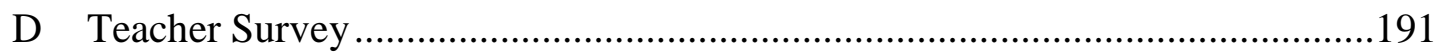

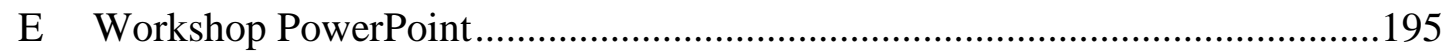

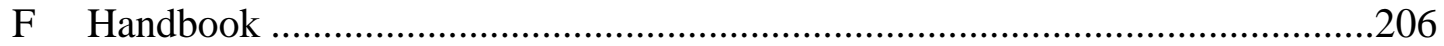


List of Tables

Table

1 Leadership Strategies to Create Active Followers ...... .28

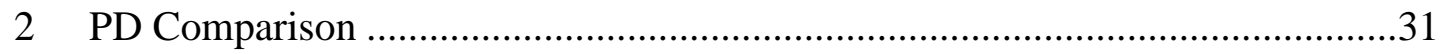

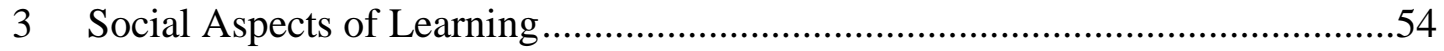

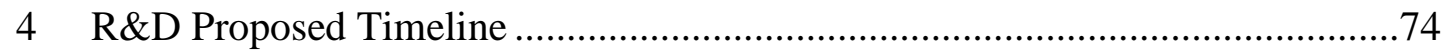

5 Workshop for School Administrators Utilizing the Handbook: Teachers Teaching Teachers: Designing Successful Professional Development on a Shoestring Budget.

6 Primary and Secondary Research Questions ..............................................8

7 Sections and Information Included in Preliminary Form of the Product ..........106

8 Demographics of Participants in Preliminary Field Testing Mini Workshop...109

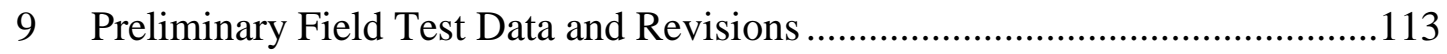

10 Administration Interview Responses Following PD Planning and Implementation Using the Handbook, Teachers Teaching Teachers:

Designing Successful Professional Development on a Shoestring Budget ...116

11 Main Field Test Activities and Data Collection Strategies

12 Workshop Agenda for School Administrators Using the Handbook, Teachers Teaching Teachers: Designing Successful Professional Development on a Shoestring Budget.

13 Demographics of Main Field Test Participants

14 Pre-Workshop Survey Summary of Responses.......

15 Handbook Scavenger Hunt Responses

16 Small Group Feedback on the Handbook

17 Post-Workshop Survey Data 137 


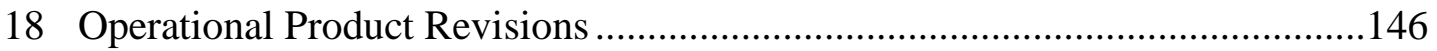

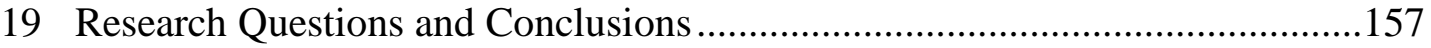

20 Teachers' Perceptions of the Impact PD Activities Have on Student

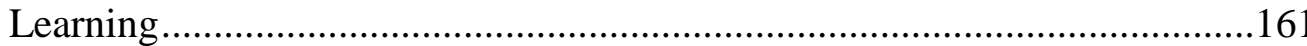


List of Figures

Figure $\quad$ Page

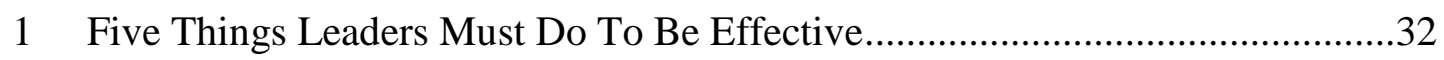

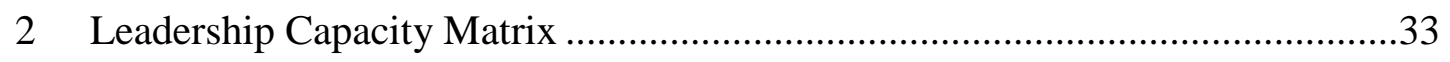

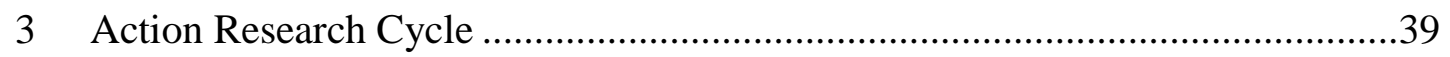

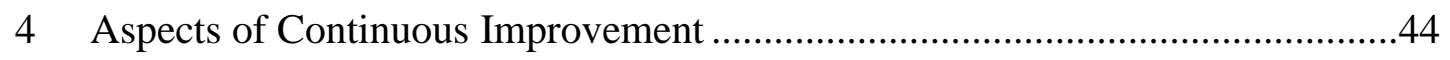

5 Relationship Between Professional Learning and Student Learning .................56

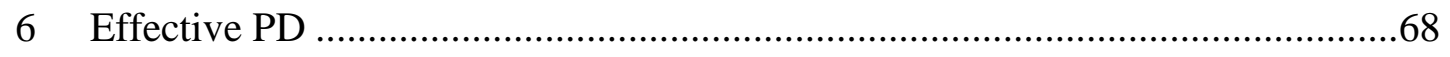

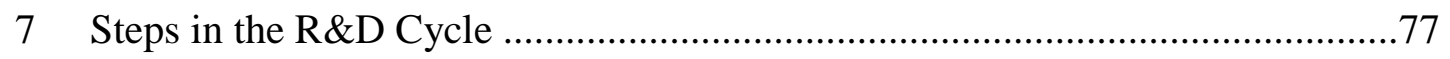

8 Activities That Have a Considerable to Large Impact on Student Learning.......81

9 Activities That Have Little or No Impact on Student Learning ........................82

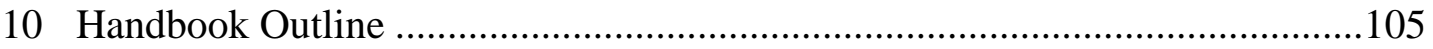


Preface

\section{One-Hit Wonder Professional Development: A Personal Reflection}

"See you tomorrow at the workshop," I said to my science teacher colleague as we walked out of the building.

"I won't be there tomorrow," he replied. "I made an appointment for my dog to get his nails trimmed and then I'm going to catch up on some grading. Besides, the professional development meetings are pointless. We spend the whole day talking about what we should be doing and then nothing changes."

"I heard they are bringing in an expert on differentiation and instructional strategies."

"Really!" he exclaimed sarcastically. "I have been teaching in this district for 15 years and the PD is always the same, "one-hit wonders," with no follow-up, socalled experts claiming they have the answers and initiatives that never get fully implemented. Besides, I don't have room for another binder."

"One-hit wonders, inoculations" and activities that do not include any follow-up summarize my own professional development experiences. In 25 years in the classroom, in two different schools, in two different states, the professional development opportunities offered to me were boring, disconnected from the realities of the classroom, lacked sustainability or resources and were very predictable. While I never missed the professional development days (mostly because I did like meeting with my colleagues) the staff absenteeism on those days seemed to be higher than a regular school day.

Most of the so-called expert presenters brought in from outside the district, provided demonstrations, lectures, books, binders and even research to support the claim that they had discovered the secret to student success. Most used the latest education jargon, newest fads in teaching and their workshops included expensive registration fees. These experts talked about their expertise, how their strategies would enhance student 
learning and always included an advertisement for additional materials or books that could be purchased in the lobby.

I attended one "professional development summit" with approximately 1,500 teachers in which the key note speaker arrived an hour late and left an hour early via helicopter. I wondered how much the transportation alone cost the budget-strapped districts that organized the workshop. None of these presenters were currently teaching and some had never been in a classroom. While a few of the professional development opportunities provided relevant effective teaching strategies, it was difficult to implement the strategies due to inadequate funding, insufficient time to plan and/or lack of follow-up by the experts who facilitated the presentations.

Another example of "one-hit” wonder professional development I experienced occurred during my third year as a high school principal. For three years, I worked with teachers and an instructional specialist to develop protocols for peer observation and action research as part of our professional development plan. With grant funds exhausted, the district asked for input on how to spend the district professional development budget. I applied for $\$ 8,000$ to host a curriculum camp for middle and high school teachers to collaborate on curriculum alignment and literacy strategies. I learned about the curriculum camp format through a local colleague and literacy expert. She hosted weeklong camps in the summer for teachers who wished to collaborate on unit plans connected to a common text. During the camp, teachers spent most of the time working together to create lessons and teaching strategies related to literacy (reading and writing). 
As a teacher, I participated in one of these camps and developed curriculum with a social studies teacher and an English teacher using the novel, Secret Life of Bees by Sue Monk Kidd. When I became a principal, I hired the literacy expert to host a curriculum camp for teachers which was well received by those who participated. I secured the same literacy specialist, as part of my professional development proposal, who had been doing work with teachers in my building and was very familiar with our district and the challenges we faced. She was also currently teaching in a high school with a high minority population and a significant percentage of at-risk students. Similar "camps" on a smaller scale had been held the previous two years and were highly successful. My request was denied and funds were allocated to bring in the author of a new book, with a catchy title. The fee for this expert for one half day of professional development was almost twice the cost of my proposed weeklong curriculum camp. There was no followup professional development and teacher collaboration days had to be cut that year due to budget limitations. This return to the status quo of teacher professional development was disappointing, as I had spent three years thinking outside the box and getting input from teachers to develop a relevant, sustainable format for professional learning.

During my first few years as a principal, I learned that it does not require a huge budget to offer professional development that teachers find meaningful and relevant to their teaching practice. Following is the story of my journey in pursuit of discovering how relevant, sustainable professional development can be implemented with little or no budget. 
In 2007, I was one of five principals hired as part of the restructuring of a suburban high school in the Pacific Northwest. The school received a \$3 million grant from the Bill and Melinda Gates Foundation as well as a local partnership with E3 (Employers for Educational Excellence), which also provided funding to support transforming the 1,600+ students and 100 staff members into five small schools. The high school was fortunate to also receive a $\$ 1.5$ million Federal Smaller Learning Communities Grant that began the year after the Gates grant was completed. The federal grant funds were spread over 4 years and financial distribution was based on selfreporting and outside evaluation of changes stipulated in the original grant application. The grants allowed us to make structural changes at the high school such as dividing the campus into small school areas which included some slight remodeling expense, paying stipends for teachers to participate on committees that worked on staff and student placement, hiring outside consultants to provide advice on the specifics of the reform and the purchase of equipment so that all schools had equitable access to technology. The grants also stipulated that a significant amount of money be spent on staff professional development. In this situation, the funds were available and time was allocated (several professional development days were built into the school calendar).

Based on my own mediocre professional development experiences, I wanted to design opportunities that teachers found useful and applicable to their classrooms, that addressed current problems of practice and that could be revisited and sustained without a huge monetary investment. I set out on a mission to learn how to design professional learning experiences that teachers would look forward to and that would be viewed as 
more important and more compelling than getting their dogs' nails trimmed. While there were funds available, I decided to use them sparingly and to design a plan that could be sustainable every year regardless of the funding availability.

As a new principal, I wanted to first build relationships with teachers (now, I believe building relationships is a necessity for any successful school leader, regardless of years of experience). We began the year with a survey in which teachers identified professional learning opportunities they had experienced and then rated those experiences on a scale of 1-5 with one being "had no influence on my teaching practice or student achievement" and five being "had significant impact on my teaching practice, student achievement and professional learning." It was clear, after the survey, that the teachers in this school had experienced the same type of professional development as I had. Most of the professional development experiences had little or no impact on teaching practice. I solicited the help of a local educator, author and renowned literacy expert to help me analyze the surveys and design a year-long professional development plan that relied on the expertise of teachers, recognizing the art of teaching as something that could be shared among colleagues and did not require an outside expert. Our first year included peer observations, visits to other schools and classrooms and a "curriculum camp" during the summer. I had become familiar with curriculum camps during my own teaching experience and found them extremely useful and collaborative. The week-long camps were usually offered to groups of teachers across content areas who wanted to collaborate on the development of units with a social justice theme and focused on literacy. We used the curriculum camp to engage all teachers, across content areas, to collaborate on 
integrated units with the expectation that at the end of the camp, they would turn in a unit organizer, list of activities, differentiation strategies, assessments and a calendar for the unit. It was a lot of trial and error, but what I noticed almost immediately was that teachers were talking to one another about teaching.

The end of the year survey indicated that most teachers found the professional development valuable and wanted to continue with the same format. The following year we developed a design team composed of teacher volunteers who met twice monthly to design the professional development calendar. That year we instituted model teaching, unit planning with a focus on literacy and action research. We also continued the peer observations. Again, the teachers rated their experiences very high and could clearly see how teaching practices influenced student achievement. Our students test scores were higher, special education and English language learner students were achieving at higher rates and the overall climate of the school was improving. By the third year, we were sustaining a model in which teachers were teaching teachers with collaboration and collegiality at a high level.

Every teacher also completed an action research project and presented their results to the staff. Some of the presentations influenced teachers to try similar practices. It was during the third year that we decided to host our own full day of professional development in which selected teachers would present 90-minute workshops on a unit they had created, a teaching strategy or literacy activity. Nearly $100 \%$ of the teachers rated it as the best professional development they had ever participated in. Based on these experiences and teacher feedback, I realized there was no magic formula and that all 
teachers could experience high-quality professional development by collaborating with each other. It was also evident that it was important to include teachers in the planning and implementation of professional development activities.

Chapter 1 provides information on the setting for the research, identifies the problem which was addressed in the study, provides context and identifies important terms connected to the topic of teacher professional development. 


\section{CHAPTER I}

\section{PROBLEM STATEMENT AND SIGNIFICANCE}

\section{Introduction}

High school principals have the responsibility of developing professional learning opportunities for teachers. While this is a common expectation for school administrators, there is no magic formula or template from which to design a successful professional development (PD) program. In my first administrative position, I was not offered any support or guidance on how to plan professional learning opportunities for teachers. It is no surprise that principals resort to the latest hot topic in professional journals and rely on district leadership and initiatives to design PD. Teachers participate in the activities yet there is often little change in the classroom or instruction.

I do not mean to imply that there are no worthwhile PD programs or that all principals are incapable of designing outstanding PD opportunities. What I do know is

that the high school principal job is demanding, time-consuming and stressful. Principals can find it difficult to give PD the attention it deserves due to so many competing factors. What I seek to do with this study is design a resource for principals to use in creating PD plans.

A PD plan should encompass opportunities for teachers to examine and improve instructional practice, protocols for teachers to receive ongoing feedback and regularly 
scheduled collaboration time. A plan is not a series of disconnected presentations or workshops with no follow-up.

This chapter identifies the problem, provides an overview of the study and includes a preview of next steps. The chapter also includes a discussion of the study setting, the impact PD should have on teaching and learning and the dilemma of reduced or nonexistent funding resources. Finally, the chapter ends with definitions of terms relevant to PD.

\section{Study Setting}

This study takes place in an urban school district and a suburban school district in the Pacific Northwest. Both have experienced significant budget shortfalls for the past several years. The urban school district serves approximately 47,000 K-12 students in 78 schools including 10 high schools. Student ethnic breakdown is as follows: $11 \%$ AfricanAmerican, $8 \%$ Asian, 16\% Hispanic and 55\% White. The English language learner population is approximately $8 \%$. The district employs more than 2,800 teachers. There is very little funding for PD and no ongoing professional learning opportunities. Funding is almost solely dependent on grants and is inconsistent from year to year. Principals are given very little guidance on how to develop PD plans and the activities provided by the district are very sporadic. In addition, there are no building budgets for PD. Even though, School Improvement Plans usually include goals that require PD, principals are left to figure out how to find funds from already limited resources. Schools that have been fortunate enough to receive grant monies (mostly schools not meeting state and federal performance standards) are able to do more than schools who are not eligible for grants. 
This sends the incorrect message that only teachers in struggling schools need and can benefit from professional learning.

The suburban school district serves approximately 10,700 students. The district is composed of 11 elementary schools, three middle schools, one high school and three alternative high schools. The following is the ethnic breakdown of students in this district: 11\% Latino, 54\% white, 7.9\% African American, 9.3\% Asian and 1.1\% Native American. The district has implemented professional learning communities as the primary form of PD. Principals are responsible for planning PD but there is no formalized training or supports in place for principals to assist with the planning. Money is tight in this district and there is limited funding for teacher PD.

The background for this study includes my experiences, trial and error accounts, anecdotal data and evidence from my own experience as a high school principal as well as a literature review on teacher PD. As a result of my own experiences and research, I created a handbook for principals to use in the design and assessment of teacher PD that requires very little monetary investment, addresses current problems of practice that teachers face and provides opportunities for teachers to learn from their colleagues, whom I would argue are the real experts. My goal with this study was to further develop, field test and revise the handbook: Teachers Teaching Teachers: Designing Successful Professional Development on a Shoestring Budget.

I was drawn to school leadership because of my desire to positively impact public education. Teachers are responsible for, among other things, helping each student experience success and for ensuring students leave school prepared, literate and able to 
contribute and function in our society. The achievement gap between white students and students of color as well as other minority groups is more prevalent today than ever. Yet, teachers are not compensated with huge salaries, benefit packages, incentives or other compelling rewards. I believe teachers (good ones, anyway) do what they do because they are intrinsically compelled to help children.

As a principal, I believe it is my job to help teachers improve through honest dialogue, collaboration with colleagues and professional learning that values personal reflection and meaningful exchange directly connected to teaching practice and student achievement.

In the next section I address the problem in teacher PD programs that do not take into account the skills and experiences of those currently practicing the art of teaching and instead rely on outside professionals and expensive programs. It is time to stop spending our precious and limited funds on "helicopter rides," expensive programs and experts who are not currently, and possibly never have been, in a classroom. In my experience, teachers are the true experts and are a resource often left untapped.

\section{Statement of the Problem}

We have selected the term professional learning over the more narrow conceptual terms of professional development or professional learning communities because "Breakthrough" means focused, ongoing learning for each and every teacher. (Fullan, Hill, \& Crevola, 2006, p. 21)

In the quote above, Fullan et al. (2006) used the term "professional learning" to define focused, ongoing learning for teachers. The concept of professional learning challenges us to look beyond PD activities and establish a philosophy of learning for 
teachers that is an ongoing process and not a one-time event. Fullan et al.'s description of professional learning in the book, Breakthrough, is not what I experienced in my teaching career. Planned, thoughtful, collaborative and ongoing learning led by school or district administrators was rare in the schools I worked in. Good teachers did, however, find ways to learn and grow without district led PD.

The PD I experienced as a teacher rarely had a direct impact on my teaching practice and never included any kind of accountability or ongoing learning. The most valuable experiences I had were when I was given opportunity to collaborate with other teachers and when teachers presented workshops on their own teaching strategies. I believe teachers teaching teachers and ongoing research based PD are what truly impacts teaching and learning.

During the last three decades, schools have experienced an increase in accountability, new curriculum and instructional strategies and the introduction of standards for every content area (Shakrani, 2008). In response, many high schools have chosen to redesign and have implemented strategies such as creating small schools and/or smaller learning communities. These structural changes have little impact, if any, on instructional practice (Little, 1999).

According to Royce (2010) the PD for teachers in this country has barely changed since the 1950s. It is still common for school districts to provide generic training that is disconnected from the actual teaching practice and needs of the individual teacher (Royce, 2010). School districts nationwide are still providing PD that is focused on a particular topic such as assessment, use of learning targets, teaching strategies, etc. While 
this type of teacher training ensures everyone gets the same message and reaches a common level of understanding; a "one-size-fits-all” PD program is not the most effective way to meet the needs of individual teachers (Royce, 2010). Reform efforts at schools almost always include enhancing instructional practices with the goal of raising student achievement. Continual PD for teachers and school leaders is essential for successful reform (Seltz, 2008).

Respondents in a high school reform study (Council of the Great City Schools, 1999), reported that the most effective school reform strategy was PD initiatives for teachers. Other effective strategies included the implementation of instructional coaches and ninth grade academies. Instructional coaches were described as teachers in leadership roles who help plan PD, work with teachers on implementing new instructional strategies and who observe teachers and provided feedback. Ninth grade academies are a means to enhance relationship building (usually implemented in larger high schools). The academy model allows teachers in different content areas to share the same group of students. For example, a freshman class of 500 might be divided into five academies of 100 students each. Each group of 100 might share the same English, Biology and History teachers. This creates opportunity for teachers to work collaboratively on integrated units and instructional strategies (Feldman, López, \& Simon, 2006). The study by Council of the Great City Schools (1999) also reported that lack of PD in a sustainable format plays a significant role in the demise of reform efforts.

Little (1999) was even more specific in identifying subjects in which PD is crucial. Math and English are gate-keeping subjects that dictate success in other content 
areas. Student must meet Math and English proficiency levels in order to enter 4-year universities as well as some training programs and employment opportunities.

Restructuring a school will not have any lasting impact unless PD is focused on teaching practices, especially in Math and English.

Overall, it appears that Hacienda's relatively strong focus on teaching practice and its strong commitment to professional development are weakened by a stance of passive individualism (participate if you wish) and by overlooking the potential of subject departments to operate as resources or constraints in the pursuit of whole-school reform. This results in quite different investments in the improvement of classroom practice. (p. 13).

Little (1999) explained a phenomenon that was prevalent throughout my teaching

career; 1-day workshops, participate if you wish, with no connection to department curriculum, teaching practices or school specific needs. How can teachers grow professionally if the opportunities are sporadic, disjointed and come with no accountability?

\section{Context: Demographics}

The handbook developed for this study was used in a workshop with high school principals and district level administrators in two school districts. Both districts in this study, have been, and are still facing, budget challenges similar to most districts across the nation. One district is the largest in the state serving approximately 47,000 students in grades K-12. There are 10 high schools as well as several alternative high school options. Eight of the 10 high schools are comprehensive and 2 are focus option schools. One of the focus schools is partnered with a community college and functions as a middle college allowing students to take courses on the college campus while in high school. The 
other focus school emphasizes career technical education and provides internships and apprenticeship opportunities for students.

The second district in the study is a suburban district serving approximately 10,700 students in grades K-12. This district has one large comprehensive high school with approximately 2,500 students. The district also includes 11 elementary schools, three middle schools and three alternative high schools.

All school principals are responsible for PD within their buildings. Principals and leadership teams in both districts determine the activities for PD and implement with varying degrees of success. In 2013, district initiatives included the implementation of professional learning communities, examination of grading practices with movement toward a proficiency model and a transition to common core state standards. While there have been presentations to principals at monthly leadership meetings on aspects of these initiatives, there has been an absence of structured time for principals to develop a PD plan for their buildings and there is limited accountability regarding the PD provided in individual schools. The district calendar provides approximately 10-12 hours of dedicated PD time per month for teachers.

In the urban district, principals attend an all-day leadership meeting once per month. The meetings include presentations on leadership practices, updates on district data, budgetary reports, equity professional learning communities, cluster meetings (elementary and middle schools that feed into the same high school) and a high school leadership meeting. During these monthly meetings there is rarely time for administrators to collaborate and/or participate in a work session to develop strategies or plans. While 
there are numerous initiatives that principals are required to address in teacher PD activities, there is a lack of modeling and/or support for principals as they design the PD plans. In the next section the purpose and significance of the study is more clearly defined.

\section{Purpose and Significance of the Study}

Since the onset of No Child Left Behind (Shear et al., 2008), many schools have had to initiate some form of school improvement strategy. Solutions tend to include quick fixes such as sending teachers to workshops, buying curriculum from companies and hiring expensive experts to give presentations on how to improve student achievement. Federal and local grant monies have been awarded to schools instituting various types of reform efforts. Textbook companies have developed sets of curriculum that are connected to state standards and set up elaborate displays at conventions and workshops to convince teachers that their materials hold the key to student success. Finally, experts advertise in educational journals and on the internet, claiming to have discovered the magic strategy or strategies that will transform teaching and learning. The cost for these experts can range from hundreds to thousands of dollars, usually involve travel and hotel expenses and require a significant purchase of materials and/or follow-up sessions. There is useful information that can come from the solutions mentioned above, but without teacher collaboration, accountability and ongoing conversation, the transfer to the classroom can be minimal.

The purpose of this study was to develop and implement a PD handbook that assists principals and teachers in the design of PD programs that meets the needs of 
teachers and impacts student learning. The PD program outlined in the handbook can be implemented at little or no cost and includes opportunities for teachers to learn from other teachers through peer observations, professional learning teams and action research.

The primary research question for this study is:

1. How useful is the handbook, Teachers Teaching Teachers: Designing Successful Professional Development on a Shoestring Budget, in building school leader efficacy and confidence in regards to professional development planning?

Secondary research questions are:

1. What is missing from the handbook?

2. Does the handbook encourage school leaders to utilize teacher expertise?

3. Do the research participants find the handbook usable and accessible?

4. What suggestions do school leaders have for the improvement of the handbook?

\section{Research Methodology}

The theoretical model used for this study is problem-based learning which was introduced by Bridges and Hallinger (1995). The problem addressed in this study is the lack of guidance and resources for principals in planning teacher PD. I identified the problem based on my own experience as a principal. As a teacher, I experienced PD that was fragmented and had little impact on my instructional practice and/or professional growth. I sought out teacher colleagues who wanted to work together and share academic conversation about teaching and learning. When I became a principal 7 years ago, I became interested in designing PD that would focus on teacher collaboration and result in improved instruction. 
In my first principal position, I experienced some success designing PD with a team of teachers. The teachers input unanimously supported PD that focused on collaboration and teachers teaching teachers. My role included providing protocols, information on various activities that focused on collaboration and building in time for teachers to work together. In the subsequent 6 years I continued to build on the collaboration model and have identified three main PD activities that promote teachers learning from each other and that cost very little to implement. Based on my own experience as a teacher and my most recent experience as a principal, I developed a handbook for principals to use in designing PD. Most school districts in Oregon have reduced budgets dedicated to PD. The handbook is focused on low-cost and no-cost PD activities.

This study follows the research and development cycle (Borg \& Gall, 1989) to create and field test a handbook for school leaders who are responsible for planning teacher PD:

Steps in the Research and Development Cycle

1. Research and information collecting

2. Planning objectives, learning activities, and small-scale testing

3. Develop preliminary form of the product

4. Preliminary field testing

5. Main product revision

6. Main field testing

7. Operational product revision

8. Operational field testing

9. Final product revision

10. Dissemination and implementation. (Borg \& Gall, 1989, pp. 784-785) 
The research methodology is discussed in detail in chapter 3. Following is a summary of the steps and processes that were used in this study:

\section{Step 1: Research and Information Collecting}

In this step I conducted preliminary research on the topic of teacher PD by interviewing teachers in the schools where I worked and principal colleagues, collecting data on the success of various types of PD activities and administering surveys to teachers on the effectiveness of PD. I also reviewed the literature including an in-depth review of three types of PD (peer observation, action research and professional learning communities). I chose those three activities because they area activities in which teachers learn from each other. In this step I also began to identity the format for a handbook to assist principals in the planning of PD for teachers.

\section{Step 2: Planning Objectives, Learning Activities, and Small-Scale Testing}

In step two, I further developed the protocols and activities that teachers and principals found useful. Principal colleagues in an urban district used some of the protocols and the forms were posted on the district resource page for administrators to access. Feedback was solicited from principals in two different schools regarding the protocols that were implemented. The defense of the dissertation research proposal occurs in this step and includes completion of the first three chapters of the dissertation.

\section{Step 3: Develop Preliminary Form of the Product}

Step three was primarily focused on the completion of the first draft of the handbook. 


\section{Step 4: Preliminary Field Testing}

School and district administrators were invited to participate in field testing of the handbook. This step included information from focus groups who reviewed the product. The feedback was qualitative and provided information that influenced revision of the handbook before the main field testing.

\section{Step 5: Main Product Revision}

After receiving feedback and input from school administrators, step five was focused on revising the handbook in preparation of the main field testing.

\section{Step 6: Main Field Testing}

A workshop model was used for the main field testing. School and district administrators participated in a 3-hour workshop which included an overview of the handbook, review of protocols and PD activities and time to use the handbook to develop a year-long PD plan for their own schools. Upon completion of the workshop, participants responded to survey questions regarding the usefulness of the handbook.

\section{Step 7: Operational Product Revision}

This step includes analysis of data from the main field testing and surveys. Based on the data, the handbook was refined and further developed.

\section{Steps 8, 9, and 10: Operational Field Testing, Final Product Revision and Dissemination and Implementation}

Steps 8,9 , and 10 go beyond the scope of this study. In these steps the product is further refined and distributed on a much wider scale. Publication of the handbook would 
also be considered in step 10. Chapter 5 includes a discussion of the last three steps in product development.

\section{Summary}

The problem addressed in this study is the lack of guidance provided for principals to develop meaningful, sustainable, low-cost PD programs. The end result of this project is a handbook, based on literature and my own field experience, that will assist principals in the selection, implementation and assessment of PD programs.

Chapter 1 provides my own personal reflection on the PD opportunities that were offered to me over a 25-year teaching career. As a principal, I was ill-prepared to design the PD plan for my staff but knew exactly what had not worked for me. The administrative licensure program did not include any significant training on how to provide relevant, impactful learning opportunities for teachers. The districts I worked in did not have any type of training for principals or guidelines to follow in planning PD. My negative experiences as a teacher, lack of district funding and lack of guidance as a principal inspired me to try an approach opposite of what seemed to be the norm: tap into the available resources in my building and find ways to improve practice that were inexpensive yet yielded significant changes in instruction.

In this chapter I also painted a picture of the schools and districts used in this study. In order to identify what PD will be most impactful, it is necessary to understand the historical background of the school, the school culture, school climate and the district philosophy. I believe there is a strong connection between the success of PD and the level of support for teacher collaboration. 
The final section of chapter 1 includes a summary of the research methodology. The research focused on the effectiveness and usefulness of a handbook designed for principals to use in planning teacher PD. The research includes input from principals who participated in focus groups and from principals who participated in a workshop in which they used the manual to plan PD for their own teaching staffs.

\section{Definition of Terms}

Following are definitions of terms used in this study.

Professional Learning Communities (PLCs): educators committed to working collaboratively in ongoing processes of collective inquiry and action research to achieve better results for the students they serve. PLCs operate under the assumption that the key to improved learning for students is continuous, job-embedded learning for educators (DuFour, DuFour, \& Eaker, 2008; Hord \& Sommers, 2008; Little, 1999, 2006; Lujan \& Day, 2010; O’Malley, 2010).

Professional Learning: focused ongoing learning for every teacher (Eisenberg, 2010; Hileman, 2010).

PD (professional development): a collaborative learning process that nourishes the growth of individuals, teams, and the school through a daily job-embedded, learnercentered, focused approach (Desimone, 2011; DuFour, DuFour et al., 2008; Hileman, 2010).

Action Research: action research is undertaken in a school setting. It is a reflective process that is undertaken in a school setting. It includes inquiry and discussion as components of the "research." Action research can be a collaborative activity among 
colleagues searching for solutions to everyday, real problems or looking for ways to improve instruction and increase student achievement (Alber \& Nelson, 2002; Arhar, Holly, \& Kasten, 2001; Ferrance, 2000; Glassman, Erdem, \& Bartholomew, 2012; Gould, 2008; Schmuck, 2006, 2009).

Peer Observation: collegial process where one teacher observes another teacher delivering instruction and then provides supportive and constructive feedback. Both parties reflect on and discuss the observation with the goal of improving instruction and student achievement (Hendry \& Oliver, 2012; Showers \& Joyce, 1996).

NCLB (No Child Left Behind Act of 2001): the legislation was proposed by President George W. Bush in 2001 (Dee \& Jacob, 2011). It was coauthored by Representatives John Boehner and George Miller and Senators Edward Kennedy and Judd Gregg. The bill was passed on May 23, 2001, in the House of Representatives. The Senate passed the bill on June 14, 2001, and President Bush signed it into law on January 8, 2002. The purpose of the Act was to promote standards-based education. In order to receive federal funding for schools, states were required to develop basic skills assessments at different grades throughout the school year (Dee \& Jacob, 2011).

AYP (adequate yearly progress): the NCLB requires the annual determination of whether schools, districts, and states have made adequate yearly progress toward the goal of having all students meet rigorous state academic standards by the 2013-2014 school year targets (Oregon Department of Education, 2012). Each year, the performance of all students in the school and district, as well as subgroups of students, is measured against annual performance targets (Oregon Department of Education, 2012). 
School Reform: a new vision of a struggling school is adopted and school leaders take ownership of a strategic improvement plan that is based on research and student data and implement that plan within a sufficient network of support and funding (Chenoweth \& Everhart, 2002; Feldman et al., 2006; Levine, 2010; Seltz, 2008).

OAKS: Oregon State Standardized Test used to measure student achievement. Currently students are required to pass tests in Reading, Writing and Mathematics. Oregon will be switching to the Smarter Balanced Assessment in 2015 (Oregon Department of Education, 2013).

Curriculum Camp: structured time for teachers to collaborate on integrated units. The camps are held in the summer and are 5 days in length.

At-risk students: students who are identified as more likely to drop out of school. Indicators include attendance, performance on standardized tests, grades, behavior, etc. Bill and Melinda Gates Foundation: this foundation is one of the largest private foundations in the world. The foundation funds projects related to healthcare, poverty, education and information technology.

E3 (Employers for Educational Excellence): E3 is an independent, nonprofit organization founded in 1996 by the Oregon Business Council to bring together employers and schools to improve student achievement.

Federal Smaller Learning Communities Grant: funded by the Federal Government, these grants were awarded to large high schools to support the creation of smaller learning communities or academies within the large school. 
SpEd (Special Education): Students with disabilities who are on individualized education plans.

English Language Learners (ELLs): students whose first language is something other than English.

School Improvement Plans: usually completed once a year or every other year. The plan is formulated with stakeholder input (students, teachers, parents, community members) and includes academic, culture, climate and equity goals. Goals are based on data and progress is tracked throughout the length of the plan.

Ninth Grade Academies: students are divided into smaller academies in which 7090 students share the same group of teachers. For example, 360 freshmen students are divided into 4 academies of 90 students each. Each group of 90 students shares the same Biology, English and History teachers.

Instructional Coaches: teacher leaders designated as instructional support staff. Instructional coaches help plan and deliver PD, work with individual teachers on lesson plans and unit plans, and act as a resource for teachers regarding instructional practice.

Alternative High School: a nontraditional school that is available for students who need a different setting, online credit options or have extenuating circumstances that require they be removed from the traditional setting.

Focus Option Schools: schools with a particular focus or theme. For example, Benson High School in Portland focuses on Career, Technical Education.

Career Technical Education: focus on career themes such as electric, construction, digital media, nursing, etc. 
Proficiency Model: the proficiency model includes evaluating students only on the basis of their demonstration of skills rather than including things such as attendance, timeliness, behavior, etc.

Common Core State Standards (CCSS): the standards were initiated in 2009 through a collaborative effort between state leaders from 48 states. The purpose is to ensure all students, regardless of where they live, are graduating high school prepared for college, career and life. Most states are in the process of adopting the standards in reading, writing and math.

Re-culturing: changing the values, beliefs and way of being of a particular group Continuous Improvement: PD activities should be ongoing and provide opportunities for teachers to experience continuous improvement.

Chapter 2 includes the literature review and information on instructional leadership, historical information on teacher PD, current PD examples, funding for PD and the evaluation of PD programs. 


\section{CHAPTER II}

\section{LITERATURE REVIEW}

\section{Introduction}

Chapter 2 explores the literature relevant to teacher PD, with an emphasis on teacher-led activities. The specific types of PD described in this chapter include action research, peer observation and PLCs. These three activities support the claim that teachers can be experts and can learn from each other. This chapter also includes a discussion of the importance of school leadership in designing, implementing and maintaining a continuous PD plan that promotes a culture of learning. With significant budget cuts over the past several years, school districts have reduced the amount of time dedicated to PD including funds to use for travel to workshops, for bringing in guest speakers and presenters and for hiring instructional coaches. This leaves school level administrators with the task of improving teacher practice and raising student achievement with less time for teacher training and fewer resources than ever before.

In some countries, where students standardized test scores are higher than those in the U.S., teacher PD has a very different model. In Finland, for example, schools provide time during the work week for teachers to collaborate, plan and develop curriculum and share materials (Darling-Hammond, 2010). Schools in the United States usually provide planning time for teachers during the school day, however, according to Sawchuk (2010), teachers in Asian and European countries spend fewer minutes teaching and more time 
working on their lessons in collaboration with other teachers. According to DarlingHammond (2010) approximately $80 \%$ of U.S. teachers' work time is spent teaching. Most grading and planning occurs after the work day. Comparably in South Korea, Japan, and Singapore-approximately 35\% of work time is spent teaching with the remaining 65\% spent on shared planning, PD and meeting with parents (Darling-Hammond, 2010).

School districts face tremendous budget challenges and often reduce spending in areas not directly connected to teacher salaries and materials. PD has been "trimmed" from many school budgets and the result is less time spent on teachers reflecting and improving their craft. Teachers need more than a few in-service days per year to make significant changes in teaching practice (Habegger \& Hodanbosi, 2011).

Even though school budgets have been challenging, many schools have been able to secure grant funds to address student achievement, which sometimes includes restructuring and/or some type of school reform. School restructuring initiatives often lack vision. Overwhelmed by the complexity of change, school reformers who want to create better educational options for all children suggest tinkering with nineteenthcentury schools instead of creating twenty-first century schools (Benitez, Davidson, \& Flaxman, 2009). In other words, school reform has not resulted in significantly different methods of delivering education than what was available more than 100 years ago. Restructuring has mostly been focused on minor fixes such as schedules, building configurations and structural changes rather than the delivery of instruction to meet the needs of a more modern age. Most of the "tinkering" does not stick and reforms that were 
popular a few years ago have been discarded in favor of new initiatives or a return to the previous status quo (Horowitz, 2006).

One example of a popular school reform model is the small school initiative spearheaded by the Gates Foundation (Shear et al., 2008). Ten years ago, this was a popular type of reform for large urban and suburban high schools. The $\$ 1.5$ billion initiative supported two strategies to help personalize education, which in turn, would improve student academic performance. The strategies focused on keeping high schools small. Districts building new schools were able to get the grant funding if they kept the schools small (approximately 400 students or less). Large high schools could receive funding to support dividing the school into "small schools" or "smaller learning communities.”

Today, few schools have been able to maintain the small school format due to budget cuts or other limitations. While there were positive outcomes for some schools that received Gates funding (mainly those that started new small schools), most of the large urban schools that tried the small school format have since returned to their original structure, mostly due to budget cuts. This is an example of a reform that was not sustainable and that did not have much effect on teaching practice. According to Shear et al. (2008), the conversion of large schools into small schools steers a lot of effort into structural change and assignment of staff and students and less effort into curriculum and instruction. What appears to have the most impact is sustainable change that comes from within; practitioners collaborating and identifying issues related to teaching and learning (Barth, 1990; Gordon, 2008; Smith \& Rowley, 2005). NCLB legislation included 
opportunities for schools to apply for federal monies to implement PD opportunities for teachers (Hardy, 2003). Yet, in a typical school, the money was spent to hire experts to provide a script for teachers with the promise of improving test scores. Not surprisingly, this approach ignored the needs of the students, the experience of the teacher, and the endless opportunities for engaging students in learning. Instead of promoting a culture of professional learning, these workshops supported a culture of compliance. This culture of compliance did not promote teacher PD but reliance on quick fixes, scripted curriculum and outside experts to identify and remedy the problems related to instruction and achievement (Lieberman \& Mace, 2008).

School reform initiatives are often accompanied by additional funding from state and federal grants. However, the focus of most reform initiatives is on program change, rather than systemic change that includes policy as well as instructional practices (Massachusetts Insight Education Research Institute, 2007). For example, program changes can include additional classes, remediation, sequencing of courses, reduction of barriers for students to access advanced classes, longer school day, etc. Moreover, school reform initiatives may include teacher PD but the funds are typically spent on workshops and outside expert facilitators rather than the building of internal capacity, collaboration and research. Effective PD for teachers can be the focal point of many school reform plans however teachers have often rated PD experiences as low in meaning and quality. The programs are described as faddish, lacking a research base, having no connections to real classrooms, often taught by unqualified individuals, and presented in a format that minimizes teacher involvement (Coggins, Zuckerman, \& McKelvey, 2010; Torff \& 
Byrnes, 2011). Unfortunately structural changes have little lasting impact unless change occurs in the culture (assumptions, beliefs, expectations, values and habits) or norms for the school. The culture of the school shapes how teachers think, feel and act, how they view the world and how they interpret events. The success or failure of any PD program will depend on the ability to make profound cultural shifts (Loertscher, DuFour, DuFour, \& Eaker, 2010). Sarason (2004) stated that federal initiatives for reform do not change the status quo unless there is a change in culture and definition of the school. Major school reform initiatives are primarily focused on changes at the macro level rather than micro problems, even though decades of research shows that classroom teachers have the most influential role on school success (Sarason, 2004). The PD activities reviewed in this chapter are aimed at continuous improvement (ongoing feedback and opportunities for growth) and re-culturing (changing from a culture of compliance to a culture in which teachers value PD because it improves practice, promotes collaboration and is sustainable).

PD programs can be very vague and hard to define. School districts can have a difficult time allocating funding to help improve instruction (Sawchuk, 2010). Hence, the purpose of PD must be clearly defined and focused on student learning. The problem with the traditional view of PD is that it is externally driven and typically focuses on teacher inadequacy or practices in need of remediation. Furthermore, a critical problem addressed in this study is the glaring lack of principal guidance and know-how needed to develop meaningful, sustainable, low-cost PD programs. Tight resources should force school leaders to become more intentional in designing PD. Better choices and more 
focus on quality can help learning communities thrive, even in challenging times (City, 2013).

The following literature review begins with an exploration of the relationship and importance of leadership in the design of PD. It is followed by an investigation of three critical types of teacher led PD: action research, peer observation and PLCs. The review concludes with a discussion of some preliminary research and information collecting on teacher led PD that I conducted at several regional high schools.

\section{Leadership to Promote Collaboration}

Leadership is the reciprocal processes that enables participants in an educational community to construct meanings that lead toward a shared purpose of schooling. (Lambert, 2003, p. 423)

In the story that was shared in the preface, I defined my own PD as a series of ineffective, short, inoculations of information usually provided by so-called experts. There was no continuity or follow-up to most of the activities and accountability was rare. It was difficult to connect the learning opportunities to what was happening in my classroom and even more difficult to see the training that was offered as having any significant impact on student learning. As a teacher, I was solely responsible for making connections to the PD activities and my own teaching and for subsequent decisions to implement new strategies. The following section examines the importance of leadership in the design and implementation of PD.

The search for a bureaucratic route to the "one best system" of education began in the $20^{\text {th }}$ century and was based on the assumptions that students all learn the same way and education practice can be prescribed. During this time, teachers were viewed as 
needing little knowledge about their own PD since teaching decisions were handed down from administrators (Royce, 2010). In this model, there are no problems of practice: there are only problems of implementation. Schools were designed to operate without teacher PD and without opportunity for teachers to collaborate (Darling-Hammond, 2000). Schools of the $21^{\text {st }}$ century demand more of teachers and administrators; however, one still finds examples of teaching practices that are better suited for the past bureaucratic factory model of schooling.

Today, school level administrators are often held responsible for designing PD. Previously, many districts had curriculum directors that planned teacher PD. With recent budget cuts there has been a decrease in curriculum director positions coupled with an increased accountability for principals to become instructional leaders (Finkel, 2012). Teachers are often overlooked as resources in the development of professional learning opportunities. "Policymakers seldom ask successful classroom educators for their ideas about creating a modern teaching profession” (Moore \& Berry, 2010, p. 37). Administrators need to work side by side with teachers to create professional learning opportunities that are relevant and allow teachers to collaborate and spread their expertise and knowledge (Moore \& Berry, 2010). A collaborative approach between administrators and teachers fosters leadership opportunities. Every teacher has talents to share and some are viewed as "teacher experts" (Semadeni, 2010). Developing a culture of inquiry supports a model of collaborative learning. Teachers feel honored as professionals if they are asked to study a problem of practice, discuss it with peers and implement some change in teaching practice (Hanson, 2010), 
Learning in the setting where you work, or learning in context, is the learning with the greatest payoff because it is more specific (customized to the situation) and because it is social (involves the group). (Fullan, 2001, p. 126)

According to Fullan (2001), learning in the setting where you work has the greatest impact on performance because it is relevant to the situation and it includes interactions with colleagues. This has great relevance for principal leadership and professional learning opportunities. As principals design PD for teachers, they are also creating learning opportunities for themselves. Effective leaders have a substantial impact on student learning (Robinson \& Timperley, 2007). The impact can be direct through supervision and evaluation but also indirect through the planning and promotion of teacher PD and learning. The challenge for administrators is to plan and provide PD that works by changing teacher practices and raising student performance. What does not work is simple, short-term, one-way solutions, or "business as usual" PD (Boudah, Blaire, \& Mitchell, 2003).

Erkens (2008) provided a summary of requirements that must be met in order for leaders to reach selected outcomes (see Table 1). Erkens defined leadership as "the practice of guiding and inspiring others to journey willingly toward an identified target" (p. 40). When leadership is successful, it nurtures a culture of risk-taking and learning. Table 1 shows the relationship between acceptance, trust, honesty and safety when teachers are expected to examine current practices and beliefs. Ultimately, good leaders create the opportunity for change in practice, beliefs, values and skills of individuals, groups and the organization itself. Successful leaders guide and facilitate rather than 
simply share strategies or procedural steps. Exceptional leaders evoke the exceptional leader in others through serving, modeling and celebrating (Erkens, 2008).

\section{Table 1}

\section{Leadership Strategies to Create Active Followers}

\begin{tabular}{|l|l|l|}
\hline If leaders want to: & Then followers must: & And followers will require: \\
\hline Establish a guiding coalition... & $\ldots$ participate in leadership effort. & $\begin{array}{l}\text { Peer acceptance for risk-taking } \\
\text { and leading. }\end{array}$ \\
\hline $\begin{array}{l}\text { Identify essential learner } \\
\text { outcomes... }\end{array}$ & $\begin{array}{l}\text {...challenge each other's } \\
\text { thinking. }\end{array}$ & Open and honest dialogue \\
\hline $\begin{array}{l}\text { Create and implement common } \\
\text { assessments... }\end{array}$ & $\begin{array}{l}\text {...share personal achievement } \\
\text { results. }\end{array}$ & Trust \\
\hline $\begin{array}{l}\text { Challenge practices that interfere } \\
\text { with mission and vision... }\end{array}$ & $\ldots$ explore beliefs. & Safety \\
\hline $\begin{array}{l}\text { Solicit feedback regarding current } \\
\text { plans... }\end{array}$ & $\ldots$ provide honest input. & $\begin{array}{l}\text { Administrative receptiveness to } \\
\text { feedback. }\end{array}$ \\
\hline
\end{tabular}

Source: Erkens (2008).

To create an atmosphere of shared leadership the administrator must view collaboration among teachers as the basis for improvement in instruction. This can be unfamiliar territory for many teachers. Administrators can create anxiety, especially with the expectation that teaching become less isolated and more observable by colleagues (Musanti \& Pence, 2010). The recent implementation of CCSS has prompted researchers such as Phillips and Hughes (2012) to identify teacher collaboration as one of the key strategies in helping teachers plan instruction and develop assessments for the new standards. The standards provide an opportunity to rethink teacher PD and design 
programs that encourage teachers to examine student work. Teachers will need to strategize ways to implement the CCSS, reflect and make adjustments in their practice, and work in real time to incorporate strategies that help students achieve at higher rates. However, the expectations of the CCSS are not enough to make teacher collaboration successful. To make collaborative learning opportunities less intimidating for teachers, administrators will need to spend time building trust and changing the norms associated with the privacy of teaching.

According to Lambert et al. (2002), a constructivist approach in leadership and in the design of PD can help individuals and organizations to increase learning and growth. Constructivist leadership allows individuals to bring past experiences, beliefs, cultural histories and world views into the process of learning. Through personal perspectives and inquiry new knowledge is developed together in community (Lambert et al., 2002).

The concept of constructivism has roots in classical antiquity, going back to Socrates's dialogues with his followers, in which he asked directed questions that led his students to realize for themselves the weaknesses in their thinking. The Socratic dialogue is still an important tool in the way constructivist educators assess their students' learning and plan new learning experiences. In this century, Piaget (1976), Dewey (1938) and others have promoted experience as a crucial part of acquisition knowledge and application of skill. Dewey included this summary of conflicts in how instruction is delivered and recommended that the latter in each statement is how students learned best:

- Imposition from above vs. expression and cultivation of individuality

- External discipline vs. free activity

- Learning from texts and teachers vs. learning from experience 
Dewey called for education to be grounded in real experience. He also described learning as a process that includes study, consideration of alternate possibilities and inquiry.

Similar ideas were developed by Vygotsky (Kozulin, \& Gindis, 2003) who proposed that learning and remembering take place through activity and the best learning situations are those that develop in social situations. Vygotsky introduced the social aspect of learning into constructivism (Kozulin \& Gindis, 2003). Vygotsky defined the "zone of proximal learning" in which students solve problems beyond their actual developmental level (but within their level of potential development) under adult guidance or in collaboration with more capable peers (Kozulin \& Gindis, 2003).

These early ideas regarding learning proposed by Piaget, Dewey, and Vgotsky are widely accepted as applicable and relevant in how we design instruction for students today. Constructivist leadership is based on the same components of constructivist learning such as meaning and knowledge construction, inquiry, participation, collaboration and reflection. The function of constructivist leadership is to engage teachers in processes that create the conditions for learning to occur (Lambert et al., 2002).

In Table 2, a comparison is made between a traditional/hierarchical centralized approach to PD and a collaborative/constructivist approach. Table 2 distinguishes collaborative and constructivist practices in designing PD from traditional approaches. Leaders who design more collegial PD promote teacher autonomy, self-analysis, selfdirection and encourage reflection on practice. As a result, teacher leaders emerge as peer 
coaches, researchers, mentors and develop learning relationships with their colleagues (Lambert et al., 2002).

Table 2

PD Comparison

\begin{tabular}{|l|l|}
\hline \multicolumn{2}{|c|}{ PD } \\
\hline \multicolumn{1}{|c|}{ Traditional/Hierarchical Approach } & \multicolumn{1}{|c|}{ Collaborative/Constructivist Approach } \\
\hline $\begin{array}{l}\text { Emphasis on knowledge acquisition and prescribed } \\
\text { training. Delivery through formal workshops, } \\
\text { courses. }\end{array}$ & $\begin{array}{l}\text { Emphasis on multiple learning opportunities, } \\
\text { authentic tasks, collaboration, action research, PLCs } \\
\text { and mentoring. }\end{array}$ \\
\hline $\begin{array}{l}\text { Individual PD plans based on teacher evaluation by } \\
\text { administrator. }\end{array}$ & $\begin{array}{l}\text { PD plans are personal, collegial and school based } \\
\text { and include choice and multiple forms of learning. }\end{array}$ \\
\hline $\begin{array}{l}\text { PD days are scheduled and structured by the } \\
\text { district and primarily reflect district/state/federal } \\
\text { mandates. }\end{array}$ & $\begin{array}{l}\text { PD days are designed by staff and include reciprocal } \\
\text { processes, action research, PLCs, leadership } \\
\text { development, team coaching and collaborative } \\
\text { planning. }\end{array}$ \\
\hline $\begin{array}{l}\text { District goals drive the school improvement plan. } \\
\text { School plans are viewed as instrumental in moving } \\
\text { toward district goals. }\end{array}$ & $\begin{array}{l}\text { School improvement plans have ongoing PD at the } \\
\text { center. School plans inform and are informed by } \\
\text { district goals and vision. }\end{array}$ \\
\hline
\end{tabular}

(Adapted from Lambert et al., 2002, p. 194).

Freedom to choose and the availability of time appear to be two of the most important and motivating factors in the success of teacher PD. A school in Wyoming, for example, saw a significant increase in teacher participation in PD when the sessions were held during contract hours. There was also increased motivation among teachers when there was an element of choice connected to the activities (Semadeni, 2010). Ainsworth (2010) interviewed a principal in California regarding the facilitation of PD. In the interview, Principal Jay Trujillo recommended five things school leaders must do to be 
effective in raising student achievement and in accomplishing desired outcomes related to teacher practice. These five behaviors are represented in Figure 1.

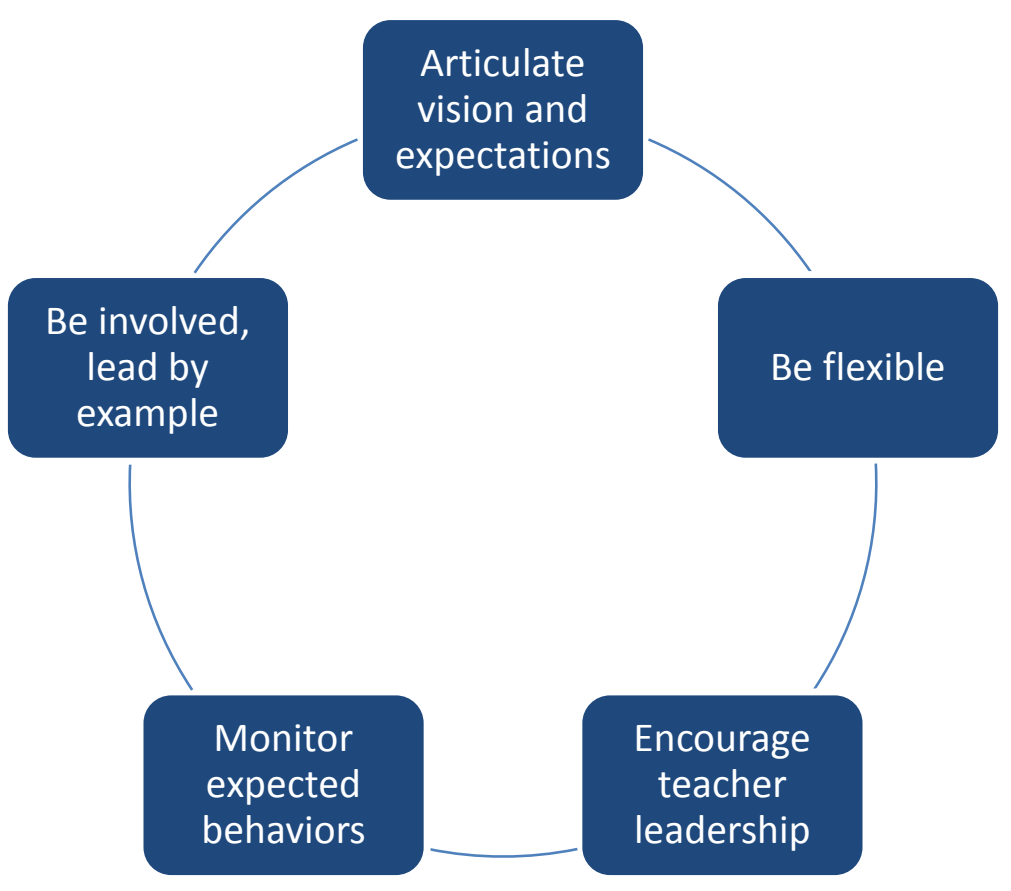

Figure 1. Five things leaders must do to be effective.

Teachers tend to be more invested if there is a shared vision and clear expectations. During the academic year, PD activities may need to be adjusted or modified based on data, teacher growth or other factors. Flexibility is important and demonstrates ongoing evaluation of the activities with appropriate adjustments when necessary (Ainsworth, 2010). Lambert (2000) supported the idea of shared leadership and proposes that leadership needs to be embedded in the school community with shared responsibility and a shared purpose. She further described a four-quadrant leadership matrix (see Figure 2). In Quadrant 1 the leadership style is autocratic with very few 
people contributing to decision making. In Quadrant 2, people are mostly doing their own thing and the school administrators are making the decisions. Quadrant 3 describes schools with leadership teams but very few people are involved. Teachers who are not part of the team can become alienated and resist proposed changes. Quadrant 4 is the desired modality with broad distribution of authority and leadership opportunities for students, parents and teachers. Information in this quadrant is not top-down. People develop their own meaning, raise their own questions and construct information from the inside-out. In Quadrant 4 there is discovery through evidence, investigation of problems of practice, review of student work and examination of issues in a broad-based way.

\begin{tabular}{|c|c|c|}
\hline Breadth of Parti & ipation & \\
\hline $\begin{array}{l}\text { LOW } \\
\text { Quadrant } 1 \\
\text { Autocratic administration } \\
\text { Limited flow of information } \\
\text { Co-dependent, paternal relationships } \\
\text { Rigidly defined roles } \\
\text { Norms of compliance } \\
\text { Lack of innovation in teaching and } \\
\text { learning } \\
\text { Student achievement poor, or } \\
\text { showing short-term improvements }\end{array}$ & $\begin{array}{l}\text { High } \\
\text { Quadrant } 2 \\
\text { Laissez-faire administration } \\
\text { Fragmentation and lack of coherence } \\
\text { of information and programs } \\
\text { Norms of individualism } \\
\text { Undefined roles and responsibilities } \\
\text { Both excellent and poor classrooms } \\
\text { Spotty innovation } \\
\text { Student achievement static overall }\end{array}$ & \\
\hline $\begin{array}{l}\text { Quadrant } 3 \\
\text { Trained leadership or site-based } \\
\text { management team } \\
\text { Limited use of data } \\
\text { Polarized staff, pockets of strong } \\
\text { resistance } \\
\text { Designated leaders act efficiently, } \\
\text { others serve in traditional roles } \\
\text { Pockets of strong innovation and } \\
\text { excellent classrooms } \\
\text { Student achievement static, or } \\
\text { showing slight improvement }\end{array}$ & $\begin{array}{l}\text { Quadrant } 4 \\
\text { Broad-based, skillful participation in } \\
\text { the work of leadership } \\
\text { Inquiry-based use of information to } \\
\text { inform decisions and practice } \\
\text { Roles and responsibilities reflect } \\
\text { broad involvement and collaboration } \\
\text { Reflective practice/innovation is the } \\
\text { norm } \\
\text { High student achievement }\end{array}$ & $\begin{array}{l}\text { Level of } \\
\text { Skillfulness }\end{array}$ \\
\hline
\end{tabular}

Figure 2. Leadership capacity matrix. Level of participation and skillfulness. Source: Lambert (2000). 
According to Hess (2013), there are self-imposed traps that prevent leaders from making sound decisions regarding teaching and learning. One of these traps is the "More, Better" trap in which leaders believe that improvement is only possible if there are more dollars to spend. More money and resources definitely help, but what matters most is how the resources are utilized. One of the benefits of teacher-led PD and teacher leadership is the availability of resources. Teachers can collaborate and discuss problems of practice regularly with follow-up conversations that improve teaching practice. Another benefit is the reduced cost of building local capacity to lead PD, especially in light of the shrinking budgets in school districts (City, 2013; Morones, 2013).

Lieberman and Wood (2001) identified components of the National Writing Project that have made it a successful PD program where others have failed. The components are listed below and closely resemble the qualities of a constructivist approach to teacher learning.

1. Each colleague is a potentially valuable contributor and it is important to learn what they believe and what they think. This de-emphasizes the isolation that some teachers experience.

2. NWP honors teacher knowledge. The knowledge is not held by authority figures or recognized experts. Teachers share what they know.

3. NWP creates a public forum for teachers. Teachers are expected to be public in their practice. They make presentations for parents and colleagues, write articles and contribute to newsletters.

4. Ownership of learning is turned over to the learners. Teachers are responsible for their own learning. Teacher accountability becomes part of a reflective process and collegiality.

5. NWP sees the importance of building community. No one is expected to teach in isolation. The learning community provides constructive and helpful suggestions in an authentic way. 
6. NWP provides multiple entry points into learning community. PD has been designed by so-called experts. The NWP offers the opportunity for teachers to come together to investigate their own challenges and problems of practice. There is no reliance on ready-made solutions or "cookie cutter" remedies that promise to work for any student.

7. NWP guides reflection on teaching through reflection on learning. When NWP teachers alter their practice it is because they learned from their own learning not simply because they learned new ideas and/or strategies.

8. NWP promotes shared leadership. PD means becoming more professional on all levels, not just learning new strategies. Many teachers become consultants for colleagues and lead teams of teachers in inquiry and research.

9. NWP promotes an inquiry stance. Teachers are encouraged to conduct research in their own classrooms and collect data to support strategies that successfully raise student achievement. Teachers ask themselves, "What else should I be doing here?"

The National Writing Project is recognized as one of the most successful forms of

PD focused on literacy. The components of the program identified as successful by

Lieberman and Wood (2001) are similar to components identified by Desimone (2011) as features common to effective PD. These core features include:

- Content focus-subject matter content and how students learn.

- Active Learning-teachers observe and receive feedback, analyze student work and make presentations.

- Coherence-what teachers learn is consistent with other PD, with their knowledge and beliefs, with school district initiatives and with state reforms and policies.

- Duration-activities should be spread over a semester or year and include 20 hours or more of contact time.

- Collective Participation-groups of teachers should participate in PD activities together to build a learning community. 
According to Desimone (2011), studies of PD have traditionally focused on teacher satisfaction, attitude change or commitment to implement new strategies, rather than on the results or processes that make it work. With the recent emphasis on datadriven decision making and accountability, administrators need to more closely evaluate the PD in their schools.

The next section of the literature review focuses on action research, one of three low-cost or no-cost PD activities reviewed in the literature.

\section{Action Research}

Inquiry and action research appear deceptively simple, but in reality faithfully and thoughtfully following these approaches is one of the most challenging aspects of school reform. (Chenoweth \& Everhart, 2002, p. 54)

Problem-solving work is necessary for successful change. Chenoweth and Everhart (2002) wrote that action research is necessary in order for teachers to know whether or not changes they have made have been successful. The inquiry and action research process should be modeled, facilitated and encouraged by school leaders. As indicated in the quote at the beginning of this section, action research is a simple idea but challenging to sustain. It is not a new idea and has strong ties to a significant number of education theorists.

Action research was developed through the work of Eduard Lindeman, Kurt Lewin, John Dewey and Jean Piaget during the early to mid- $20^{\text {th }}$ century. Most recently it has expanded and become more developed by the ideas of Paulo Freire and Budd Hall (Glassman et al., 2012). Kurt Lewin, a social psychologist, is credited with creating the term "action research" during the 1930s (Mills, 2003). According to Glassman et al. 
(2012), the term was first used in an academic article by Ronald Lippitt who worked with Lewin on various research projects. The action research approach described by Glassman et al. and Mills (2003) was based on small group dynamics and identified problems of the organization. It included the development of an action design and a focus on community members as the change agents. While the term action research can be traced to the 1930s, the process very closely resembles John Dewey's five stages of the scientific process (Schmuck, 2009):

- Suggestion-identifying a problem or question to research

- Intellectualization-learning as much as possible about the topic

- Hypothesizing-predicting the outcome if something is changed

- Reasoning-identifying a course of action

- Testing the hypothesis by action-implementing and collecting data

These principles are evident in how action research is approached today (Glassman et al., 2012). Action or classroom research can be a powerful component of PD (Bondy \& Ross, 1998). Darling-Hammond (1996) reported there was a growing body of research suggesting that one way to improve teaching and learning was to encourage teachers to do research in their own classrooms to promote inquiry, reflection and problem solving. Mertler (2006, p. 423) proposed five reasons why teachers should do action research:

1. Action research deals with your problems, not someone else's.

2. Action research is very timely; you can begin whenever you are ready and obtain immediate results.

3. Action research provides teachers with opportunities to better understand, and therefore improve, their educational practices. 
4. As a process, action research can also promote the building of stronger relationships among colleagues.

5. Action research provides teachers with alternative ways of viewing and approaching educational questions and problems and with new ways of examining their own educational practices.

Action research is an activity that teachers do for themselves and involves a series of steps such as those identified by Mills (2003):

1. Identify an area of focus.

2. Collect data.

3. Analyze and interpret data.

4. Develop an action plan.

All action research has the potential to increase knowledge about teaching and how teachers can change instruction to impact student learning (Hendricks, 2006).

Action research has a long history in education. Corey (1949) described action research as, research undertaken by teachers to improve their practice. Corey was one of the first to use action research in the field of education (Ferrance, 2000). Corey held the opinion that if teachers were to improve student learning and achievement, they would need to study problems scientifically in the form of action research. The tradition of action research is grounded in data collection and analysis, conducted in a field setting and addresses problems of practice (Pathak, 2008). There are four basic themes that occur consistently in definitions of action research: "empowerment of participants, collaboration through participation, acquisition of knowledge, and social change" (Ferrance, 2000, p. 9). Figure 3 illustrates the movement through routines of continuous 
confrontation with data during the action research process. The routines are guided by the following five phases of inquiry:

1. Identification of problem area

2. Collection and organization of data

3. Interpretation of data

4. Action based on data

5. Reflection

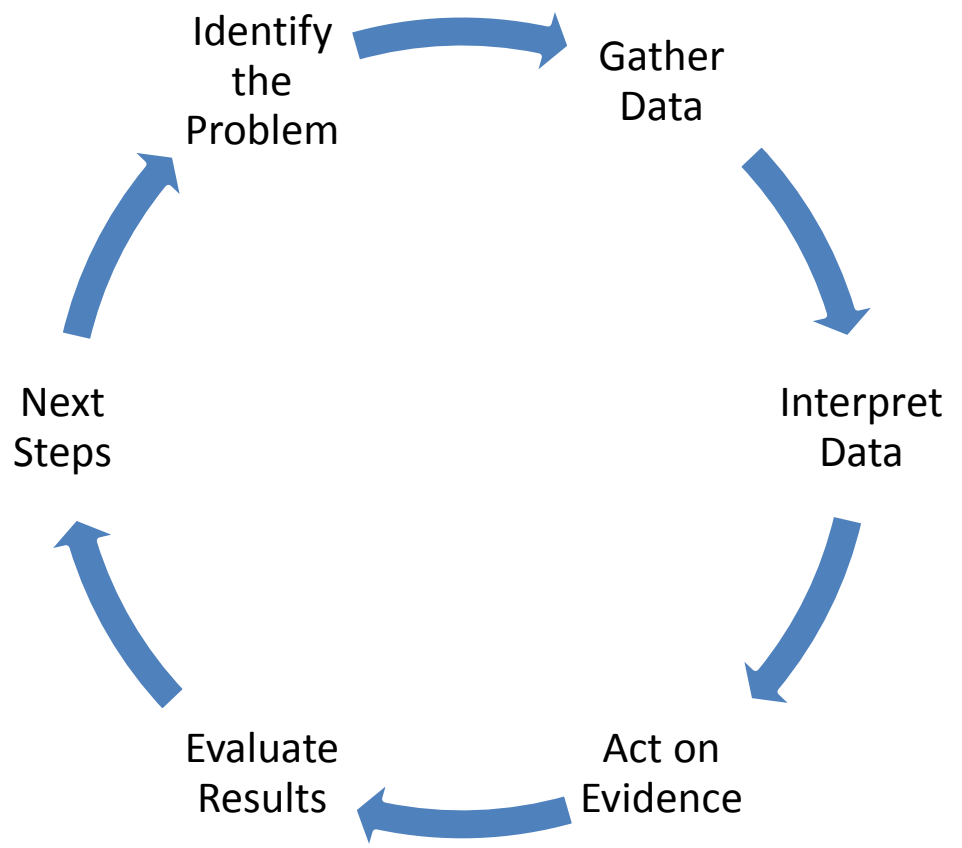

Figure 3. Action research cycle. Source: Ferrance (2000).

Modern Action Research includes an individual, a group or a school and involves problem identification, data collection, analysis and action to improve practice. Schmuck (2009) describes action research as a systematic process for problem solving that includes 
inquiry, reflection and experimentation. Action research is a type of applied research and is action-oriented. It is a problem-solving approach to improve conditions and/or processes. In education, action research involves a commitment to improve and/or learn about instructional pedagogy. It is often used in teacher education programs in the form of an Action Research class or project (Arhar et al., 2001). Action research is defined by Mills (2003) as a systematic inquiry conducted by teacher researchers to gather information on how they teach and how well students learn. Action researchers are committed to "taking action" and "effecting positive educational change" based on the results of their findings (Mills, 2003, p. 3). A 1986 study completed by Rorschach and Whitney supports the collaborative PD model and found that significant changes in teacher practice occurred when the teacher identified a problem of practice and worked with peers on developing the appropriate activities for the pedagogical problems they wanted to investigate.

It is common knowledge that teachers seldom apply what they learn in the traditional types of PD (Zhang, Lundeberg, \& Eberhardt, 2010). Yet, why do school districts continue to pour millions of dollars into ineffective types of PD? The reasons likely include lack of training for administrators in how to plan effective PD, lack of follow through and accountability for teachers and administrators and lack of time in the school calendar for ongoing PD. According to Zhang et al. (2010), teacher research has gained positive support from administrators and teachers and should be considered a "best practice" in designing PD. 
Action research is based on a systematic, reflective, and collaborative process that examines classroom and school issues to plan, implement, and evaluate change (Warren, Doorn, \& Green, 2008, p. 261).

Teachers consistently have asked for the following: collaboration time built into the schedule, teacher input, strong leadership, teacher talk, PD woven throughout the year, whole staff activities, school goals, and strong collegial relationships. (Little, 1999). Action research by teachers has been shown to help develop a community of learners, a culture of respected professionalism, reflection and self-study. Action research also cultivates leadership among teachers, empowering them to believe in the research process as a means to grow as practitioners (Farrell \& Weitman, 2007; Mueller, Devlin-Scherer, \& Mitchel, 2006).

Action research is a type of PD that teachers can do within their own classrooms. It can also support collaboration if teachers are given opportunity to share their research results. Action research focuses on teacher practices that increase student achievement (Farrell \& Weitman, 2007). Teachers are often forced to participate in PD that is "topdown" and "piecemeal" (Farrell \& Weitman, 2007, p. 36) which is not effective and at best, achieves only short term goals in raising student achievement. The National Commission on Teaching and America's Future (1996) reported the following:

Throughout their careers, teachers should have ongoing opportunities to update their skills. These opportunities should offer sustained work on problems of practice that are directly connected to teachers' work and student learning. They should allow for in-depth inquiry, peer coaching, and sharing of knowledge so that real transformation of practice is possible. (p. 96)

School-wide collaboration with action research as the focus could change school culture and impact teaching and learning. Since action research involves studying real 
problems and is focused on improving teaching practice, teacher buy-in can be easier to cultivate (Henry, Tryjankowski, DeCamillo, \& Bailey, 2010). The culture change includes teachers engaging in conversations with colleagues because they want to rather than because they have to. Since teachers are conversing about what is important to them in their own teaching, there is greater motivation and commitment to PD.

PD most recently has been influenced by the imposition of CCSS, high-stakes testing and accountability. Teachers often feel that their professionalism, creativity and efficacy is being minimized by PD that is only connected to state or national mandates (Warren et al., 2008). Fullan and Hargreaves (1996) stated that educational improvement and reform success are dependent on what happens in individual classrooms and with individual teachers. Action research is empowering for teachers. It is a structured means for including them in the school improvement process.

Action research is usually part of pre-service teacher education and typically takes place during the student teaching experience. Action research is considered to be an important part of the growth beginning teachers experience and beneficial as a means to evaluate teaching strategies (Auger \& Wideman, 2000). With increasing accountability measures being imposed on schools and teachers, it is not surprising that growing numbers of practicing teachers are using action research for the purpose of professional growth.

Teachers respond positively to PD that includes professional reading, collaboration with colleagues and data analysis of student achievement (Habegger \& Hodanbosi, 2011). Farrell and Weitman (2007) supported this claim and further stated 
that engagement in action research and classroom-based inquiry supports critical thinking, collaboration, problem solving and reflection, with the most important result of teacher research being metacognition. Metacognition is exemplified by teachers' ongoing reflection regarding their teaching practice and how it impacts student learning (Farrell \& Weitman, 2007). In action research, teachers are studying their own situation to improve the quality and processes within it. The research method helps define what will improve practice continuously (see Figure 4). In this diagram, continuous improvement is at the center and is ongoing with action research as one of the three main components that promote continuous improvement. Action research is a preferred alternative to reading traditional research, which can provide ideas and insights, but rarely connects with an individual teacher's situation like the personal connection action research can provide. (Schmuck, 2006). Warren et al. (2008) stated that, "the use of action research is a key component for teacher development" (p. 260), and even with strong support in the literature, action research is often overlooked in PD plans required by schools and school districts. Due to lack of training and sufficient resources principals do not readily facilitate action research and instead typically rely on traditional models of delivering PD such as workshops led by outside experts. 


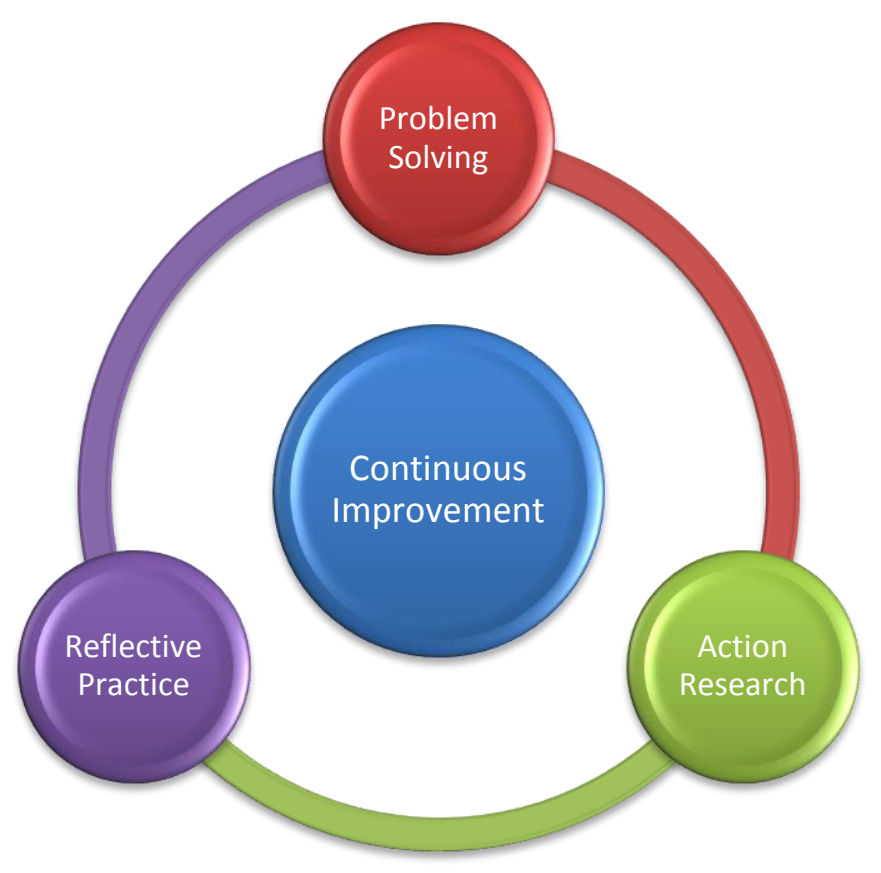

Figure 4. Aspects of continuous improvement. Adapted from Schmuck (2006, p. 24).

A study done by Auger and Wideman (2000) found support for the claim that action research of one's own practice results in change in instruction at the classroom level. They further stated the purpose of PD is to improve the quality of teaching and learning so that all students can be successful. According to Auger and Wideman, action research honors teachers' professionalism and is therefore more likely to impact teaching practice than other traditional approaches to PD and replaces "teacher training" with “teacher learning" (p. 124).

Action research supports a learner-centered view of teaching rather than a training-focused view. Teachers need opportunities to be active learners and grow in professional knowledge in the classroom. This critical reflection of their own practice is what changes perception about content, pedagogy and students. The action research 
process and outcomes promote personal and professional growth. It helps create an atmosphere of inquiry and contributes to a sense of efficacy among teachers, especially in urban schools in which the challenges can be enormous (Crocco, Faithfull, \& Schwartz, 2003).

In action research, students are an important source of information. Teachers will not feel the investment is worth the effort unless classroom practice and student learning improve (Chou-hui, 2011). Measurement of student learning can include observations, examination of student work and performance on assessments (Ross-Fisher, 2008). Mertler (2006) described action research as a systematic inquiry into teacher practice. It allows teachers to better understand the effectiveness of instruction and the quality of assessments. Students are also a focal point as they provide important feedback and evidence.

Action research, like most PD activities, has strengths and weaknesses. When teachers are performing research on their own practices the most obvious limitation is that the researcher is biased. Some school leaders do not ask teachers to perform action research "because they are already so overwhelmed that it will push them over the edge" (Reeves, 2010, p. 80). However, one of the strengths of action research is that it is a means to allow teachers to try, and possibly fail, in search of better teaching strategies. Without a willingness to collect data and accept disconfirming results, teachers can become complacent in their practice and not adaptable to new teaching strategies. Reeves' (2010) model for action research includes four main components: research question, student population, student achievement data and professional practices to be 
observed. Followed with integrity to the process, action research can have profound effects on teaching and learning. To summarize, action research is not what we typically think of when we hear the word "research." Action research is not a library project or a problem-solving exercise. This type of research is used to discover how to improve skills, techniques and strategies in order to have a positive impact on students (Ferrance, 2000).

This study was designed with the premise that no book, workshop or presentation can have more of an impact on teaching and learning than teachers themselves. This is why I have included action research as a significant factor in teacher PD. The next section describes another type of PD in which teachers observe one another, provide feedback, learn new teaching strategies and promote collegiality.

\section{Peer Observation}

Reform movements in education result in band-wagons and rallying cries, but they also represent a debilitating form of dependency and superficiality. (Fullan, 1995, p. 230)

Historically the basic structure of schools has been an obstacle for teacher leadership and collaboration. Often schools do not provide opportunities for teachers to engage in professional dialogue and district initiatives often overshadow any changes teachers would like to implement. (Fullan, 1995). Quick fixes never last and teachers resent going to workshops where someone tells them what to do but do not offer help or follow-up. There has been an unprecedented interest in instructional improvement since the 2002 NCLB legislation. With attention now focused on how students and teachers learn, school administrators are discovering that traditional models of teacher PD do not work. Instead they are looking for strategies that engage teachers in the pursuit of 
continuous instructional improvement (Knight, 2007). This section focuses on a type of collaborative teacher PD known as peer observation which emphasizes the expert knowledge of teachers.

Peer review, peer coaching and peer observation are all terms that refer to processes that are collaborative and systematic and include teachers observing one another teach and giving feedback. Feedback can be in the form of a face to face followup meeting, a checklist or other type of written notes. Usually teachers who are participating in peer observation agree on a protocol to be used for information collecting. For example, participating teachers may read an article on peer observation, discuss what type of data they would find helpful and develop a form for collecting information. Following the observation, teachers meet to discuss what was observed and use the information to plan future lessons. Couper (2004) described the peer observation process as: Teachers receive feedback, teachers reflect on their own teaching, teachers consider the feedback and teachers revise teaching practices. Darling-Hammond (2010) identified peer observation as the most successful way to assist new and experienced teachers. Darling-Hammond (2010) further stated that in schools that use a peer observation or coaching model, teacher retention rates have been found to be higher than in schools without similar programs.

Peer coaching became prevalent in the 1980s, mostly due to the work of Joyce and Showers (1996). Joyce and Showers (1996), after an extensive review of literature on how teachers improve, contended that the most productive training design included modeling, practice and feedback. Through subsequent studies, the aspects of coaching 
that most impacted teacher growth and expertise were identified (Joyce \& Showers, 2006). Following is a list of the benefits of peer coaching.

Teachers who had a coach:

- practiced new strategies more frequently.

- used new strategies with greater success.

- $\quad$ retained knowledge and skill.

- explained new strategies to students and clearly articulated expectations.

- were more likely to understand the purpose and usefulness of new strategies. Additionally, peer coaching and peer observation promote and support professional and collaborative relationships among teachers (Joyce \& Showers, 2006).

The traditional view of peer observation is teachers learning from constructive feedback from teachers who have observed them teaching. There is increasing evidence that learning from watching a colleague teach can even be more beneficial than receiving feedback (Hendry \& Oliver, 2012). Other benefits that have been reported by school districts with fully implemented peer observation programs include retention of more beginning teachers and less isolation of teaching practice (Johnson \& Fiarman, 2012). Universities have also adopted peer observation programs for teaching staff. A study by Bell and Mladenovic (2008) reported that a university peer observation program was perceived as valuable by students and that the majority of participants actually changed their teaching practices as a result of the experience. In another study by Donnelly (2007), participants in a peer observation program as part of postgraduate certificate program, also valued the experience. Observers and those being observed both 
reported gaining significantly from the program by receiving helpful feedback and by watching the teaching of others.

In addition, there is psychological research that supports the improvement of selfefficacy by vicarious experiences. Bandura's (1989) social cognitive theory includes an explanation of how people strengthen their self-efficacy by observing others engaged in successful performance. It is feasible that by observing peers in successful teaching demonstrations, observing teachers could strengthen their own self-efficacy and, over time, become better teachers.

Until the 1970s, there was little research on how teachers learned and implemented new teaching strategies were implemented. It was assumed that teachers would attend workshops, learn new teaching strategies and then return to their schools and successfully implement them. The organization of the school, however, did not support the training teachers had received in the workshops. Teachers were wrongly blamed for being unmotivated or for having a negative attitude when implementation of new teaching strategies failed to take hold (Showers \& Joyce, 1996). In 1980, Joyce and Showers proposed that "modeling, practice under simulated conditions, and practice in the classroom, combined with feedback" (p. 384) was the most successful type of training for teachers. Subsequent studies by Joyce and Showers (1982, 1987a) reported that teachers who shared aspects of their teaching practice such as lesson planning and various teaching strategies via a peer coaching model, actually applied their newly learned skills more frequently and more successfully than did their counterparts who continued to work in isolation. 
It is a challenge to design instruction that addresses the variety of learning needs and interests that come from a diverse group of students. Teaching should not occur in isolation because teachers themselves hold a tremendous amount of knowledge and experience (Rorschach \& Whitney, 1986). Peer coaching can provide teachers with the opportunity to see each other's classrooms and to view the classroom as a laboratory in which the teachers are engaged in collaborative inquiry about teaching and learning.

When there is a belief (either perceived or real) that teachers' deficits are the main reason for $\mathrm{PD}$, resistance and resentment can undermine the success of the activity (Musanti \& Pence, 2010). According to Nazareno (2013),

the use of peer observation, ongoing feedback, and evaluation gives teachers opportunities to learn from and support one another. It allows teachers to hold one another accountable for improving practice, which is a key characteristic of other respected professions like law and medicine. (p. 51)

Peer observation is most successful in promoting growth by teachers when it is a two-way learning pathway, in which the observed and the observer are reflecting, conversing and collaborating on teaching and learning (Musanti \& Pence, 2010). Following are some compelling reasons to consider using peer observation as a PD activity.

School classrooms are typically designed to promote isolation. While this may be unintentional, the physical structure does not provide an easy way for teachers to view each other and/or to provide feedback (Osten \& Gidseg, 1998). There is growing agreement among education researchers that teachers can successfully lead the learning of each other (Margolis, 2009). Margolis (2009) further stated that teachers appear to 
learn best when they are actively engaged, when they can use prior knowledge and when they are comfortable in the learning environment. Beyond that, teachers often learn better from another teacher. Peer observation may decrease the sense of isolation that might be felt by faculty with regard to teaching (Ammons \& Lane, 2012).

Key components of peer observation (Race et al., 2009):

1. Developmental-forward looking, leading to action

2. Reciprocal-not evaluative or judgmental

3. Varied protocols-dependent on teacher preference

4. Negotiated agenda-teacher priorities, chosen observer

5. Not shared with managers-beyond the fact that it took place

6. Reflective-impacts future practice

7. Not burdensome-does not significantly increase workload

Another type of peer observation is called "instructional rounds" (Teitel, 2009). In this model, there is a defined problem of practice that is the focus of the observations and there are usually groups of teachers and/or administrators observing the same classes and teachers. Following is Teitel's (2009) four steps of instructional rounds.

Instructional Rounds-A Four-Step Process

- Problem of Practice

- Observation of Practice

- Observation Debrief

- Next Level of Work 
In this model, the school identifies a problem of practice that is observable, that can be improved and that if acted on will make a significant difference for student learning. The observation team collects data that is descriptive (not evaluative), specific and related to the problem of practice. The observation team discusses the data, analyzes the descriptive evidence and predicts how learning is impacted. The final discussion includes brainstorming the next steps or level of work (Teitel, 2009).

Reeves (2010) defined high-impact professional learning as having three essential characteristics: (a) focus on student learning, (b) measurement of adult decisions, and (c) a focus on people and practices, not programs. Peer observation/coaching has all three of these characteristics. The combination of feedback on student performance, observation of adult practices and focus on people rather than programs promotes a high level of implementation and accountability. The next section is an overview of another PD activity which promotes the three essential characteristics identified by Reeves.

\section{PLCs}

As previously stated, bureaucratic school models are no longer sufficient to prepare students for their future. Administrators and teachers must share in decisions that impact instruction and student achievement (O’Malley, 2010). One type of structure for teachers to develop trusting, collaborative relationships that support growth of the individual, the school and the organization is called a PLC.

The PLC is a concept that was first developed in the business sector. The idea of professional collaboration began around 1924 with Mary Parker Follett. Follett was a social worker, management consultant and pioneer in the fields of organizational theory 
and organizational behavior. She studied human relations and ways of relating in the workplace and recognized that positive relations and sharing of ideas translated into professional growth and improved performance. Since her time, professional collaboration in the educational setting has transformed into the development of PLCs (Williams, 2013). In the late 1960s through the 1980s, attention to collaboration continued to grow in organizations. Collaboration in the workplace was supported as it fostered the new learning required to keep up with rapidly changing technology and kept workers current in best practices. Workers shared new ideas, problem solved and tested new ways of doing things that often resulted in increased output and a more positive working environment (Williams, 2013).

The term PLC was coined by DuFour and Eaker more than 15 years ago. In 1998, DuFour and Eaker presented the idea that the most effective strategy for improving teaching and learning was to develop PLCs (Eaker, DuFour, \& DuFour, 2002). Several books and thousands of workshops later, they are considered to be two of the country's greatest practitioners. In the education world, a PLC is defined as a group of teachers who meet regularly as a team to identify goals for student learning, develop common formative assessments, analyze current achievement, set goals, share strategies and create lessons. During the regular meetings lessons are adjusted based on results. There is an expectation that this collaboration among teachers will produce ongoing improvement and gains in achievement (Schmoker, 2005a, 2005b).

According to DuFour and Mattos (2013) the PLC model provides the opportunity to focus on the collective analysis of student learning rather than the micromanagement 
of instruction thus creating a collaborative culture. Educators in schools that have established PLCs are more likely to experience the most useful and relevant PD (Little, 2006).

Learning is not a solely individual phenomenon, but rather a combination of social experiences and practice. The strategies that promote building a "community of learners" have been successful with students and have recently become widely accepted as best practice in the classroom. Professional learning is no different and should be constructed to help participants feel a sense of belonging and a sense of contributing to a community. The aspects of social learning as described by Lieberman and Mace (2008) are illustrated in Table 3. By instituting a structure that includes the social aspects of learning, through developing a sense of community, teachers learn how to facilitate learning for others. They become part of a collaborative culture and more aware of the complexity of their own work in their classrooms (Lieberman \& Mace, 2008). In Table 3, one of the four social aspects of learning presented by Lieberman and Mace is learning as participating or being part of a community.

\section{Table 3}

Social Aspects of Learning

\begin{tabular}{|l|l|l|l|}
\hline \multicolumn{4}{|c|}{ Social Aspects of Learning } \\
\hline Practice & Meaning & Community & Identity \\
Learning as doing & Learning as intentional & Learning as participating & $\begin{array}{l}\text { Learning as changing who } \\
\text { we are }\end{array}$ \\
\hline
\end{tabular}

Adapted from Lieberman and Mace (2008). 
The PLC model includes time for teachers to meet to examine student work and address problems of practice. These kinds of opportunities seem to appeal to teachers and engage them in a more effective way than top-down mandated PD that gives little control to teachers. Teachers also discount the PD that is seen as remediation for poor performance rather than a process for school wide improvement (Sawchuk, 2010). The definition of professional community varies depending on the source, however, there seems to be a connection between high levels of school community and higher student achievement (Youngs, 2001). When staff members work together, teachers experience less isolation. When there are conversations about teaching and learning, participants often demonstrate a higher commitment to the goals, mission and vision of the school. The desired outcome of establishing a community of learners structure is staff learning in order to increase student learning (Hord \& Sommers, 2008). Figure 5 demonstrates this relationship and identifies steps in a planning backwards model to reach desired student outcomes. In the PLC model, the staff is engaged in professional learning that identifies what they need to do to work more effectively with students. Other important aspects of the PLC process are availability of resources, leadership, policies and a school culture that supports continuous improvement. 


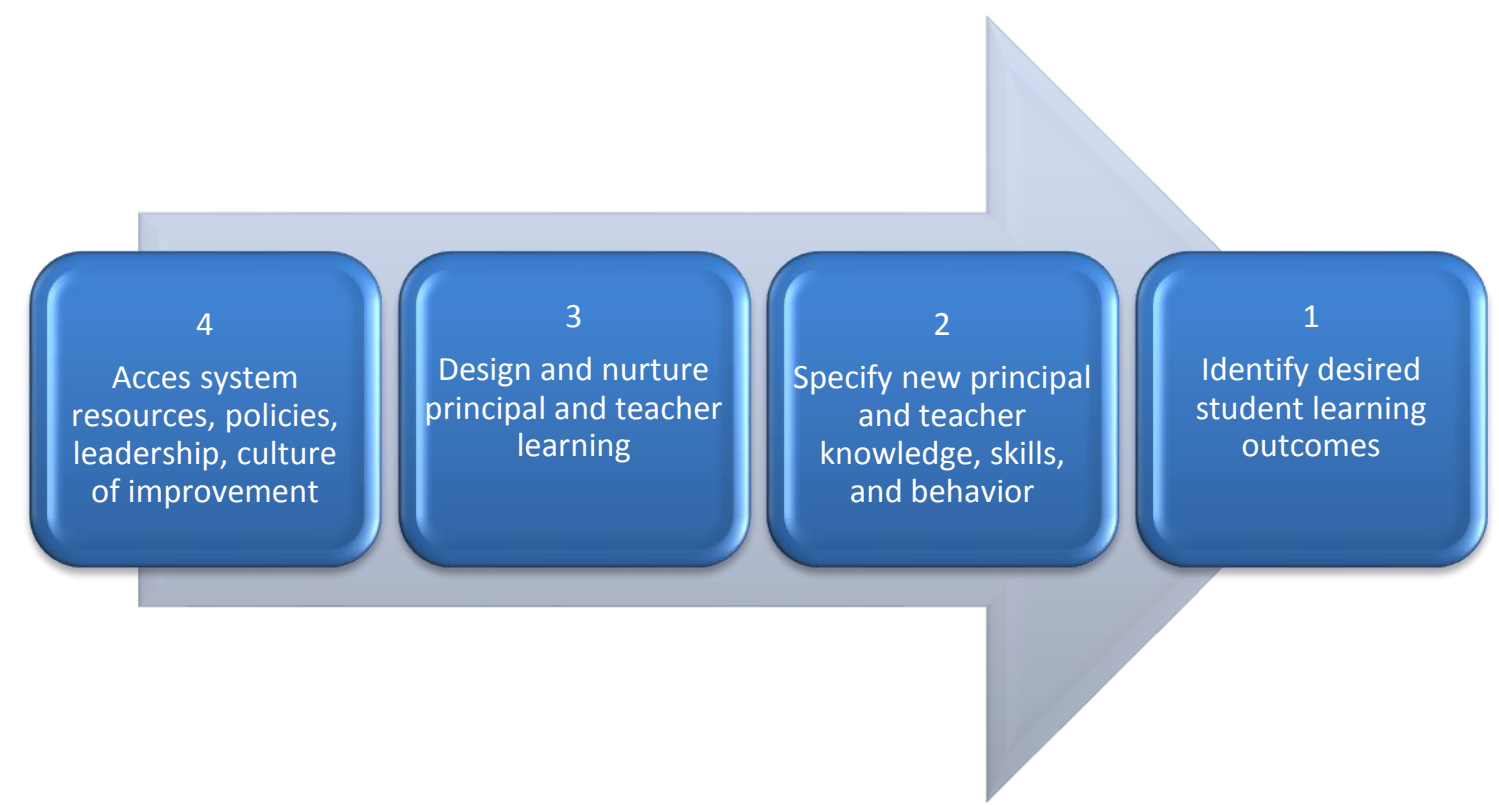

Figure 5. Relationship between professional learning and student learning. Adapted from Hord and Summers (2008, p. 18).

School improvement processes typically include structural changes that have little lasting impact on the school's culture. The assumptions, beliefs, expectations, values and habits that represent the norms for a school shapes how people think, feel and act. The culture of the school has a much greater impact on student learning than any structural change. The development of PLCs with learning as the central purpose of the school has the potential to create a significant cultural shift (DuFour, DuFour, Eaker, \& Karhanek, 2004). Establishing PLCs for ongoing PD creates collaboration and the sharing of practice that breaks down the private and isolative nature of teaching. According to DuFour, DuFour et al. (2004)

As educators develop their capacity to function as a PLC, they create a culture that stretches the hopes, aspirations, and performance of students and adults alike. Students are encouraged to stretch beyond their comfort zone and pursue 
challenging curriculum. Teachers are stretched to develop and implement more effective strategies in their classrooms. The commitment to high levels of learning for all students and the focus on results inspires even the highest performing schools to strive for continuous improvement. (p. 179)

Continuous improvement is something that is challenging to sustain when teachers only participate in one-size-fits-all types of workshops and presentations with no follow-up or accountability. In my experience, districts typically could not afford follow-up materials or fees associated with long-term contractual agreements with PD companies or programs. What little money was available was often spent on half-day or full day group trainings that had little or no impact on instruction or learning.

PLCs provide an opportunity for teachers to learn a new way of interacting with their peers, increasing their level of comfort in talking about their teaching practice and ultimately improving their teaching. Structured collaboration can replace uniformity or cookie-cutter teaching and put teacher knowledge and expertise at the center of curriculum development (Lieberman \& Mace, 2008).

\section{Preliminary Small-Scale Research and Testing}

In my first principal position, 7 years ago, I began experimenting with various types of PD activities and protocols. When there were funds available, I fell into the same trap as many administrators and sent teachers to "one size fits all" presentations and one day "inoculations." What I realized, was that I was promoting the perception that teachers were unable to learn about the effectiveness of their practice from within their own classrooms. I was actually supporting the traditional way that PD had been delivered, 
which was disconnected from the teaching and learning process, and which I had found ineffective during my own teaching career.

In my first principal position in 2007 , I began the school year with a survey that allowed teachers to identify PD activities they had participated in and to evaluate those activities using a Likert Scale on the amount of influence each activity had on their teaching. In this pre-assessment, I noticed that almost $100 \%$ of teachers found time to collaborate as the most beneficial type of PD. The survey also showed a high number of teachers found workshops and presentations the least helpful type of PD. I have used this survey in three different schools and the results were similar.

That first year, I included action research as an option for teachers to incorporate PD into the district requirement that all teachers set professional and student achievement goals. Teachers set goals every year, but they were not revisited during the year and there was no data collection to determine if goals had been met or not. There was very little teacher buy-in for the goal setting process. By connecting an action research protocol to the goal setting, teachers had to identify a problem of practice, what type of treatment they were going to implement, how and what data would be collected and the analysis process they would use. The teachers were also required to present their mid-year progress and final data analysis to the staff. At that time, the school was undergoing major reform and action research allowed teachers to take on a professional role in an activity that informed good teaching practice. Being an active participant in determining best teaching practices increased the sense of efficacy and the willingness of teachers to continue to teach, modify, teach, and so forth. 
One of the most important findings I learned during this preliminary research was that teachers were more engaged in the school improvement process if they felt that change was happening because of them, rather than happening to them. The PD activities became an opportunity for teachers to be active participants in developing school-wide instructional frameworks as well as an avenue for removing the isolation of traditional teaching practice. The teachers who participated in action research exhibited a high level of satisfaction with themselves and their projects when they presented their findings at the end of the year. They believed their projects yielded personal and professional benefits. I observed an increase in teachers' self-efficacy and self-esteem after the first year of required action research projects. In addition, the culture of the staff shifted from individualistic and self-centered to a shared, collaborative, goal-oriented learning community.

Throughout the preliminary research, I looked for ways to incorporate teacher leadership which greatly enhanced participation and teacher buy-in. Teacher led miniworkshops, sharing of implemented strategies and data and teacher led professional learning teams promoted the idea that teachers have skills and expertise that should be utilized. Similar to best practice in teaching students; learning targets were provided to teachers and accountability measures were clearly articulated. For example, teachers in the preliminary research were more likely to implement new strategies when they had to document the completion of a task related to the desired outcome. During the PD on creating reading work samples in content areas, teachers were required to submit one sample to the instructional specialist who provided feedback. During the PD on CCSS, 
teachers were required to submit unit plans with the standards listed for each unit. This also supported the desired outcome of a yearly plan for each course. It was also important to embed the PD within the work day. Teachers were more likely to miss after school sessions and were appreciative of the opportunity to have common prep periods and/or collaboration opportunities during contract hours. Lastly, all PD opportunities included best practice strategies that could be implemented in the classroom and administrators attended and participated in teacher led sessions throughout the school year. My preliminary research indicated a relationship between the effective leadership strategies identified in Figure 2 and successful implementation of PD activities.

In the preliminary research I found the most influential factor for change in instruction is using teachers' own practice and expertise. Yet teachers are often overlooked when it comes to leading school improvement. As a teacher I did not view myself as a change agent nor did I see myself as having any impact on much outside of my own classroom. It wasn't until a colleague asked if I would do a presentation to other teachers on some of the literacy strategies I was using in science that I even considered the possibility that teachers could be resources for each other. My colleague worked to set up PD opportunities for teachers that were led by other teachers. It was a pivotal time in my teaching career that reinvigorated my practice and opened my eyes to the opportunities for learning that existed within my own building. This experience has also impacted my philosophy on instructional leadership and PD.

In my second principal position, 4 years later, I continued to build on what I learned about PD. Students who attended this school were required to complete a number 
of credits in a technical rotation and ultimately choose a "major" for their junior and senior year, while also completing core coursework required for graduation. The junior and senior technical courses award postsecondary credit which allows students to earn up to 40 college credits. Since the school was founded in 1915 the focus has been on technical skill development alongside academic coursework. During the past 97 years, graduates have become industrial engineers, business owners, inventors, mechanical engineers, architects, doctors, lawyers, production workers, etc. It is difficult to find a family in the city who does not have a connection to this school.

During the course of its nearly 100 year existence, the school has undergone significant demographic changes. It began as an all-boys school and remained so until the mid-1970s. While there is still a slight majority of boys enrolled in the school, the freshmen applications are evenly split between boys and girls. The technical programs have provided a foundation for girls to enter technical trades as well as careers which were traditionally male dominated such as engineering, manufacturing, electrical and construction. Despite the focus on technical education and technical careers, many students attend this high school for a hands-on education and go on to pursue a totally different career in college.

The racial diversity has changed significantly during the past 10 years. The Federal, No Child Left Behind guidelines allowed families to attend schools other than their neighborhood school if the neighborhood school was rated as a failing school. The failing schools in this district were located in neighborhoods with predominantly Black and Hispanic families. Today, the school in this study has almost equal numbers of 
Black, Hispanic, Asian and white students which makes it the most racially diverse school in the district. The school has also seen an increase in the number of students from poverty with $67 \%$ of students on free or reduced lunch.

Academically, the majority of students do well. This school has the second highest graduation rate in the district, graduates the largest percentage of minority students and last year made AYP (one of two high schools in the district to meet these requirements). AYP (Average Yearly Progress), which is no longer used as a means to evaluate schools, calculated student growth on standardized testing. Teachers, alumni, parents and students attest to the pairing of core academics with the hands-on technical programs as the main contributing factor to the high graduation rate and student academic success. Similar to other urban high schools, there are achievement gaps at this school. Hispanic and Black students meet standards on state tests at a lower rate than white and Asian students. Eighty-four percent of juniors met the state standard on the writing test in 2012 while only $43 \%$ of black students and $34 \%$ of Hispanic students met. Math scores show similar gaps. The school achievement data from 2012 shows vastly different data. A higher percentage of Black students in junior math classes received satisfactory grades than white students in the same math classes.

The staff at this school is predominantly white which doesn't match the diversity of the student body. The lack of racial diversity among school staffs is common across the district and there is a racial achievement gap at all schools. The district has recognized cultural competency as an area of improvement and recently adopted an initiative to improve cultural competency, especially with regards to race. Glenn 
Singleton (Pacific Education Group), author of Courageous Conversations About Race, and his staff are providing ongoing workshops, institutes, trainings and other PD opportunities for all district staff.

From my own experience as a high school principal, I found it is easier to simply hire an expert to be responsible for improving teacher practice than to take on the task of designing and implementing activities and experiences on your own. However, the payoff outweighs the effort, which is why I decided to write a manual to support principals in their role as instructional leaders. The handbook is an alternative to cookie-cutter, inoculation types of PD with the ultimate goal of providing transformative PD experiences for teachers. The handbook focuses on PD activities that encourage collaboration among teachers such as peer observation and PLCs. It also highlights action research as a way for teachers to investigate problems of practice, implement new strategies and share results using a scientific process and data analysis.

Teachers learn best in the same ways that most students learn best: actively, drawing from prior knowledge, and in a comfortable environment (Margolis, 2009). Margolis suggested that teacher-led PD has more impact than off-site workshops that seem disconnected to the "real" situations in classrooms.

\section{Summary}

Smart principals know that capitalizing on teachers' leadership and instructional strengths is smart leadership. (Stronge, 2013, p. 61)

Chapter 2 begins with an overview of the history of teacher PD. The literature supports the claim that a significant portion of PD is viewed by teachers as disconnected 
from their practices and mostly as one-shot workshops with little or no follow-up, practical application or accountability. Thus, teachers often perceive PD as idiosyncratic and irrelevant (Lieberman \& Mace, 2008). Traditional PD activities such as attending lectures and workshops may not be transferrable to the classroom as teachers are expected to deliver education to an increasingly needy and diverse student population. Consequently, teaching in the traditional format is no longer effective. No longer will working in isolation be the norm. Teachers must communicate with one another, talk about teaching and learning and observe colleagues to adequately serve the students who are in our public schools (Lieberman \& Mace, 2008). Changes to instructional practices that are mandated are insufficient. Teachers are the experts and should be called on to take formal and informal leadership roles (Margolis, 2008).

The National Staff Development Council (Hirsch, 2009) recommended a PD system so that "every educator engages in effective professional learning every day so every student achieves" (p. 2). This premise includes regular opportunities for teachers to collaborate, regular and continuous feedback and time for teachers to share teaching strategies. This type of PD translates into improved teaching and ultimately improved student achievement. To be successful, schools and districts should implement PD that is sustainable and ongoing. Darling-Hammond (2009) also supported the idea of professional learning focused on student achievement and opportunities for teachers to collaborate regarding curriculum planning and teaching practices. The literature review provides numerous examples of successful PD and arguments supporting the elimination of the one day inoculation type of training for teachers. There is much that can be learned 
and applied when teachers collaborate in a teachers teaching teachers model. Administrators and school leaders (including teacher leaders) can provide the frameworks, tools, time and support for teachers to acquire a sense of professionalism, responsibility, efficacy and motivation to constantly reflect on teaching practice and their impact on student learning.

Haley (2004) wrote in her article about teacher PD that teachers are profoundly affected by reflective practices. I have observed teachers become energized and excited about the shift in pedagogy when given the opportunity to conduct research in their classrooms, collaborate with colleagues, observe other teachers and reflect on how they might use this information to grow as professionals. Fullan (2007) reported that PD programs are rarely "powerful enough, specific enough, or sustained enough to alter the culture of the classroom and school" (p. 35). Regardless of years of experience, teacherdirected PD that is ongoing and more personalized appears to have the most impact on classroom instruction. It is classroom instruction that has the most impact on student learning. If this is true, then why are there so many short, fragmented, outsider-led training sessions? Lotter, Hardwood, and Bonner (2006) claimed that the shift from shorter more formulaic PD to long-term, reflective PD can be complex and timeconsuming.

Admittedly, it is true that simply writing a check for an expert to present a workshop is easier and less time consuming that planning ongoing, collaborative opportunities for teachers. However, the benefits that can be derived from teachers working together to improve their instructional practice, at a much reduced financial 
burden on school districts, surely challenges administrators to devote the time and energy it will take to sustain high quality PD that impacts classroom instruction.

Finding ways to improve teacher performance has become a focus in education reform. Common approaches to PD include one-shot presentations, videos of artificially created scenarios in classrooms which teachers were told to mimic, how-to-books and teaching materials such as colorful slides that promise to engage students in learning. These approaches are rarely related to the reality of a typical classroom or to what teachers need to improve their practice. A personalized approach to PD yields the best results. Colleagues working together, nurturing and supporting each other in nonthreatening and non-evaluative ways improves thinking and teaching (Eisenberg, 2010). In my 30 years in education (24 as a teacher and 6 years as a high school principal), I can attest to the lack of attention paid to what really matters to teachers and what can impact instruction. After participating in many of the one-shot presentations, after watching dozens of how-to videos and after reading countless books by authors claiming to have discovered the "magic bullet," I sought my own PD through likeminded colleagues.

During my last 10 years as a classroom teacher, I engaged in collaborative dialogue, observed teachers and allowed teachers to observe me. We exchanged feedback, presented ideas for lessons during teacher workshop days and encouraged other teachers to do the same. I modified my teaching practices based on data I collected in my own classroom and shared student work with a group of teachers that agreed to meet on our own as a Critical Friends group. 
I believe the frustrations I experienced as a teacher regarding PD are still common today. Futernick (2010) claimed that some teachers leave the profession or are removed due to inherent problems within the system that promotes isolation and individualism with little opportunity to learn from colleagues. Admittedly, there are teachers who struggle and some are unfit for the teaching profession. However, I concur with Futernick and believe we must ensure that teachers have meaningful and regular performance evaluations, PD that includes collaboration, reasonable class sizes and time for planning.

In the literature review, I focused on three types of PD: Action Research, Peer Observation, and PLCs. These activities can be transformative for teachers. Providing teachers the ability to analyze teaching can be enriching and when accomplished with colleagues, reduces the isolative nature of the one-teacher classroom (Rorschach \& Whitney, 1986). School leaders play a critical role in designing PD that promotes collaboration and allows teachers to emerge as leaders. The constructivist approach described by Lambert (2000) has provided an atmosphere of collaboration and reciprocity. The $\mathrm{PD}$ activities described and tested in this study are constructivist in nature and rely heavily on prior experience, collegiality and reflection. In my preliminary research, it was evident that teachers valued the opportunity to contribute to the planning and evaluation of their PD. Constructivist learning for teachers provides the opportunity for reciprocal processes that lead toward a shared purpose in teaching and learning. Margolis (2009) wrote, The complexity of today's schools requires teacher collaboration and leadership. If teacher leaders work intentionally to help their colleagues build bridges from existing approaches to new ones, they may be uniquely positioned to get local 
buy-in for reforms in ways that education officials, even principals, cannot. ("Teachers as Adult Learners," para. 3)

PD needs to be effective (focused on instruction and impact student learning), sustainable and continuous, provide opportunities for teaches to learn from each other, provide opportunities for teachers to influence how and what they learn and inspire teachers to think about what they need to know. Figure 6 represents the components of effective PD.
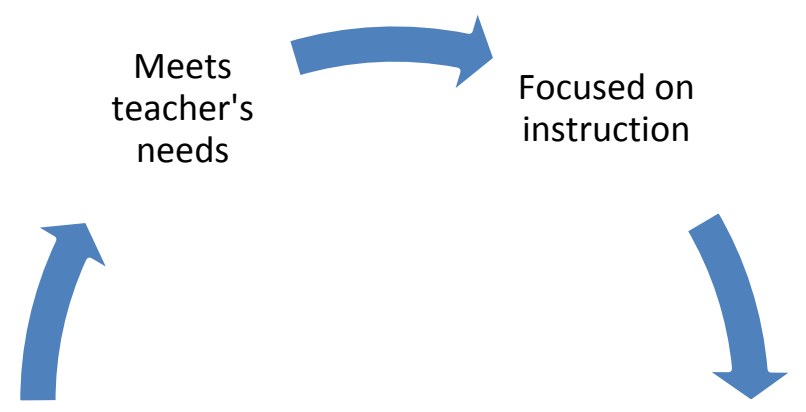

Collaborative Sustainable

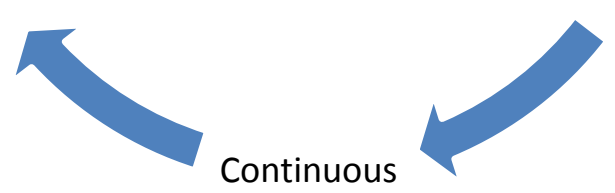

Figure 6. Effective PD. Adapted from Lieberman and Mace (2008).

Why should administrators be concerned about the type of PD that is offered to teachers? It is likely that every administrator has been involved with some type of school reform focused on student learning. I don't think any educator would argue that what takes place in the classroom is largely dependent on the teacher. Therefore, the teacher has the greatest impact on student learning. Standards-based reform tends to be a carrot- 
and-stick approach with teachers being told what to teach and rewarded for students' performance on standards-based exams. This process is designed to motivate teachers to teach to the standards. We have learned that this approach alone does not lead to dramatic gains in student achievement. Teacher PD focused on only the implementation of state standards leads to minimum competency and is more of a control than a commitment strategy (Smith \& Rowley, 2005). Administrators also are charged with ensuring there are equitable practices within schools. Unless effective instructional practices are identified, taught and reinforced, instructional inequities will prevail that divide students into elite high performers and struggling low performers (Kent, 2004).

The literature presented in this paper suggests that teachers are more likely to benefit from PD activities that are content focused, ongoing, collaborative and connected to activities within the school. Teachers also are more likely to support and benefit from PD activities they themselves select. Administrators can choose PD that is remedial and controlling or include teachers in assessing needs and planning activities. There are external control factors such as local, state and national accountability systems, however, the teachers should have some influence on the kinds of training and growth activities needed in their school. This approach increases teacher professionalism, which can have a positive influence on their commitment to improving teaching practice. I believe it is rare for a school district and/or school leader to require teachers to do action research. I was required to do an action research project in my master's program but it was never suggested as PD in my subsequent 26 years in the classroom. 
Consistent, ongoing, high quality PD must be provided if efforts to improve teaching and learning are going to be successful. PD must have a direct connection to teacher practice. The focus must shift from out of school training by experts, to schoolbased, embedded learning in classrooms. PD will only be successful if it is sustainable and directly related to what goes on in actual classrooms.

I embarked on this journey and chose this project because I believe there is a lack of support, expertise and resources within school systems to implement professional learning/development in a way that increases teacher efficacy and raises student achievement. Also, I wanted to research and develop a plan that did not require a huge budget or financial investment since most PD monies have been greatly reduced or eliminated. The next chapter describes the research methodology proposed for this study. It focuses on qualitative data collected from principals and school administrators through surveys, interviews, focus groups and observation. This preliminary research has helped me formalize my own approach to designing PD, guided by work as a school leader and helped to refine the tools and processes in the handbook. I believe teachers are the experts and, with the right information and tools, principals can design PD that is relevant, ongoing and that changes instruction to improve student achievement. 


\section{CHAPTER III}

\section{RESEARCH DESIGN AND METHODOLOGY}

\section{Introduction}

PD for teachers in this country has hardly changed since the 1950s. It is still common for school districts to provide generic training that is disconnected from actual teaching practice and the needs of its teachers (Royce, 2010). The problem addressed in this study is the lack of guidance provided for principals to develop meaningful, sustainable, low-cost PD programs.

In this study, a problem-based learning model designed by Bridges and Hallinger (1995), was used to address the following research question: Can a resource handbook titled, Teachers Teaching Teachers: Designing Successful Professional Development on a Shoestring Budget, be useful in building capacity and confidence in principals to design meaningful, collaborative, inexpensive PD opportunities for teachers? The study includes data from preliminary research and testing of an emerging resource handbook used in my previous assignments. The study includes the further development and field testing of the handbook at an urban high school and the development and implementation of a workshop for high school principals utilizing the handbook.

The handbook assisted school leaders in the design, implementation and evaluation of a teacher PD program that focused on teacher-led workshops, teachers teaching teachers, collaborative teams, action research and peer observation. The 
handbook was peer reviewed by school principals and information from the review and pilot test was used to revise the handbook. The handbook provided school leaders with tools and information that helped with the evaluation of current PD and with the design of future professional learning opportunities. It also provided suggestions for developing opportunities for shared leadership, accountability and a framework for creating buy-in from staff.

The handbook, Teachers Teaching Teachers: Designing Successful Professional Development on a Shoestring Budget, includes background information and a rationale for designing PD that focuses on teachers teaching teachers. Three areas of PD are identified and described: Action Research, Peer Observation, and PLCs. The handbook includes historical information, research, definition of terms, steps for implementation, forms and activities. The handbook concludes with a list of resources related to designing teacher PD. In the next section, I outline the work/action plan to complete the design and evaluation of the handbook.

\section{Work/Action Plan}

The first part of the work/action plan was to complete the online exam on human subjects research and request a waiver from the Human Subjects Committee at Portland State University. There was no risk to the participants in the study as the study was designed to assess the effectiveness of the handbook and not to analyze or review human subjects.

The preliminary research and testing started during my teaching career from 1983-2007. I used my own experiences to influence how I designed teacher PD in my 
role as a principal beginning in September 2007. I found it frustrating to discover a glaring lack of district resources and guidance. During my first year as a principal it was clear that I would be evaluated as an instructional leader, including my ability to plan and implement a teacher PD plan.

Accordingly, I began to investigate what had been done in the past and the current teacher's perceptions of these previous activities. I found a high level of dissatisfaction with workshops and trainings provided by so-called experts and a high level of satisfaction with structured opportunities for teachers to collaborate and talk to each other. I began the planning process by including teachers in dialogue about their past experiences, their current problems of practice, current student achievement data and teacher PD preferences. Five teachers volunteered to be part of a PD planning team and we met the weekly the first month of school to formulate a draft of PD activities for the upcoming school year. From the data collected from teachers and conversations with the PD planning team, we proposed a plan that provided collaboration, choice and recognition of the professionalism and expertise of teachers. We also folded into the PD plan, PLCs as one of the protocols as this was identified as a district initiative. Teachers participated enthusiastically, proudly shared their work during presentations at staff meetings and in many cases, influenced other teachers to reflect on their own teaching strategies. In the next 5 years, at two different schools, I implemented a similar process with the same results. I have done preliminary research and testing of an emerging handbook. I followed the research and development (R\&D) process to formally design, field test and assess the usefulness of the handbook to build capacity and confidence of 
high school principals to begin a collegial approach to teacher PD in their schools. Table

4 represents the work plan used to complete the study and handbook. The main field testing of the handbook occurred in June 2014.

Table 4

$R \& D$ Proposed Timeline

\begin{tabular}{|c|c|c|}
\hline \multicolumn{3}{|r|}{ WORK PLAN } \\
\hline Timeline & $\begin{array}{l}\text { Step in Product } \\
\text { Development }\end{array}$ & Activity \\
\hline $\begin{array}{l}\text { September } 2007- \\
\text { September } 2012\end{array}$ & $\begin{array}{l}\text { Step 1: } \\
\text { Research and } \\
\text { Information } \\
\text { Collecting }\end{array}$ & $\begin{array}{l}\text { - Preliminary research } \\
\text { - Review of literature } \\
\text { - Conduct testing of protocols, processes and forms } \\
\text { - Survey teachers on PD } \\
\text { - Begin identification of format for the handbook }\end{array}$ \\
\hline $\begin{array}{l}\text { September } 2012- \\
\text { June } 2013\end{array}$ & $\begin{array}{l}\text { Step 2: } \\
\text { Planning Objectives, } \\
\text { Learning Activities, } \\
\text { and Small-Scale } \\
\text { Testing }\end{array}$ & $\begin{array}{l}\text { - Meet with group of principals to discuss PD planning } \\
\text { - Refine protocols and processes to be included in } \\
\text { handbook } \\
\text { - Provide forms from handbook to be posted on district } \\
\text { resource page for principals } \\
\text { - Testing of various protocols and activities }\end{array}$ \\
\hline September 2013 & $\begin{array}{l}\text { Step 3: } \\
\text { Develop Preliminary } \\
\text { Form of the Product }\end{array}$ & $\begin{array}{l}\text { - Complete draft of handbook } \\
\text { - Organize handbook combining narrative with protocols } \\
\text { and activities } \\
\text { - Add resources to the handbook } \\
\text { - Design cover, table of contents and bibliography }\end{array}$ \\
\hline April-May 2014 & $\begin{array}{c}\text { Step 4: } \\
\text { Preliminary Field } \\
\text { Testing }\end{array}$ & $\begin{array}{l}\text { - Invite high school principals from Portland Public } \\
\text { Schools to participate in focus groups to provide } \\
\text { feedback about the handbook } \\
\text { - Online survey for feedback from district administrators } \\
\text { - Continued field testing at Franklin High School } \\
\text { - Survey Franklin High School Administrators }\end{array}$ \\
\hline April-May 2014 & $\begin{array}{l}\text { Step 5: } \\
\text { Main Product } \\
\text { Revision }\end{array}$ & $\begin{array}{l}\text { Revise handbook based on feedback from school } \\
\text { administrators }\end{array}$ \\
\hline
\end{tabular}


Table 4 (continued)

\begin{tabular}{|c|c|c|}
\hline \multicolumn{3}{|r|}{ WORK PLAN } \\
\hline Timeline & $\begin{array}{l}\text { Step in Product } \\
\text { Development }\end{array}$ & Activity \\
\hline May 2014 & $\begin{array}{c}\text { Step 6: } \\
\text { Main Field Testing }\end{array}$ & $\begin{array}{l}\text { - Workshop for high school administrators } \\
\text { - Observations, surveys and interviews on the } \\
\text { effectiveness of the handbook } \\
\text { - Interviews of district office administrators on the } \\
\text { potential usefulness of the handbook }\end{array}$ \\
\hline May-June 2014 & $\begin{array}{c}\text { Step 7: } \\
\text { Operational Product } \\
\text { Revision }\end{array}$ & $\begin{array}{l}\text { - Analyze data from main field testing and surveys } \\
\text { - Refine handbook based on data analysis }\end{array}$ \\
\hline August 2014 & $\begin{array}{c}\text { Step 8: } \\
\text { Operational Field } \\
\text { Testing } \\
\text { Step 9: } \\
\text { Final Product } \\
\text { Revision } \\
\text { Step 10: } \\
\text { Dissemination and } \\
\text { Implementation }\end{array}$ & $\begin{array}{l}\text { Steps } 8,9 \text { and } 10 \text { include distribution of the product district } \\
\text { wide to use in planning PD as well as final revisions and } \\
\text { possibly publishing the handbook for distribution beyond } \\
\text { the district. } \\
\text { For the purposes of this study, only steps } 1-7 \text { will be } \\
\text { completed. }\end{array}$ \\
\hline
\end{tabular}

\section{Restatement of the Problem}

School administrators, primarily principals, are often held responsible for designing teacher PD. While some districts adopt frameworks or specific types of growth activities for teachers, many provide little guidance or accountability for the PD that takes place within school buildings. Principals struggle to keep up with the day to day demands of the job and teacher PD can be far down on the list of priorities. As a result, many school leaders have enlisted the help of very expensive "outside experts" to present short, fragmented workshops or lectures (Lotter et al., 2006). This shorter more prescriptive approach to PD is less complex and less time-consuming for principals to organize; however, research confirms that, long-term, reflective practice learning opportunities 
have greater impact on teaching and learning (Eisenberg, 2010). Reeves (2010) stated that effective PD is sustainable and provides opportunities for application, practice, reflection and reinforcement. Teachers are also likely to keep new strategies when they receive coaching (by peers or mentors) and when there is feedback about their efforts (Joyce \& Showers, 1987b).

Most schools do not have the budgets to hire outside consultants to provide teacher PD. Across the nation, school districts have experienced severe budget cuts and teacher PD budgets have been reduced or eliminated in most cases (Habegger \& Hodanbosi, 2011). There are two problems addressed in this project:

1. the lack of funding for PD

2. the lack of resources for principals to use in designing a program that is sustainable and continuous.

The goal of this study was to determine if the handbook builds the capacity and confidence of high school principals to institute a low-cost PD program that promotes teacher collaboration and improves teaching and learning.

\section{Research Design}

The design of the product for this study is based on the R\&D process described by Borg and Gall (1989). The R\&D model fits nicely with problem based learning as it begins with a question, in this case related to a problem of practice, and does not simply test a hypothesis. The model is described by Borg and Gall as "a process used to develop and validate educational products" (p. 782). The product tested in this project is a handbook for school principals to use to design PD for teachers. There are 10 steps in the R\&D cycle (see Figure 7). 
- Research and information collecting

- Planning objectives, learning activities, and small-scale testing

- Develop preliminary form of the product

- Preliminary field testing

- Main product revision

- Main field testing

- Operational product revision

- Operational field testing

- Final product revision

- Dissemination and implementation

Figure 7. Steps in the R\&D Cycle. Adapted from Borg and Gall (1989, pp. 784-785).

Before beginning the 10 steps in the R\&D process and continuing into step 1 , a problem is identified. In this project the problem, simply stated, is the lack of resources provided to principals to help in the design of teacher PD. The complexity of the problem includes lack of funding sources, PD that is fragmented and not continuous and a dependency on outside experts to deliver PD. The R\&D process provides a step by step road map to assist in the planning, design, implementation and evaluation of the product. The following discussion describes the $R \& D$ process as it pertains to this project.

\section{Research and Information Collecting}

After identifying the problem, a lack of resources for principals in designing teacher PD, I began to research literature related to the topic. I had already experienced 
firsthand the frustration of being a principal with minimal financial resources and no guidance on how to plan an effective teacher PD program.

The literature review provided information that supported the problem identified for this project. While there are effective models for PD activities that transform teaching and impact student learning, there does not seem to be any kind of resource for principals to use in selecting and implementing a plan that is affordable, continuous and collaborative. Leadership plays a significant role in PD that results in teacher learning and implementation of effective teaching strategies. The literature review includes a description of a constructivist approach to leadership that promotes the idea that teachers are the real experts. The activities included in the manual are designed to engage teachers in collaboration and reflection.

\section{Planning Objectives, Learning Activities, and Small-Scale Testing}

This step in the R\&D process further develops the details of the product. It was in this stage that I began to identify the specific activities that should be included in the manual as well as some of the tools that principals would need to successfully assess and implement various aspects of teacher PD. One challenge for principals that was identified in the literature, interviews and my own experience was the lack of continuity in PD activities. District led workshops and/or presentations from outside experts were disjointed and lacked follow-through. Information from these one-stop experiences was not translating into improved instruction or student learning. This information was valuable as it informed my decisions on which activities to include and emphasized the importance of designing a product that not only explained activities but also provided 
suggestions on how to sustain the program with little or no budget and how to make the activities continuous learning opportunities for teachers. It was also during this process that I made the decision to focus on teachers teaching teachers and shift the emphasis of teacher PD as only being delivered by outside experts to the teacher as expert and the teacher as lifelong learner.

During my own teaching career of 25 years, I had experienced mediocre, at best, PD and sought out opportunities on my own to grow as a professional. In my first year as a principal, I was faced with the arduous task of designing PD for the entire teaching staff with no support or guidance from district leaders. Rather than mimic what my own experience had been, I decided to enlist the help of teachers to identify what activities they would find useful. The process was very informal and lacked a clear vision but there were some positive outcomes the first year. Teachers used data and student work to identify problems of practice, some teachers researched specific strategies and reported the outcomes at staff meetings and some teachers agreed to observe each other during the school year.

I collected information for this project over a 6-year period in three different high schools. I tested various types of PD activities and protocols from 2007 to 2011 in a large suburban high school and from 2011 to 2013 in two large urban high schools. Although the settings were different, the preliminary research results were identical. Following is a description of the high school settings and the information collected that was helpful in the product design. 
The suburban high school had just been divided into four small schools and was undergoing major reform. There was no formal PD plan or program provided by the district but there was an expectation that building principals would design and implement a PD plan each year. There were some funds available through a smaller learning communities grant, however the funds were used sparingly as one of the goals was to design PD that was not dependent on additional funding.

The initial research included surveying teachers regarding PD experiences and the level of satisfaction and influence on teaching practice. The surveys indicated a high degree of satisfaction with collaborative, ongoing activities and a low level of satisfaction with "one shot" types of workshops. The first thing I did before proposing any type of PD plan was survey the staff to see what they thought of previous opportunities that had been provided. I adapted a survey that was used in a large urban district which included a Likert scale to rate each of the activities.

The survey information was then categorized to show which types of activities teachers believe yield the greatest impact on student learning. Activities that were brief and presented by experts were rated by teachers as having the least impact on learning (see Figure 8). Activities that were held over several days or weeks and presented by colleagues had the most impact on student learning (see Figure 9). 


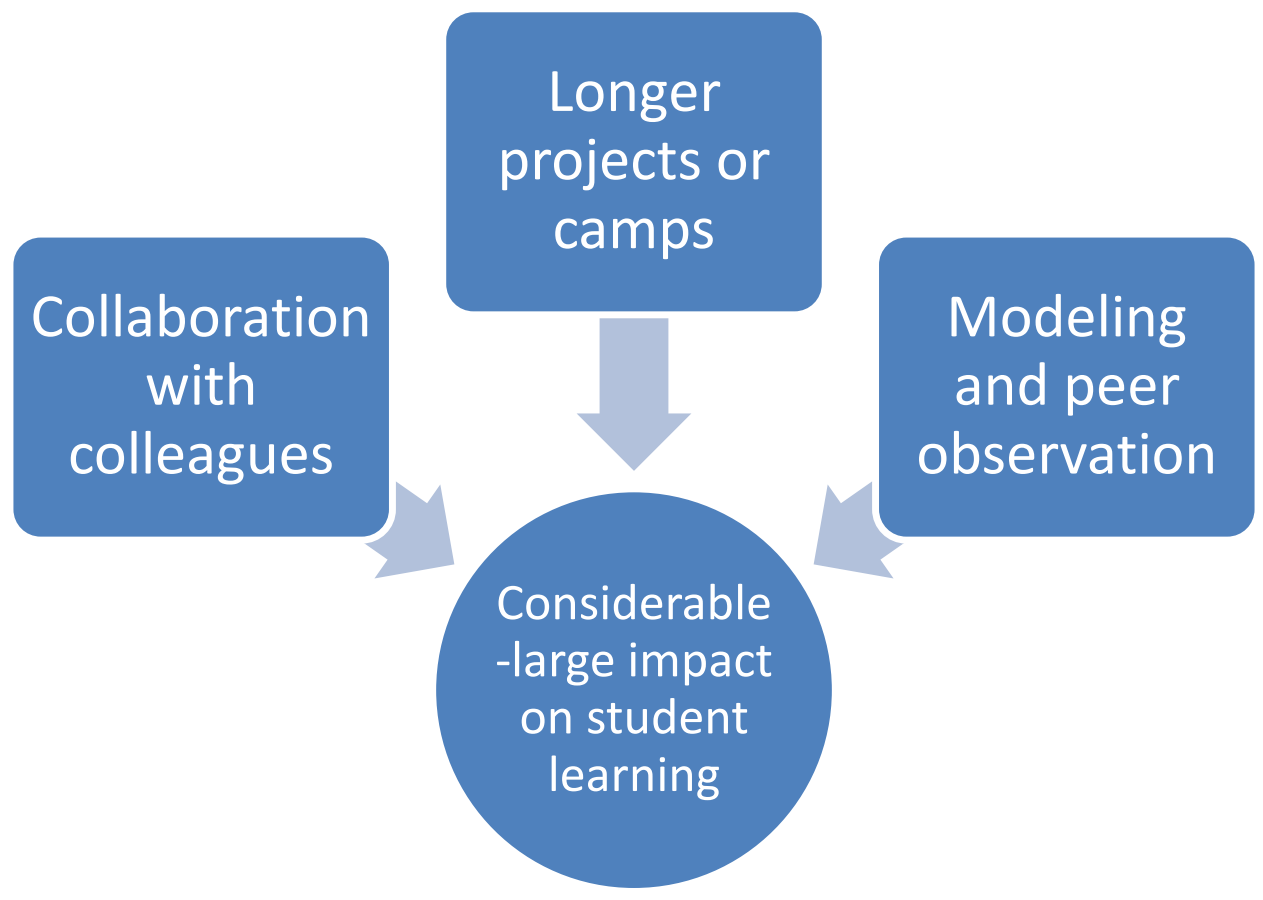

Figure 8. Activities that have a considerable to large impact on student learning.

It was apparent from the survey that teachers believed the greatest impact on student learning were the types of activities that promote collaboration and sharing of ideas between teachers. There was also a strong indication that teaches did not think oneday workshops provided by experts (other than teachers) had very much impact on teaching and learning. 


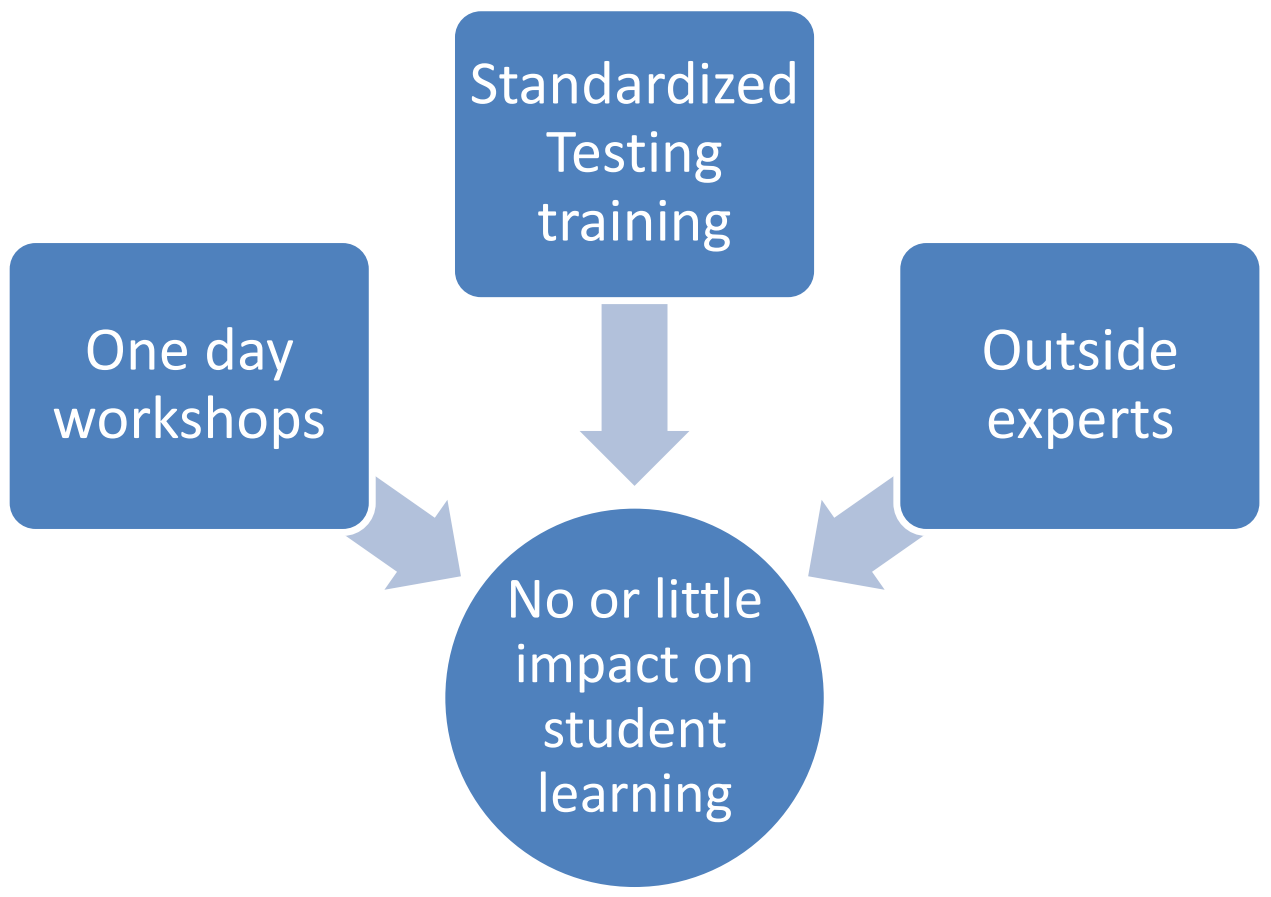

Figure 9. Activities that have little or no impact on student learning.

Approximately 40 teachers participated in the year-long PD plan. Surveys were given at the conclusion of each activity and following are some of the responses shared by teachers:

I found the experience to be valuable and relevant to my teaching. Teachers seem to be more in tune with the current needs of teachers.

I continue to appreciate the opportunity to observe my colleagues, especially those in a different discipline. It really helps to create a positive, professional community.

I liked talking and listening to my colleagues. I learned some valuable things from them that I can immediately implement in my classroom.

I immediately put the ideas I learned today into a lesson.

This was the most helpful PD I have had in 20 years of teaching

I have many new strategies and a new enthusiasm to take back to my students. 
Most of the responses were positive and indicated a desire by teachers to have more opportunities to collaborate with colleagues. It was this type of feedback that compelled me to continue to look for ways to engage teachers in the planning and implementation of PD opportunities.

The two activities that received the most positive responses from teachers were action research and peer observation. I presented action research as a way to make the goal setting process in the teacher evaluation tool more relevant and measurable.

Historically, at this school, teachers wrote down their goals at the beginning of the year but had no plan in place to measure whether or not the goals were met. At the end of the year conference, it was merely a ritualistic conversation with the principal on whether or not the goal(s) had been met and was lacking in any kind of data to support the claims. I provided teachers with a form to identify a problem and design a plan to test something that they believed would impact student learning. Their plan had to include some form of new strategy or "treatment" and some type of data analysis. As the year progressed and teachers did monthly check-ins, I realized that these projects were having a significant impact on teacher efficacy and student learning. Teachers were excited about the results they were seeing and had a sense of pride about their implementation of the action research project.

During the last few staff meetings of the year, teachers presented their action research results. Presentations included elaborate charts and graphs as well as student feedback. Some teachers shared that this project transformed their teaching. The action research projects and presentations by teachers also supported my beliefs that teachers 
learn best from each other, are capable of making changes within their own practice and are the single most influential factor in raising student achievement.

\section{Development of the Preliminary Form of the Product}

My interest in teacher PD began during my own teaching career. I was

disappointed in the opportunities I was given during my career and had often sought out colleagues to discuss problems of practice and teaching strategies. When I became a principal and had to design a PD plan, I was determined not to model what I had experienced but to attempt to provide opportunities that would engage teachers in collaborative learning from each other. It was evident that there were very few resources for principals in designing a coherent plan that focused on teachers teaching teachers.

The preliminary form of the product was beginning to take shape from the initial identification of the problem. However, the information collected in steps 1 and 2 of the R\&D cycle provided a deeper understanding of the problem and how the product would address it. The literature supported the following ideas or rationale for the design of the handbook:

- Teacher PD was often fragmented and a series of one shot workshops with no follow through

- Principals often do not have resources to assist in the planning of teacher PD.

- Outside experts are often used to provide teacher PD (although budget cuts have significantly reduced the ability of districts to hire outside contractors).

- School leadership plays a significant role in the success and/or failure of teacher PD programs.

Before actually designing a handbook, I had experimented with three main types of PD activities: peer observation, action research and PLCs. These three activities were 
chosen as they were low cost or no cost, could be implemented without additional training and did not require any outside expert to implement and instead, relied on teachers teaching teachers. These activities also require multiple sessions that can help establish continuity within the PD plan. With the activities selected, it was now time to field test parts of the product.

\section{Preliminary Field Test}

The initial draft of the handbook was reviewed and implemented by the administrative team at a large urban public high school in the Pacific Northwest. They were not required to field test all parts of the handbook but chose activities and resources that were most relevant and applicable to their school. The administrative team at this school used the handbook to plan and implement peer observation and PCs for teacher PD. The school has approximately 1,500 students and 80 teachers. Teachers participated in PD approximately 10 hours per month. I asked for volunteer high school principals in an urban public school district to participate in focus groups to review the handbook, complete a scavenger hunt and answer questions about the usefulness of the handbook.

Evaluation of the handbook was qualitative and in the form of oral interviews, written feedback and a survey.

\section{Main Product Revision}

The administrators from the preliminary field testing provided feedback regarding the effectiveness of the handbook in building their capacity and confidence for planning and implementing collegial teacher PD. Refinements to the handbook were made following the preliminary field testing. Effectiveness, for this project, is whether or not 
the principals and/or vice principals reported gaining the knowledge and confidence to design and implement a collegial PD program in their schools. Feedback from the administrators indicated that there are parts of the handbook that are unclear, parts that need more explanation and/or parts that need revision. I made revisions to the product based on this feedback.

\section{Main Field Testing}

The main field testing included participants from a large urban school district. Principals and school administrators participated in a 3-hour workshop on designing a PD plan. The workshop format included using the handbook: Teachers Teaching Teachers: Designing Successful Professional Development on a Shoestring Budget. Following the workshop, participants were asked to complete an anonymous survey on the usefulness of the handbook.

During the workshop, participants used the handbook and provided summative feedback on the usefulness of the handbook in designing a PD plan. The feedback was in the form of anonymous surveys following the workshop.

Table 5 outlines the format for the workshop. 
Table 5

Workshop for School Administrators Utilizing the Handbook: Teachers Teaching Teachers: Designing Successful PD on a Shoestring Budget

\begin{tabular}{|l|l|}
\hline Activity & Time \\
\hline Introductions, Review Agenda & 10 Minutes \\
\hline $\begin{array}{l}\text { Create small groups, Scavenger hunt of the handbook, group share out, record group } \\
\text { feedback }\end{array}$ & 20 minutes \\
\hline Presentation-How to utilize the handbook and sample PD plan & 20 minutes \\
\hline Small group work-create individual and/or group PD plan for next school year & 60 minutes \\
\hline Share out PD plans, collect plans & 30 minutes \\
\hline Small groups identify strengths and weaknesses of the handbook, record & 20 minutes \\
\hline Group discussion of activities and suggestions for future workshops & 10 minutes \\
\hline Individuals complete survey on the usefulness of the handbook & 10 minutes \\
\hline Follow-up in three days with online survey & \\
\hline
\end{tabular}

\section{Operational Product Revision}

Once main product revisions were completed, the handbook was professionally edited and refined for distribution to principals in the school district. From the preliminary field testing and main field testing of the product, I learned more about the handbook and its usefulness to school administrators. I explained the findings and made recommendations for future practice.

Steps 8, 9, and 10 were not pursued for the purposes of this study but are discussed in chapter 5. Step 8 involves making the product available to a broader 
audience and using the feedback in Step 9 to make final product revisions. In Step 10, the product could be professionally published for distribution to an even wider audience.

\section{Research Questions}

The primary and secondary research questions are listed in Table 6.

Table 6

Primary and Secondary Research Questions

Primary Research Question

How useful is the handbook, Teachers Teaching Teachers: Designing Successful Professional

Development on a Shoestring Budget, in building school leader efficacy and confidence in regards to PD planning?

Secondary Research Questions

1. What is missing from the handbook?

2. Does the handbook encourage school leaders to utilize teacher expertise?

3. Do the research participants find the handbook usable and accessible?

4. What suggestions do school leaders have for the improvement of the handbook?

\section{Data Collection Procedures}

I have been informally collecting information regarding this topic for the past seven years. In my role as a high school principal I have been able to test various PD activities, survey teachers, observe teachers engaged in PD and interview teachers and other school leaders about their own experiences with PD. The first draft of the handbook was based on the research included in the literature review, the information I collected as 
a school leader and on the PD activities I experienced during my 25 years as a classroom teacher.

The first assessment of the handbook included feedback from approximately 30 school administrators who are responsible for planning PD. I asked them to review the handbook and assess its usefulness by responding to an online survey. Some of the questions were specifically regarding items in the handbook and others were open ended to allow for more detailed responses. Creswell (2002) identified electronic surveys as an easy and quick form of data collection. A limitation of this type of information gathering is that respondents must have access to a computer and the internet and some may not be comfortable responding in this format. In developing the survey questions, I used the strategies outlined in Creswell including the following:

1. Write different types of questions (closed and open-ended).

2. Construct questions that use clear language and are applicable to all participants.

The surveys were confidential and results were stored in a data file for analysis. A form was developed that explained the purpose of the study, the data that were collected and confidentiality protection of the respondents. I used the information gathered from the online surveys to edit and refine the handbook.

The handbook was assessed again by 38 school administrators who agreed to use the handbook in planning PD for their teaching staff. In the fall of 2013 I invited one high school to participate in this study. I met with the school vice principal to review the expectations and formulate a timeline for implementation. The vice principal volunteered to participate and this was not a requirement of their job description. The vice principal 
was briefed on the purpose of the study. The vice principal had the option to discontinue using the handbook at any time. The data collected from the feedback was used to further develop the handbook. I interviewed the vice principal at the end of the school to gather information on the usefulness of the handbook.

The final assessment of the handbook was a workshop for up to 10 high school administrators. The workshop took place in June 2014 during a district leadership meeting. Approximately 38 volunteer participants used the handbook during the workshop to plan PD for the upcoming school year. Participants responded to surveys using Likert scale, rank-order and open-ended questions. They also submitted a copy of the PD plan developed during the workshop. All participant information was anonymous and pseudonyms were used in the reporting of data.

\section{Data Analysis/Interpretation Strategies}

During the data analysis of the surveys collected from the preliminary field testing (Step 3) and the main field testing (Step 6), I examined the effectiveness of the handbook: Teachers Teaching Teachers: Designing Successful Professional Development on a Shoestring Budget, and identified areas of the handbook that needed revision. The feedback from school administrators identified the information, processes, protocols, forms and activities that were useful and those that were not.

In this study surveys were used to collect qualitative data. The surveys were administered to principals who participated in the preliminary field testing and main field testing. Data collection from the surveys took place in May and June of 2014. In order to prepare the data for analysis it had to be organized. Numbers were assigned to questions 
on the surveys using continuous and categorical scales depending on the question. I conducted a descriptive analysis of the data using measures of central tendency (mean, median and mode). I also utilized the features provided by google survey to categorize and organize participants' responses.

This study incorporated a variety of settings, participants and activities. Information was collected via surveys, interviews and observation from school administrators, district administrators and workshop participants. I recorded the vice principal interview and transcribed the responses before analyzing the data. I organized the data by question to compare respondents and their answers. This allowed me to identify consistencies and differences. The information from the interviews, surveys and observations was coded which is the "crux of qualitative analysis" (Powell \& Renner, 2003, p. 2). A descriptive label was created for each category to organize the responses. These categories were created after data collection and were based on themes or issues that were recurring in the data. Surveys were used following the small-scale testing (Step 2), preliminary field testing (Step 4) and main field testing (Step 6).

There is the possibility for bias to occur in this type of study. I had to be aware of any possible influence I may have on the outcome of the study. To guard against bias, I ensured the participants understood the confidentiality of their responses and input and that the purpose of the study was to design a handbook that could be useful for principals. I do not supervise any of the participants and their responses were not shared with other district employees and/or made public. I requested that they provide feedback regarding 
the usefulness of the handbook and workshop in building their capacity and confidence to implement a collegial PD program in their particular schools.

\section{Summary}

The purpose of this study was to use a problem-based learning approach and apply the R\&D process to design, field test, refine and evaluate a handbook called: Teachers Teaching Teachers: Designing Successful Professional Development on a Shoestring Budget. The purpose of the handbook is to assist high school principals in planning PD for teachers. During the process, the handbook was tested and refined with the end result being a product that is ready for distribution to principals in the district. Two of the guiding principles in the design of the handbook were to create no-cost or low-cost options for PD and to include activities that allow teachers to learn from one another defined as "teachers teaching teachers."

Chapter 3 focuses on the research design and methodology of the study. The problem-based research design (Bridges \& Hallinger, 1995) begins with the identification of a problem. In this study the problem is the lack of resources for school administrators to utilize in planning PD for teachers. Borg and Gall's (1989) R\&D Process is utilized to develop, test and refine a handbook resource with PD information, activities, processes, and forms that principals find useful.

Following the design and methodology of the study, the data collection and analysis procedures are described and include strategies to eliminate bias. Qualitative survey questions were utilized to evaluate the effectiveness of the handbook. Responses were coded and organized for analysis. The handbook was reviewed by approximately 30 
principals in a large urban district and 38 school and district leaders in a suburban district. The tools, forms, and data sheets are available on the district webpage and accessible to school leaders.

The formal research included a mixed methods approach utilizing surveys, observations, focus groups and interviews. The study incorporated the R\&D Process as described by Borg and Gall (1989) and includes the following:

- Preliminary field testing of the handbook

- Main product revision

- Main field testing of the handbook

- Operational product revision

Most of the data were collected from administrators who reviewed the preliminary version of the handbook and utilized a revised version of the handbook to design a PD plan for their respective schools. Participation was voluntary and all responses were confidential. Additional data were collected from interviews with district officials including the Chief Academic Officer, the Director of Curriculum and Instruction and Regional Administrators. The interview questions focused on the tools and training available for principals regarding PD planning and the potential usefulness of the handbook: Teachers Teaching Teachers: Designing Successful Professional Development on a Shoestring Budget. 


\section{CHAPTER IV}

\section{DATA ANALYSIS}

\section{Chapter Overview}

This research study was focused on determining the usefulness of the handbook, Teachers Teaching Teachers: Designing Successful Teacher Professional Development on a Shoestring Budget. The purpose of the handbook is to provide support and resources for school leaders in the planning of teacher PD. The handbook includes descriptions of three PD activities that promote teacher collaboration; action research, peer observation and PLCs.

As a teacher I experienced teacher PD that was disconnected from actual teaching practice and disjointed with no follow-up, accountability or practicality. As a high school principal I felt ill-prepared to design PD that would impact teacher practice. I spoke with my principal colleagues and they expressed similar concerns and frustrations. It was clear that teacher leaders, vice principals, principals and those involved in designing teacher PD could benefit from a handbook designed to help in the planning of PD, especially if it included activities that allowed teachers to collaborate and learn from each other.

During the course of my 25 year teaching career, I experience a variety of PD activities. For the most part, the professional learning I experienced was delivered by socalled experts, in one-day workshops with no follow-up or accountability. I sought collaboration from my colleagues on my own time and the professional conversations 
that resulted were what had the most impact on my instructional practice. I was very fortunate to cross paths with a teacher leader during the last five years of my teaching career, who changed my perception of PD and greatly influenced my role as an instructional leader. She organized workshops and activities that allowed teachers to demonstrate lessons and share problems of practice. The organization of the activities included observation, collegial conversation and opportunities to plan instruction implementing new strategies.

According to Fullan et al. (2006), teacher PD should be focused and ongoing. Darling-Hammond (2009) supported the idea of PD that includes opportunities for teachers to collaborate and learn from each other. The handbook is designed to promote teacher growth and professional learning through conversation, peer observation and action research.

This chapter includes a review of the study's research questions, goals, development and implementation. The seven steps of the R\&D cycle (Borg \& Gall, 1989) are described and explained as they pertain to the study. This chapter concludes with an analysis of the usefulness of the handbook, Teachers Teaching Teachers: Designing Teacher Professional Development on a Shoestring Budget.

\section{Review of Research Questions and Goals of the Study}

The study was designed using the R\&D learning process defined by Borg and Gall (1989). The process encompasses 10 steps that culminate in the development and refinement of a product that addresses a specific problem. The problem associated with this study is the lack of guidance for principals in the planning of teacher PD. The 
product is a handbook titled, Teachers Teaching Teachers: Designing Teacher Professional Development on a Shoestring Budget. The goal of the study was to determine if utilizing the handbook can increase the confidence level and efficacy of school leaders as they design PD programs. The first seven steps of the R\&D process provided a framework and data collection procedures that helped develop, implement and assess the usefulness of the handbook. The R\&D process also provided the opportunity to use qualitative measures to test the effectiveness of the handbook as it relates to designing teacher PD.

This study included development, field testing and refinement of a handbook for school leaders. The data collected during the $\mathrm{R} \& \mathrm{D}$ process informed revisions made to the handbook in order to better meet the needs of school leaders. The final product is a field tested handbook that is ready for practical use in school settings.

\section{Review of the Research Questions}

The research questions were focused on the usefulness of the handbook and incorporated such indicators as:

$>$ the practicality of the handbook (relevant to everyday practice of school leaders)

$>$ the applicability of the information in the handbook (easily applied and implemented)

$>$ whether or not the information meets the needs of school leaders

These indicators were included in interview and survey questions to determine the usefulness of the handbook.

The primary and secondary research questions are listed in Table 6 . 


\section{Review of Research Goals}

This study was designed with two goals in mind: (a) to determine the usefulness of the handbook, Teachers Teaching Teachers: Designing Successful Professional Development on a Shoestring Budget, in supporting school leaders as they plan PD for teachers and (b) to provide school leaders (principals, vice principals, teacher leaders, district administrators) with a product that has been field tested and is ready for implementation in their schools. The study included a preliminary field test of the product and a main field test of the product. Both field tests provided feedback that was used to make revisions to the handbook in order to have a product that better meets the needs of school leaders who participated in the study and those who might use the product in the future. The next section describes the activities included in the first seven steps of the R\&D process.

\section{Development and Implementation (Field Testing) of the Problem Based Learning Project}

\section{Step 1: Research and Information Collecting}

Borg and Gall (1989) described educational R\&D as "a process used to develop and validate educational products" (p. 782). The initial step in the process is to identify a problem or set of issues that a product will address. This step includes a literature review and possibly interviews with practitioners who are knowledgeable about the problem with the goal being to develop a deeper understanding of the problem and how it will be addressed by the product (Bridges \& Hallinger, 1995). Following is a brief summary of my gathering of knowledge about the topic of teacher PD. 
I spent 24 years as a classroom teacher and experienced a variety of PD activities. In the beginning years of my career I eagerly volunteered to attend workshops and seminars looking for the latest teaching strategies to implement in my own classroom. Many of these workshops were in other cities and included expensive hotel stays and required the purchase of additional materials. I also attended presentations that were provided by the school district in which outside experts were brought in to tell us what we needed to do to ensure our students were successful. These presentations also usually included a binder or book that contained all the information we needed to implement the magic strategy. What I quickly discovered about the PD I experienced was that it had little or no impact on my teaching or student academic achievement. There was no follow-up or accountability after the workshop and no time to collaborate or discuss the workshop with colleagues. Very little, if any of the information from these PD activities impacted my instructional practice.

In 2000, I attended a collaborative weeklong curriculum camp at the recommendation of a literacy expert and teacher with whom I worked. This event transformed my teaching and enlightened me to the possibilities of teacher professional growth via collaboration and discussion with colleagues. I spent the next several years creating opportunities to observe other teachers, participating in discussions with other teachers on problems of practice and promoting collaboration among teachers in my department and school. It was clear to me that the magic strategies could be found right down the hall. 
In 2007, I began my first high school principal position. During the first week, I found out that I would be solely responsible for designing teacher PD in my building and was given a list of district initiatives that needed to be addressed in the PD activities. There was very little support or guidance from the district office and due to budget cuts, no money available to hire presenters to come in or to send teachers to off-site trainings or workshops. Budget cuts had also eliminated district level administrative roles to support principals in designing PD. I relied on what I had learned as a teacher and decided to implement a PD plan that was teacher driven and focused on teachers learning from each other. During the next seven years I worked as a principal in three different schools and continued to develop and refine teacher PD activities. I included teachers in the planning and implementation of the activities and collected teacher feedback throughout the process at all three schools. The three activities that seemed to generate the most satisfaction from teachers and that seemed to have the greatest impact on teacher practice were peer observation, action research and PLCs. Some of the benefits I observed from these three PD activities include:

$>$ Increased enthusiasm for PD activities

$>$ Continued collaboration beyond the scheduled meeting time

$>$ Increased teacher participation in leading PD activities

$>$ Implementation of strategies based on research

It was during the research and information collecting step that I refined and narrowed the vision I had for the product. During this part of the cycle, I also interviewed colleagues who provided information which was helpful in the preliminary planning of the product. 
Borg and Gall (1989, p. 785) provided four salient questions that help the researcher determine the appropriateness of the product being developed. The four questions are:

1. Does the proposed product meet an educational need?

2. Is the state of the art (in relation to the need or problem) sufficiently advanced that there is a reasonable probability that a successful product can be developed?

3. Are personnel available who have the skills, knowledge, and experience necessary to build this product?

4. Can the product be developed within a reasonable period of time?

Based on my own experience as a teacher and principal, I was confident that the product, a handbook for school leaders to use in designing PD, would meet a need in education. The handbook would provide school leaders with resources and information on how to implement PD that relies on the expertise of teachers and requires a minimal amount of funding. From my personal experience and from conversations with administrator colleagues, it was evident that there was very little training and/or support provided to principals on how to design a year-long PD plan. Nor was there any guidance on how to provide meaningful PD opportunities without funding resources for the traditional model PD model of bringing in outside experts.

I was able to find a significant amount of literature and it was reasonable to assume I could develop a successful product. During the review of the literature, it became clear that there were plenty of primary sources and research in the area of teacher PD. It was my goal to learn as much as possible about the history, development and 
current strategies related to teacher growth and improving instruction and use the information to develop a handbook for principals.

The literature review included an extensive search for information on three types of PD activities; Action Research, Peer Observation and PLCs. These activities are collaborative and allow teachers to share ideas and problems of practice. Rorschach and Whitney (1986) identified collaborative activities as enriching and instrumental in reducing the isolative nature of teaching. A constructivist leadership style seemed to fit well with the collaborative activities and the literature review supported an approach described by Lambert (2000) that promoted collegiality, reflection and shared leadership. The literature review supported the rationale for the development of a handbook to support principals and also enhanced my learning regarding leadership and PD.

Regarding Borg and Gall's (1989) third question: Are personnel available who have the skills, knowledge, and experience necessary to build this product?, I felt confident that my experience as a teacher and as a high school principal prepared me to successfully develop this product. I have participated in numerous types of PD and can relate examples of experiences that influenced my teaching and examples that were insignificant to my practice. I have collaborated with teachers to design PD that meets their needs and promotes student achievement. I have observed teachers engaged in meaningful professional learning activities and seen firsthand how this translates into improved instruction. Lastly, I have collected data and teacher feedback over the past 7 years and believe that the experts school leaders should be utilizing are the teachers. The 
handbook suggests various ways to create a community of learners among the teaching staff and provides protocols for the sharing of ideas and research.

The timeline for creating the handbook was reasonable. I planned to formulate a product, test the product and make revisions during a 1-year period. The revisions are a result of feedback from school leaders who tested the product and from workshop participants who reviewed and discussed the product.

Small-scale research. Bridges and Hallinger (1995) suggested that small-scale research include observations and interviews with practitioners and researchers who are very familiar with the problem. Some of the small-scale research for this product began before I had even considered entering into a doctoral program. As a teacher I became interested in the design of PD and had informal discussions with teacher leaders, school administrators and curriculum directors in three different districts. I worked closely with a local literacy expert who was an excellent mentor in the area of PD design that utilized a "teachers teaching teachers" framework. I participated in collaborative sessions with teachers from other content areas and found myself re-energized and excited about curriculum development. I reached out to other teachers and formed book study groups that met during lunch, facilitated a Critical Friends Group that met twice a month to discuss problems of practice and presented mini workshops to groups of teachers on literacy strategies. It was during the last five years as a teacher that I gained insight into utilizing teachers as experts. I reflected on these experiences after I decided to create a handbook and they provided a strong foundation for the purpose and rationale for this study. 
There are two educational organizations that played a significant role in the development of my approach to teacher PD. One is the Oregon Writing Project (OWP). After my first year as a principal, I participated in a 4-week summer session with teachers and learned side-by-side with them. OWP is a collaborative, intensive workshop that focuses on the teaching of writing. OWP Director, Linda Christensen (2014) stated that the philosophy of the writing project is that "the best teachers of teachers are other teachers." It was my participation in the writing project and the opportunities I had to work with Linda Christensen that had the greatest influence on the teachers teaching teachers format of the handbook.

The second organization that greatly influenced the handbook is Rethinking Schools. Rethinking Schools was founded in 1986 by activist teachers. The organization advocates for the reform of education at all levels with an emphasis on equity and social justice. The publication that comes from this organization is composed of articles mostly contributed by teachers for other teachers. Not only is the handbook consistent with a collaborative model in which teachers learn from each other but also provides an excellent model for "rethinking" teacher PD.

My 24 years as a teacher and the last seven years as a high school principal have afforded me the opportunity to experience firsthand a variety of PD activities. As a result I was able to formulate my own philosophy about the most effective strategies for promoting teacher growth and the improvement of instruction. 
In addition to conducting small-scale research, I also sought out literature related to the topic to include in the literature review. The literature review included the following sections:

Instructional leadership

Action research

$>$ Peer observation

$>$ PLCs

The first step of the R\&D process enhanced my understanding of the challenges associated with designing PD that is valued by teachers and that impacts instruction. The literature review supported the idea that collaboration should be an important part of PD for teachers and provided evidence that school leaders play a significant role in designing successful PD.

The next section describes step two of the R\&D cycle: Planning Objectives, Learning Activities, and Small-Scale Testing.

\section{Step 2: Planning Objectives, Learning Activities, and Small-Scale Testing}

During step two of the R\&D cycle an initial description of the product is

developed, the target audience is identified and potential testing sites and participants are considered. During this step, research and information collecting continues through literature and conversations with people knowledgeable about the topic (Bridges \& Hallinger, 1995).

Initially, I identified high school principals as the target audience for the handbook, however, the handbook can support any educator (teacher leaders, principals, 
vice principals, curriculum directors, etc.) who is responsible for designing PD plans. My hope is that the handbook will be a valued resource in the planning of teacher PD in any educational setting.

During this stage, I developed an outline for the handbook. Based on my own experience as a teacher and principal and what I learned in the literature review, I selected three PD activities to be included in the handbook. I also decided to include reproducible forms for the activities which I drafted in step 3 of the R\&D cycle. Figure 10 represents the handbook outline.

\begin{tabular}{|cl} 
Handbook Outline \\
I. & About the Author \\
II. & Introduction \\
III. & Leadership \\
IV. & Getting Started \\
& a. Surveys \\
& b. Sample plans \\
V. & Action Research \\
& a. Forms \\
& b. Design and Presentation \\
VI. & Peer Observation \\
& a. Schedule/Format \\
VII. & b. Professional Learning Communities \\
& a. Social Learning \\
VIII. & Conclusion and Next Steps \\
IX. & References
\end{tabular}

Figure 10. Handbook outline. 
At this point I was not sure about the subtopics for the major sections but would add and delete after field testing and revising the handbook in steps 4, 5, 6 and 7. I shared the outline with a few principal colleagues, members of my doctoral cohort and my doctoral advisor. All agreed that the product sounded relevant and applicable. Colleagues suggested I include a section on equity as our district is heavily engaged in racial equity work. My doctoral cohort and advisor suggested including the section on leadership and a discussion on adult learning. The next section describes step 3 of the R\&D cycle: Develop Preliminary Form of the Product.

\section{Step 3: Develop Preliminary Form of the Product}

Step 3 of the R\&D cycle is primarily focused on the development of the product. The information I gathered in the first two steps was used to develop a preliminary form of the product, Teachers Teaching Teachers: Designing Successful Professional Development on a Shoestring Budget. The preliminary form of the product included the sections and information shown in Table 7.

\section{Table 7}

Sections and Information Included in Preliminary Form of the Product

\begin{tabular}{|l|l|}
\hline Section & Summary of Information \\
\hline About the Author & $\begin{array}{l}\text { In this section I described my own experience with PD as a teacher and as } \\
\text { a principal. This experience provided the basis and rationale for the } \\
\text { development of a handbook for principals. I wanted the audience to } \\
\text { understand that I had firsthand experience and knowledge with the topic } \\
\text { of PD and could relate with teachers and principals in the pursuit of } \\
\text { relevant, successful PD. }\end{array}$ \\
\hline
\end{tabular}


Table 7 (continued)

\begin{tabular}{|c|c|}
\hline Section & Summary of Information \\
\hline Introduction & $\begin{array}{l}\text { This section provides an overview of the handbook, including the focus on } \\
\text { teachers as experts. The intended audience is described as any school or } \\
\text { district leader responsible for designing teacher PD. The conceptual } \\
\text { framework is defined as "teachers teaching teachers." The social aspects of } \\
\text { learning as described by Lieberman and Mace (2008) provided additional } \\
\text { evidence of why a collegial approach to PD is desirable. } \\
\text { The introduction concludes with three short sections that describe the } \\
\text { organization of the text, special features and acknowledgements. }\end{array}$ \\
\hline $\begin{array}{l}\text { Leadership to Promote } \\
\text { Collaboration }\end{array}$ & $\begin{array}{l}\text { This section also describes the theoretical background for the handbook. } \\
\text { Lambert (2003) has defined leadership as reciprocal processes that enable } \\
\text { members of an educational community to construct meaning toward a } \\
\text { shared purpose. The handbook is based on a constructivist approach to } \\
\text { leadership and learning. }\end{array}$ \\
\hline Getting Started & $\begin{array}{l}\text { A PD plan should include input from teachers and information on what PD } \\
\text { has already been implemented. This section includes a pre-planning survey } \\
\text { and a sample PD plan. }\end{array}$ \\
\hline Action Research & $\begin{array}{l}\text { This section provides a definition and explanation of action research and } \\
\text { how it can be utilized in a PD plan. Reproducible forms and protocols for } \\
\text { action research activities are included. }\end{array}$ \\
\hline Peer Observation & $\begin{array}{l}\text { Another important collaborative type of PD is peer observation. This } \\
\text { section describes peer observation and provides research that identifies } \\
\text { observing teachers as one of the most successful PD activities. Also } \\
\text { included are testimonials from teachers who have participated in peer } \\
\text { observation activities and a sample protocol for peer observation. }\end{array}$ \\
\hline PLCs & $\begin{array}{l}\text { The third PD activity described in the handbook is PLCs. Providing time } \\
\text { for teachers to collaborate, plan and share ideas has been described by } \\
\text { DuFour and Eaker (2002) as a highly effective strategy for improving } \\
\text { teaching and learning. The PLC structure is described and examples are } \\
\text { provided. This section also includes testimonials from teachers who have } \\
\text { participated in PLCs. At the end of this section there are reproducible } \\
\text { forms that can be used to set up PLC groups and record meeting notes. }\end{array}$ \\
\hline Summary & $\begin{array}{l}\text { This section summarizes the information in the handbook and the idea that } \\
\text { improved teaching and ultimately improved student achievement is } \\
\text { dependent on teachers learning from one another. Classroom instruction } \\
\text { has the most impact on student learning and PD must include opportunities } \\
\text { for teachers to work together to improve instructional practice. }\end{array}$ \\
\hline Criteria Sheet for Instruction & $\begin{array}{l}\text { The final tool in the handbook is a sample criteria sheet for teachers to } \\
\text { evaluate their own professional growth and accomplishments following the } \\
\text { implementation of a PD plan. }\end{array}$ \\
\hline
\end{tabular}

After completing the preliminary form of the handbook, I started the preliminary

field test of the product. The next section describes steps 4 and 5 of the R\&D process.

\section{Steps 4 and 5: Preliminary Field Testing and Main Product Revisions}


The preliminary field testing of the handbook Teachers Teaching Teachers: Designing Successful Professional Development on a Shoestring Budget took place in May 2014 in a large urban school district. The handbook was presented to two groups of school and district administrators (approximately 60 participants) in a mini workshop format. The handbook was also utilized by a high school vice principal between August 2013 and June 2014 as part of the preliminary field testing.

The participants in the mini workshop represented a convenience sample (a sample that is easy to reach or convenient to the researcher). Their years of experience range from 1 to 10 plus years. None of the participants had seen the handbook before the mini workshop. I specifically requested to present this mini workshop/informational session to school and district administrators as this is the target audience for the handbook. Table 8 represents the demographics of the participants in the mini workshop. 
Table 8

Demographics of Participants in Preliminary Field Testing Mini Workshop

\begin{tabular}{|c|c|c|c|}
\hline Participants & Current Role & $\begin{array}{l}\text { Years of Experience in } \\
\text { Current Role }\end{array}$ & $\begin{array}{l}\text { Responsible for PD } \\
\text { Planning }\end{array}$ \\
\hline 1 & HS Principal & $1-3$ & Yes \\
\hline 2 & MS Principal & $4-6$ & Yes \\
\hline 3 & HS Principal & $7-9$ & Yes \\
\hline 4 & HS VP & $1-3$ & Yes \\
\hline 5 & HS VP & $1-3$ & Yes \\
\hline 6 & Elem. Principal & $10+$ & Yes \\
\hline 7 & Elem. Asst. Principal & $1-3$ & Yes \\
\hline 8 & District Admin. & $3-5$ & Yes \\
\hline 9 & HS Principal & $7-9$ & Yes \\
\hline 10 & MS Principal & $4-6$ & Yes \\
\hline 11 & MS Principal & $7-9$ & Yes \\
\hline 12 & Elem. Principal & $7-9$ & Yes \\
\hline 13 & Elem. Principal & $4-6$ & Yes \\
\hline 14 & Program Director & $1-3$ & Yes \\
\hline 15 & HS VP & $4-6$ & Yes \\
\hline 16 & HS VP & $1-3$ & Yes \\
\hline 17 & Regional Director & $1-3$ & No \\
\hline 18 & Program Coordinator & $1-3$ & No \\
\hline 19 & HS Principal & $4-6$ & Yes \\
\hline
\end{tabular}

HS=high school MS=middle school $\quad$ VP=vice principal 
Purpose of preliminary field testing. The preliminary field test provided the opportunity to collect data regarding the usefulness of the product. The activities included in the preliminary field test are listed below:

1. Introduction of myself and overview of the $R \& D$ process

2. Distribute preliminary form of the product to participants

3. Participants review the handbook, make margin notes and respond to survey

4. Collect and analyze participant feedback

Participants were asked to write feedback/suggestions in the handbooks, which were collected at the end of the session. They were also provided a link to an online google survey and requested to fill out the survey within the next three days. The participants provided information about the product, its usefulness and what needed to be added and/or deleted from the handbook.

In addition to the workshop/information session, the handbook was used by a colleague to plan and implement PD over the course of the 2013-2014 school year. The activities included in this portion of the preliminary field test included:

1. Introductory meeting and discussion

2. Monthly check-ins

3. End of year summary meeting and interview

A high school vice principal utilized the handbook to plan and implement a PD plan for approximately 80 teachers. The purpose of this portion of the field test was to determine the usefulness of the handbook and whether or not the activities and resources were user friendly and applicable to other school settings. The information from this portion of the 
preliminary field test was useful in determining revisions to explanations, protocols and resources included in the handbook.

Preliminary field test findings (Step 4). The information collected from participants in the preliminary field testing was used to make revisions to the first draft of the product, Teachers Teaching Teachers: Designing Successful Professional Development on Shoestring Budget. I analyzed the data from the preliminary field test using the primary research question as the focal point: How useful is the handbook, Teachers Teaching Teachers: Designing Successful Professional Development on a Shoestring Budget, in building school leader efficacy and confidence in regards to PD planning? The feedback provided by participants was categorized and coded which indicated some commonalities in how administrators viewed the handbook. These common themes were used to make revisions to the product.

One common theme that emerged from the preliminary field test was the need for a section on equity and how the activities could be used to promote the equity work in the district. The workshop/information session included administrators from the same district and this feedback, while useful, would not necessarily be the same in a field test in another district. I decided not to add a section on equity but to include a brief discussion on the importance of including district initiatives, such as equity work, in PD planning. Another area of improvement that was identified in the preliminary field testing was the need for more graphics and a more appealing design. One participant said, "It could be more graphically appealing. These days there is a lot of visual space, bolding of critical concepts, etc. in education tools. But this is not a deal-breaker. The content speaks 
for itself." I agree with this comment and made revisions throughout all sections of the handbook to increase the visual appeal. The changes included adding large, bold text at the beginning of paragraphs, adding pictures and images where applicable and including more text boxes with quotes and testimonials. I also added color whenever possible.

Two other common themes that came up include: (a) the addition of information specifically for elementary principals and (b) the addition of a section on how these activities impact student achievement. I did design the product with high school principals in mind as that is my area of expertise, however, I do not think the activities included in the handbook are specific to high school teachers and administrators. I decided not to add any specific information about the similarities and/or differences between designing PD plans for elementary teachers vs. high school teachers but did make it more clear in the introduction that the handbook could be utilized by school and district leaders throughout a K-12 system.

A few participants commented that they would like to see more evidence that these PD activities improve student achievement. This was not the purpose of the project and would require an entirely different approach, including a long-term research study. I do believe that improving teacher collaboration and sharing of practice enhances classroom instruction which ultimately should improve student achievement. The purpose of this study is to test the usefulness of the handbook not whether or not teacher PD improves student achievement. I decided to make sure this is clear in the introduction section of the handbook and to provide examples based on my own experience that connect teacher PD to student achievement. 
Main product revisions (Step 5). Based on feedback from participants in the

preliminary field test, I made several revisions and edits throughout the handbook. Table

9 lists and describes the revisions.

Table 9

Preliminary Field Test Data and Revisions

\begin{tabular}{|c|c|c|}
\hline Data Code & Specific Feedback & Revision \\
\hline Equity & $\begin{array}{l}\text { "I would like to see a section on } \\
\text { equity. This is an important } \\
\text { district initiative." } \\
\text { "How does this support our } \\
\text { equity work?" }\end{array}$ & $\begin{array}{l}\text { I enhanced the section, Getting } \\
\text { Started, and included a discussion } \\
\text { of district initiatives and how } \\
\text { they should be included in the PD } \\
\text { planning process. }\end{array}$ \\
\hline Handbook Design and Format & $\begin{array}{l}\text { "It could be more graphically } \\
\text { appealing. These days there is a } \\
\text { lot of visual space, bolding of } \\
\text { critical concepts, etc. in education } \\
\text { tools. But this is not a deal- } \\
\text { breaker. The content speaks for } \\
\text { itself." } \\
\text { "It needs some editing, as you } \\
\text { likely know." }\end{array}$ & $\begin{array}{l}\text { Added graphics, color, text boxes } \\
\text { and edited the entire handbook. }\end{array}$ \\
\hline Student Achievement & $\begin{array}{l}\text { "I would be interested in seeing } \\
\text { any connections between student } \\
\text { achievement increases and } \\
\text { teacher investment in PD." } \\
\text { "How does PD impact student } \\
\text { achievement?" }\end{array}$ & $\begin{array}{l}\text { This was not the purpose of the } \\
\text { product but is a valid question. I } \\
\text { plan to include a discussion of the } \\
\text { connection between improved } \\
\text { instruction and student } \\
\text { achievement in the summary } \\
\text { section of the handbook and to } \\
\text { provide examples from my own } \\
\text { experience. }\end{array}$ \\
\hline Target Audience & $\begin{array}{l}\text { "As a K-8 administrator I would } \\
\text { like additional perspectives } \\
\text { beyond just high school." } \\
\text { "Maybe add some suggestions } \\
\text { about implementation at the K-5 } \\
\text { and/or K-8 level." }\end{array}$ & $\begin{array}{l}\text { Clarified in the introduction that } \\
\text { the handbook and activities were } \\
\text { based on my experience as a high } \\
\text { school teacher and administrator } \\
\text { but are applicable to any level. }\end{array}$ \\
\hline
\end{tabular}


Table 9 (continued)

\begin{tabular}{|c|c|c|}
\hline Data Code & Specific Feedback & Revision \\
\hline Action Research & $\begin{array}{l}\text { "I appreciate the focus on Action } \\
\text { Research in particular. I see the } \\
\text { new goal setting process as a } \\
\text { perfect opportunity for teachers to } \\
\text { engage in Action Research. One } \\
\text { of the big differences, of course, } \\
\text { is that Action Research projects } \\
\text { are ultimately shared with an } \\
\text { authentic audience (fellow } \\
\text { teachers) whereas the goal-setting } \\
\text { process (as currently envisioned) } \\
\text { is a private interaction between a } \\
\text { teacher and principal." } \\
\text { "The action research activity is } \\
\text { very useful." } \\
\text { "Teachers can benefit from action } \\
\text { research regarding their own } \\
\text { practice." }\end{array}$ & No changes to this section. \\
\hline Activities and Resources & $\begin{array}{l}\text { "PD activities, Resources, } \\
\text { Narrative explanation about } \\
\text { activities." } \\
\text { "Resources are very useful and } \\
\text { user friendly." } \\
\text { "Appreciated the reproducible } \\
\text { handouts." } \\
\text { "Are there electronic versions of } \\
\text { the resources?" } \\
\text { "I like the variety of approaches } \\
\text { and resources related to these. } \\
\text { There is enough information to } \\
\text { help principals facilitate a more } \\
\text { meaningful PD program." }\end{array}$ & $\begin{array}{l}\text { Keep activities and resources as } \\
\text { written. Possibly add additional } \\
\text { resources such as webpages, } \\
\text { books, etc. } \\
\text { Make an electronic version of the } \\
\text { handbook available. }\end{array}$ \\
\hline About the Author & $\begin{array}{l}\text { "I can tell it was written by } \\
\text { someone who actually carries out } \\
\text { these activities and has a direct } \\
\text { connection to the outcomes. It is } \\
\text { very practical." }\end{array}$ & No changes to this section. \\
\hline
\end{tabular}

In addition to the preliminary field test data listed in Table 9, many participants indicated a desire to collaborate with colleagues on the planning of PD. The handbook promotes collaboration and sharing of practice among teachers and administrators in the 
preliminary field test shared a strong desire to do the same with other administrators. One administrator commented, "I think the "Teachers Teaching Teachers" model could be applied to collaboration among administrators. We, too, often work in isolation and could learn from each other." Another administrator wrote, "I would really like to work with other administrators on PD planning. The handbook is a great tool and very practical. We should be modeling collaborative practices for our teachers." Based on these and other comments, I decided to add information in the Leadership Section on the importance of collaboration among school leaders.

In addition to the information gathered at the preliminary field test workshop, I also compiled additional data from a colleague who used the handbook during the 20132014 school year to design and implement PD for approximately 80 teachers. This vice principal was solely responsible for the PD planning and volunteered to use the activities and resources in the handbook. This was an important part of the preliminary field test as it provided information on the applicability and usefulness of the handbook as well as the impact on the efficacy of an administrator in planning and implementing PD. I had experienced success in utilizing the activities in the handbook but was interested in how useful the handbook would be to another administrator. This provided valuable information related to my primary research question: How useful is the handbook, Teachers Teaching Teachers: Designing Successful Professional Development on a Shoestring Budget, in building school leader efficacy and confidence in regards to PD planning? In June 2014, I interviewed the administrator about the handbook. Table 10 provides a summary of her responses. 
Table 10

Administrator Interview Responses Following PD Planning and Implementation Using the Handbook, Teachers Teaching Teachers: Designing Successful Professional Development on a Shoestring Budget

\begin{tabular}{|c|c|}
\hline Question & Response \\
\hline What PD did you implement this past year? & $\begin{array}{l}\text { "I used the three activities from the handbook: Peer } \\
\text { Observation, Action Research and PLCs." }\end{array}$ \\
\hline $\begin{array}{l}\text { What new things did you implement or discover that } \\
\text { made the PD more useful? }\end{array}$ & $\begin{array}{l}\text { "I modified the protocols to fit our needs and } \\
\text { provided a menu of activities with explanations at } \\
\text { the beginning of the year. We also included some } \\
\text { teacher choice regarding PLC selection." }\end{array}$ \\
\hline What Resources did you use from the handbook? & "I utilized all of the resources in the handbook." \\
\hline What worked? & $\begin{array}{l}\text { "Staff really appreciated the fact that they could } \\
\text { choose their PLC focus and group. I believe this } \\
\text { made the activity more successful than in the past. } \\
\text { The note-taking process was also useful and } \\
\text { provided accountability for PLC work. Another } \\
\text { thing that enhanced our work was the sharing of } \\
\text { practice at the end of the year. Teachers were proud } \\
\text { of their work and this provided a way to celebrate } \\
\text { their efforts." }\end{array}$ \\
\hline What didn't work? & $\begin{array}{l}\text { "We did not get } 100 \% \text { buy-in but most teachers } \\
\text { were engaged in the activities. Only a few chose } \\
\text { Action Research." }\end{array}$ \\
\hline How were the resources helpful? & $\begin{array}{l}\text { "The narrative in the handbook was helpful and } \\
\text { provided information that helped in the planning } \\
\text { and implementation. The handouts were easily } \\
\text { adaptable and user friendly. The protocols made the } \\
\text { PD activities more successful and increased teacher } \\
\text { participation and follow-through. I also appreciated } \\
\text { the sample PD plans as it helped me design a year- } \\
\text { long plan for my own staff. This helped staff see the } \\
\text { big picture and enhanced engagement in the various } \\
\text { activities." }\end{array}$ \\
\hline
\end{tabular}


Table 10 (continued)

\begin{tabular}{|l|l|}
\hline Question & Response \\
\hline $\begin{array}{l}\text { Do you plan to use any of the resources next year? } \\
\text { Which ones and why? }\end{array}$ & $\begin{array}{l}\text { "I will be transitioning from a high school VP } \\
\text { position to an elementary principal position. I plan } \\
\text { to use the handbook and resources in planning PD } \\
\text { for the staff at my new school. The activities are } \\
\text { appropriate for any grade level teacher." }\end{array}$ \\
\hline $\begin{array}{l}\text { Do you feel more confident planning PD for } \\
\text { teachers? }\end{array}$ & $\begin{array}{l}\text { "I definitely feel more confident in planning PD. } \\
\text { Every year provides additional experience, but the } \\
\text { handbook helped me formulate a year-long plan and } \\
\text { provided resources. I have felt overwhelmed every } \\
\text { year when it comes to planning PD and this year } \\
\text { was by far, the most successful. Teachers expressed } \\
\text { a high level of satisfaction with the PD activities } \\
\text { and participation was increased from previous } \\
\text { years. The end of year celebration was profound and } \\
\text { I could see that teaching practice was improved." }\end{array}$ \\
\hline
\end{tabular}

The administrator who used the handbook during the 2013-2014 school year had requested to try out the activities after I shared the handbook at one of our leadership meetings. I explained that the handbook was part of my dissertation and asked if she would be willing to participate in part of the preliminary field testing. She agreed to meet with me at the beginning of the year to review the activities and to check in monthly. I agreed to be a resource if she had any questions about the activities or handbook during the school year. In June 2014, we met for about an hour to discuss the PD plan she developed and the usefulness of the handbook. She provided me with samples of the activities she implemented. The overall PD plan she developed is included in Appendix A of the handbook. During the interview process, I realized that I was learning more about PD planning and was also gaining knowledge about ways the activities and resources 
could be enhanced. It was clear that collaboration between administrators could be a valuable experience in successful PD planning,

The next section describes step six of the R\&D process: main field testing.

\section{Step 6: Main Field Testing}

The main field test is designed to implement the product (handbook) and collect data regarding its effectiveness. The process in this step includes collecting formative data, which is used to revise the product and summative data, which is used to determine the level of effectiveness of the product. In the main field testing for the product, Teachers Teaching Teachers: Designing Successful Professional Development on a Shoestring Budget, K-12 principals, vice principals and district office administrators from Columbia School District (pseudonym) participated in a workshop utilizing the handbook to design teacher PD.

Columbia School District serves approximately 10,700 students. The district is composed of 11 elementary schools, three middle schools, one high school and three alternative high schools. The ethnic breakdown of students in this district is: 11\% Latino, 54\% white, $7.9 \%$ African American, 9.3\% Asian and 1.1\% Native American. The district has implemented PLCs as the primary form of PD. Principals are responsible for planning PD but there is no formalized training or supports in place for principals to assist with the planning. Money is tight in this district and there is limited funding for teacher PD.

The superintendent of the district invited me to present a 3-hour workshop on PD planning at the district's leadership retreat in June of 2014. I had originally pursued a different site for the main field test but had trouble scheduling a time that worked for the 
district. The fact that this group consisted of K-12 and district office administrators

allowed me to get feedback on the usefulness of the handbook from administrators at all levels.

Table 11 lists the activities for the main field test, information about the participants and data collection procedures.

Table 11

Main Field Test Activities and Data Collection Strategies

\begin{tabular}{|l|l|l|}
\hline \multicolumn{1}{|c|}{ Activity } & \multicolumn{1}{|c|}{ Description of Participants } & \multicolumn{1}{c|}{ Data Collection } \\
\hline Pre-Workshop Survey & $\begin{array}{l}\text { 14- Elementary and Middle } \\
\text { School Administrators, 5-High } \\
\text { School Administrators, 17- } \\
\text { District Office Administrators }\end{array}$ & $\begin{array}{l}\text { The data collected in this activity } \\
\text { included baseline information on } \\
\text { participant's perception of their } \\
\text { own level of efficacy regarding } \\
\text { the planning of PD. }\end{array}$ \\
\hline Scavenger Hunt & $\begin{array}{l}\text { 14- Elementary and Middle } \\
\text { School Administrators, 5-High } \\
\text { School Administrators, 17- } \\
\text { District Office Administrators }\end{array}$ & $\begin{array}{l}\text { This activity provided data on the } \\
\text { ease at which participants could } \\
\text { find information in the handbook. } \\
\text { The data were used to revise and } \\
\text { improve the handbook. }\end{array}$ \\
\hline Workshop Observation & $\begin{array}{l}\text { Participants were observed during } \\
\text { the workshop. }\end{array}$ & $\begin{array}{l}\text { During the workshop, participants } \\
\text { were observed to determine if the } \\
\text { handbook was being utilized, and } \\
\text { to what extent, in the design of } \\
\text { PD plans. }\end{array}$ \\
\hline Post-Workshop Survey & $\begin{array}{l}\text { 14- Elementary and Middle } \\
\text { School Administrators, 5-High } \\
\text { School Administrators, 17- } \\
\text { District Office Administrators }\end{array}$ & $\begin{array}{l}\text { The post-survey provided data on } \\
\text { the usefulness of the handbook in } \\
\text { increasing the participant's view } \\
\text { of their own efficacy in designing } \\
\text { PD. }\end{array}$ \\
\hline
\end{tabular}

The 38 participants in the workshop were identified by a colleague as available and willing to participate. This is referred to as convenience sampling (Creswell, 2002). While they may not be representative of the entire population of school administrators, 
the information they provided was beneficial in determining the usefulness of the handbook.

Workshop at Columbia School District. On June 23, 2014, I facilitated a workshop that included 38 participants from the Columbia School District. Participants were gathered together for a full day retreat. The morning session was facilitated by an outside presenter hired by the district. The afternoon workshop served as the main field test of the handbook, Teachers Teaching Teachers: Designing Successful Professional Development on a Shoestring Budget. The purpose of the workshop was to gather information from current school and/or district administrators regarding their perception of the potential usefulness of the handbook and to gather feedback which I could use to make revisions to the handbook. The workshop agenda is displayed below in Table 12 .

\section{Table 12}

Workshop Agenda for School Administrators Using the Handbook, Teachers Teaching Teachers: Designing Successful Professional Development on a Shoestring Budget

\begin{tabular}{|c|l|l|}
\hline Activity & Time & \\
\hline Introductions, Review Agenda & 30 Minutes & \\
$>$ Distribute materials & & \\
$>$ Background information on project/study & & \\
$>$ Rationale for the handbook & & \\
$>$ Pre-Workshop Survey & & \\
\hline
\end{tabular}


Table 12 (continued)

\begin{tabular}{|c|c|}
\hline Activity & Time \\
\hline $\begin{array}{l}\text { Preliminary Handbook Review } \\
>\text { Create small groups } \\
>\text { Scavenger hunt of the handbook (in groups) } \\
>\text { Group share out } \\
>\text { Record group feedback }\end{array}$ & 30 minutes \\
\hline $\begin{array}{l}\text { Presentation-How to utilize the handbook and sample PD plan } \\
>\text { Getting started (staff survey) } \\
>\text { District initiatives } \\
>\text { District calendar } \\
>\text { Design of handbook } \\
>\text { Sample PD plan and calendar }\end{array}$ & 20 minutes \\
\hline $\begin{array}{l}\text { Small group or individual work } \\
\quad>\text { Utilizing the handbook, create PD plan for next school year } \\
>\text { Have sample PD plans available } \\
>\text { Observe and assist when necessary }\end{array}$ & 60 minutes \\
\hline $\begin{array}{l}\text { Share out PD plans, collect plans } \\
\quad>\text { Each group share what they created }\end{array}$ & 30 minutes \\
\hline $\begin{array}{l}\text { Small groups identify strengths and weaknesses of the handbook } \\
>\text { Work in small groups to discuss usefulness of the handbook } \\
>\text { Provide note-taking form } \\
>\text { Questions: What was helpful? What was missing? Suggestions } \\
\text { for revisions? } \\
>\text { Groups share out summary of their discussion }\end{array}$ & 30 minutes \\
\hline $\begin{array}{c}\text { Group discussion of activities and suggestions for future workshops } \\
>\text { Whole group discussion of the workshop } \\
>\text { Suggestions for future workshops } \\
>\text { Suggestions for activities to help plan PD }\end{array}$ & 20 minutes \\
\hline $\begin{array}{l}\text { Individuals complete survey on the usefulness of the handbook } \\
\text { Hard copy } \\
\text { Online survey to follow in three days }\end{array}$ & 20 minutes \\
\hline
\end{tabular}

I began the workshop with a brief introduction of myself and my dissertation. I also explained problem based learning (Bridges \& Hallinger, 1995), the R\&D cycle (Borg \& Gall, 1989) and the purpose of the workshop: To determine the usefulness of the 
handbook in increasing the confidence and efficacy of administrators regarding designing teacher PD. I concluded the introduction with an explanation of the research questions associated with the workshop, interviews and data collection. The research questions are listed below.

Primary Research Question

1. How useful is the handbook, Teachers Teaching Teachers: Designing Successful Professional Development on a Shoestring Budget, in building school leader efficacy and confidence in regards to PD planning?

Secondary Research Questions

1. What is missing from the handbook?

2. Will the handbook encourage school leaders to utilize teacher expertise?

3. Do the research participants find the handbook usable and accessible?

4. What suggestions do school leaders have for the improvement of the handbook?

After describing the workshop and data collection procedures, participants were given consent forms and provided the opportunity to decline to participate in the workshop and/or to contribute feedback during and after the workshop. All participants (38) agreed to participate in the workshop and follow-up surveys knowing that, at any time, they could opt-out of any portion of the workshop or subsequent activities. Participants also completed a pre-workshop survey with included demographic information. The demographic information is displayed in Table 13. 
Table 13

\section{Demographics of Main Field Test Participants}

\begin{tabular}{|c|c|c|c|c|c|c|}
\hline Participants & $\begin{array}{l}\text { Elem. } \\
\text { Principal }\end{array}$ & $\begin{array}{l}\text { Elem. } \\
\text { AP }\end{array}$ & HS Principal & HS VP & $\begin{array}{l}\text { District Office } \\
\text { Admin. }\end{array}$ & $\begin{array}{l}\text { Years of Experience } \\
\text { as Admin. }\end{array}$ \\
\hline 1 & & & & & $\mathrm{X}$ & $10+$ \\
\hline 2 & $\mathrm{X}$ & & & & & $1-3$ \\
\hline 3 & $X$ & & & & & $1-3$ \\
\hline 4 & & & & & $\mathrm{X}$ & $1-3$ \\
\hline 5 & & & & & $X$ & $1-3$ \\
\hline 6 & $\mathrm{X}$ & & & & & $1-3$ \\
\hline 7 & & & & & $\mathrm{X}$ & $4-6$ \\
\hline 8 & $\mathrm{X}$ & & & & & $1-3$ \\
\hline 9 & & & & & $\mathrm{X}$ & $10+$ \\
\hline 10 & & & & $\mathrm{X}$ & & $4-6$ \\
\hline 11 & & $\mathrm{X}$ & & & & $1-3$ \\
\hline 12 & & $\mathrm{X}$ & & & & $1-3$ \\
\hline 13 & $\mathrm{X}$ & & & & & $4-6$ \\
\hline 14 & & $\mathrm{X}$ & & & & $4-6$ \\
\hline 15 & $\mathrm{X}$ & & & & & $1-3$ \\
\hline 16 & & & & & $\mathrm{X}$ & $1-3$ \\
\hline 17 & $\mathrm{X}$ & & & & & $1-3$ \\
\hline 18 & & & & $X$ & & $1-3$ \\
\hline 19 & $X$ & & & & & $1-3$ \\
\hline 20 & $\mathrm{X}$ & & & & & $4-6$ \\
\hline 21 & & & & $X$ & & $7-10$ \\
\hline 22 & & & & & $\mathrm{X}$ & $4-6$ \\
\hline 23 & & & & & $X$ & $1-3$ \\
\hline 24 & & & & & $X$ & $1-3$ \\
\hline 25 & & & $\mathrm{X}$ & & & $1-3$ \\
\hline 26 & & & & & $\mathrm{X}$ & $1-3$ \\
\hline 27 & $X$ & & & & & $1-3$ \\
\hline 28 & & & & & $X$ & $1-3$ \\
\hline 29 & & & & & $\mathrm{X}$ & $1-3$ \\
\hline 30 & $\mathrm{X}$ & & & & & $4-6$ \\
\hline 31 & & & & & $X$ & $1-3$ \\
\hline 32 & & & & $X$ & & $1-3$ \\
\hline 33 & & & & & $X$ & $1-3$ \\
\hline 34 & $\mathrm{X}$ & & & & & $1-3$ \\
\hline 35 & & & $X$ & & & $1-3$ \\
\hline 36 & & & & & $X$ & $1-3$ \\
\hline 37 & $\mathrm{X}$ & & & & & $1-3$ \\
\hline 38 & $X$ & & & & & $1-3$ \\
\hline Totals & 15 & 3 & 2 & 5 & 17 & \\
\hline
\end{tabular}


Participant demographics are summarized below:

Professional Role:

- $35 \%$ Elementary Principals

- $7 \%$ Elementary Assistant Principals

- $4 \%$ High School Principals

- $11 \%$ High School Vice Principals

- $40 \%$ District Office Administrators

Years of Experience:

- $74 \%$ with 1-3 years of experience in current role

- $16 \%$ with 4-6 years of experience in current role

In order to collect baseline data on how the participants viewed their own efficacy in designing PD and to gather information on what supports and training they had experienced, a pre-workshop survey was issued to all participants. Both the survey and the demographic information were anonymous but they were linked to allow for comparison in responses based on roles, years of experience and whether or not they were responsible for PD planning. The pre-workshop survey is included in Appendix B. The pre-workshop survey information is summarized in Table 14. Participant responses were grouped by roles and similarities were identified to summarize answers. For example, of those participants in the role of elementary principal, all responded yes that they were responsible for planning PD. On the question about competence level, eleven elementary principals responded that they were confident and three responded that they were somewhat confident. 
Table 14

Pre-Workshop Survey Summary of Responses

\begin{tabular}{|c|c|c|c|c|c|}
\hline & Elem. Prin. & Elem. AP & HS Prin. & HS VP & Dist. Admin. \\
\hline $\begin{array}{l}\text { Currently plan } \\
\text { PD? }\end{array}$ & Yes & Yes & Yes & Yes & $\begin{array}{l}\text { 7-No } \\
\text { 8-Yes }\end{array}$ \\
\hline $\begin{array}{l}\text { Confidence } \\
\text { Level }\end{array}$ & $\begin{array}{l}\text { 11-Confident } \\
\text { 3-Somewhat } \\
\text { confident }\end{array}$ & $\begin{array}{l}\text { 1-Confident } \\
\text { 2-Depends on } \\
\text { the topic }\end{array}$ & Very confident & $\begin{array}{l}\text { 1-Confident } \\
\text { 3-Not very } \\
\text { confident }\end{array}$ & $\begin{array}{l}\text { 9-Confident } \\
\text { 3-Fairly } \\
\text { confident } \\
\text { 3-Not very } \\
\text { confident }\end{array}$ \\
\hline Training & $\begin{array}{l}\text { 6-None } \\
\text { 6-Workshops, } \\
\text { experience as a } \\
\text { teacher, outside } \\
\text { experts }\end{array}$ & $\begin{array}{l}\text { 1-none } \\
\text { 1-teacher } \\
\text { leader } \\
\text { 1-workshops } \\
\text { with } \\
\text { companies and } \\
\text { outside experts }\end{array}$ & $\begin{array}{l}\text { 1-none } \\
\text { 1-conferences } \\
\text { modeling }\end{array}$ & $\begin{array}{l}\text { 2-none } \\
\text { 1-district } \\
\text { workshops } \\
\text { 1-coursework } \\
\text { and } \\
\text { certification }\end{array}$ & $\begin{array}{l}\text { 7-None } \\
\text { 2-Workshops, } \\
\text { outside experts } \\
\text { 4-Experience } \\
\text { as a teacher }\end{array}$ \\
\hline $\begin{array}{l}\text { Support } \\
\text { Provided }\end{array}$ & $\begin{array}{l}\text { Dates, topics, } \\
\text { framework } \\
\text { 1-none }\end{array}$ & Dates, topics & $\begin{array}{l}\text { Dates, topics, } \\
\text { materials }\end{array}$ & $\begin{array}{l}\text { Dates and } \\
\text { topics }\end{array}$ & $\begin{array}{l}\text { 5-did not } \\
\text { answer } \\
\text { 1-inservice (2 } \\
\text { days) } \\
\text { 3-provides } \\
\text { initiatives } \\
\text { 2-as needed } \\
\text { 3-none } \\
\text { 1-materials and } \\
\text { activities }\end{array}$ \\
\hline
\end{tabular}


Table 14 (continued)

\begin{tabular}{|c|c|c|c|c|c|}
\hline & Elem. Prin. & Elem. AP & HS Prin. & HS VP & Dist. Admin. \\
\hline Yearly Plan & Yes & $\begin{array}{l}1 \text {-yes } \\
1 \text {-sometimes } \\
1 \text {-no }\end{array}$ & Yes & Yes & $\begin{array}{l}\text { 9-yes } \\
\text { 3-no } \\
\text { 3-no answer }\end{array}$ \\
\hline $\begin{array}{l}\text { Support } \\
\text { Needed }\end{array}$ & $\begin{array}{l}\text { 8-Time and } \\
\text { flexibility to } \\
\text { meet building } \\
\text { needs } \\
\text { 1-clear vision } \\
\text { 2-PD for } \\
\text { admin. } \\
\text { 3-collaboration } \\
\text { with peers }\end{array}$ & 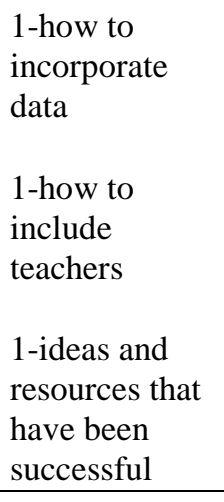 & $\begin{array}{l}\text { Time to plan, } \\
\text { alignment, } \\
\text { collaboration }\end{array}$ & $\begin{array}{l}\text { 3-Specific } \\
\text { activities } \\
\text { 1-Strategies on } \\
\text { how to include } \\
\text { teachers in } \\
\text { planning and } \\
\text { delivery }\end{array}$ & $\begin{array}{l}\text { 1-flexibility } \\
\text { 3-time, } \\
\text { collaboration } \\
\text { 1-how to } \\
\text { engage adult } \\
\text { learners }\end{array}$ \\
\hline $\begin{array}{l}\text { Current PD } \\
\text { Activities }\end{array}$ & $\begin{array}{l}\text { PLC, } \\
\text { workshops } \\
\text { presented by } \\
\text { teachers and } \\
\text { outside experts }\end{array}$ & $\begin{array}{l}\text { PLC, } \\
\text { workshops } \\
\text { presented by } \\
\text { teachers and } \\
\text { outside experts }\end{array}$ & $\begin{array}{l}\text { PLC, } \\
\text { workshops } \\
\text { presented by } \\
\text { teachers and } \\
\text { outside experts }\end{array}$ & $\begin{array}{l}\text { PLC, } \\
\text { workshops } \\
\text { presented by } \\
\text { teachers and } \\
\text { outside experts, } \\
\text { workshops } \\
\text { presented by } \\
\text { curriculum } \\
\text { VP's }\end{array}$ & $\begin{array}{l}\text { PLC, } \\
\text { workshops } \\
\text { presented by } \\
\text { teachers, } \\
\text { workshops } \\
\text { presented by } \\
\text { district } \\
\text { administrators, } \\
\text { peer } \\
\text { observation } \\
\end{array}$ \\
\hline $\begin{array}{l}\text { Is Current PD } \\
\text { Effective? }\end{array}$ & $\begin{array}{l}\text { 10-Yes } \\
\text { 4-No }\end{array}$ & $\begin{array}{l}\text { 2-Yes } \\
1-\mathrm{No}\end{array}$ & $\begin{array}{l}1-Y e s \\
1-N o\end{array}$ & $\begin{array}{l}\text { 1-Yes } \\
\text { 3-No }\end{array}$ & $\begin{array}{l}\text { 6-Yes } \\
\text { 5-No } \\
\text { 2-Somewhat } \\
\end{array}$ \\
\hline
\end{tabular}

The Pre-Workshop Survey provided information about the participant's perceptions of the current PD being offered, their confidence level in delivering PD, the PD supports provided by the district office, supports needed and whether or not they perceive the PD as effective. The pre-workshop survey indicated that over half of the 
participants felt confident about their ability to plan PD yet less than half had been provided any training. The training that was provided was mostly from workshops presented by outside experts. Many of the participants indicated that "time to plan" was the greatest need. Slightly more than half of the participants felt that the current PD for teachers was effective.

The next portion of the workshop was an opportunity for participants to review the handbook. Participants worked in small groups to complete a scavenger hunt of the handbook. The purpose of this activity was to get feedback on the usability and ease of finding resources in the handbook and suggestions on information that is missing in the handbook. Table 15 summarizes the small group feedback from the scavenger hunt.

Table 15

Handbook Scavenger Hunt Responses

\begin{tabular}{|c|c|}
\hline Question & Summary of Responses \\
\hline $\begin{array}{l}\text { 1. What are the three types of PD discussed in the } \\
\text { handbook? }\end{array}$ & $\begin{array}{l}\text { - All nine groups were able to list the three types: } \\
\text { Action Research, Peer Observation and PLCs }\end{array}$ \\
\hline $\begin{array}{l}\text { 2. Can you think of any other type of PD that } \\
\text { should be included (collaborative and teacher- } \\
\text { led)? }\end{array}$ & $\begin{array}{l}\text { - Five out of nine groups could not think of any } \\
\text { other type of PD that should be included. } \\
\text { - Two groups suggested teacher-led workshops. } \\
\text { - Two groups suggested teacher coaching } \\
\text { activities. }\end{array}$ \\
\hline $\begin{array}{l}\text { 3. Chapter } 2 \text { includes suggested steps in } \\
\text { designing PD. Review the steps and discuss at } \\
\text { your table. Is there anything missing? }\end{array}$ & $\begin{array}{l}\text { - Four groups did not think there was anything } \\
\text { missing. } \\
\text { - One group suggested including more resources, } \\
\text { definition for successful implementation and } \\
\text { reflective exercises. } \\
\text { - Two groups suggested a focus on achievement } \\
\text { data. } \\
\text { - One group suggested including more PD } \\
\text { activities. } \\
\text { - One group suggested resources for getting staff } \\
\text { feedback. }\end{array}$ \\
\hline
\end{tabular}


Table 15 (continued)

\begin{tabular}{|c|c|}
\hline Question & Summary of Responses \\
\hline $\begin{array}{l}\text { 4. Find the High School PD Survey. Discuss } \\
\text { whether or not you think this tool is helpful. } \\
\text { Why or why not? }\end{array}$ & $\begin{array}{l}\text { • All nine groups thought the survey was helpful. } \\
\text { Quotes from Groups: } \\
\text { "It allows for reflection on what's been done in the } \\
\text { past, it incorporates outside PD evaluation and it } \\
\text { allows for authentic reflection." } \\
\text { "Keeping the survey anonymous is important so } \\
\text { teachers are more likely to answer honestly." } \\
\text { "Important to evaluate what has been offered thus } \\
\text { far." } \\
\text { "It might be useful to compare teacher perceptions } \\
\text { to documented achievement gains by students." } \\
\text { "Absolutely! Would allow for differentiation of PD. } \\
\text { Would add a question for teachers to identify a topic } \\
\text { they would feel comfortable presenting on." } \\
\text { "Great data collected. Very Thorough." }\end{array}$ \\
\hline $\begin{array}{l}\text { 5. There are two types of Action Research } \\
\text { models in chapter } 3 \text {. If you were going to } \\
\text { implement AR, which model do you think } \\
\text { would work best? Why? }\end{array}$ & $\begin{array}{l}\text { - Four groups responded that they did not have a } \\
\text { preference between the two models. } \\
\text { - Two groups chose the first model and made the } \\
\text { following comments: } \\
\text { "It is more usable and would be helpful to start } \\
\text { with." } \\
\text { "We prefer the first model, especially for teachers } \\
\text { with less experience, due to the structure and } \\
\text { framework being easily laid out." } \\
\text { - Two groups chose the second model and made } \\
\text { the following comments: } \\
\text { "It is only one page and has open-ended } \\
\text { responses." } \\
\text { "This would work best for teachers with } \\
\text { experience." } \\
\text { - One group responded that they would use both } \\
\text { models and made the following comments: } \\
\text { "The first model presents the idea well." } \\
\text { "The second model has an easy to use template." } \\
\text { "Both need a mid-way reflection piece and } \\
\text { opportunity to adjust." }\end{array}$ \\
\hline
\end{tabular}

Table 15 (continued) 


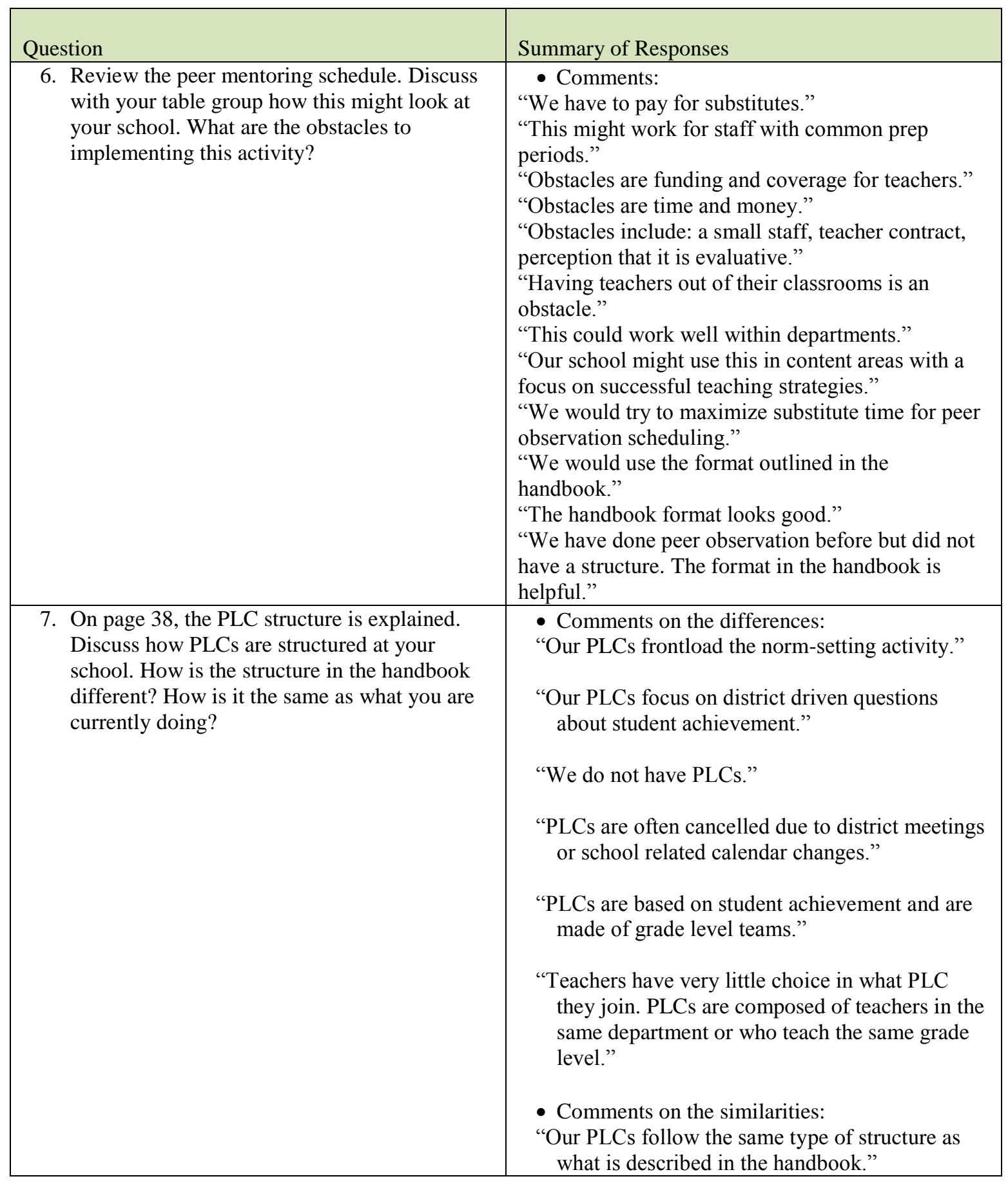


Table 15 (continued)

\begin{tabular}{|c|c|}
\hline Question & Summary of Responses \\
\hline $\begin{array}{l}\text { 8. Review the Criteria Sheet for Instruction. How } \\
\text { could this be useful? What are the challenges } \\
\text { to implementing this type of expectation? }\end{array}$ & $\begin{array}{l}\text { - Comments of the usefulness of the criteria } \\
\text { sheet: } \\
\text { "Checklist is useful." } \\
\text { "The checklist could be helpful for teachers. It is } \\
\text { specific and could support accountability." } \\
\text { "It would provide insight on the } \\
\text { strengths/improvements (staff audit)." } \\
\text { "It would help us find the hidden gems of teacher } \\
\text { knowledge." } \\
\text { "It is similar to what we want teachers to do with } \\
\text { students; identify the expectations at the } \\
\text { beginning." } \\
\text { "The Criteria Sheet could be useful in identifying } \\
\text { the goals for the year and specific evidence that } \\
\text { teachers must provide." } \\
\text { " Comments on the challenges of implementing } \\
\text { the Criteria Sheet: } \\
\text { "Could be repetitive for some teachers." } \\
\text { "Teacher contract/union may be an obstacle." } \\
\text { "District initiatives get in the way." }\end{array}$ \\
\hline What do you like about the handbook? & $\begin{array}{l}\text { - Comments from groups: } \\
\text { "Handbook is short and readable." } \\
\text { "It has practical tools and applications." } \\
\text { "The PD survey tool." } \\
\text { "It includes resources." } \\
\text { "The examples are immediately usable." } \\
\text { "The focus on teachers teaching teachers." } \\
\text { "The collaboration." } \\
\text { "Teachers doing research." } \\
\text { "It is connected to our work." }\end{array}$ \\
\hline
\end{tabular}


Table 15 (continued)

\begin{tabular}{|c|c|}
\hline Question & Summary of Responses \\
\hline $\begin{array}{l}\text { 10. What is missing from the handbook? What } \\
\text { changes would you make? }\end{array}$ & $\begin{array}{l}\text { - Comments from groups: } \\
\text { "How these activities juxtapose with current } \\
\text { teacher contracts and/or teacher evaluation } \\
\text { systems." } \\
\text { "The PD survey could include a ranking to } \\
\text { prevent teachers from ranking PD too low." } \\
\text { "There could be more depth if only one type of } \\
\text { PD was covered. There is a lot of information." } \\
\text { "More examples of resources." } \\
\text { "The peer observation/mentoring form on page } 34 \\
\text { is too general." } \\
\text { - Four groups left this question blank. }\end{array}$ \\
\hline
\end{tabular}

The Scavenger Hunt activity provided useful information about the handbook and answers relevant to the following research questions:

Primary research question:

1. How useful is the handbook, Teachers Teaching Teachers: Designing Successful Professional Development on a Shoestring Budget, in building school leader efficacy and confidence in regards to PD planning?

\section{Secondary Research Questions}

1. Do school administrators have resources to help them plan PD?

2. Will the handbook encourage school leaders to utilize teacher expertise?

3. What is missing from the handbook?

4. What suggestions do school leaders have for the improvement of the handbook? 
After the Scavenger Hunt activity, I facilitated a whole group discussion in which participants were asked to share their initial thoughts about the handbook. The discussion elicited the following responses:

The handbook was easy to follow and sections were clearly labeled.

I thought the resources were helpful and wondered if there were more that could be included? The examples will be useful when planning PD.

I could see this being extremely useful for new principals and teacher leaders. The explanations of PD activities are clear and the protocols are helpful. I have not seen a handbook that is designed to help school leaders plan PD and this is a valuable resource.

The responses during the discussion were positive and demonstrated an overall satisfaction with the handbook following the scavenger hunt. The next portion of the workshop was dedicated to using the handbook to develop the framework of a year-long PD plan.

The participants spent approximately one hour using the handbook to develop a draft of a year-long PD plan. Some worked in small groups with administrator colleagues who worked at the same level (elementary or secondary). Some chose to work with their school administrative teams (principal and assistant or vice principal). The district office administrators collaborated in small groups by department (curriculum, testing, human relations, etc.). In addition to the handbook, participants received PD plans that served as models. During the work session, all participants were engaged and appeared to be using the handbook and models to plan PD. Participants asked questions as I was walking around and observing. Questions included: 
1. How are the PLC topics chosen?

2. How do you build in district initiatives?

3. What is the ideal length of PLC meetings?

4. What is the ideal size of PLC groups?

5. What are some examples of action research projects?

The questions were useful and I used this information to make revisions to the handbook. The work session provided information on the practicality and usability of the handbook. At the end of this portion of the workshop, participants shared the draft of their PD plan with the larger group. All plans included PLCs and peer observation components. Approximately half of the plans included some form of action research. Participants shared that they were not as familiar with action research as they were with other activities and participants were not exactly clear on how to implement. This part of the workshop was extremely important as it gave me an opportunity to observe administrators using the handbook and also provided information that influenced final revisions made to the handbook.

The next portion of the workshop was an opportunity for small groups to identify strengths and weaknesses of the handbook. Each group selected a recorder and used a note-taking form to summarize the group discussion. There were seven small groups and each group had between four and eight members. Each group discussed four questions and shared out their responses to the larger group. The questions and individual group responses are displayed in Table 16. 
Table 16

Small Group Feedback on the Handbook

\begin{tabular}{|c|c|c|c|}
\hline Group \# & What was helpful? & What was missing? & Revision suggestions \\
\hline 1 & $\begin{array}{l}\text { "The handbook was easy to } \\
\text { use and organized." } \\
\text { "All three activities } \\
\text { promote collaboration." } \\
\text { "The sample survey was } \\
\text { very helpful." } \\
\text { "How to begin the planning } \\
\text { was useful." }\end{array}$ & $\begin{array}{l}\text { "Details about action } \\
\text { research." } \\
\text { "Examples" } \\
\text { "Process for evaluating the } \\
\text { success of the activities." }\end{array}$ & $\begin{array}{l}\text { "Elaborate more on how to set } \\
\text { up each PD activity." } \\
\text { "Provide more examples for } \\
\text { PLC notes and action research } \\
\text { projects." } \\
\text { "Possibly a post-survey for } \\
\text { staff after implementing PD } \\
\text { activities." }\end{array}$ \\
\hline 2 & $\begin{array}{l}\text { "We found the handbook to } \\
\text { be very helpful and would } \\
\text { like to have more time to } \\
\text { really apply the resource." } \\
\text { "The handbook } \\
\text { organization made it easy to } \\
\text { use and to find } \\
\text { information." }\end{array}$ & $\begin{array}{l}\text { "A way to measure success } \\
\text { of the activities." } \\
\text { "What to do if PD isn't } \\
\text { going well." } \\
\text { "How peer observation is } \\
\text { funded." }\end{array}$ & $\begin{array}{l}\text { "Add a post-survey for staff." } \\
\text { "Add a troubleshooting section } \\
\text { for each activity." } \\
\text { "Provide information on how } \\
\text { to fund activities such as } \\
\text { substitutes for peer } \\
\text { observation." }\end{array}$ \\
\hline 3 & $\begin{array}{l}\text { "The handbook is well } \\
\text { organized and easy to } \\
\text { follow." }\end{array}$ & $\begin{array}{l}\text { "The connection to common } \\
\text { core and other initiatives." }\end{array}$ & $\begin{array}{l}\text { "A section with more detail on } \\
\text { how to meet district initiatives } \\
\text { and provide other PD } \\
\text { activities." }\end{array}$ \\
\hline 4 & $\begin{array}{l}\text { "The survey is a good way } \\
\text { to find out what kind of PD } \\
\text { teachers have had and what } \\
\text { they prefer." } \\
\text { "The arguments on why } \\
\text { teachers should do action } \\
\text { research." }\end{array}$ & $\begin{array}{l}\text { "A section that lists other } \\
\text { types of PD." } \\
\text { "How activities are funded." }\end{array}$ & $\begin{array}{l}\text { "Include a section that lists } \\
\text { other types of PD for } \\
\text { administrators to consider." } \\
\text { "It would be helpful to have the } \\
\text { details on how things like } \\
\text { substitutes are funded." }\end{array}$ \\
\hline 5 & $\begin{array}{l}\text { "The handbook is a good } \\
\text { resource for administrators } \\
\text { and/or teacher leaders." }\end{array}$ & "Nothing is missing." & $\begin{array}{l}\text { "Include electronic versions of } \\
\text { the resources." }\end{array}$ \\
\hline
\end{tabular}


Table 16 (continued)

\begin{tabular}{|c|c|c|c|}
\hline Group \# & What was helpful? & What was missing? & Revision suggestions \\
\hline 6 & $\begin{array}{l}\text { "Our group liked the survey } \\
\text { and examples of tools." } \\
\text { "The handbook was easy to } \\
\text { use." } \\
\text { "We liked the action } \\
\text { research section because it } \\
\text { is something that we had } \\
\text { not thought of for teacher } \\
\text { PD." }\end{array}$ & $\begin{array}{l}\text { "We wondered about } \\
\text { funding for substitutes for } \\
\text { the peer observation PD." }\end{array}$ & $\begin{array}{l}\text { "The handbook could use more } \\
\text { diagrams and color. It has a lot } \\
\text { of text." }\end{array}$ \\
\hline 7 & $\begin{array}{l}\text { "We liked the fact that the } \\
\text { handbook was written by an } \\
\text { educator and that the } \\
\text { activities were tested." } \\
\text { "The handbook was easy to } \\
\text { follow and descriptions } \\
\text { were thorough." } \\
\text { "The survey is useful when } \\
\text { planning what PD to } \\
\text { implement." }\end{array}$ & $\begin{array}{l}\text { "We could not come up with } \\
\text { anything that was missing." }\end{array}$ & $\begin{array}{l}\text { "Make the resources available } \\
\text { electronically." }\end{array}$ \\
\hline
\end{tabular}

This portion of the workshop provided small groups the opportunity to discuss the strengths and weaknesses of the handbook. Highlights of this activity included the following themes:

1. What was helpful:

- Staff survey

- Ease of use

- Action research protocol

- Handbook organization

2. What was missing:

- Post-survey or way to measure success of the PD activities

- How to fund peer observation (substitutes) 
3. Suggestions for revisions:

- More examples

- Post-survey example (way to evaluate PD)

- Funding suggestions

- Electronic version of handouts and resources

When planning the workshop, I debated on whether or not to include this small group activity as the requested feedback was similar to what was requested for the scavenger hunt at the beginning of the workshop. After using the handbook to create a PD plan, the participants were more familiar with the handbook and specific details found in each section. The feedback from the small group discussion after the PD planning session was extremely helpful and provided more guidance on what revisions to make to the handbook.

Final survey. The final activity of the workshop was completion of a postworkshop survey (Appendix C). By completing the survey, participants provided summative feedback on the handbook including suggestions for changes to the handbook, additional supports that would be useful for administrators, PD activities that they planned to implement and any new learning they experienced by utilizing the handbook and participating in the workshop. There were six questions on the post-workshop survey and 20 out of 38 participants responded to the survey either at the workshop or electronically. The data from the post-workshop survey provided information on the following topics:

$\checkmark$ Confidence level of participants regarding planning PD

$\checkmark$ Additional resources needed

$\checkmark$ PD activities planned for implementation 
$\checkmark$ Other supports needed

$\checkmark$ Suggested changes for the handbook

$\checkmark$ New learning as a result of the workshop

The data collected from the survey is summarized in Table 17.

Table 17

Post-Workshop Survey Data

\begin{tabular}{|c|c|}
\hline Survey Question & Responses \\
\hline $\begin{array}{l}\text { What is your confidence level regarding } \\
\text { the planning and implementation of PD? }\end{array}$ & $\begin{array}{l}75 \% \text {-increased confidence } \\
25 \% \text {-same level of confidence }\end{array}$ \\
\hline $\begin{array}{l}\text { What additional supports do you need to } \\
\text { assist in designing teacher PD? }\end{array}$ & $\begin{array}{l}83 \% \text {-time to plan and collaborate with colleagues and } \\
\text { teacher leaders } \\
10 \% \text {-more direction from district office on initiatives and } \\
\text { requirements } \\
7 \% \text {-other (funding, practical examples) }\end{array}$ \\
\hline $\begin{array}{l}\text { Which PD activities do you plan to } \\
\text { implement? }\end{array}$ & $\begin{array}{l}38 \% \text {-PLC } \\
31 \% \text {-Peer Observation } \\
16 \% \text {-Action Research } \\
16 \% \text {-Other }\end{array}$ \\
\hline $\begin{array}{l}\text { Do you have any suggestions for PD } \\
\text { activities that should be included in the } \\
\text { handbook? }\end{array}$ & $\begin{array}{l}97 \% \text {-no suggestions } \\
3 \% \text {-Instructional coaching cycles }\end{array}$ \\
\hline $\begin{array}{l}\text { Please explain any new learning you } \\
\text { experienced by participating in the } \\
\text { workshop. }\end{array}$ & $\begin{array}{l}62 \% \text {-teachers as experts } \\
15 \% \text {-power of peer observation } \\
13 \% \text {-benefit of staff survey } \\
10 \% \text {-other (new processes, protocols for PD, shared } \\
\text { language) }\end{array}$ \\
\hline
\end{tabular}

The final survey provided valuable feedback regarding the workshop and handbook. The responses assisted me in evaluating the usefulness of the handbook and provided information that I could use in planning future workshops. Even though the workshop was only three hours long, $75 \%$ of the participants reported that they felt more 
confident in planning PD. One participant commented on the survey that, "I feel more confident now that I have seen examples of peer observation.” Another participant commented that, "The workshop underscored the value of empowering teachers to collaborate to design and implement their PD programs.”

The second question on the post-workshop survey asked participants to identify any additional supports they need. The majority (83\%) responded that they need more time to collaborate with each other with teacher leaders to plan PD. One participant stated that, "I often feel like I am recreating the wheel. I need more time to plan with my colleagues."

The participants reported that PLCs and Peer Observation were the activities they were most likely to implement. These two activities were well received by participants. One participant commented that, "The step-by-step information in the peer observation section was very good and helpful." Another participant commented that, "I am inspired by the many examples of teachers teaching each other, especially in the peer observation protocol." Some of the feedback indicated that there needed to be more information and explanation about action research.

Interestingly, $97 \%$ of the participants responded that they had no suggestions for additional activities that should be included in the handbook. With all of the PD options available, it was surprising to me that there weren't more suggested topics to include in the handbook. This was also feedback that was useful as I decided what revisions to make to the handbook. I decided not to add any additional topics but to make some additions to 
the action research section as suggested by the feedback from participants during the small group discussions.

Survey responses to Please explain any new learning you experienced by participating in the workshop, indicated a large number of the participants (62\%) experienced new learning in the area of teachers as experts. One participant commented that, "I now have new ways of involving staff in the PD planning process." Another participant contributed the following, "The handbook sheds new light on creative ways to explore teacher input into building level decision-making."

Table 17 summarizes the responses to the post-workshop survey; however the individual comments provide important data regarding the usefulness of the handbook and workshop related to the confidence level of administrators in planning teacher PD. Below are specific, positive comments from the post-workshop survey:

I can see how many of the components would be helpful in planning staff development work.

Great work. Very valuable tool that will definitely help me in the planning process.

The workshop and handbook introduced new ideas for PD.

By participating in the workshop with other colleagues, we developed a shared language and have a resource (handbook) to turn to when we are planning our PD.

In addition, the survey also yielded suggestions for improvement. Following are comments from the post-workshop survey that helped me determine what revisions to make:

Perhaps more detail on the action research PD. 
I need more specific models that incorporate scheduling solutions for teachers engaged in peer observation protocols.

Ideas on how to utilize the talents of current staff.

Summary of data collection. The data collected in this study were used to answer primary and secondary research questions which were stated previously in this chapter. The data included formative and summative information that was used to determine the usefulness of the handbook and to direct the revision of the handbook. Following is a discussion of the data as it relates to the research questions.

What suggestions do school leaders have for the improvement of the handbook? Participant feedback included adding more specific examples in each section and a more in depth discussion of the implementation of action research. During the scavenger hunt activity, small groups identified areas for improvement and things they thought were missing from the handbook. Their responses are summarized in Table 17 and include the following responses:

How these activities juxtapose with current teacher contracts and/or teacher evaluation systems.

The PD survey could include a ranking to prevent teachers from ranking PD too low.

There could be more depth if only one type of PD was covered. There is a lot of information.

More examples of resources.

The peer observation/mentoring form on page 34 is too general.

The post-workshop survey included the question; do you have any suggestions for PD activities that should be included in the handbook? Ninety-seven percent of 
participants responded that they did not have any suggestions. One participant suggested adding Instructional Coaching Cycles as an additional PD activity. While I believe instructional coaching is a valuable activity it was only mentioned by one participant, therefore I decided not to include it or any additional activities in the handbook revision. The participant responses indicate that there might be some changes that could be made based on individual preferences, but in general, the handbook is viewed as including activities that are useful and applicable. Based on the feedback from participants I decided to include more resources for the activities in the handbook rather than add additional activities.

Does the handbook encourage school leaders to utilize teacher expertise? The data collected in this study indicated that administrators often design PD in isolation, with little input from teachers and use district initiatives to guide the PD plan. The preliminary field test and main field test elicited feedback from administrators that included a desire to incorporate expert teachers into PD planning and implementation, a need to find ways to comply with district initiatives and provide meaningful PD opportunities and a need for more collaboration time with teachers and colleagues during the PD planning process.

The preliminary field test included a year-long implementation process utilizing the handbook and activities. The administrator field testing the handbook conducted staff surveys throughout the year and reported, during the interview, that the staff overwhelmingly had a positive response to the collaborative opportunities. The administrator reported that, "Staff really appreciated the fact that they could choose their PLC focus and group. I believe this made the activity more successful than in the past. 
The note-taking process was also useful and provided accountability for PLC work. Another thing that enhanced our work was the sharing of practice at the end of the year. Teachers were proud of their work and this provided a way to celebrate their efforts." At the end of the year, the staff held a celebration and shared their work. The administrator conducting the preliminary field test made the following comment: "Teachers expressed a high level of satisfaction with the PD activities and participation was increased." Even though I had experienced a high degree of satisfaction from teachers when implementing the activities in the handbook, when another administrator experiences the same level of satisfaction from a different group of teachers, it is supportive evidence that a PD plan focused on teacher collaboration is preferred by teachers.

Do participants find the handbook usable and accessible? The workshop provided time and space for administrators to review and utilize the handbook, collaborate with colleagues and begin to develop a PD plan for the upcoming school year. $75 \%$ of the participants felt more confident in the process of PD planning after the workshop. $83 \%$ responded that they wanted more time from their own districts to collaborate and learn from each other. One participant specifically referenced the workshop in the final survey and stated:

The workshop was very good and provided step by step information. Another participant commented:

The workshop underscored the value of empowering teachers to collaborate to design and implement their professional development programs. The workshop introduced new ideas for professional development and ways to get teachers involved. 
Both of these participants mentioned the workshop as helpful in the PD planning process. The workshop design was collaborative and allowed administrators to share their ideas and to get feedback on their PD plans. I do not believe the effectiveness of the handbook is dependent on participating in a workshop, however, I do think the workshop demonstrated the benefits of collaboration in the planning of PD. Based on this feedback, I decided to add a section to the handbook on planning PD in collaboration with colleagues.

What is missing from the handbook? The participants reported that the workshop provided an opportunity to review the tool, ask questions and apply the resources to their own work. There was a common theme emerging throughout the workshop regarding a need for time to collaborate and plan, with $83 \%$ of participants responding that time to collaborate is the main support needed to generate effective PD plans. The time that was provided in the workshop for the scavenger hunt and handbook evaluation allowed the participants to become familiar with the layout of the handbook and resources that were included in the handbook. One participant also responded that, "by doing this as a group, we now share a language and have a common resource to turn to when planning our PD." Based on this feedback, I decided to include a section in the handbook for district administrators on the benefits of hosting a workshop session in which principals could utilize the handbook and collaborate as they design PD.

How useful is the handbook, Teachers Teaching Teachers: Designing Successful Professional Development on a Shoestring Budget, in building school leader efficacy and confidence in regards to PD planning? This was the primary research question for this 
study. $75 \%$ of the workshop participants indicated on the post-workshop survey that their level of confidence in planning PD was increased after completing the workshop. More than $60 \%$ felt confident implementing peer observation and PLCs and the main support they felt they needed was time to collaborate with colleagues. In the preliminary field test, the administrator indicated in the final interview that she experienced a huge increase in her confidence level and sense of efficacy after utilizing the handbook to plan and implement PD. Based on the data, I can safely assume that the handbook is a useful tool and can increase building leader efficacy and confidence in regards to PD planning.

After analyzing the data from the field testing of the handbook, I entered into step 7 of the R\&D cycle: operational revisions.

\section{Step 7: Operational Product Revisions}

In this step, revisions are made to the product based on data collected in the main field test. The data provided information on the usefulness of the product and suggestions for improving the product. This section includes detailed information on the revisions made to the product and the data that was used to support the changes.

\section{Revision 1: Addition of workshop agenda to use for collaborative PD}

planning session. Administrators who participated in the main field test were asked to identify additional supports they needed to assist in the design of teacher PD. While there were some suggestions related to specific activities, $83 \%$ of the participants identified time to collaborate with colleagues and teachers in the planning of PD as the most needed support. 
The participants in the workshop included building level and district office administrators. The fact that such a high percentage of participants expressed a desire for more time to collaborate was an indication that it would be useful to provide a protocol for collaborative planning. I decided to include a modified version of the workshop agenda in the handbook for administrators to utilize in organizing work groups to plan PD.

Revision 2: Sample staff surveys for feedback after PD. One participant noted that it might be helpful to have samples of staff surveys that could be used after implementation of PD activities. The administrator in the preliminary field test created staff surveys and used them throughout the year to get feedback on PD activities. She reported that this was extremely useful in designing future activities and in gauging how useful staff perceived the PD activities.

Revision 3: Mid-way reflection activity for action research. Participants in the main field test made general suggestions about adding resources for the activities. One of the more specific suggestions was to add a mid-way reflection for the action research protocol. Considering the length of most action research projects (several weeks to an entire year), this made sense and was also consistent with other protocols in the handbook.

Revision 4: Suggestions for funding peer observation. Several participants in the main field test asked questions about funding. Two of the three PD activities do not require any additional funding and can be accomplished by utilizing school or district provided PD time. The challenge with the peer observation activity is that teachers need 
to be released for a half or full day to observe other teachers. The protocol includes observing another teacher and having time to plan a lesson or unit utilizing strategies from the observation. I decided to include some suggestions in the peer observation section on how to implement this type of PD with little or no additional funding.

Revision 5: More details on PLCs. I presented some standard protocols for facilitating PLCs in the workshop for administrators. I noticed in the feedback and questions that there needed to be more detail in how to set up the PLCs, the ideal size for a PLC, how long PLCs should meet, what is the ideal frequency of meetings and how are district initiatives include in PLCs.

Revision 6: Examples of action research projects. The handbook provides examples of protocols, handouts and topics. One common request from participants in the main field research was to include examples of action research projects. I decided to make this addition by including examples from teachers I have worked with. I eliminated their names and any other identifying information to provide models for administrators to use when implementing action research as a PD activity.

Table 18 organizes the data and the operational revisions. 
Table 18

\section{Operational Product Revisions}

\begin{tabular}{|c|c|}
\hline Data from Main Field Testing & Revision \\
\hline $\begin{array}{l}\text { "It would be helpful to have time to plan with } \\
\text { teachers." } \\
\text { "We need to find experts among our ranks." } \\
\text { "We need administrator collaboration time." } \\
\text { "I would like facilitation for us to share ideas." } \\
\text { "We need time together to develop plans for our } \\
\text { buildings." } \\
\text { "Doing this as group/district, allowed us to share } \\
\text { ideas." }\end{array}$ & $\begin{array}{l}\text { Added workshop agenda to resource section of } \\
\text { handbook. The workshop agenda could be used to } \\
\text { facilitate collaboration among administrators, } \\
\text { building leaders and/or teachers in PD planning } \\
\text { sessions. }\end{array}$ \\
\hline $\begin{array}{l}\text { What is missing: } \\
\text { - Post-survey or way to measure success of } \\
\text { the PD activities } \\
\text { Suggestions for revisions: } \\
\text { - Post-survey example (way to evaluate PD) }\end{array}$ & $\begin{array}{l}\text { Added sample surveys to give to staff during the } \\
\text { year to evaluate PD activities. }\end{array}$ \\
\hline $\begin{array}{l}\text { "The first model presents the idea well." } \\
\text { "The second model has an easy to use template." } \\
\text { "Both need a mid-way reflection piece and } \\
\text { opportunity to adjust." }\end{array}$ & $\begin{array}{l}\text { Added mid-way reflection in action research } \\
\text { protocol. }\end{array}$ \\
\hline $\begin{array}{l}\text { "We have to pay for substitutes." } \\
\text { "This might work for staff with common prep } \\
\text { periods." } \\
\text { "Obstacles are funding and coverage for teachers." } \\
\text { "Obstacles are time and money." } \\
\text { "We would try to maximize substitute time for peer } \\
\text { observation scheduling." }\end{array}$ & $\begin{array}{l}\text { Added suggestion funding source for peer } \\
\text { observation. }\end{array}$ \\
\hline $\begin{array}{l}\text { Questions included: } \\
\text { 1. How are the PLC topics chosen? } \\
\text { 2. How doteacher you build in district } \\
\text { initiatives? } \\
\text { 3. What is the ideal length of PLC meetings? } \\
\text { 4. What is the ideal size of PLC groups? }\end{array}$ & $\begin{array}{l}\text { Added more details about PLC design and structure } \\
\text { Included the following: } \\
\text { - Selection of topics } \\
\text { - Recommended size } \\
\text { - Length of meetings } \\
\text { - Frequency of meetings }\end{array}$ \\
\hline $\begin{array}{l}\text { What is missing? } \\
\text { - Examples of action research projects. }\end{array}$ & $\begin{array}{l}\text { Added three examples of action research projects to } \\
\text { the action research section. }\end{array}$ \\
\hline
\end{tabular}




\section{Field Testing Issues and Challenges}

This study posed several issues and challenges. Following is a discussion of the issues and challenges that surfaced during the research study.

\section{Sample}

The sample group for the main field test was identified over a year ago. However, a month prior to the main field test, the sample group was no longer accessible. I was able to secure another sample group but the demographics of the group were different than what I had originally planned. I wrote the handbook with high school principals and vice principals in mind and the original sample group members were all currently in one of those positions. The replacement sample group was composed of K-12 administrators and district office administrators. I do not think the sample group affected the outcome of the study. In fact, having all levels of administrators actually added a dimension to the study that I found useful. The feedback from participants indicated that the handbook could be useful to K-12 building administrators and district office administrators.

\section{Post-Workshop Survey Results}

The post-workshop survey was administered at the end of the workshop. Only 10 participants turned in the survey before leaving that day. I followed up with all participants within one week after the workshop and was able to get post-workshop surveys from 10 more participants. While there were 38 participants in the workshop, I only received 20 post-workshop surveys. Although I only received responses from slightly more than half of the participants, I still found the data to be useful. Based on the preliminary field test and observations made during the workshop, I think the conclusion 
would have been the same; The handbook, Teachers Teaching Teachers: Designing Successful Professional Development on a Shoestring Budget, is useful for school leaders. In future workshops, I would attempt to administer and collect the post-workshop survey at the conclusion of the workshop. Since a large number of the administrators found the handbook useful, it might have been an incentive to offer a copy of the revised handbook to those who respond to the post-workshop survey.

\section{Chapter Summary}

Chapter 4 begins with the focus of the study, the research questions and goals. After setting the stage, the next portion of the chapter is dedicated to describing the activities in each stage of the R\&D cycle (Borg \& Gall, 1989). The preliminary field testing and main field testing data were organized and discussed with an emphasis on common themes that emerged from the participant's feedback. The feedback was then used to identify operational product revisions that were made to the handbook based on the data received in the main field testing. The final portion of the chapter discussed the issues and challenges that surfaced before, during and after the main field testing.

The next chapter includes information relative to conclusions drawn from the study. Topics to be covered include: recommendations for further study, recommendations for school and district administrators regarding planning teacher PD and future plans for the development and use of the handbook. 


\section{CHAPTER V}

\section{CONCLUSIONS, SPECULATIONS, AND RECOMMENDATIONS FOR LEADERSHIP}

\section{Chapter Overview}

Teacher collaboration is an overlooked and underutilized form of PD, and one of the main motivators for choosing this research project. Another challenge in providing PD is the budget crisis which has forced schools to allocate little or no money toward PD opportunities. Creating good PD is not totally free, however finding expertise among the teaching staff is cost effective and affordable (Locke, 2012). There is an education funding crisis across the nation and most schools are not able to set aside funds for teachers to attend workshops, to bring in experts or to pay for teachers to travel to state or national conventions. Even with funding, the workshops and experts do not produce lasting changes or have a significant impact on teaching practice or student learning.

According to Sawchuk (2010) there are few PD activities linked to outcome measures that indicate instruction and/or learning has improved due to a change in practice. In my own experience as a teacher, I would concur that none of the PD opportunities I experienced over a 25-year teaching career required any accountability or outcome measure on my part. Very few even asked for feedback from participants regarding the effectiveness of the workshop, presentation or activity.

PD for teachers has not changed much since the 1950's. It is still common practice in this country, for school districts to provide one-day workshops by outside 
experts that are disconnected from teaching practice (Royce, 2010). The budget challenges of the past decade have greatly reduced spending in the area of teacher PD and, in some cases, professional learning opportunities for teachers have been reduced to a few in-service days per year (Habegger \& Hodanbosi, 2011). The handbook, Teachers Teaching Teachers: Designing Successful Professional Development on a Shoestring Budget, is a resource that administrators can use to design learning opportunities for teachers that promote collaboration, continuous processes and the utilization of current teachers as experts. This chapter discusses the outcomes of the study and makes suggestions for future handbook research, development and use. The chapter concludes with recommendations for school and district leaders on developing PD plans.

This study provided a workshop for 38 building level and district office administrators. The participants engaged in a review of the handbook, small group discussion and a work session with colleagues to develop a year-long PD plan for teachers. Participants also completed pre- and post-surveys regarding the usefulness of the handbook and their level of competency before and after the workshop. The workshop, which was a form of PD itself, modeled how PD activities can be collaborative and provide opportunities for continuous growth.

The design of this study was a replication of problem based learning as described by Bridges and Hallinger (1995). The model includes three stages:

- Stage 1: Problem identification and proposal development

- Stage 2: Development of the Problem Based Learning Project

- Stage 3: Field Test, Data Collection and Analysis, Product Revision 
The problem based learning model fits perfectly with a problem of practice, in this case, the problem related to designing teacher PD that is sustainable and continuous with little or no budget. The study began with an initial question: Can a handbook be created that successfully guides principals in the development of low cost, sustainable, continuous, collaborative teacher PD? The nature of the study and initial question fits best with qualitative methodology and were designed to capture attitudes, sense of efficacy, level of satisfaction and opinions regarding the effectiveness of the handbook and activities.

All of the participants in the study were volunteers. The workshop was presented at a Columbia School District PD session. The group was composed of elementary principals, elementary assistant principals, high school principals, high school vice principals and various district office directors, assistant directors and the superintendent. All participants had the following characteristics:

- Currently a school principal, vice/assistant principal or district office administrator

- Responsible for designing PD for teachers

- Willingness to participate in a workshop on designing teacher PD.

In the workshop, school and district office administrators used the handbook to explore three types of PD: peer observation, action research and PLCs. In all three models, the emphasis was on teachers teaching teachers. The workshop included a preand post-assessment utilizing participant feedback to evaluate the usefulness of the activities, impact on confidence level and sense of efficacy in designing PD as well as suggestions for revisions to the handbook. 
The next section discusses the conclusions drawn after the R\&D experience.

\section{Conclusions}

This study involved creating a product that addressed the need for a handbook to support school administrators in the planning of PD for teachers. The R\&D cycle (Borg $\&$ Gall, 1989) provided a process to develop, test and refine the product. Bridges and Hallinger's (1995) problem based approach provided a conceptual foundation that guided me through the process of collecting data on the effectiveness and usefulness of the handbook. The following section identifies conclusions reached as a result of the preliminary and main field tests as well as the revisions that were made to the handbook following the field testing.

\section{Preliminary Field Testing}

The preliminary field test was conducted with the first draft of the handbook, Teachers Teaching Teachers: Designing Successful Professional Development on a Shoestring Budget. The purpose of the preliminary field test was to gather information about the handbook and identify areas that needed improvement before beginning the main field test. The preliminary field test involved two separate formats. The initial draft of the handbook was reviewed and implemented by the vice principal at a large urban comprehensive high school between August 2013 and June 2014. The handbook was also presented to two groups of school and district administrators (approximately 60 participants) in a mini workshop format.

The vice principal implemented the handbook and collected information throughout the year from teachers regarding their level of satisfaction with the activities. 
She also read the handbook and made margin notes with suggestions for revision. The mini workshop with administrators included a brief overview of the handbook followed by an opportunity for participants to review and discuss the handbook in small groups. A follow-up survey was issued to get feedback on the perceived usefulness of the handbook and suggestions for revision. The following revisions were suggested by participants in the preliminary field test:

- Add graphics in the handbook

- Add discussion on how to integrate district initiatives into the PD plan.

- Add discussion of the connection between good instruction and student achievement.

- Add resources and examples.

- Include electronic version of handouts and resources.

In addition, all participants indicated that the handbook was useful and that they would be interested in a workshop using the handbook to plan PD.

After the mini workshop, I was contacted by several of the participants requesting consultation about their PD plans. Some participants also e-mailed with questions about activities in the handbook. Three of the workshop participants scheduled a one-on-one meeting with me to get feedback on their PD plans. I believe administrators and teachers find collaboration with colleagues to be extremely valuable and helpful. In addition to getting feedback on the handbook, I was able to see completed PD plans resulting from the exposure to the handbook. I had not expected continued contact with the participants in the mini workshop, but I was not surprised at the efforts to collaborate and get feedback. 
Following the preliminary field testing, revisions were made to the handbook. The main field testing would elicit even more information and determine what, if any, revisions were still needed. The purpose of the field testing was to get feedback pertaining to the handbook. The ultimate goal of the study was to create a handbook that is useful to administrators and that increases the confidence level and sense of efficacy among administrators in the planning of PD. The next section identifies the conclusions drawn from the main field test.

The participants in the main field test were all responsible for planning PD. The workshop for the main field test was more detailed and longer than the mini-workshop in the preliminary field test. The participants completed a pre- and post-survey, reviewed the handbook, participated in small group discussions about the handbook, utilized the handbook in collaborative groups to develop a PD plan for the next school year and shared their plans with the larger group. The data from the workshop included pre- and post-surveys, observations, sample PD plans and discussion. Three main conclusions were made from the data collected during the main field test.

Post-workshop survey data indicated that $75 \%$ of the workshop participants experienced an increase in their confidence level regarding PD planning as a result of participating in the workshop and using the handbook. The usefulness of the handbook was also evident during the PD planning portion of the workshop. Participants collaborated and utilized the handbook to map out a draft of actual PD activities for the next school year. All of the PD plans included activities from the handbook. I can conclude from the post-workshop survey data and observations during the workshop that 
the handbook was useful to administrators and increased their confidence and sense of efficacy in PD planning, which clearly answered the primary research question.

The handbook had a positive impact on administrator's view of teachers as experts. Sixty-two percent of the participants commented on the post-survey that the new learning they experienced was related to utilizing teachers as experts. This allowed me to conclude that administrators who use the handbook can see teachers as major contributors in the PD planning and implementation process, which addressed one of the secondary research questions. Table 19 summarizes the conclusions drawn from the main field test.

In addition to the conclusions previously discussed, the main field test provided information and data to validate the following revisions to the handbook:

- The addition of the workshop agenda for administrators to use for collaborative PD planning sessions.

- Include sample staff surveys for feedback on the PD activities.

- Include a mid-year reflection activity for action research.

- Include suggestions for funding peer observation.

- Add examples of action research projects.

The next section includes recommendations for future research in the area of teacher PD as well as the development and use of the handbook, Teachers Teaching Teachers: Designing Successful Professional Development on a Shoestring Budget. 


\section{Table 19}

\section{Research Questions and Conclusions}

Primary Research Question

How useful is the handbook, Teachers Teaching Teachers: Designing Successful Professional

Development on a Shoestring Budget, in building school leader efficacy and confidence in regards to PD planning?

Conclusion

The handbook is useful in building school leader efficacy and confidence regarding PD planning.

Secondary Research Questions

5. What is missing from the handbook?

Conclusion

The handbook needs more graphics and additional information on how to integrate district initiatives.

6. Does the handbook encourage school leaders to utilize teacher expertise?

Conclusion

The handbook can encourage school leaders to utilize teacher expertise in PD.

7. Do the research participants find the handbook usable and accessible?

Conclusion

The participants in the preliminary field test and main field test found the handbook usable and accessible.

8. What suggestions do school leaders have for the improvement of the handbook?

Conclusion

The handbook could be improved by adding a discussion of the potential impact of improved instruction on student achievement, additional resources and examples, and electronic versions of the handouts.

\section{Suggestions for Future Research, Development, and Use of the Product}

Doing the research for this study was rewarding and directly impacted my own practice as a high school principal. I plan to continue to learn and grow in the area of PD 
planning as it is one of the most important aspects of my job as an instructional leader. There were challenges to completing the study which are listed below:

1. District initiatives that drive the PD

2. Lack of time for teachers to collaborate

3. Finding opportunities to share the handbook via a workshop

I overcame the challenges by incorporating district initiatives into the PD models, utilized the district PD time for teacher collaboration and was fortunate enough to find an alternate site for the workshop when the original site was no longer available.

When I began researching this topic informally, more than 8 years ago, I was not thinking of a particular problem or issue. The motivation to learn about this topic was connected to my own work and a desire to improve. The job of a principal is very demanding, and at times, seems impossible. Superhero work ethic, extraordinary resiliency and a high level of skill in situational adaptability all come to mind when I think of the demands principals face on a daily basis. In addition, principals are charged with designing learning experiences for teachers that are engaging, relevant and that meet the needs of a diverse workforce. What began as a resource composed of activities that were proven successful and endorsed by teachers, turned into a handbook that could assist principals with the daunting task of designing teacher PD.

Several years ago I gave a survey to teachers regarding their PD experiences. A PD plan was designed after analyzing the survey results. In the case of that particular high school, a teacher-led team met with me to discuss what activities would be part of the PD plan for the upcoming school year. Survey results indicated that teachers preferred 
collaboration, sharing of ideas and opportunities to observe each other. The team decided to focus on three areas: action research, peer observation and PLCs.

Significant findings during this process included:

- Teacher's participation increased when there was accountability included in the activity (reflection, note-taking, feedback). Each activity suggests that teachers provide evidence of the work they accomplish. For example, PLCs set goals, agree on norms and take notes during their meetings which are shared with the staff. Teachers also seemed motivated to participate in the activities when there was a required presentation at the end of the year in which teachers would share their work.

- Teacher feedback indicated a preference for collaboration and choice in PD activities. On a PD survey, teachers rated one-day workshops and presentations with no follow-up as having little or no impact on instructional practices. Based on survey responses, the activities that teachers believe have the most impact on instruction include, peer observation, teacher led workshops, PLCs and curriculum camps.

- There is no specific guidance given to principals other than the expectation that it was the principal's responsibility to design teacher PD.

- PD is not regularly evaluated by school or district personnel. While I did not collect data specific to this finding, in the conversations I had with teachers and administrators this was often mentioned as a problem of practice.

My principal colleagues at the time, verified that their experience was similar to mine; no guidance on how to plan and/or implement PD but accountability for the quality of instruction and student achievement. The handbook is designed to provide guidance and support for principals as they plan PD, but it is not a "magic wand" that, by itself, will guarantee a successful PD plan.

It became clear to me very early in my principal career, that my experience with PD as a teacher was only useful in terms of identifying what not to do. In 25 years as a teacher, I had mostly experienced PD in the form of one-day workshops hosted by 
outside experts. None of those experiences had any lasting effect on my teaching. The first real validation and "aha" moment; that my experience with PD was similar to what other teachers had experienced came when I gave a survey to teachers during my first year as a principal. The survey results are displayed in Table 20 and illustrate, from teacher's perspectives, what types of PD have the most impact on student learning. The survey supported the idea that teachers prefer collaborative, ongoing, teacher-led PD activities. Table 20 illustrates the results of the survey from a suburban high school with approximately 65 teachers.

The results from the survey inspired me to seek out PD activities that allowed teachers to collaborate and learn from each other. I used my own experiences and input from teachers to determine which activities to include in the handbook. There is always more to learn and the handbook should be revised regularly based on the needs of school leaders and teachers.

Ongoing research will be necessary to keep the handbook relevant and up to date. In the preliminary field test, a vice principal utilized the handbook over the course of a year and provided feedback and suggestions for improvement. The year-long field test provided a means to get information about the usefulness of the handbook and the appropriateness of the PD activities. In the main field test, 38 administrators participated in a workshop that included information, access to the handbook and opportunities to collaborate in the development of a draft PD plan for their own schools. In future research, it would be valuable for more administrators to plan and implement the activities in the handbook over a longer period of time. This would provide additional 
data on the usefulness of the handbook and the impact it has on administrator confidence and on instructional practices.

Table 20

\section{Teachers' Perceptions of the Impact PD Activities Have on Student Learning}

\begin{tabular}{|c|c|}
\hline PD Activity & Impact Average (60 respondents) \\
\hline 3-4 day curriculum camp & Considerable impact on student learning \\
\hline 4-week Writing Project & Large impact on student learning \\
\hline Curriculum mapping & No impact on student learning \\
\hline Modeling (TOSA, instructional specialist, colleague) & Considerable impact on student learning \\
\hline Unit planning & Some impact on student learning \\
\hline Collaborative planning & Considerable impact on student learning \\
\hline Peer observation & Large impact on student learning \\
\hline SIOP strategies workshops & Little impact on student learning \\
\hline Literacy strategies workshops & Some impact on student learning \\
\hline Teacher-led PD (demonstration lessons) & Large impact on student learning \\
\hline ESL endorsement classes & Little impact on student learning \\
\hline $\begin{array}{l}\text { OAKS work sample scoring classes (OAKS is the } \\
\text { Oregon State Standards Assessment) }\end{array}$ & No impact on student learning \\
\hline OAKS test prep workshops & No impact on student learning \\
\hline University courses & Little impact on student learning \\
\hline 1-2 day workshops by experts in the field & No impact on student learning \\
\hline
\end{tabular}

Note: See Appendix D for actual survey.

Impact scale:

$1=$ No impact on student learning $2=$ A little impact on student learning 
3 = Some impact on student learning

4 = Considerable impact on student learning

$5=$ Large impact on student learning

More than one participant in the main field test commented that the handbook should have a section on how PD activities are connected to student achievement. While this was not the purpose of the handbook or this dissertation, it is something that could be included in a longitudinal study. It would be beneficial to examine the relationship between administrator confidence in designing PD, teacher participation in one or more of the activities in the handbook and student achievement.

Lastly, I believe the most significant impact on student learning is what happens in the classroom and whether or not the teacher uses effective, data-driven instructional strategies. I relied heavily on teacher feedback to choose the PD activities to include in the handbook but realize there are other types of PD that teachers prefer. Future research should incorporate additional types of PD based on teacher input.

Possible next steps in the refinement and use of the handbook might include pursuing district wide implementation. I know my principal colleagues are very interested in the work I am doing and have asked for copies of the handbook. Based on the responses following the mini workshop, I believe there is a need for this type of resource. The handbook could be refined to address specific district initiatives and goals. I would also like to pursue the possibility of presenting at conferences for school and district leaders. The handbook is adaptable to any school or district and I think it would be 
interesting to pursue opportunities to act as a consultant for districts or schools as they work on PD planning.

\section{Recommendations for Leadership}

School leaders, in particular high school principals, face overwhelming hurdles on a daily basis. Budget shortfalls have left schools understaffed, yet high stakes testing continues and principals are held accountable for student performance on local, state and national tests.

My first year as a principal was challenging in a lot of ways, but the most significant challenge was designing a PD plan. I could have developed a plan that resembled what I had experienced as a teacher, but I knew that was not adequate nor what teachers really needed or preferred. I learned through trial and error how to plan and implement professional learning activities.

The handbook, Teachers Teaching Teachers: Designing Successful Professional Development on a Shoestring Budget is the result of 31 years of experience in education and the belief that teachers are the real experts and an often an untapped resource utilized in planning PD. The handbook is a tool to help principals and other school leaders design learning opportunities for teachers that are collaborative, ongoing and that improve instructional practice.

The successful implementation of activities in the handbook is dependent on the leadership expertise of the administrator. I believe a strong leader promotes community and collaborative processes. In the literature review I discussed a constructivist approach to leadership, which began with the following: Leadership is the reciprocal processes that 
enable participants in an educational community to construct meanings that lead toward a shared purpose of schooling (Lambert, 2003). The end result of this study is a handbook that promotes reciprocal processes, a sense of community and a shared purpose. The leadership required to implement this type of PD must support components of constructivist learning such as inquiry, collaboration and reflection. The activities in the handbook are designed to engage teachers and school leaders in processes that create the optimal conditions for learning to occur.

When I designed the preliminary and main field tests, I envisioned a research study in which all of the participants were high school principals. I was designing a handbook based on my own experiences and at first, did not consider the possibility that the handbook might be useful to school leaders at any level. I had identified constructivism as the theoretical leadership model and intended to target high school administrators only.

The preliminary and main field tests ultimately included administrators from elementary, middle and high school as well as district office administrators. The handbook incorporates activities that are focused on teachers learning from each other, however, administrators can promote the process by reinforcing a school culture that values collaboration, continuous learning, shared leadership and accountability. Through observation and analysis of feedback from the preliminary and main field test, I can conclude that the handbook is relevant and useful for educational leaders at any level. 


\section{Assessment of Experience}

The problem based dissertation project (Bridges \& Hallinger, 1995) with implementation of the R\&D cycle (Borg \& Gall, 1989) was a worthwhile experience. It was engaging to investigate a problem related to my own practice. It was also inspiring to be able to use the input from others to refine and improve a product that addresses the problem. The problem that I chose to address fit perfectly with this process because it challenged me to reflect on my own experience and develop a product that could possibly support others experiencing the same struggle. I feel fortunate to have had the opportunity to learn about this process and it is likely that I will utilize aspects of the process to address future problems of practice.

When I began the literature review, I was overwhelmed by the amount of information on teacher PD. After perusing through several articles and texts, I realized that what the research was describing as best practice in teacher PD was not what I had experienced or observed during my teaching career. The disconnect between theory and practice was evident and this motivated me even more to develop a resource for principals that would support PD that meets the needs of teachers.

The literature review helped me gain a deeper understanding of school funding challenges and the impact on PD opportunities for teachers. During economic booms, schools tended to use money for travel, one-day workshops delivered by expensive outside experts and investments in boxed set of curriculum. When the economy was less fruitful and school budgets were cut, schools tended to eliminate PD that cost money and positions connected to improving instruction such as curriculum directors and 
instructional specialists. In hard times, districts eliminated monies set aside for teacher collaboration, extended hours and substitutes for teachers who wanted to observe other teachers. In some cases, a reduction in funding resulted in the elimination of all PD opportunities.

I also discovered in the literature review that teachers prefer PD that is collaborative, ongoing and connected to problems of practice. The PD that costs the most money is not necessarily what teachers want or need. I was able to find evidence to support this when I issued a survey to teachers my first year as a principal. The survey results showed that most teachers believed that one-day workshops and outside experts had little impact on student learning.

Reviewing the literature also helped me develop an opinion on the type of leadership that is necessary to promote collaboration and ongoing learning. The constructivist approach has always been at the forefront of my leadership style. I was able to find evidence in the literature that constructivist leadership could engage teachers in collaborative processes that would promote learning (Lambert et al., 2002).

I focused on three types of PD: (a) action research, (b) peer observation, and (c) PLCs. I had field experience implementing these activities as part of teacher PD plans but was now able to talk about them from a theoretical perspective and cite research to support their relevance. The literature review greatly increased my knowledge base and confidence throughout the R\&D cycle.

After the literature review was complete, I focused on developing the handbook, Teachers Teaching Teachers: Designing Successful Professional Development on a 
Shoestring Budget. I looked at other handbooks such as Individualizing Professional Development (Husby, 2005), Navigating Comprehensive School Change (Chenoweth \& Everhart, 2002), and Teaching for Joy and Justice (Christensen, 2009) to get ideas for organization and formatting and started collecting the resources and activities I thought would be useful. I was already implementing the peer observation and action research resources with my staff at the time and felt confident that they would provide a good starting point. The PLC resources were more difficult to select because there were so many formats and protocols. The preliminary field test provided the necessary information I needed to revise the first draft of the handbook.

I was surprised at the overwhelmingly positive response to the handbook during and after the preliminary field test. I suspected the handbook might be useful to some school leaders but did not expect it to be as well received as it was. I knew it could be much better after the revisions and suspected participants were not looking at it with a critical eye. Instead, they were grateful to have some support for PD planning. After the preliminary field test I was contacted by participants and others who heard about the handbook to see if they could get a copy. This was very flattering, but I knew I still had a long way to go before it was in the final stage of development. I was invited to a meeting with the district PD department members and the director of teaching and learning to discuss the handbook and its possible implementation district wide. I made myself available to consult with principals who had questions about the activities in the handbook and met with several principal colleagues to collaborate on their PD plans for 
the upcoming school year. The interactions following the preliminary field test were very motivating and I continued to look at ways to improve the handbook.

I had originally hoped to do the main field test in my own district but was unable to find a time that fit with the district PD schedule. I was invited to do the main field test at a neighboring district as part of a full day retreat at the end of June 2014. The main field test included a wide variety of administrators, including district office leaders and a superintendent. I was nervous about presenting a 3-hour workshop in the afternoon of their retreat and hoped that the information would keep them interested and alert as it was after their morning session (with an outside expert) and their lunch break. I was, again, pleasantly surprised by the high level of interest and positive responses. I left feeling relieved and overwhelmed at the same time. The data analysis process I was facing, seemed daunting.

It took almost two months to get all of the data organized. I had to code and categorize paper surveys, demographic information, online survey results, interview notes, observation notes, samples of PD plans, focus group notes and pre-workshop and post-workshop reflections. I wondered during the data analysis if it would have been easier to do a study that utilized quantitative data as numbers might be easier to organize than answers to open-ended questions. Finally, I was able to use the results to draw conclusions and discuss the findings of the study.

I would highly recommend this process for doctoral students in education. If I had the opportunity and time to address a future problem of practice, I would definitely do it again. 


\section{Chapter Summary}

Chapter 5 is the final chapter in the dissertation. The chapter includes a discussion

of the data collected during the R\&D process. The first part of the chapter is an overview of the study and a brief review of the purpose of the study.

This chapter provides conclusions based on the data collected during the preliminary and main field tests. The conclusions were connected to the primary and secondary research questions. Additional findings and revision suggestions were also discussed.

A portion of the chapter was devoted to speculations for future R\&D. Three of the main recommendations for future research include ongoing research to keep the handbook up to date, teacher feedback on activities and resources and research on the impact of teacher PD on student achievement.

Chapter 5 concludes with a rationalization of the recommendations for leadership and a personal assessment of the problem based research model and the R\&D cycle. 


\section{REFERENCES}

Ainsworth, L. (2010). Rigorous curriculum design: How to create curricular units of study that align standards, instruction, and assessment. Englewood, CO: The Leadership and Learning Center.

Alber, S., \& Nelson, J. (2002). Putting research in the collaborative hands of teachers and researchers: An alternative to traditional staff development. Rural Special Education Quarterly, 29(4), 24-30.

Ammons, J. L., \& Lane, S. J. (2012, April). Making teaching visible: Sharing and evaluating using peer observation. Allied Academies International Conference: Proceedings of the Academy of Educational Leadership (AEL), 17(1), 77-81.

Arhar, J. M., Holly, M. L., \& Kasten, W. C. (2001). Action research for teachers: Traveling the yellow brick road. Upper Saddle River, NJ: Prentice Hall.

Association for Supervision and Curriculum Development. (2007). The ASCD High School Reform Proposal. Retrieved from http://www.ascd.org/publicpolicy/High-School-Reform/High-School-Reform-Summary.aspx

Auger, W., \& Wideman, R. (2000). Using action research to open the door to life-long professional learning. Education, 121(1), 120-127.

Bandura, A. (1989, September). Human agency in social cognitive theory. American Psychologist, 44(9), 1175-1184.

Barth, R. (1990). Improving schools from within: Teachers, parents, and principals can make the difference. San Francisco, CA: Jossey-Bass.

Bell, A., \& Mladenovic, R. (2008, June). The benefits of peer observation of teaching for tutor development. Higher Education, 55(6), 735-752.

Benitez, M., Davidson, J., \& Flaxman, L. (2009). Small schools big ideas: The essential guide to successful school transformation. San Francisco, CA: Jossey-Bass.

Bondy, E., \& Ross, D. (1998). Teaching teams: Creating the context for faculty action research. Innovative Higher Education, 22(3), 231-250.

Borg, W., \& Gall, M. (1989). Educational Research: An Introduction (5 ${ }^{\text {th }}$ ed.). White Plains, NY: Longman. 
Boudah, D. J., Blaire, E., \& Mitchell, V. J. (2003). Implementing and sustaining strategies instruction: Authentic and effective professional development or "business as usual." Exceptionality, 11(1), 3-23.

Bridges, E., \& Hallinger, P. (1995). Implementing project-based learning in leadership development. Eugene, OR: University of Oregon, Center for Teaching Quality: Teaching and Learning Conditions Improve High School, ERIC Clearinghouse on Educational Management.

Center for Teaching Quality. (2007). Teaching and learning conditions improve high school reform efforts. Retrieved from http://www.teachingquality.org/sites/ default/files/Teaching\%20and\%20Learning\%20Conditions\%20Improve\%20High $\% 20$ School\%20Reform\%20Efforts.pdf

Chenoweth, T. G., \& Everhart, R. B. (2002). Navigating comprehensive school change: A guide for the perplexed. Larchmont, NY: Eye on Education.

Chou-hui, C. (2011). Teachers' professional development: Investigating teachers' learning to do action research in a professional learning community. The AsiaPacific Education Researcher, 20(3), 421-437.

Christensen, L. (2009). Teaching for joy and justice: Re-imagining the language arts classroom. Milwaukee, VI: Rethinking Schools, Ltd.

Christensen, L. (2014). The Oregon Writing Project [Video]. Retrieved from http://graduate.lclark.edu/programs/oregon_writing_project/

City, E. (2013). Leadership in challenging times. Educational Leadership, 70(7), 10-14.

Coggins, C., Zuckerman, S., \& McKelvey, L. (2010). Holding on to gen Y. Educational Leadership, 67(8), 70-74.

Common Core State Standards Initiative. (2014). Development process. Retrieved from http://www.corestandards.org/

Corey, S. M. (1949). Curriculum development through action research. Educational Leadership, 7(3), 147-153.

Council of the Great City Schools. (1999, Spring). Council of the Great City Schools High School Reform Survey, School Year. Urban Indicator. Retrieved from http://www.cgcs.org/cms/lib/DC00001581/Centricity/domain/35/publication\%20d ocs/Urban_Indicator09.pdf 
Couper, L. (2004). Professional development in a rural cluster of schools. Victoria, New Zealand: University of Wellington, University Teaching Development Center. Retrieved from http://researcharchive.vuw.ac.nz/search?scope=/\&order= ASC\&rpp $=10 \&$ sort_by $=2 \&$ page $=39 \&$ query $=$ peer+observation \&etal $=0$

Creswell, J. W. (2002). Educational research: Planning conducting, and evaluating quantitative and qualitative research. Upper Saddle River, NJ: Pearson, Merrill, Prentice Hall.

Crocco, M. S., Faithfull, B., \& Schwartz, S. (2003). Inquiring minds want to know: Action research at a New York City professional development school. Journal of Teacher Education, 54(19), 19-29.

Darling-Hammond, L. (1996). The right to learn and the advancement of teaching: Research, policy, and practice for democratic education. Educational Researcher, 25(6), 5-17.

Darling-Hammond. L. (2009). Teacher learning: What matters in teacher professional development. Education Leadership, 66(5), 46-53.

Darling-Hammond, L. (2010). The flat world and education. How America's commitment to equity will determine our future. New York, NY: Teachers College Press.

Dee, T., \& Jacob, B. A. (2011). The impact of the No Child Left Behind Act on student achievement. Journal of Policy Analysis and Management, 30(3), 418-446.

Desimone, L. M. (2011). A primer on effective professional development. Kappan, 92(6), 68-71.

Dewey, J. (1938). Experience and education. New York, NY: Touchstone.

Donnelly, R. (2007). Perceived impact of peer observation of teaching in higher education. International Journal of Teaching and Learning in Higher Education, 19(2), 117-129.

DuFour, R., DuFour, R., \& Eaker, R. (2008). Revisiting professional learning communities at work. Bloomington, IN: Solution Tree.

DuFour, R., DuFour, R., Eaker, R., \& Karhanek, G. (2004). Whatever it takes: How professional learning communities respond when kids don't learn. Bloomington, IN: SolutionTree.

DuFour, R., Eaker, R., \& DuFour, R. (2005). On common ground: The power of professional learning communities. Bloomington, IN: Solution Tree. 
DuFour, R., \& Mattos, M. (2013). How do principals really improve schools. Educational Leadership, 70(7), 34-40.

Eaker, R., DuFour, R., \& DuFour, R. (2002). Getting started: Reculturing schools to become professional learning communities as work. Bloomington, IN: Solution Tree.

Eisenberg, E. (2010). Personalizing professional development. Education Week, 29(32), $30-31$.

Employers for Educational Excellence. (2010). The big picture on Oregon's small schools. Retrieved from http://orbusinesscouncil.org/docs/archive/ BigPictureonSmallSchools.pdf

Erkens, C. (2008). Growing teacher leadership. In R. DuFour \& R. Eaker (Eds.), The collaborative administrator: Working together as a professional learning community (pp. 39-54). Bloomington, IN: Solution Tree.

Farmer, J. D., Gettetson, H., \& Lassak, M. (2003). What teachers take from professional development: cases and implications. Journal of Mathematics Teacher Education, 6, 331-360.

Farrell, J. B., \& Weitman, C. (2007). Action research fosters empowerment and learning communities. Delta Kappa Gamma Bulletin, 73(3), 36.

Feldman, J., López, M., \& Simon, K. (2006). Choosing small: The essential guide to successful high school conversion. San Francisco, CA: Jossey-Bass.

Ferrance, E. (2000). Action research: Themes in education booklet. Providence, RI: Northeast and Islands Regional Educational Laboratory, Office of Educational Research and Improvement, Department of Education, at Brown University.

Finkel, E. (2012, June). Principals as instructional leaders. District Administration, pp. 50-55.

Fullan, M. (1995). The school as a learning organization: Distant dreams. Theory into Practice, 34(4), 230-235.

Fullan, M. (2001). Leading in a culture of change. San Francisco, CA: Jossey-Bass.

Fullan, M. (2007). Change the terms for teacher learning. Journal of Staff Development 28(3), 35-36.

Fullan, M., \& Hargreaves, A. (1996). What's worth fighting for in your school. New York, NY: Teachers College Press. 
Fullan, M., Hill, P., \& Crevola, C. (2006). Breakthrough. Thousand Oaks, CA: Corwin.

Futernick, K. (2010). Incompetent teachers or dysfunctional systems? Phi Delta Kappan, 92(2), 59-64.

Glassman M., Erdem, G., \& Bartholomew, M. (2012). Action research and its history as an adult education movement for social change. Adult Education Quarterly, 63(3), 272-288.

Gould, M. (2008). Teacher as researcher: A paradigm for professional development. Kappa Delta Pi Record, 45(1), 5-7.

Gordon, S. (2008). Dialogic reflective inquiry: Integrative function of instructional supervision. Catalyst for Change, 35(2), 4-11.

Hahs-Vaughn, D., \& Yanowitz, K. (2009). Who is conducting teacher research? The Journal of Educational Research, 102(6), 415-426.

Habegger, S., \& Hodanbosi, P. (2011). Embedded instructional coaching: What works. Principal Leadership, 11(6), 36-37, 40-41.

Haley, M. H. (2004). Teacher action research: studies informing practice. Academic Exchange.

Hanson, S. (2010). What mentors learn about teaching. Educational Leadership, 67(8), 76-80.

Hardy, L. (2003). No child left behind? Show me the money! American School Board Journal, 190, 29-32.

Hendricks, C. (2006). Improving schools through action research: A comprehensive guide for educators. Upper Saddle River, NJ: Pearson.

Hendry, G. D., \& Oliver, G. R. (2012). Seeing is believing: The benefits of peer observation. Journal of University Teaching and Learning Practice, 9(1), 1-9.

Henry, J., Tryjankowski, A., DeCamillo, L., \& Bailey, N. (2010). How professional development schools can help to create friendly environments for teachers to integrate theory, research, and practice. Childhood Education, 86(5). doi:10.1080/00094056.2010.10521419

Hess, F. M. (2013). Be a cage-buster. Educational Leadership, 70(7), 30-33.

Hileman, E. (2010). $21^{\text {st }}$ century professional development. Principal Leadership, 11(2), 66-67. 
Hirsh, S. (2009, June) Ensuring high quality teaching for all students through comprehensive approaches to professional development - part 1. Paper presented at the American Youth Policy Forum, Washington, DC. Retrieved from http://www.aypf.org/documents/062609HirshPPTPresentationI.pdf

Hord, S. M., \& Sommers, W.A. (2008). Leading professional learning communities: Voices from research and practice. Thousand Oaks, CA: Corwin.

Horowitz, J. (2006). Sustaining school reform. Curriculum Review, 45, p. 14.

Husby, V.R. (2005). Individualizing professional development: A framework for meeting school and district goals. Thousand Oaks, CA: Corwin.

Inhelder, B., \& Chipman, H. H. (Eds.). (1976). Piaget and his school: A reader in developmental psychology. New York, NY: Springer-Verlag.

Johnson, S. M., \& Fiarman, S.E. (2012). The potential of peer review. Educational Leadership, 70(3), 20-25.

Joyce, B., \& Showers, B. (1980). Improving inservice training: The messages of research. Educational Leadership 37(5), 379-385.

Joyce, B., \& Showers, B. (1982). The coaching of teaching. Educational Leadership, 40(1), 4-10.

Joyce, B., \& Showers, B. (1987a). Staff development and student learning: A synthesis of research on models of teaching. Educational Leadership, 45(2), 11-23.

Joyce, B., \& Showers, B. (1987b). Synthesis of research on staff development: A framework for future study and a state-of-the-art analysis. Educational Leadership, 45(3), 77-87.

Joyce, B., \& Showers, B. (1996). Evolution of peer coaching. Educational Leadership, $53(6), 12-17$.

Joyce, B., \& Showers, B. (2006). Student achievement through staff development. Alexandria, VA: Association for Supervision and Curriculum Development.

Keiffer-Barone, S. (2005). Course makes a compelling case for action research. National Staff Development Council, 26(4), 69.

Kennedy, E. (2010). Improving literacy achievement in a high-poverty school: Empowering classroom teachers through professional development. Reading Research Quarterly, 45(4), 384-387. 
Kent, A. M. (2004). Improving teacher quality through professional development. Education, 124(3), 427-435.

Knight, J. (2007). Instructional coaching: A partnership approach to improving instruction. Thousand Oaks, CA: Corwin.

Kozulin, A., \& Gindis, B. (2003). Vgotsky's educational theory in cultural context. Cambridge, United Kingdom: Cambridge University Press.

Lambert, L. (2000). Building leadership capacity in schools. Retrieved from http://research.acer.edu.au/apc_monographs/2

Lambert, L. (2003). Leadership redefined: An evocative context for teacher leadership. School Leadership and Management, 23(4), 421-430.

Lambert, L., Walker, D., Zimmerman, D. P., Cooper, J. E., Lambert, M. D., Gardner, M. E., \& Szabo. (2002). The constructivist leader ( $2^{\text {nd }}$ ed.). New York, NY: Teachers College Press.

Levine, A. (2010). Teacher education must respond to changes in America. Phi Delta Kappan, 92(2), 19-24.

Lieberman, A., \& Mace, D. H. (2008). Teacher learning: the key to educational reform. Journal of Teacher Education, 59(3), 226-234.

Lieberman, A., \& Wood, D. (2001). The work of the National Writing Project: Social practices in a network context. Palo Alto, CA: Carnegie Foundation.

Little, J. W. (1999). Teachers' professional development in the context of high School reform: Findings from a three-year study of restructuring schools. ERIC Document Reproduction Service Number ED448154. Retrieved from: http://eric.ed.gov/?id=ED448154

Little, J. W. (2006). Professional community and professional development in the learning-centered school. Washington, DC: National Education Association. Retrieved from www.nea.org/assets/docs/HE/mf_pdreport.pdf

Locke, M. (2012). Back to school. Scholastic Administrator, 12(3), 28-30.

Loertscher, D., DuFour, R., DuFour, R., \& Eaker, R. (2010). Revisiting professional learning communities at work: New insights for improving schools. Teacher Librarian, 37(4), 75-84. 
Lotter, C., Harwood, W. S., \& Bonner, J. J. (2006). Overcoming a learning bottleneck: Inquiry professional development for secondary science teachers. Journal of Science Teacher Education, 17, 185-216.

Lujan, N., \& Day, B. (2010). Professional learning communities: Overcoming roadblocks. Delta Kappa Gamma Bull, 76(2), 10-17.

Margolis, J. (2008). When teachers face teachers: Listening to the resource right down the hall. Teaching Education, 19(4), 293-310.

Margolis, J. (2009). How teachers lead teachers. Educational Leadership, 16(5).

Retrieved from www.ascd.org

Massachusetts Insight Education Research Institute. (2007). The turnaround challenge: Why America's best opportunity to dramatically improve student achievement lies in our worst performing schools. Retrieved from http://www.massinsight.org/stg/ research/challenge

Mata-Segreda, A. (2006). Action research for the change in education. Delta Gamma Bull, 72(3), 18-22.

Mertler, C. (2006). Action research: Teachers as researchers in the classroom. Thousand Oaks, CA: Sage.

Mills, G. E. (2003). Action research: A guide for the teacher researcher. Upper Saddle River, NJ: Pearson.

Moore, R., \& Berry, B. (2010). The teachers of 2030. Educational Leadership, 67(8), 36-39.

Morones, A. (2013). Iowa district reimagines the five-day school week. Education Week, $33(4), 10-11$.

Mueller, M., Devlin-Scherer, R., \& Mitchel, L. (2006). Teachers in action. Academic Exchange quarterly, 10(3), 203-207.

Musanti, S., \& Pence, L. (2010). Collaboration and teacher development: Unpacking resistance, constructing knowledge, and navigating identities. Teacher Education Quarterly, 37(1), 73-89.

National Commission on Teaching and America's Future. (1996). What matters most: Teaching for America's future. New York, NY: Author. Retrieved from http://nctaf.org/wp-content/uploads/2012/01/WhatMattersMost.pdf 
National Staff Development Council. (2009). NSDC's definition of professional development. Retrieved from www.nsdc.org/standfor/definition.cfm

Nazareno, L. (2013). Portrait of a teacher-led school. Educational Leadership. 71(2), 51-54.

No Child Left Behind Act of 2001 (2002).

O’Malley, G. (2010). Designing induction as professional learning community. The Educational Forum, 74(4), 318-327.

Oregon Department of Education. (2012). 2011-12 adequate yearly progress (AYP) policy and technical manual. Retrieved from http://www.ode.state.or.us/ initiatives/nclb/pdfs/aypmanual1112.pdf

Oregon Department of Education, (2013). State Board adopts common core assessment. Retrieved from http://www.ode.state.or.us/news/Announcements/announcement. aspx $?$ ID $=9099$

Osten, M., \& Gidseg, E. (1998). Teachers as learners: How peer mentoring can improve teaching. Rethinking Schools, 12(4). Retrieved from www.rethinkingschools.org

Pathak, R. P. (2008). Methodology of educational research. New Delhi, India: Atlantic Publishers.

Phillips, V., \& Hughes, R. (2012). Teacher collaboration: The essential ingredient. Education Week, 32(13), 32-35.

Piaget, J. (1976). Piaget's theory. In B. Inhelder, H. Chipman, \& C. Zwingman (Eds.), Piaget and his school: A reader in developmental psychology (pp. 11-23). New York, NY: Springer-Verlag.

Powell, E. T., \& Renner, M. (2003). Crux of qualitative analysis. Madison, WI: University of Wisconsin-Extension Co-op Extension Service. Retrieved from http://www.uwex.edu/ces/pdande/evaluation/evaldocs.html

Quint, J., Thompson, S. L., \& Bald, M. (2008). Relationships, rigor, and readiness: Strategies for improving high schools. Retrieved from http://files.eric.ed.gov/ fulltext/ED502973.pdf

Race, P., Chapman, F., Cooke, B., Leggott, D., Moore, D., Morris., S.,...UK National Teaching Fellows. (2009). Using peer observation to enhance teaching. Leeds, England: Leeds Metropolitan University Press. 
Reeves, D. (2010). Transforming professional development into student results. Alexandria, VA: Association for Supervision and Curriculum Development.

Richardson, J. (2004). Teaching teachers about learning. Education Digest, 70(3), 49-50.

Richardson, M. O. (2000). Peer observation: learning from one another. Thought and Action, 16(1), 9-20.

Robinson, V., \& Timperley, H. S. (2007). The leadership of the improvement of teaching and learning: Lessons from initiatives with positive outcomes for students. Journal of Educational Change, 51(3), 247-262.

Rorschach, E., \& Whitney, R. (1986). Relearning to teach: Peer observation as a means of professional development for teachers. English Education, 18(3), 159-172.

Ross-Fisher, R. (2008). Action research to improve teaching and learning. Kappa Delta Pi Record, 44(4), 160-164.

Royce, C. A. (2010). A revolutionary model of professional development. Science Scope, $34(3), 6-9$.

Sakshaug, L., Wohlhuter, K., \& Lach, T. (2008). A teacher's professional development through action research. Investigations in Mathematics Learning, 1(1), 27-40.

Sarason, S. B. (2004). Change question: What is needed to resolve the social and Critical issues affecting large scale reform? Macro demands, micro involvement. Journal of Educational Research, 5(3), 292-295.

Sawchuk, S. (2010). Cost of teacher training lost in district budgets. Education Week, $30(11), 14-16$.

Schmoker, M. (2005a). Here and now: Improving teaching and learning. In R. Eaker, R. DuFour, \& R. DuFour (Eds.), On common ground: The power of professional learning communities (pp. xi-xiv). Bloomington, IN: Solution Tree.

Schmoker, M. (2005b). No turning back: The ironclad case for professional learning communities. In R. Eaker, R. DuFour, \& R. DuFour (Eds.), On common ground: The power of professional learning communities: The power of professional learning communities (pp. 135-154). Bloomington, IN: Solution Tree.

Schmuck, R. (2006). Practical action research for change. Thousand Oaks, CA: Corwin.

Schmuck, R. (2009). Practical action research: A collection of articles. Thousand Oaks, CA: Corwin. 
Seltz, J. (2008). A focus on high school reform. Educational Leadership, 65(8), 96.

Semadeni, J. (2010). When teachers drive their learning. Educational Leadership, 67(8), 66-69.

Shakrani, S. (2008). A big idea: Smaller high schools. East Lansing, MI: Michigan State University, Education Policy Center.

Shear, L., Means, B., Mitchell, K., House, A., Gorges, T., Joshi, A., Smerdon, B., \& Shkolnik, J., (2008). Contracting paths to small-school reform: Results of a 5-year evaluation of the Bill and Melinda Gates Foundation's National High School Initiative. Teachers College Record, 110(9), 1986-2039.

Showers, B., \& Joyce, B. (1996). The evolution of peer coaching. Educational Leadership, 53(6), 12-17.

Smith, T. M., \& Rowley, K. J. (2005). Enhancing commitment or tightening control: The function of teacher professional development in an era of accountability. Educational Policy, 19(1), 126-153.

Stronge, J. H. (2013). Principal evaluation from the ground up. Educational Leadership, $70(7), 60-65$.

Taylor-Powell, E., \& Renner, M. (2003). Analyzing qualitative data. Madison, WI: University of Wisconsin-Extension, Cooperative Extension, Publishing Operations.

Teitel, L. (2009). Improving teaching and learning through instructional rounds. Harvard Education Letter, 25(3), 1-3.

Torff, B., \& Byrnes, K. (2011). Differences across academic subjects in teachers' attitudes about professional development. The Educational Forum, 75(1), 26-36.

Warren, S., Doorn, D., \& Green, J. (2008). Changes in vision: Teachers engaging in action research. The Educational Forum, 72(3), 260-270.

Wilkins, E., \& Shin, E. (2011). Peer feedback: Who, what, when, why and how. Education Digest, 76(6), 49-53.

Williams, D. (2013, Winter). Urban education and professional learning communities. Delta Kappa Gamma Bulletin, pp. 31-39.

Youngs, P. (2001). District and state policy influences on professional development and school capacity. Educational Policy, 15(2), 278-301. 
Zhang, M., Lundeberg, M., \& Eberhardt, J. (2010). Seeing what you normally don't see. Phi Delta Kappan, 91(6), 60-65. 
APPENDIX A

PARTICIPANT CONSENT FORM 


\section{INFORMED CONSENT}

\section{Purpose of the Study}

The purpose of this study is to test the effectiveness of the handbook; Teachers Teaching Teachers: Designing Successful Professional Development on a Shoestring Budget. High school administrators are responsible for designing professional growth opportunities for teachers, yet there seems to be a lack of guidance and support for principals regarding how to design an effective professional development plan.

\section{Procedures}

If you agree to participate in this study, you will be asked to participate in the following ways:

1. You will be asked to take two surveys: a pre-workshop survey and a postworkshop survey.

2. You will be asked to participate in a 3-hour workshop utilizing the handbook to design a professional development plan.

3. You will be asked to participate in a face-to-face interview with the researcher regarding your experience in the design of professional development.

\section{Potential Risks and Discomforts}

There will be no potential risks for any of the participants in this study. If a participant feels uncomfortable at any time during the study, he or she may discontinue participation.

\section{Potential Benefits to Subjects and/or to Society}

School administrators can sometimes be expected to fulfill duties that are beyond their training and experience, especially at the beginning of their careers. This study will result in a research based tool that could increase the confidence and competency of principals in the area of designing effective professional development. The research process was designed by Borg and Gall (1989) and consists of ten steps that study the development and implementation of a product. Data collected during the study will help improve the product for further use. Feedback from participants will enhance the handbook which will result in increased competency in administrators as they design professional development activities for teachers, which in turn, could improve instruction and ultimately, student achievement. 


\title{
Compensation for Participation
}

Participants will not receive any payment or other compensation for participation in this study. There is no cost to participants.

\section{Confidentiality}

Information obtained in this study and that can be connected to participants will remain confidential and will be disclosed with permission of participants as required by law. Participants will be identified by a code number to allow the researcher and faculty advisor to identify participants. Names will not be used in any of the information obtained from this study or in any of the data reports. At the completion of the study, the coding information will be destroyed.

Information that identifies participants will not be released to anyone outside the study. The researcher will use the information and data in the dissertation and other publications such as professional journals. Any information used for publication will not identify participants.

\section{Participation and Withdrawal}

Participants can choose whether or not to participate in the study. Participants may withdraw at any time without consequences. Participants may refuse to answer questions without penalty or loss of benefits to which the participant is otherwise entitled, and at any time, may withdraw from the study.

\section{Identification of Investigators}

If you have any questions or concerns about the research, contact:

\author{
Carol Campbell \\ Principal Investigator \\ Doctoral Student \\ Portland State University \\ Portland, OR \\ (503)484-8081 \\ ccampbell1008@gmail.com \\ Dr. Tom Chenoweth \\ Doctoral Advisor \\ Educational Leadership \& Policy \\ Portland State University \\ Portland, OR \\ (503)396-8044 \\ chenowetht@pdx.edu
}




\section{References}

Borg, W., \& Gall, M. (1989). Educational research and development. In Educational Research: An Introduction ( $5^{\text {th }}$ ed.). White Plains, New York: Longman, 1989.

\section{Rights of Research Subjects}

The Portland State University Institutional Review Board has reviewed the request to conduct this project. If you have concerns about the study and your participation, please contact Portland State University's IRB department:

Research and Strategic Partnerships

Market Center Building $6^{\text {th }}$ floor

$1600 \mathrm{SW} 4^{\text {th }}$ Avenue

Portland, OR 97201

(503)725-2227 or $1(877) 480-4400$

http://sites.google.com/a/pdx.edu/research/integrity

\section{CONSENT}

You are making a decision whether to participate in this study. Your signature below indicates that you have read the information provided (or the information was read to you). By signing this consent form, you are not waiving any of your legal rights as a research participant.

You have had an opportunity to ask questions and all questions have been answered to your satisfaction. By signing this consent form, you agree to participate in this study. A copy of this consent form will be provided to you.

$\overline{\text { Name of Adult Subject (print) }} \overline{\text { Signature of Adult Subject }} \overline{\text { Date }}$ 
APPENDIX B

PRE-WORKSHOP SURVEY 


\section{Pre-Workshop Survey}

This survey is designed to assess your experience in designing teacher professional development, the degree of training and support you have received and your level of confidence in designing effective teacher professional development.

1. Are you currently involved in the planning and implementation of teacher professional development at your school?

- Yes

$\circ$ No

2. If you are involved in the planning of teacher professional development, how long have you been part of that process?

○ $1-3$ years

○ 4-6 years

○ 7-10 years

$\circ$ Longer than 10 years

3. How many teachers are in your school?

○ $\quad 0-10$

○ $11-20$

○ $21-40$

- 41-60

○ More than 60

4. What is your current confidence level with planning and implementing teacher professional development? Do you feel competent in this area? Please answer in as much detail as possible.

5. What type of training have you had in planning teacher professional development? Be as specific as possible.

6. What type of support does the district provide to you in the planning of teacher professional development?

7. Do you submit a yearly PD plan to the district office and/or your immediate supervisor?

- Yes

○ No

- Sometimes

8. What supports do you feel would be helpful for you to become more competent in designing teacher professional development? Be as specific as possible. 
9. What types of structured PD activities are you currently providing for teachers?

- Professional Learning Communities

- Action Research

- Peer Observation

- Workshops presented by teachers

- Workshops presented by outside experts

- Workshops presented by district administrators

○ Workshops presented by teacher leaders

- Workshops presented by curriculum vice principals

- Other (please describe)

10. Do you feel like the current PD activities you are using are effective?

○ Yes

○ No

Why or why not? Be specific.

11. What are your specific needs regarding the planning and implementation of teacher professional development?

12. How many hours per week do teachers have for professional development activities?

○ $1-2$

○ $3-4$

○ $5-6$

○ More than 6

13. Describe the types of PD you found most effective as a teacher.

14. Describe the types of PD you found least effective as a teacher. 
APPENDIX C

POST-WORKSHOP SURVEY 


\section{Post-Workshop Survey}

1. Upon completion of the workshop, what is your confidence level regarding the planning and implementation of teacher professional development? Do you feel more competent in the area of designing a professional development plan? Please provide as much detail as possible.

2. What additional supports do you still need to assist you in designing teacher professional development? Please be specific.

3. Which PD activities do you plan to implement at your school? Check all that apply.
- Action research
- Peer observation
- Professional Learning Communities
- All of the above
- None of the above
O Other (describe below)

4. Do you feel that you still need additional support and/or training to design professional development for teachers? Please explain.

5. Do you have any suggestions for PD activities that should be included in the handbook?

6. Please explain any new learning you experienced by participating in the workshop. 
APPENDIX D

TEACHER SURVEY 


\section{High School Professional Development Survey}

Please take 10 minutes to complete the survey questions below. Your responses will be used to plan future professional development

School:

Number of years teaching:

\section{Content Area:}

1. For any professional development you have participated in your teaching career, please

- Circle district or the school to show who presented the training.

- Check the box if you had the professional development in the past two years.

- Use the scale below to mark the impact of the program in your classroom.

$$
\begin{aligned}
& 1=\text { No impact on teaching and learning } \\
& 2=\text { A little impact on teaching and learning } \\
& 3=\text { some impact on teaching and learning } \\
& 4=\text { Considerable impact on teaching and learning } \\
& 5=\text { Large impact on teaching and learning }
\end{aligned}
$$

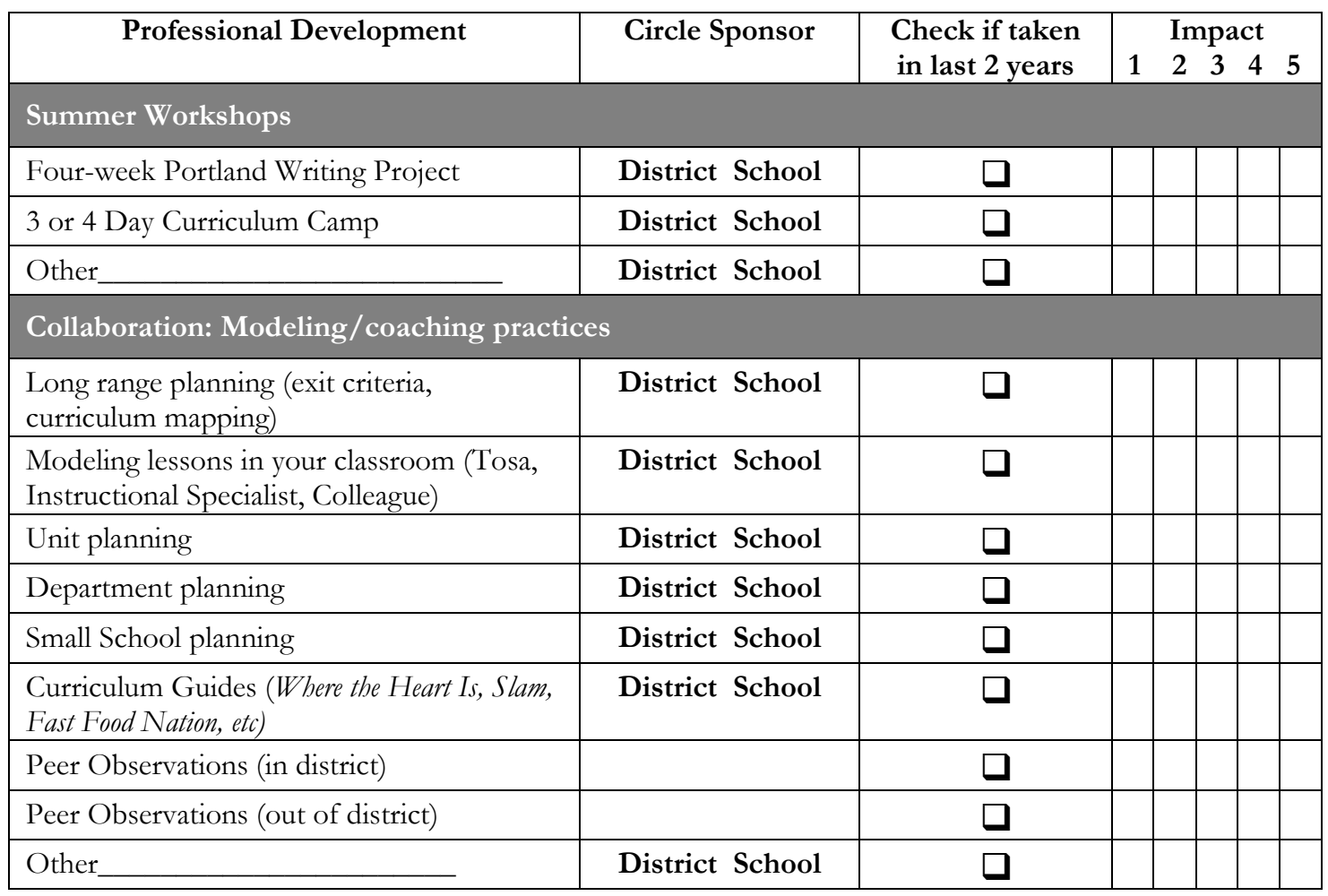




\begin{tabular}{|c|c|c|c|c|c|c|}
\hline \multirow{2}{*}{ Professional Development } & \multirow[t]{2}{*}{ Circle Sponsor } & \multirow{2}{*}{$\begin{array}{l}\text { Check if taken } \\
\text { in last } 2 \text { years }\end{array}$} & \multicolumn{4}{|c|}{ Impact } \\
\hline & & & & 2 & 3 & 5 \\
\hline \multicolumn{7}{|l|}{ Inservice } \\
\hline SIOP Strategies & District School & $\square$ & & & & \\
\hline Differentiated Instruction Strategies & District School & $\square$ & & & & \\
\hline Teacher-led professional development & District School & $\square$ & & & & \\
\hline Reading Strategies: & District School & $\square$ & & & & \\
\hline Writing Strategies: & District School & $\square$ & & & & \\
\hline Other & District School & $\square$ & & & & \\
\hline Other & District School & $\square$ & & & & \\
\hline Other: & District School & $\square$ & & & & \\
\hline Other: & District School & $\square$ & & & & \\
\hline \multicolumn{7}{|l|}{ 5/7/10 Week Classes } \\
\hline ESL Endorsement Classes & District School & ] & & & & \\
\hline Punctuation and Grammar classes & District School & $\square$ & & & & \\
\hline Reading Endorsement classes & District School & $\square$ & & & & \\
\hline SIOP & District School & $\square$ & & & & \\
\hline Other: & District School & $\square$ & & & & \\
\hline \multicolumn{7}{|l|}{ Portland Writing Project Monthly Class } \\
\hline Portland Writing Project & District School & $\square$ & & & & \\
\hline \multicolumn{7}{|l|}{ Assessment Classes/Workshops } \\
\hline OAKS Work Sample Scoring & District School & $\square$ & & & & \\
\hline OAKS Reading Test Prep Workshop & District School & $\square$ & & & & \\
\hline Other: & District School & $\square$ & & & & \\
\hline
\end{tabular}


2. Please indicate other courses, seminars, workshops or other professional development you have taken outside the district.

\begin{tabular}{|c|c|c|c|}
\hline $\begin{array}{l}\text { University Courses/ } \\
\text { Conferences/Workshops } \\
\text { (Write in title or topic) }\end{array}$ & $\begin{array}{c}\text { Provider } \\
\text { (Write in name of } \\
\text { organization) }\end{array}$ & $\begin{array}{l}\text { Check if taken } \\
\text { in last } 2 \text { years }\end{array}$ & $\begin{array}{l}\text { Impact on } \\
\text { student } \\
\text { learning } \\
12 \quad 3 \quad 4 \\
\end{array}$ \\
\hline & & $\square$ & \\
\hline & & $\square$ & \\
\hline & & D & \\
\hline & & $\square$ & \\
\hline & & $\square$ & \\
\hline & & $\square$ & \\
\hline & & $\square$ & \\
\hline & & $\square$ & \\
\hline & & $\square$ & \\
\hline & & $\square$ & \\
\hline
\end{tabular}

3. What professional development had the greatest impact on your teaching and students' learning? Why? (Implementation time? Collaboration time? Format?)

4. What professional development had the least impact on your teaching and students' learning? (Lack of implementation time? Lack of follow through? Lack of materials? Didn't intersect with your needs?)

5. What current needs do you have for professional development? What would you like to see offered? When would you like it offered — late start, summer institutes, staff meetings, etc.?

6. Other comments: 
APPENDIX E

WORKSHOP POWERPOINT 


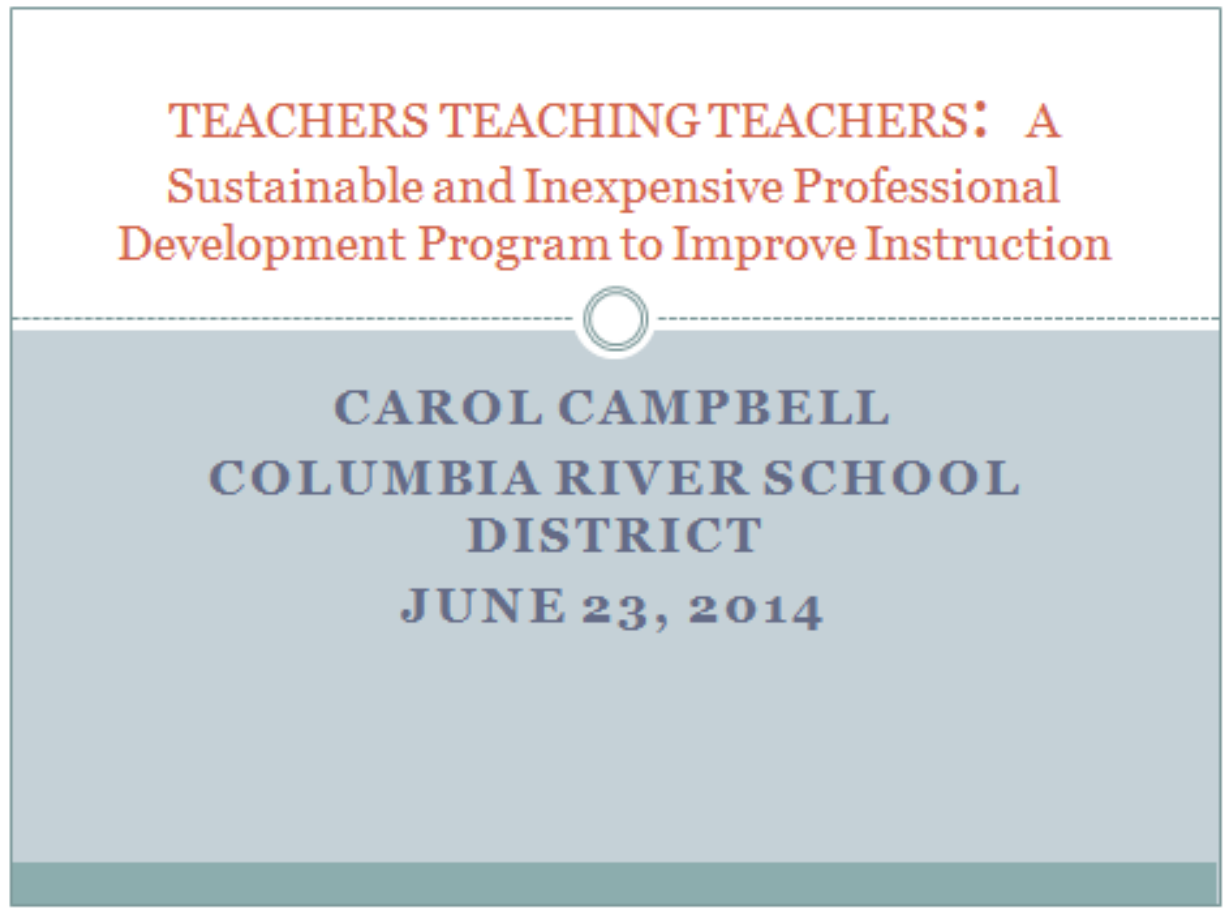

TEACHERS TEACHING TEACHERS: A Sustainable and Inexpensive Professional Development Program to Improve Instruction

CAROL CAMPBELL COLUMBIA RIVER SCHOOL DISTRICT JUNE 23, 2014 


\section{HOW IT ALL STARTED}

My Personal and Professional Journey

$>$ Teacher-23 years

> Small School Principal (Comprehensive Reform)-4 years

Focus Option High School Principal-2 years

Large Comprehensive High School Principal-1 year

\section{STATEMENT OF THE PROBLEM}

"While this type of teacher training ensures everyone gets the same message and reaches a common level of understanding; a "one-size-fits-all" professional development program is not the most effective way to meet the needs of individual teachers" (Royce, 2010).

Video:

The Wire-Season 4

Episode \#1-40:32

"Boys of Summer" 

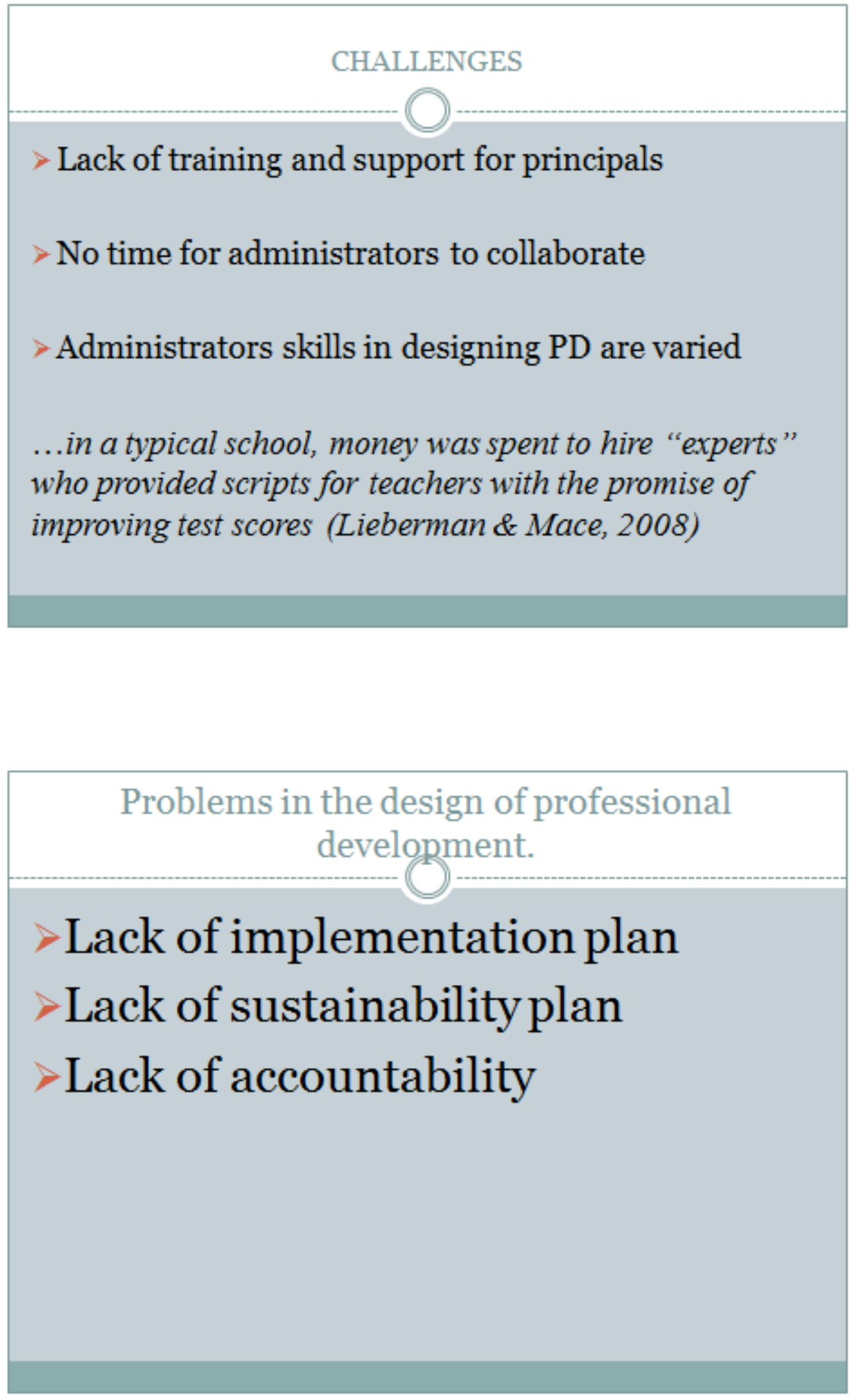


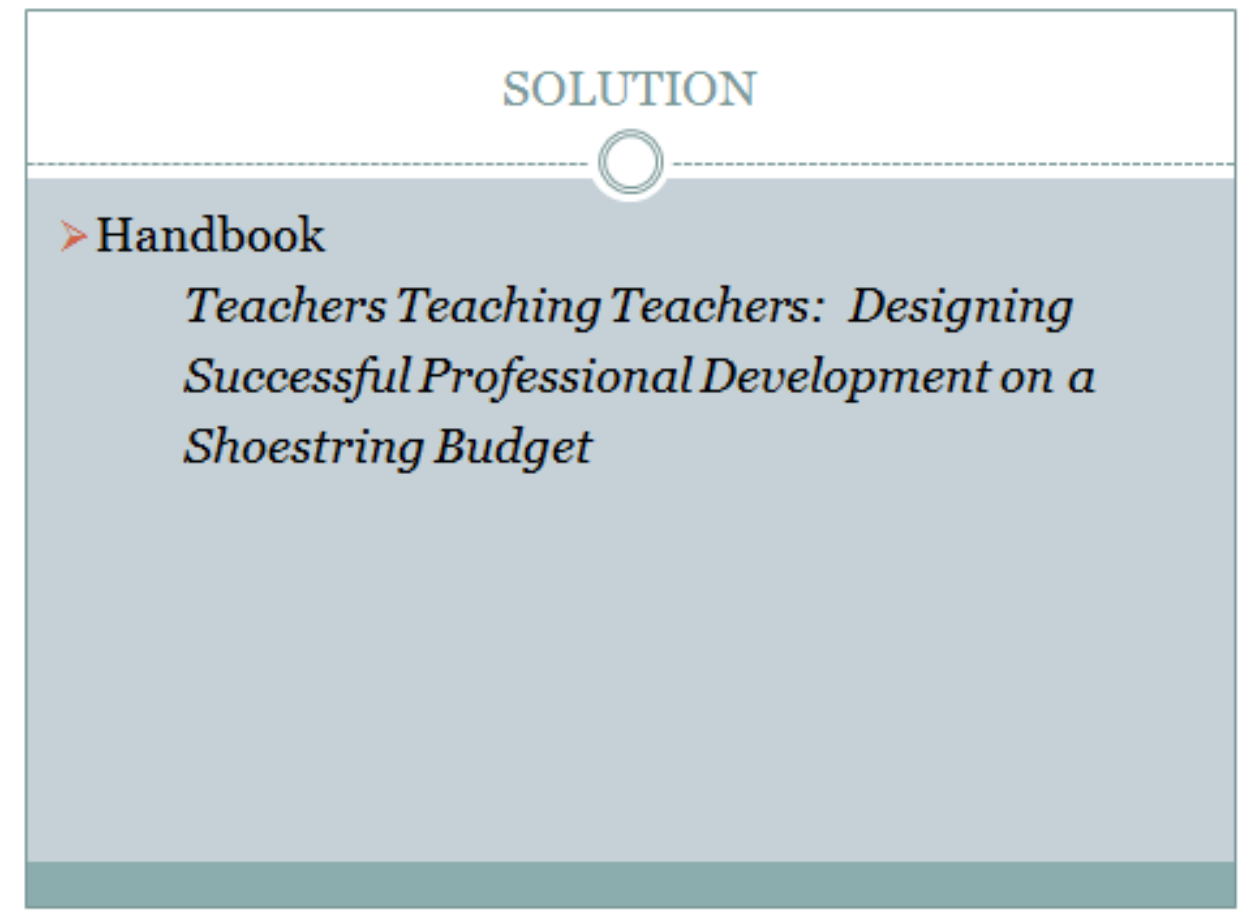

\section{RATIONALE}

\section{Introduction}

Teachers need more than a few in-service days per year to make significant changes in teaching practice (Habegger \& Hodanbosi, 2011).

What appears to have the most impact is sustainable change that comes from within; practitioners collaborating and identifying issues related to teaching and learning (Barth, 1990, Gordon, 2008, Smith \& Rowley, 2005). 


\section{IMPORTANCE OF LEADERSHIP}

Leadership is the reciprocal processes that enables participants in an educational community to construct meanings that lead toward a shared purpose of schooling.

\section{Linda Lambert (2003)}

Leadership needs to be embedded in the school community with shared responsibility and a shared purpose (Lambert, 20OO).

\section{THREE AREAS OF FOCUS}

Inquiry Model (action research)

$>$ Peer Observation

$>$ Community (professional learning communities) 


\section{INQUIRY}

Topic: Action Research

Action research is necessary in order for teachers to know whether or not changes they have made are successful (Chenoweth and Everhart, 2003).

Term can be traced to the 30's.

Process very closely resembles John Dewey's five stages of the scientific process.

\section{PEER OBSERVATION}

Topic: Peer Observation

"Reform movements in education result in band-wagons and rallying cries, but they also represent a debilitating form of dependency and superficiality."

\section{Feedback}

Michael Fullan (1995)

Joyce and Showers(2006) -peer observation promotes and supports professional and collaborative relationships between teachers

Self-efficacy

Bandura's social cognitive theory 


\section{PLC}

Topic: Professional Learning Communities

1924-Mary Parker Follett-ways of relating in the workplace and professional growth

1998-DuFour and Eaker-strategy to improve teaching and learning

The PLC model provides the opportunity to focus on the collective analysis of student learning rather than the micromanagement of instruction thus creating a collaborative culture (DuFour and Mattos, 2013).

\section{Handbook Review}

- In small groups

- Choose a recorder and reporter

- Fill out the "scavenger hunt" handout to become familiar with the handbook (20 minutes)

- Each group will share out (what was helpful, what was missing) 


\section{Utilizing the Handbook}

- Getting Started (staff survey and generating buy-in)

- District Initiatives

- District Calendar

- Sample PD plan and calendar (p. 19)

$\checkmark$ late starts $=16$ hours

$\checkmark$ Mondays $=53$ hours

$\checkmark$ August $=8$ hours ( 2 half days)

Total $=77$ hours of PD

\section{Action Research}

- Fits well with goal setting

- Promotes data collection

- Improves practice and student learning

- Teachers showcase their work and learning

Fit to Live and Learn Example:

http://vimeo.com/75179737 


\section{Peer Observation}

- Use of structure and protocol promotes dialogue between teachers

- Promotes cross content sharing of practice

Comments from participants:

"Appreciated the opportunity to observemy colleagues, especially those from different disciplines."

"I believeit is healthy to create time to celebrate and acknowledgebest practices."

"Itreally helped us createa positive, professional community oflearners."

"Teachers improve when they are given opportunities for practice, feedback and collaboration."

\section{Professional Learning Communities}

- The importance of choice

- Norms

- Accountability

p. 38 (sample topics)

Powerpoint sample PD plan from Urban High School 


\section{Sharing of Ideas}

- Each group/school share overview of PD plan.

- Each group/school share one or two ideas for PD activities or structure for 2014-15 school year.

- Audience fill out feedback form for presenters

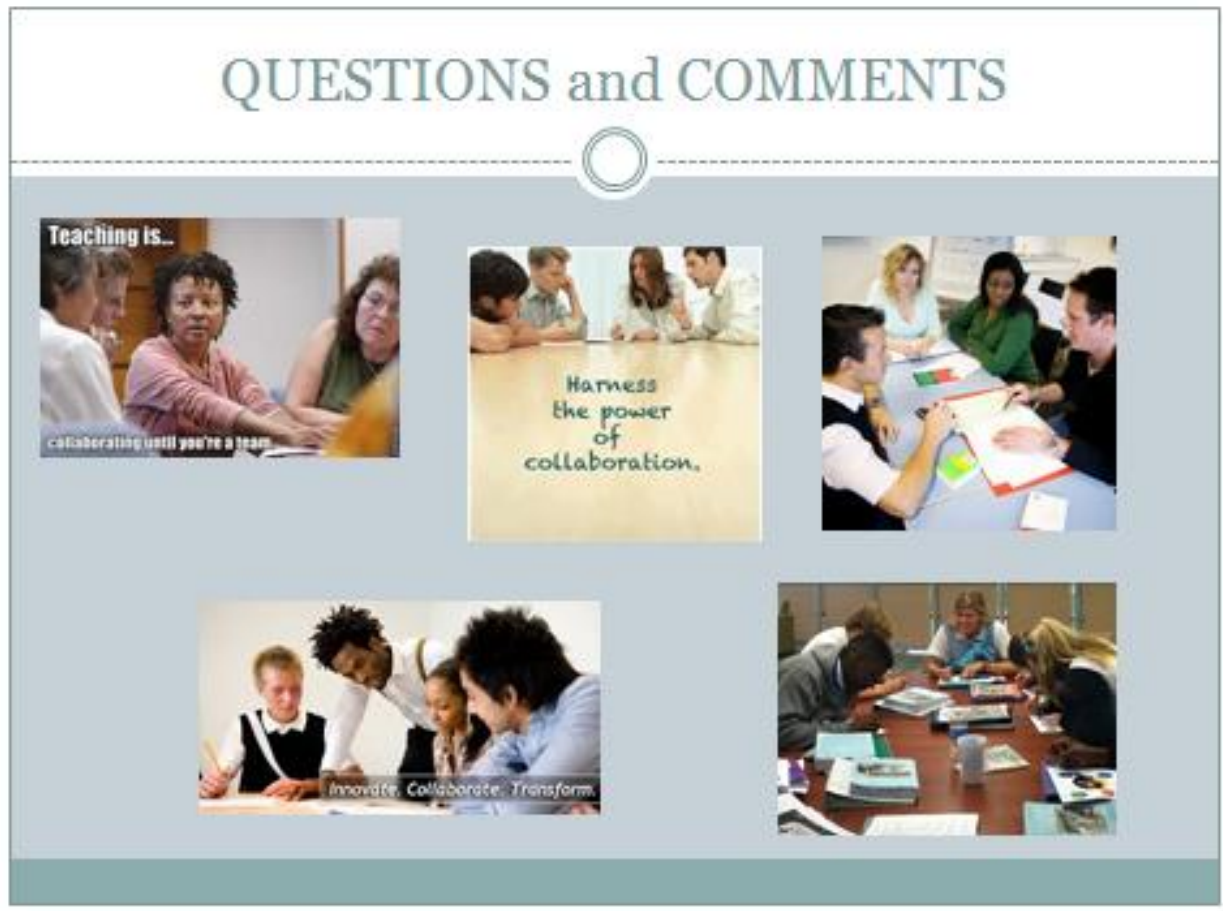


APPENDIX F

HANDBOOK 


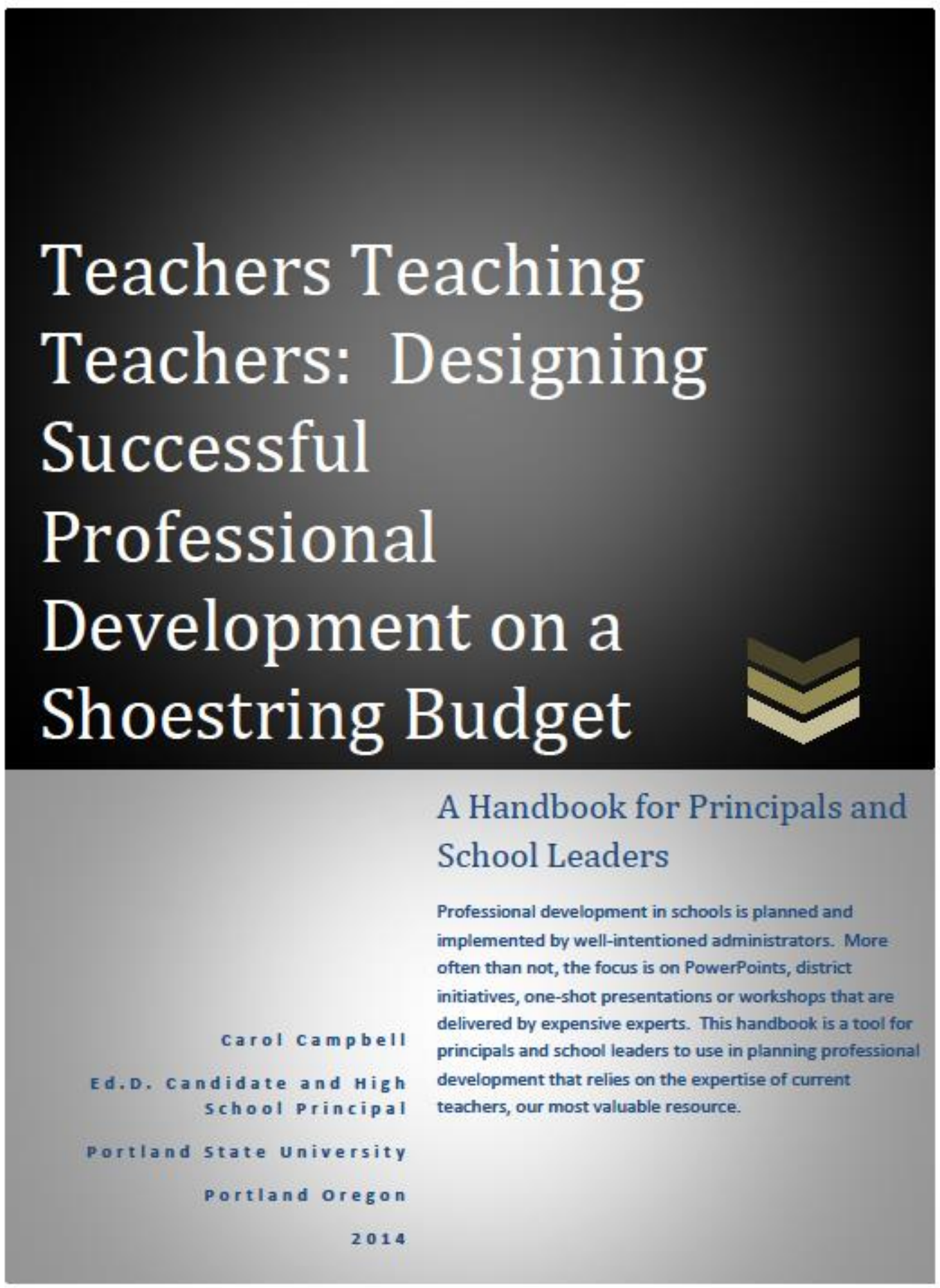


Teachers Teaching Teachers: Designing Successful Professional Development on a Shoestring Budget

A Handbook for Principals and School Leaders

Carol Campbell 


\section{About the Author}

I have been an educator for 30 years. For 23 of those years I was a high school biology teacher, 14 years in Missouri and 9 years in Oregon. For the past 7 years $I$ have been a high school principal. My experience as a principal has been varied and includes working at a large comprehensive high school undergoing major reform into 4 smaller schools with the support of a Bill and Melinda Gates Grant, working at a career technical education high school that included programs in building construction, electric, medical assisting, dental assisting, digital media, automotive, radio broadcasting and manufacturing. I am currently the principal of a large comprehensive high school in Portland, Oregon.

During my years as a classroom teacher, I became very interested in opportunities to grow and learn. I took advantage of invitations to attend workshops and trainings and even traveled out of state to large conventions and summits. These experiences had very little impact on my teaching practice. At the end of each year, I would clean my classroom and find the binders and materials from the events I attended and often times would recycle them or file them for future use (which never happened). In my $18^{\text {th }}$ year of teaching, I met a teacher and literacy coach who asked me to participate in a summer curriculum camp. The curriculum camp was an opportunity to collaborate with other teachers on integrating units of study between biology, modem world history and English. My group chose to write curriculum using the novel, The Secret Life of Bees by Sue Monk Kidd. My part of the curriculum was focused on the science of bees and I created lessons on bee development, bee behavior and other species such as homets, wasps and killer bees. This unit of study was the favorite of my students and the rate of success with science content was much higher than in other units taught in a more traditional manner. As a result of the curriculum camp I began using more writing in my biology classes and making 
more connections to real life. This changed the way I taught which helped students be more successful and invigorated me as a teacher. No workshop or conference had impacted me or my teaching practice as much as the opportunity to collaborate with colleagues.

I spent the last five years of my teaching career looking for and creating opportumities to work with other teachers. I participated in a Critical Friends Group (CFG), organized a book club that met during lunch and took advantage of workshops that were provided by teachers currently teaching. I also began to present mini lessons and workshops for other biology teachers on literacy strategies.

The last five years of my teaching career afforded me the opportunity to feel inspired about my own professional growth. As an administrator, I want to provide that same opportunity for teachers I work with. In 2007 I was hired for a principal position and for the past 7 years have been trying out various types of professional development focused on teachers learning from one another. As a principal, I have received very little training, guidance or support on how to create meaningful professional development opportunities. I discovered, mostly by trial and error and talking to teachers, that what most teachers prefer is time to talk to one another, observe one another and work on problems of practice. The three PD activities included in the handbook, professional leaming communities, peer observation and action research, have the potential to improve teacher practice and ultimately student achievement. While my experience has been solely at the high school level, the activities in the handbook can be applicable to any K-12 school. I hope this handbook will provide support for principals who desire to provide professional development that meets the needs of teachers and impacts the quality of instruction. 


\section{Table of Contents}

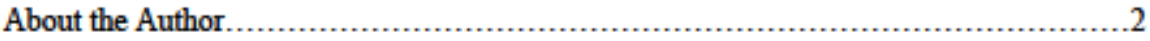

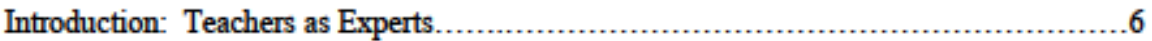

Intended Audience.

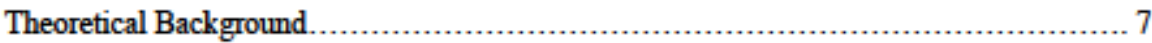

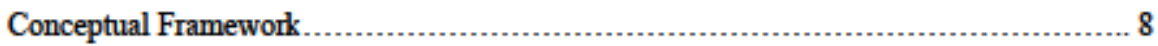

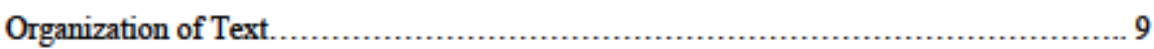

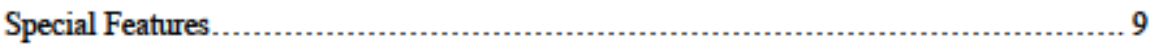

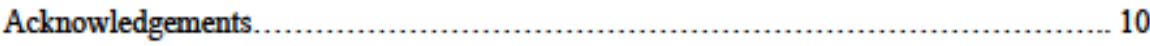

\section{CHAPTER ONE}

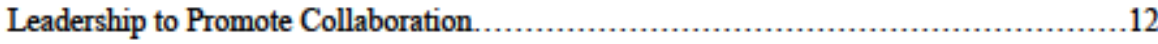

\section{CHAPTER TWO}

Getting Started.

\section{CHAPTER THREE}

Action Research.

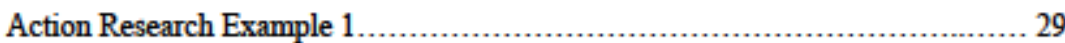

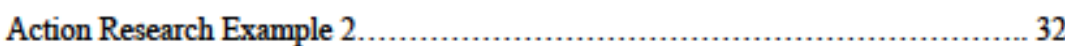

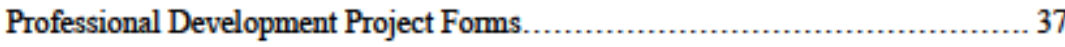

Action Research Project Design and Presentation............................ 44

\section{CHAPTER FOUR}

Peer Observation.

Peer Observation Schedule........................................................... 49

What? So What? Now What? …….............................................................. 50

\section{CHAPTER FIVE}

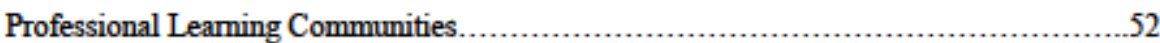




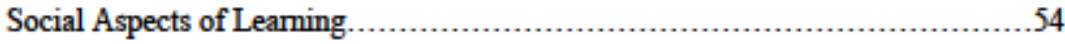

Relationship Between Professional Learning and Student Leaming ................ 55

Sample PLC Meeting Notes....................................................... 60

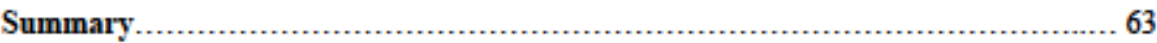

Criteria Sheet for Instruction. .......................................................... 65

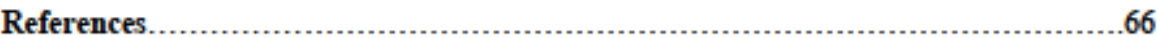

\section{Appendix}

Appendix A

Sample Professional Development Plans.

Appendix B

Teacher Professional Development Survey.

Appendix C

Sample Staff Surveys following PD Activities. 


\section{Introduction}

High school principals have the responsibility of designing professional leaming opportunities for teachers. While this is a common expectation for school administrators, there is no magic formula or template from which to design a successful professional development program. Administrators, like many teachers, work in isolation, without opportunity to collaborate with colleagues. What often results is a professional development program that has no scope and sequence, no relevancy for teachers, no follow-up and no accountability.

Principals look for the latest hot topic in professional journals and rely on district leadership and initiatives to design professional development. Teachers participate in the activities yet there is often little change in the classroom or instruction.

My intent is not to imply that there are not any worthwhile professional development programs or that all principals are incapable of designing outstanding professional development opportunities. What I do know is that the high school principal job is demanding, timeconsuming and stressful. Principals can find it difficult to give professional development the attention it deserves due to so many competing factors.

What I am attempting to do with this handbook is provide a resource for principals to use in creating professional development plans. A professional development plan should encompass opportunities for teachers to examine and improve instructional practice, protocols for teachers to receive ongoing feedback and regularly scheduled collaboration time. A professional development plan is a series of connected presentations or workshops with follow-up and accountability. 


\section{INTENDED AUDIENCE}

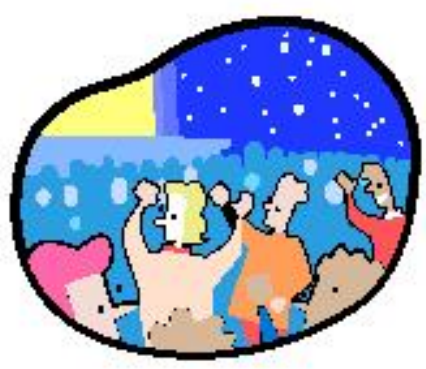

This handbook is written for school and district leaders who are responsible for the implementation of professional learning activities: district- and school-level administrators, staff developers, teacher-leaders and instructional coaches. The activities include in this book are meant to be facilitated by one or more educators within the school or district rather than an outside experts or companies. The handbook is meant to provide the facilitator(s) with the tools to plan, implement and evaluate a professional development program.

\section{THEORETICAL BACKGROUND}

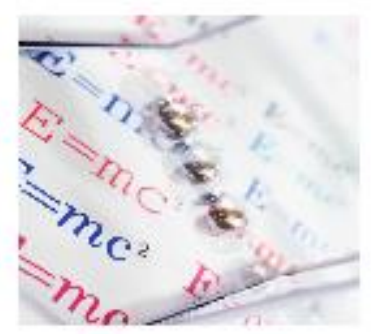

Leadership is defined by Linda Lambert (2003) as reciprocal processes that enable members of an educational community to construct meaning toward a shared purpose. Even though this book is focused on teachers teaching teachers, the activities require a skilled leader or facilitator. Administrators need to work side by side with teachers to create relevant professional learning opportunities that allow teachers to collaborate and share their expertise and knowledge. 
According to Michael Fullan (2001), learning in the setting where you work has the greatest impact on performance because it is relevant to the situation and it includes interaction with colleagues. To create an atmosphere of shared leadership the administrator must view collaboration among teachers as the basis for improvement in instruction. This book is based on a constructive approach to leadership with allows individuals to bring past experiences, beliefs, cultural histories and world views into the process of leaming. Through personal perspectives and inquiry new knowledge is developed together in community.

\section{CONCEPTUAL FRAMEWORK}

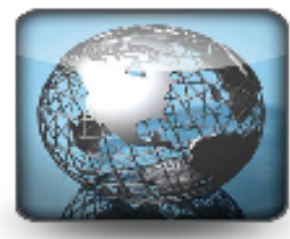

The framework of the teachers teaching teachers professional development model came from several concepts. Social aspects of leaming (Lieberman and Mace, 2008) provided the rationale. The professional development activities described in this book are constructivist in nature and rely heavily on prior experience, collegiality, reflection and accountability. Peer observation allows teachers to vicariously observe successful teaching practices and implement those practices in their own lessons. There is reciprocity in learning as those being observed receive feedback about what is working in their classroom. Action research allows teachers to investigate a problem of practice or implement a new strategy. This personal, individualized approach deepens participant leaming. Professional learning communities create opportunities 
for dialogue and sharing of ideas. Accountability is applied to all of these activities in a way that promotes reflection and discussion.

\section{ORGANIZATION OF TEXT}

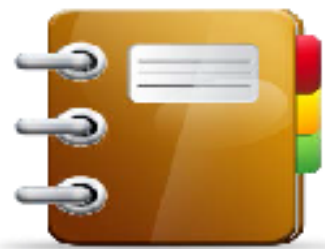

The handbook is divided into three main sections: action research, peer observation and professional learning communities. Also included is a discussion of the importance of leadership in providing optimal conditions for teacher growth. My hope is that the information in this handbook will help principals and school leaders to look beyond professional development activities and establish a philosophy of leaming for teachers that is ongoing rather than a series of one-time events.

\section{SPECIAL FEATURES}

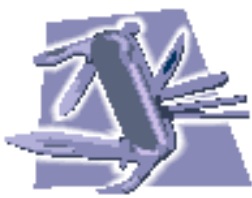

The following tools and resources are included:

1. Steps for designing and implementing a professional development program

2. Sample workshop agenda for collaborative planning

3. Sample professional development plans

4. Sample action research projects 
5. Instructions and materials for three professional development activities

6. Protocols

7. List of references

\section{ACKNOWLEDGEMENTS}

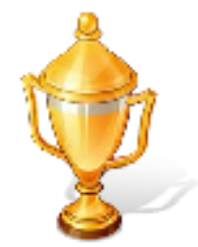

This project was influenced by the 23 years I spent in the classroom and my last seven years as a high school principal. I could not have completed the handbook without input from teachers and colleagues. During the past 30 years I have had the fortune of working with amazing educators who inspire and motivate me to seek out ways to improve my own practice. This also could not have been accomplished without students in mind. Reciprocal learning also occurs between students and teachers and I have leamed a lot about teaching from listening to my students.

There are dozens of teachers who have influenced my practice as a teacher and principal. I rely on them to keep me grounded and focused on what really matters. Linda Christensen has been a mentor for over a decade and a strong influence as I designed this handbook. Dianne Leahy provided critical analysis and feedback, constantly reminding me to remember what it was like to be a teacher. The teachers I have worked with during the last seven years tested the activities and provided feedback on what worked and what didn't. Their willingness to try new things made this project possible. 


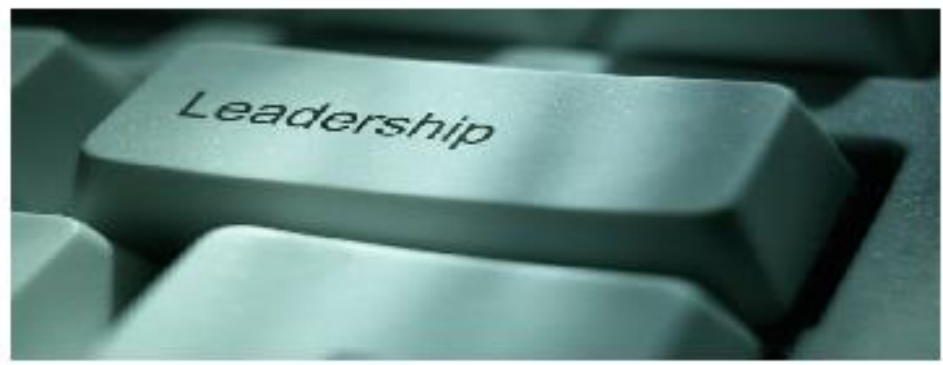

"Leadership is the reciprocal process that enables participants in an educational community to construct meanings that lead toward a shared purpose of schooling."

Linda Lambert (2003)

CHAPTER ONE

\section{Leadership to Promote Collaboration}

There are many leadership styles and philosophies. The activities in this handbook are based on a collaborative/constructivist approach to professional development. According to Lambert et al (2002), a more collegial approach to professional development promotes teacher autonomy, self-analysis, self-direction and encourages reflection. As a result, teachers can emerge as leaders, peer coaches, researchers and mentors as well as develop learming 
relationships with colleagues. Table 1 summarizes the differences between a traditional approach and a collaborative/constructivist approach to professional development

Table 1- Professional Development Comparison (Adapted from Lambert et al, 2002, p. 194).

\section{Professional Development}

\begin{tabular}{|c|c|}
\hline Traditional/Hierarchical Approach & Collaborative/Constructivist Approach \\
\hline $\begin{array}{l}\text { Emphasis on knowledge acquisition and } \\
\text { prescribed training. Delivery through formal } \\
\text { workshops, courses. }\end{array}$ & $\begin{array}{l}\text { Emphasis on multiple learning opportunities, } \\
\text { authentic tasks, collaboration, action research, } \\
\text { PLC's and mentoring. }\end{array}$ \\
\hline $\begin{array}{l}\text { Individual professional development plans based } \\
\text { on teacher evaluation by administrator. }\end{array}$ & $\begin{array}{l}\text { PD plans are personal, collegial and school based } \\
\text { and includes choice and multiple forms of } \\
\text { learning. }\end{array}$ \\
\hline $\begin{array}{l}\text { PD days are scheduled and structured by the } \\
\text { district and primarily reflect district/state/federal } \\
\text { mandates. }\end{array}$ & $\begin{array}{l}\text { PD days are designed by staff and include } \\
\text { reciprocal processes, action research, PLC's, } \\
\text { leadership development, team coaching and } \\
\text { collaborative planning. }\end{array}$ \\
\hline $\begin{array}{l}\text { District goals drive the school improvement plan. } \\
\text { School plans are viewed as instrumental in } \\
\text { moving toward district goals. }\end{array}$ & $\begin{array}{l}\text { School improvement plans have ongoing } \\
\text { professional development at the center. School } \\
\text { plans inform and are informed by district goals } \\
\text { and vision. }\end{array}$ \\
\hline
\end{tabular}

Teachers tend to be more invested if there is a shared vision and clear expectations.

During the academic year, professional development activities may need to be adjusted or modified based on data, teacher growth or other factors. Flexibility is important and demonstrates ongoing evaluation of the activities with appropriate adjustments when necessary (Ainsworth, 2010). Lambert (2000) supports the idea of shared leadership and proposes that leadership needs to be embedded in the school community with shared responsibility and a shared purpose. She further describes a four-quadrant leadership matrix (see figure 1 below). In Quadrant 1 the leadership style is autocratic with very few people contributing to decision making. In Quadrant 2, people are mostly doing their own thing and the school administrators are making the decisions. Quadrant 3 describes schools with leadership teams but very few people are involved. Teachers who are not part of the team can become alienated and resist 
proposed changes. Quadrant 4 is the desired modality with broad distribution of authority and leadership opportunities for students, parents and teachers. Information in this quadrant is not top-down. People develop their own meaning, raise their own questions and construct information from the inside-out. In Quadrant 4 there is discovery through evidence, investigation of problems of practice, review of student work and examination of issues in a broad-based way.

Figure 1- Leadership Capacity Matrix, Level of Participation and Skillfulness (Lambert, 2000).

\begin{tabular}{|c|c|}
\hline \multicolumn{2}{|c|}{ Breadth of Participation } \\
\hline $\begin{array}{l}\text { LOW } \\
\text { Quadrant } 1 \\
\text { Autocratic administration } \\
\text { Limited flow of information } \\
\text { Co-dependent, paternal } \\
\text { relationships } \\
\text { Rigidly defined roles } \\
\text { Norms of compliance } \\
\text { Lack of innovation in teaching and } \\
\text { learning } \\
\text { Student achievement poor, or } \\
\text { showing short-term improvements }\end{array}$ & $\begin{array}{l}\text { High } \\
\text { Quadrant } 2 \\
\text { Laissez-faire administration } \\
\text { Fragmentation and lack of } \\
\text { coherence of information and } \\
\text { programs Norms of } \\
\text { individualism Undefined roles } \\
\text { and responsibilities Both excellent } \\
\text { and poor classrooms Spotty } \\
\text { innovation Student } \\
\text { achievement static overall }\end{array}$ \\
\hline $\begin{array}{l}\text { Quadrant } 3 \\
\text { Trained leadership or site-based } \\
\text { management team } \\
\text { Limited use of data } \\
\text { Polarized staff, pockets of strong } \\
\text { resistance } \\
\text { Designated leaders act efficiently, } \\
\text { others serve in traditional roles } \\
\text { Pockets of strong innovation and } \\
\text { excellent classrooms } \\
\text { Student achievement static, or } \\
\text { showing slight improvement }\end{array}$ & $\begin{array}{l}\text { Quadrant } 4 \\
\text { Broad-based, skillful participation } \\
\text { in the work of leadership } \\
\text { Inquiry-based use of information to } \\
\text { inform decisions and practice } \\
\text { Roles and responsibilities reflect } \\
\text { broad imvolvement and } \\
\text { collaboration Reflective } \\
\text { practice-imnovation is the norm } \\
\text { High student achievement }\end{array}$ \\
\hline
\end{tabular}

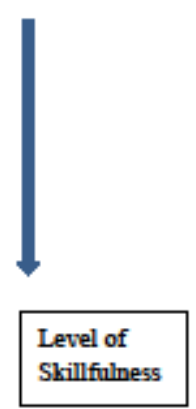

A great example of a constructivist approach to professional development is the National Writing Project. The NWP is recognized as a successful professional development program for teachers focused on literacy. The components of NWP, identified by Lieberman and Wood 
(2001), that make is successful are listed below. These components resemble the qualities of a constructivist approach to teacher learning.

1. Each colleague is a potentially valuable contributor and it is important to learn what they believe and what they think. This de-emphasizes the isolation that some teachers experience.

2. NWP honors teacher knowledge. The knowledge is not held by authority figures or recognized experts. Teachers share what they know.

3. NWP creates a public forum for teachers. Teachers are expected to be public in their practice. They make presentations for parents and colleagues, write articles and contribute to newsletters.

4. Ownership of learning is turned over to the learners. Teachers are responsible for their own leaming. Teacher accountability becomes part of a reflective process and collegiality.

5. NWP sees the importance of building community. No one is expected to teach in isolation. The learning community provides constructive and helpful suggestions in an authentic way.

6. NWP provides multiple entry points into learning community. Professional development has been designed by so-called experts. The NWP offers the opportunity for teachers to come together to investigate their own challenges and problems of practice. There is no reliance on ready-made solutions or "cookie cutter" remedies that promise to work for any student.

7. NWP guides reflection on teaching through reflection on learning. When NWP teachers alter their practice it is because they learned from their own learning not simply because they learned new ideas and/or strategies.

8. NWP promotes shared leadership. Professional development means becoming more professional on all levels, not just learning new strategies. Many teachers become consultants for colleagues and lead teams of teachers in inquiry and research.

9. NWP promotes an inquiry stance. Teachers are encouraged to conduct research in their own classrooms and collect data to support strategies that successfully raise student achievement. Teachers ask themselves, "What else should I be doing here?"

A constructivist approach to leadership allows individuals to bring past experiences,

beliefs, cultural histories and world views into the learning process. Through personal

perspectives and inquiry, new knowledge is developed together in community. Constructivism is

widely accepted as applicable and relevant in how we design instruction for students today.

Constructivist leadership is based on the same components of constructivist learning such as

meaning and knowledge construction, inquiry, participation, collaboration and reflection. 
The next 3 chapters contain explanations of activities and sample protocols that fit within a constructivist approach and promote teacher inquiry, collaboration and reflection. 


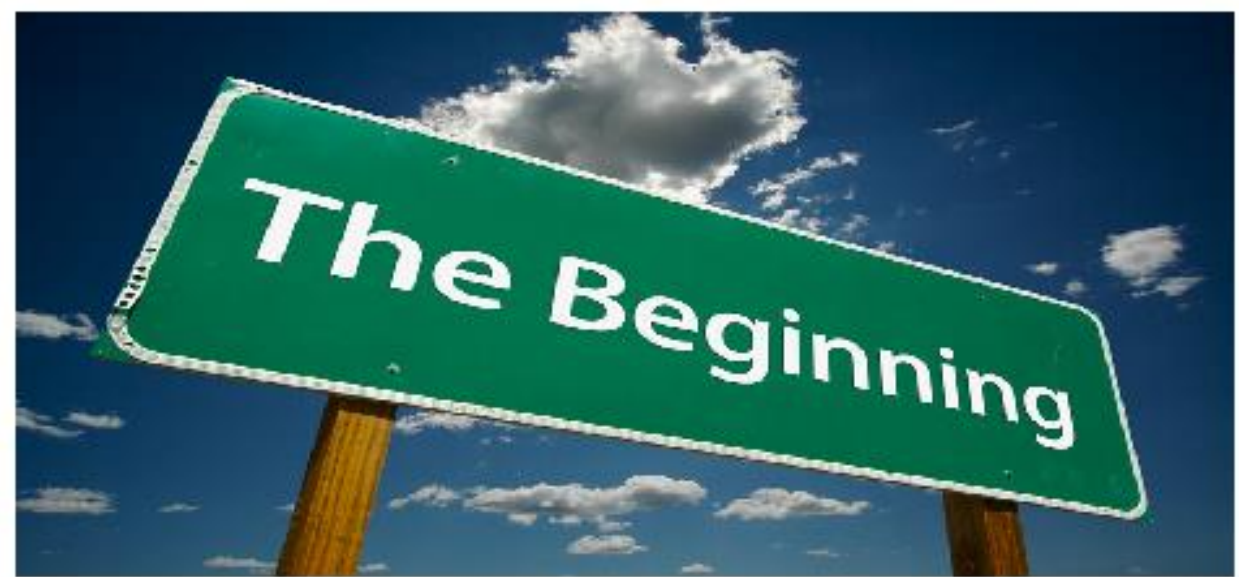

\section{CHAPTER TWO}

"This is a much needed resource. The activities are teacher-led and include resources and protocols."

High School Principal

\section{Getting Started}

The activities included in this handbook can be useful and provide the framework for a successful professional development program. Earlier in the handbook I talked about the importance of leadership and getting teachers to buy-in to any professional growth activities can be a challenge for even the most competent leaders. What seemed to be the most important things for teachers that I worked with is the ability to have input and choice on what types of activities they participate in. It may appear that I am implying that not only should teachers be 
teaching teachers but they should also design the activities. Why then do we need a principal or administrator? This is THE most important thing that I have learned in the principal role: Strong leadership is not dictating and providing all of the answers. Strong leaders facilitate, guide, provide time and space, and grow side-by-side with teachers. Here are the steps I recommend in designing a professional development program:

1. Collect data on what has been done and how teachers perceive the activities that have been provided (see sample survey in Appendix B)

2. Convene a design team that consists of administrators and teachers who will work on a PD plan together.

3. Administrator identifies district initiatives that have to be implemented in PD (common core, grading practices, PLC's, etc.)

4. Review the district calendar and create a list of dates and times for PD (Design Team).

5. Brainstorm a list of activities (using staff survey responses) to present to staff for feedback (Design Team).

6. Create a PD plan for the year and present to staff (Design Team). See sample PD Plans in Appendix A.

Following is a detailed description of each step in the PD planning process. 

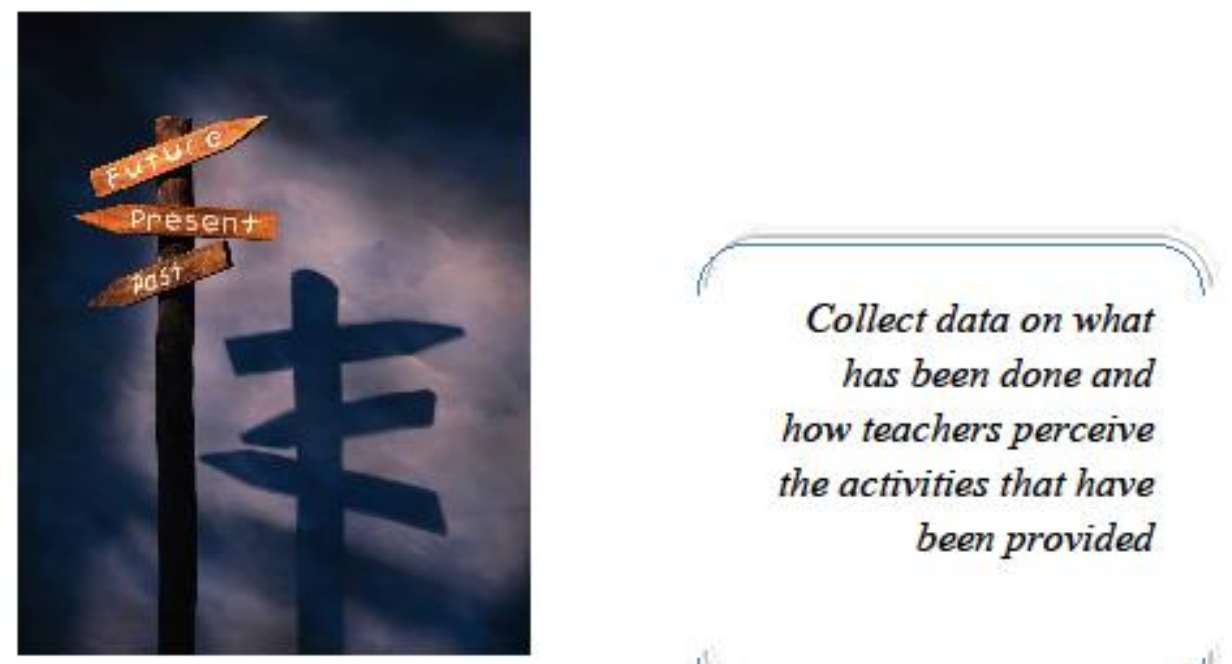

Collect data on what has been done and how teachers perceive the activities that have been provided

It doesn't make sense to plan future PD without examining what has been done in the

past. All three of the PD activities in the handbook promote collaboration and they were chosen based on feedback from teachers on what type of PD they find most meaningful and impactful to student learning (see survey in Appendix B). The survey was designed to identify themes and commonalities about PD experiences and was adapted from a survey used in a large urban school district to evaluate PD. Getting teacher input before developing a plan, models collaboration and provides transparency in the PD planning process.

Table 1.0 illustrates the results of the survey from a suburban high school with approximately 65 teachers.

Table 1.0-Suburban High School Professional Development Survey Results. See Appendix B for actual survey.

\begin{tabular}{|l|l|}
\hline Professional Development Activity & Impact Average (60 respondents) \\
\hline
\end{tabular}




\begin{tabular}{|c|c|}
\hline 3-4 day curriculum camp & Considerable impact on student learning \\
\hline 4-week Writing Project & Large impact on student learning \\
\hline Curriculum mapping & No impact on student leaming \\
\hline $\begin{array}{l}\text { Modeling (TOSA, instructional specialist, } \\
\text { colleague }\end{array}$ & Considerable impact on student learning \\
\hline Unit planning & Some impact on student learning \\
\hline Department planning & Considerable impact on student learning \\
\hline Peer observation & Large impact on student learning \\
\hline SIOP strategies workshops & Little impact on student learning \\
\hline Literacy strategies workshops & Some impact on student learning \\
\hline $\begin{array}{l}\text { Teacher-led professional development } \\
\text { (demonstration lessons) }\end{array}$ & Large impact on student learning \\
\hline ESL endorsement classes & Little impact on student learning \\
\hline $\begin{array}{l}\text { OAKS work sample scoring classes (OAKS is } \\
\text { the Oregon State Standards Assessment) }\end{array}$ & No impact on student leaming \\
\hline OAKS test prep workshops & No impact on student leaming \\
\hline University courses & Little impact on student learning \\
\hline 1-2 day workshops by experts in the field & No impact on student leaming \\
\hline \multicolumn{2}{|l|}{$\begin{array}{l}\text { Impact scale: } \\
1 \text { = No impact on student learning } \\
2 \text { = A little impact on student learning } \\
3 \text { = Some impact on student learning } \\
4 \text { = Considerable impact on student learning } \\
5=\text { Large impact on student learning }\end{array}$} \\
\hline
\end{tabular}



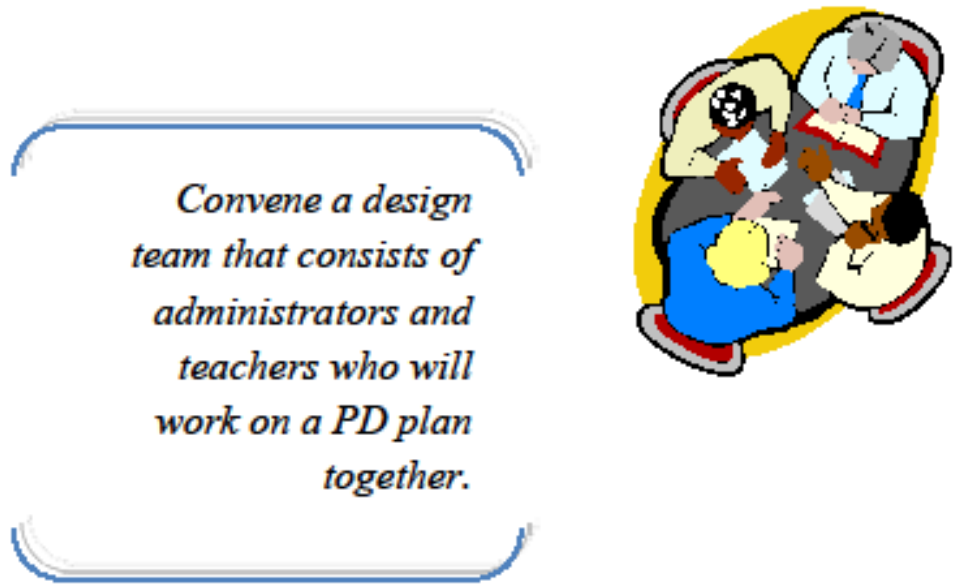

Step two is probably the most critical step in the PD planning process. Having teachers on the PD planning team ensures there is input from the perspective of those currently in the classroom. The survey results can be analyzed by the team and common themes identified. The results of the survey help identify what types of PD will be included in the plan. Teachers are more likely to embrace the PD activities if they see that the PD plan has been developed with input from them. 

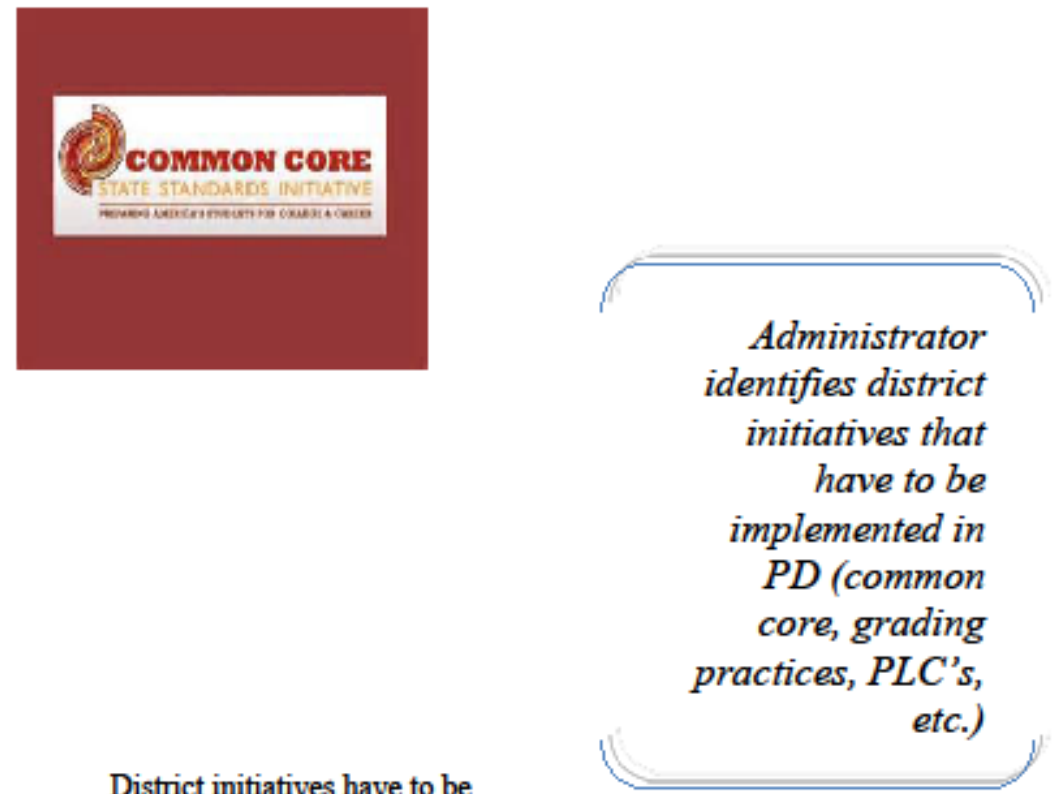

District initiatives have to be

included in the yearly PD plan. In most cases, the required PD topics can be incorporated into the $\mathrm{PD}$ plan. For example, if the district has a requirement that $\mathrm{PD}$ has to include time for teachers to work on common core standards; the PD design team can incorporate the topic into collaborative activities such as peer observation and PLC's. Department PLC's can be created to provide time for teachers to collaborate on common assessments and lesson and unit planning incorporating common core state standards. Peer observation can be implemented so teachers can observe literacy strategies across content areas to satisfy a district initiative connected to literacy. It is relatively easy to incorporate any district initiative into one or more of the PD activities in the handbook. 

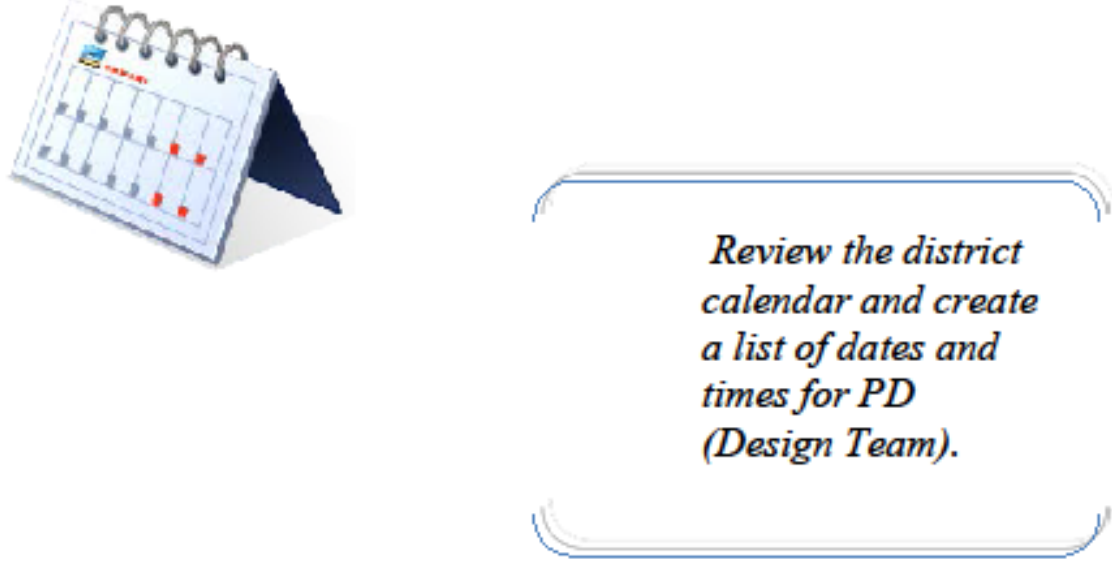

This part of the PD planning process is very similar to what teachers do when creating a yearly curriculum map. The dates and times for PD are identified and inserted into a calendar or spreadsheet. The design team might also want to consider looking at PD dates that are near progress report time, parent conferences, open house, etc. Those are good days to incorporate time for staff to make phone calls to parents or work on preparing for those events. Teachers will appreciate the time to prepare and will be more likely to buy-in and participate fully in the PD plan. 


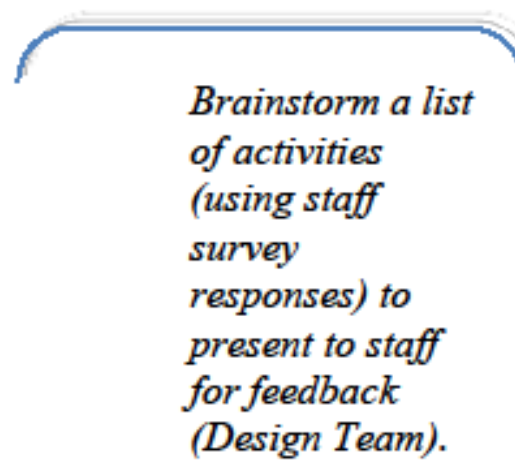

W

list of activities. The list should include activities that teachers identified as preferable on the initial survey. The design team may also want to come up with additional activities. For example, the first time I worked with a PD design team, no one suggested action research as a PD activity. I suggested we include it on the list and propose a protocol to staff and see if anyone was interested. Several staff members formed a PLC focused on action research and shared their results with the staff at the end of the year. This PD was very impactful and improved practice. Once the list of formed by the design team, it can be shared with staff for feedback and suggestions.

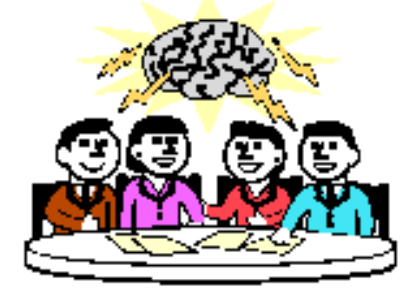

Once the dates and times for PD have been identified, the design team can begin to create a 

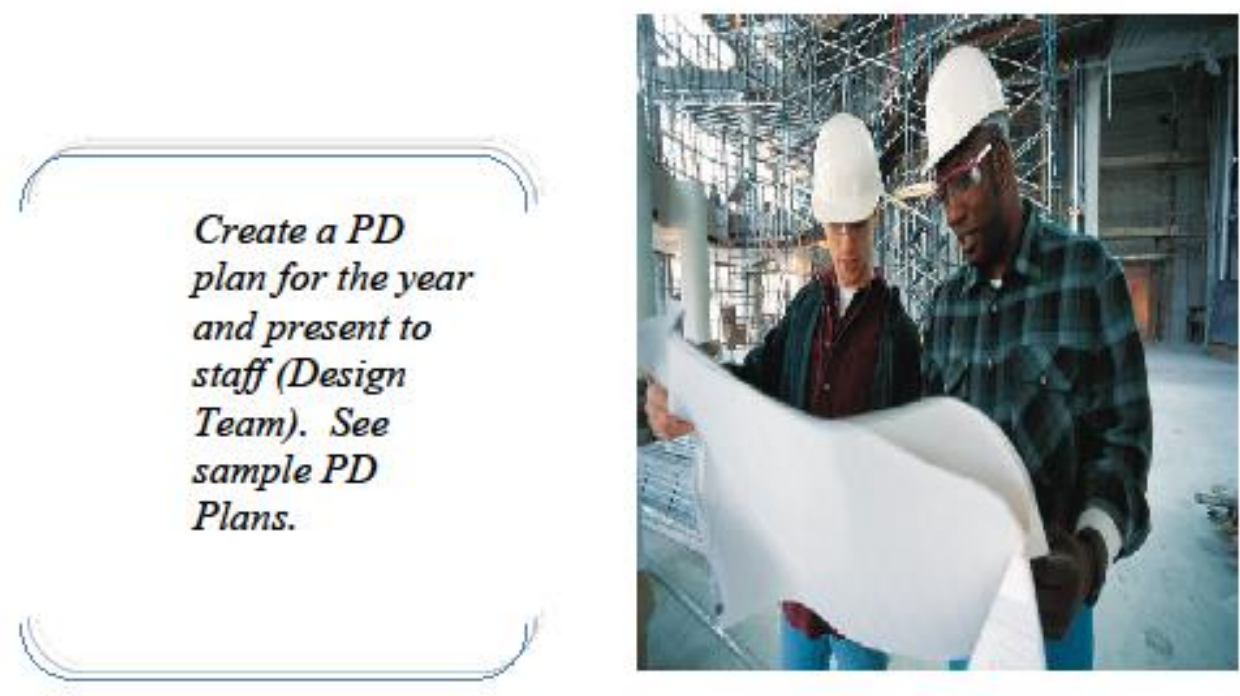

The final step in the PD planning process includes finalizing the calendar, filling in activities and sharing the plan with staff. There will probably be minor adjustments throughout the year, but cancelling PD sessions should be avoided. See sample PD plans in Appendix D.

The workshop agenda used to test the usefulness of the handbook is also a worthwhile resource. The data collected during the development of the handbook indicated that administrators need more time to collaborate with colleagues when they are planning PD. The workshop agenda is included as a tool to use in planning a collaborative session for school design teams and/or district administrators.

\section{Workshop Agenda}


Workshop for School Administrators Utilizing the Handbook: Teachers Teaching

Teachers: Designing Successful Professional Development on a Shoestring Budget.

\begin{tabular}{|c|c|}
\hline Activity & Time \\
\hline $\begin{array}{l}\text { Introductions, Review Agenda } \\
>\text { Rationale for using the handbook } \\
>\text { Purpose of workshop }\end{array}$ & 30 Minutes \\
\hline $\begin{array}{l}\text { Preliminary Handbook Review } \\
>\text { Create small groups } \\
>\text { Group share out }\end{array}$ & 30 minutes \\
\hline $\begin{array}{l}\text { Presentation-How to utilize the handbook and sample PD plan } \\
>\text { Getting started (staff survey) } \\
>\text { District initiatives } \\
>\text { District calendar } \\
>\text { Design of handbook } \\
>\text { Sample PD plan and calendar }\end{array}$ & 20 minutes \\
\hline $\begin{array}{l}\text { Small group or individual work } \\
>\text { Utilizing the handbook, create PD plan for next school year } \\
>\text { Have sample PD plans available } \\
>\text { Observe and assist when necessary }\end{array}$ & 60 minutes \\
\hline $\begin{array}{l}\text { Share out PD plans, collect plans } \\
>\text { Each group share what they created }\end{array}$ & 30 minutes \\
\hline $\begin{array}{l}\text { Group discussion of activities and suggestions for future workshops } \\
\text { Whole group discussion of the workshop } \\
\text { Suggestions for future workshops } \\
\text { Suggestions for activities to help plan PD }\end{array}$ & 20 minutes \\
\hline
\end{tabular}




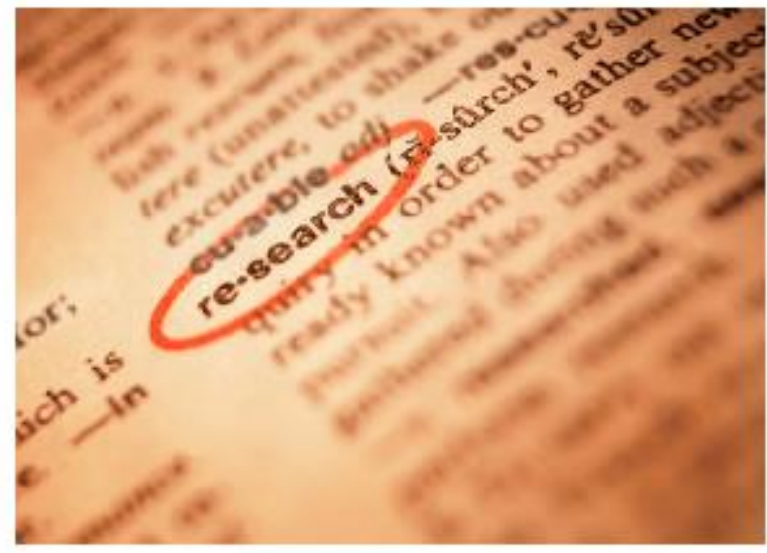

CHAPTER THREE

\author{
"Action research is based on a systematic, reflective, and collaborative \\ process that examines classroom and school issues to plan, implement, \\ and evaluate change." \\ Warren, Doorn \& Green, 2008, p. 261
}

\title{
Action Research
}

Action or classroom research can be a powerful component of professional development (Bondy \& Ross, 1998). Linda Darling-Hammond(1996) reported there was a growing body of research suggesting that one way to improve teaching and learning was to encourage teachers to do research in their own classrooms to promote inquiry, reflection and problem solving. Mertler and Charles (2005, p. 423) propose five reasons why teachers should do action research:

1. Action research deals with your problems, not someone else's. 
2. Action research is very timely, you can begin whenever you are ready and obtain immediate results.

3. Action research provides teachers with opportunities to better understand, and therefore improve, their educational practices.

4. As a process, action research can also promote the building of stronger relationships among colleagues.

5. Action research provides teachers with alternative ways of viewing and approaching educational questions and problems and with new ways of examining their own educational practices.

Action research is an activity that teachers do for themselves and involves a series of steps such as those identified by Mills (2003):

1. Identify an area of focus.

2. Collect data.

3. Analyze and interpret data.

4. Develop an action plan.

All action research has the potential to increase knowledge about teaching and how teachers can change instruction to impact student learning (Hendricks, 2006).

I chose action research as a necessity for teacher professional development in my first year as a principal. Teachers were required to set instructional and professional goal for the year as part of the evaluation process, yet there was no protocol, plan or accountability process for teachers to verify whether or not they had met their goal(s). I met with the teacher instructional coach at the time and she and I developed a process for teachers to connect their goals to action research. The process included implementing a strategy to address a problem, collecting data, 
analyzing the data and coming to a conclusion on the impact of the strategy. This process was directly connected to the instructional goal selected by that teacher. For example: a teacher wanted to improve student performance and success on a writing project. The teacher implemented strategies to teach writing and worked with the instructional coach on the development of a criteria sheet for all writing tasks. She then compared student performance and success (based on grades and completion of the assignments) of the current year to the previous year when she did not implement the writing strategies and criteria sheets. The results clearly indicated that the implemented strategies improved student success and performance. The teacher was able to use the data to address the instructional goal set at the beginning of the year which made the whole goal setting process more meaningful and relevant to teaching practice. I went one step further that first year and required teachers to present their action research results to the rest of the staff. This was an overwhelming success and the information teachers presented improved practice throughout the building.

The next section includes sample action research project presentations, protocols and forms.

Action Research Example 1 


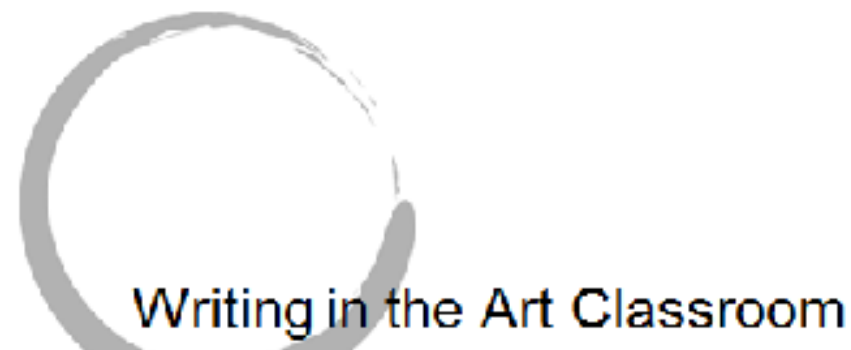

Given the opportunity to write reflective self-critiques will students be successful critiquing a historical artist's work? 

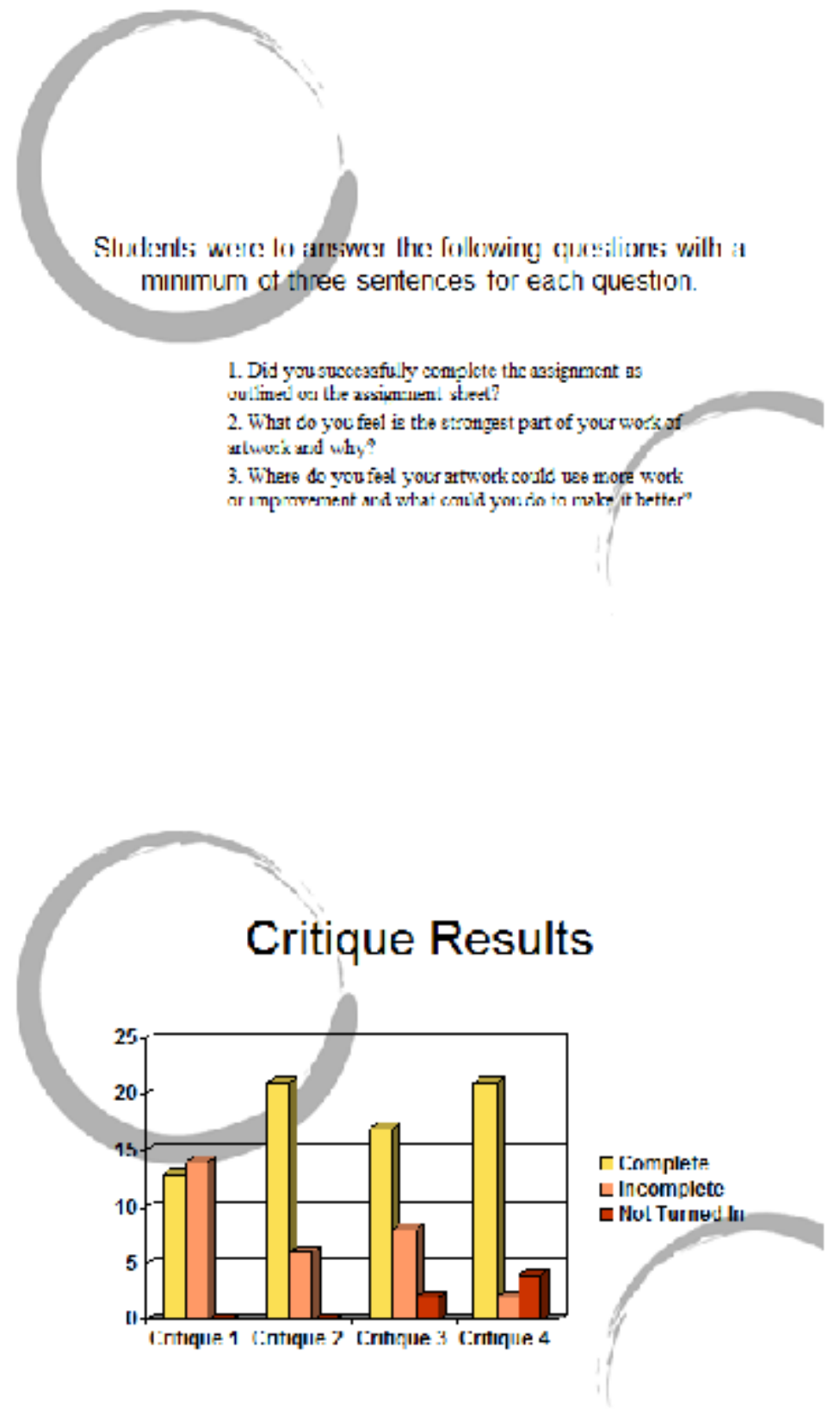


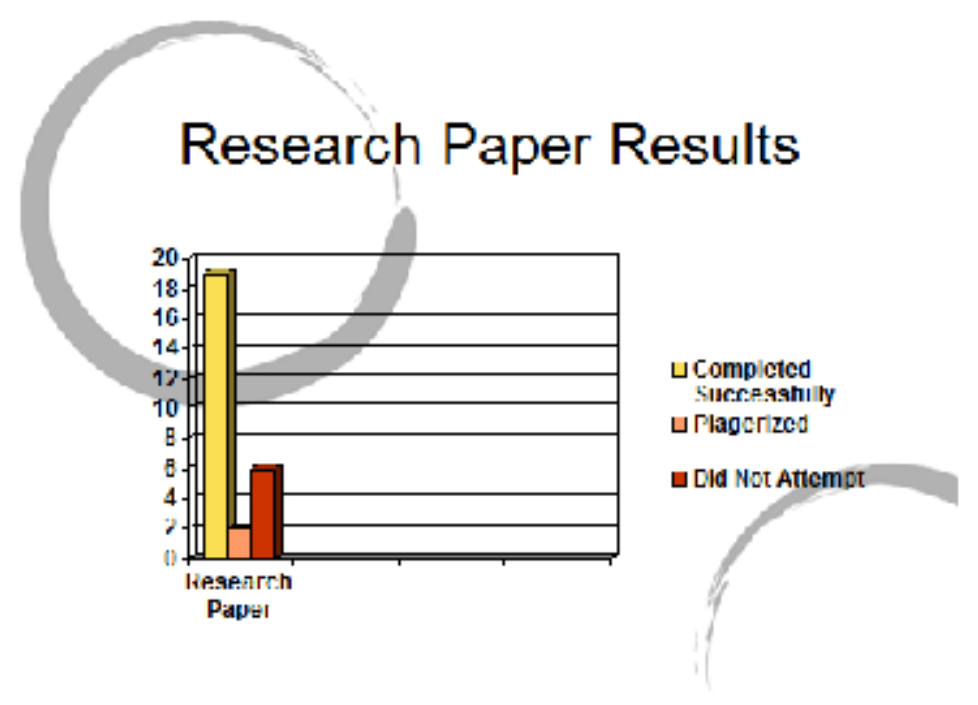

\section{Conclusions}

- 1 Making the writing assignment supplement the art making activity students will find that it is the norm and will complete them successfully.

- 2 I feel that given the data from the selfcritiques, if I were to have given the research assignment without the self-critiques there would have been a lower success rate on the research assignment. 


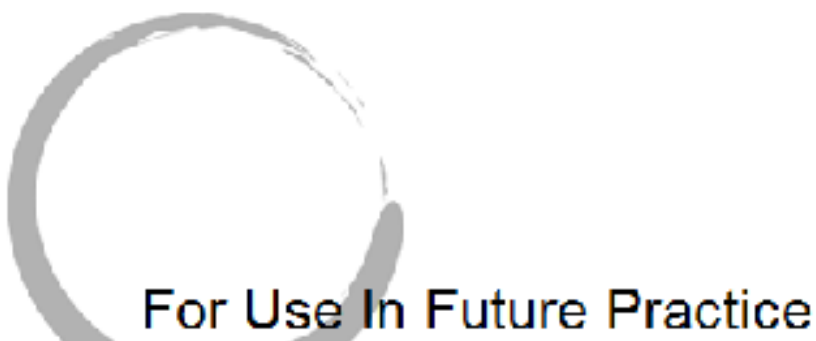

I am wo king wilh a culleague o com up un a

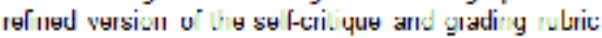

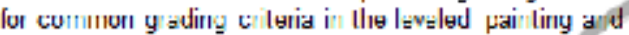

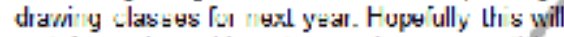
I

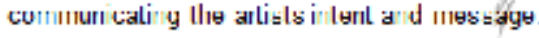


Action Research Example 2

\section{Writing to Learn Science: Work Samples and Inquiry Labs}

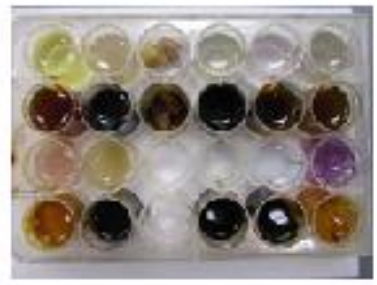

\section{Question}

- Will work sample scores increase with use ol criteria sheets to guide?

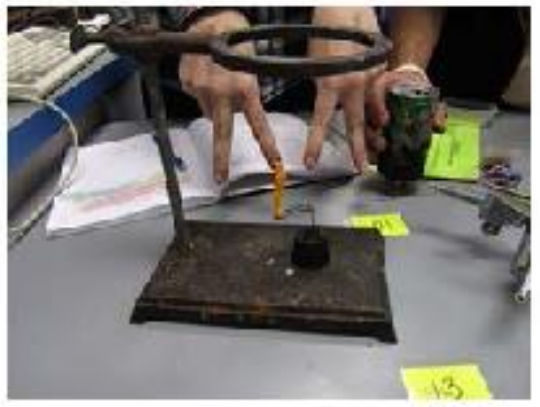




\section{Inquiry}

\begin{tabular}{|c|c|c|c|c|c|c|}
\hline $\begin{array}{l}\text { Inquiry } \\
\text { Contimuman }\end{array}$ & $\begin{array}{l}\text { Studiant } \\
\text { terilies }\end{array}$ & $\begin{array}{l}\text { Proscdure } \\
\text { Giv th }\end{array}$ & $\begin{array}{l}\text { G uided } \\
\text { question } \\
\text { or topic }\end{array}$ & $\begin{array}{l}\text { Sugg csted } \\
\text { MEiturials }\end{array}$ & $\begin{array}{l}\text { Design orn } \\
\text { inv estipation }\end{array}$ & $\begin{array}{l}\text { Generutc } \\
\text { researrb } \\
\text { quection }\end{array}$ \\
\hline $\begin{array}{l}\text { Cunfintualiov. } \\
\text { act nntes }\end{array}$ & $\mathrm{x}$ & $x$ & & & & \\
\hline $\begin{array}{l}\text { Ssuctured- } \\
\text { ixquiry }\end{array}$ & & $\mathrm{x}$ & $\mathrm{x}$ & $\mathrm{x}$ & & \\
\hline $\begin{array}{l}\text { Guided } \\
\text { it:yuiry } \\
\text { getritica }\end{array}$ & & & $x$ & $\mathrm{x}$ & $x$ & \\
\hline Opsn Inçuiry & & & & & $\mathrm{X}$ & $\mathrm{x}$ \\
\hline
\end{tabular}

\section{Inquiry Work Samples}

\section{- Inquiry Lab \#1}

- One guided inquiry lab completed prior to study

- PIce incjuiry anclivilie:

- Collecting mass and unlume data

- Calculating denzlty

- Giaphing; slupe

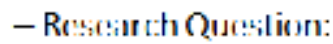

- What year did the composition of pennies change?

- Instructions:

- Common assessmentiol all NHS sludenls 


\section{Method}

- Inquiry Lab \#1

- Sluddenls givers:

- Minimal dir ections as specilied by Oregun work sample admin|stratlon guldclincs

- Sroring rubric for use while writing

- Inquiry Lab \#2 - Inquiry Lab \#1

- Sludderils givers:

- Griteria sheel for intruduction and comblusion

- Discuzslon/demo for procedures

- Student-designed data collection

- Criteria sheet for analysis and conclusion

\section{Results}

$\begin{array}{ccc}\text { Inquiry lab Inquiry lab } & \text { Ginin } \\ \# 1 & \# 4 & \text { Score }\end{array}$

$\begin{array}{llll}\text { Mean } & 2.737 & 1.787 & 2.05\end{array}$

Met

Standard 7

11

Exceceded

Standard

he $-2 \pi$

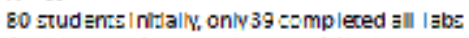

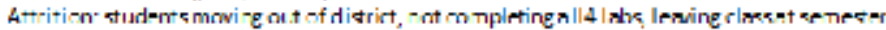




\section{Student Voices}

- $68 \%$ preferred criteria sheets

- $6 \%$ preferred "more simple" instructions

- $26 \%$ had no preference

$N=76$

\section{Student Voices}

"I liked knowing exaclly whidl I was supposed lo do."

"I don'l undersland rubrics so I liked direclions better."

"I like simple b/c I don't have to write so much"

"More thorough directions help me understand better."

"Il's casicr il you jusl explain il." 


\section{Limitations}

- Studenl engagement: Which is more lun?

$-\Gamma$ ind the vear the composition of pennies changed, Ur

- Select and carry out chemical reactions of your own choosing

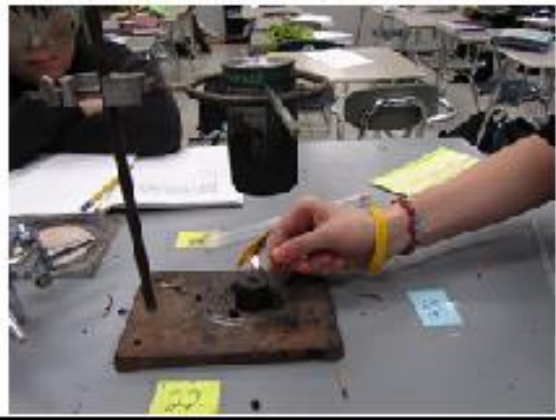

\section{Further Studies}

- Final upen inquiry lab

- Pretest posttest to assess learning 


\section{Action Research Protocols and Forms}

Resource 1 - Professional Development Project Forms (adapted from Monroe Township School District)

Resource 2 - Action Research Project Design and Presentation 
Resource 1 (Adapted from Monroe Township)

\section{HIGH SCHOOL}

\section{PROFESSIONAL DEVELOPMENT PROJECT}

ACTION RESEARCH PROJECT FORM

1. Select Area

\section{Take Action}

2. Collect Data

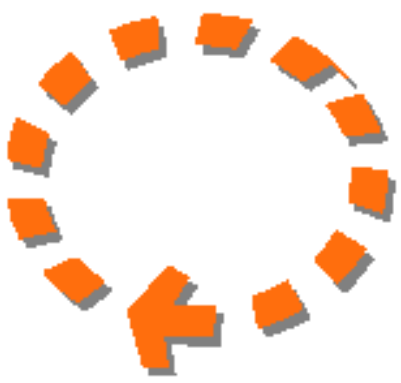

\section{Analyze and Interpret Data}

3. Organize Data

\section{SELECT AREA \& RESEARCH QUESTIONS}

a Instructional

$\square$ Behavioral/Discipline

a Curriculum Implementation

$\square$ Other

Action Research Questions: (What questions are you trying to answer by conducting your classroom research? Avoid YES/NO questions, try How, What, Why) 
A)

B)

C)

2. COLLECT DATA (What type of data will you collect?)

Observations

Survey (needs approval)

Discipline Files

a Other Data

(specify)
Test Scores

Interviews/Focus Group

a Curriculum Documents

3. ORGANIZE DATA (How will you organize the data?)

a Tables

Charts

$\square$ Figures

Darrative

Other (specify)

Parts 1-3 Due at Goals Conference 
Teacher's Signature: Date:

Administrator's Signature

Date:

\section{ACTION RESEARCH TIMELINE}

\section{Date:}

\section{COLLECT and ORGANIZE DATA}

5. Date:

ANALYZE and INTEPRET DATA

What does the data suggest about the issue under study?

\section{Date:}

DEVELOP an ACTION PLAN

Based on your data, what do you propose to do?
a.
b.
c.
d.
e.
f.

Parts 4 - 6 Reviewed by or during November

Progress was reviewed during a project review conference. 
Teacher's Signature:

Date:

Administrator's Signature

Date:

\section{Date:}

PROVIDE RESULTS

Provide a narrative for the results of the action plan. Describe insights, new knowledge, expected and unexpected outcomes.

\section{DISSEMINATION}

How will the results of your Action Research impact your teaching and students?

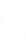

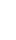


9. REFLECTIONS: What did you learn as a professional educator that will enhance your instruction in the future?

$\bullet \bullet \bullet \bullet \bullet \bullet \bullet \bullet \bullet \bullet \bullet \bullet \bullet \bullet \bullet \bullet \bullet \bullet \bullet \bullet \bullet \bullet \bullet \bullet \bullet \bullet \bullet \bullet \bullet \bullet \bullet \bullet \bullet \bullet \bullet \bullet \bullet \bullet \bullet \bullet \bullet \bullet \bullet \bullet \bullet \bullet \bullet \bullet \bullet \bullet \bullet \bullet \bullet \bullet \bullet \bullet \bullet \bullet \bullet \bullet \bullet \bullet \bullet \bullet \bullet \bullet \bullet \bullet \bullet \bullet \bullet \bullet \bullet \bullet \bullet \bullet \bullet \bullet \bullet \bullet \bullet \bullet \bullet \bullet \bullet \bullet \bullet \bullet \bullet \bullet \bullet \bullet \bullet \bullet \bullet \bullet \bullet \bullet \bullet \bullet \bullet$

Parts 6-9 Formative progress reviewed

Teacher's Signature:

Date:

Administrator's Signature ___ Date:

Final Project Review: Due by Annual End of Year Conference

The proposed project was reviewed during the annual end of year Conference

Action Research Project Abstract Completed:

口 Yes

$\square$ No

Teacher's Signature:

Date:

Administrator's Signature

Date: 


\section{HIGH SCHOOL}

\section{ACTION RESEARCH PROJECT ABSTRACT}

Title:

Name:

School:

Grade Level:

Content Area:

Objective:

Background:

Methods:

Results:

Conclusions:

Contact Information:

Can we post your abstract online to be shared with colleagues?

$\square$ Yes

$\square$ No 
Resource 2

\section{Action Research Project Desion and Presentation}

To help others learn from the research you have conducted, you will share your action research results by preparing some sort of visual (PowerPoint, handout, poster, etc.) and by giving a brief overview of your findings.

You may use the following template to create your project, visual and oral presentation.

\section{IDENTIFY THE QUESTION/PROBLEM}

What is the issue chose to explore? Why is it important--to you, to your program, to your students? What was your prediction?

DATA COLLECTION

Any information that helps you answer your question is data. What did you do?

Qualitative data - surveys, observations, anecdotal information, interviews, journals, notes

Quantitative data - achievement scores, assessments, structured observations, standardized tests

DATA ANALYSIS

What does the data tell you? How is it related to your research question?

CONCLUSION

Did the results match your prediction?

What would you do differently?

What obstacles did you encounter in your research?

What questions do you have? 


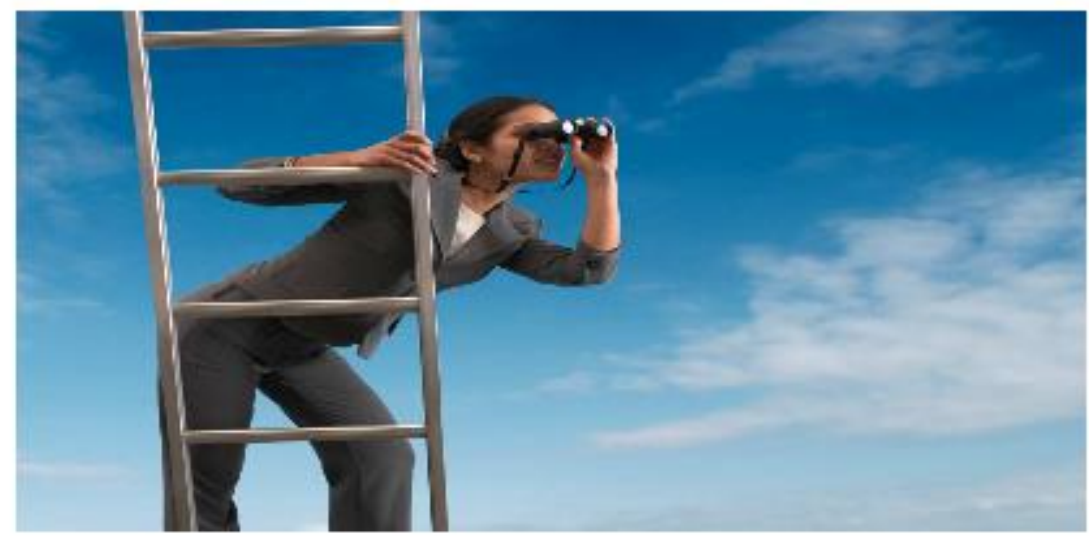

CHAPTER FOUR

"Reform movements in education result in band-wagons and rallying cries, but they also represent a debilitating form of dependency and superficiality."

Michael Fullan(1995, p. 230)

\section{Peer Observation}

Historically the basic structure of schools has been an obstacle for teacher leadership and collaboration. Often schools do not provide opportumities for teachers to engage in professional dialogue and district initiatives often overshadow any changes teachers would like to implement. (Fullan, 1995). Quick fixes never last and teachers resent going to workshops where someone 
tells them what to do but do not offer help or follow-up. There has been an unprecedented interest in instructional improvement since the 2002 No Child Left Behind (NCLB) legislation. With attention now focused on how students and teachers leam, school administrators are discovering that traditional models of teacher professional development do not work. Instead they are looking for strategies that engage teachers in the pursuit of continuous instructional improvement (Knight, 2007). This section focuses on a type of collaborative teacher professional development known as peer observation which emphasizes the expert knowledge of teachers.

The traditional view of peer observation is teachers learning from constructive feedback from teachers who have observed them teaching. There is increasing evidence that learning from watching a colleague teach can even be more beneficial than receiving feedback (Hendry and Oliver, 2012). Other benefits that have been reported by school districts with fully implemented peer observation programs include retention of more beginning teachers and less isolation of teaching practice (Johnson and Fiarman, 2012).

In addition, there is psychological research that supports the improvement of self-efficacy by vicarious experiences. Bandura's social cognitive theory (1989) includes an explanation of how people strengthen their self-efficacy by observing others engaged in successful performance. It is feasible that by observing peers in successful teaching demonstrations, observing teachers could strengthen their own self-efficacy and, over time, become better teachers.

Peer observation has been one of the most successful PD activities that I have tried over the past seven years. Teaches who have participated in this activity have almost always regarded 
it as one of the most beneficial types of PD they have ever experienced. Here are some comments from actual teachers who participated in a peer observation protocol:

"I found the experience to be valuable and relevant to my teaching. Teachers seem to be more in tune with the current needs of teachers."

"I contimue to appreciate the opportunity to observe my colleagues, especially those in a different discipline. It really helps to create a positive, professional community."

"I liked talking and listening to my colleagues. I learned some valuable things from them that I can immediately implement in my classroom."

"I immediately put the ideas I learned today into a lesson."

"This was the most helpful PD I have had in 20 years of teaching."

"I have many new strategies and a new enthusiasm to take back to my students."

I found these types of comments to be consistent in all three high schools I have worked in.

To make the peer observation experience meaningful, there should be guidance from the administrator or facilitator. The steps I suggest using for a peer observation group include:

Provide article(s) on peer observation to define what the process is.

Set norms and choose a protocol/tool for observations.

Teachers observe one another and debrief using a protocol.

Teachers observe other teachers and share experience using a protocol.

I experimented with peer observation in two different schools. In one school, I did not provide much guidance and let teachers decide what tool they would use during observations and how they would debrief. In another school I provided a more structured experience with a facilitator for the pre-observation discussion and for the debriefing activity after the observations. Teachers in the second group were able to identify more specifics during the observation and better able to articulate what was working in the classrooms they observed. They also were able to see immediately what they could transfer to their own teaching practice. While the first group did 
enjoy the activity, they were not as successful in seeing the transfer of what they saw into their own practice. For example, one teacher in the first group commented that students were compliant because they "liked the teacher." In reality, the students were participating at a high level because the teacher had clear expectations and processes that made the classroom nun smoothly.

Preparing teachers for the observations, observing with them, and debriefing afterwards is one of the ways that good leaders can facilitate teacher growth, while focusing on teacher colleagues as the experts. Below is a sample protocol I used for peer observations. In this activity, observing teachers met as a group before the observation to discuss what they were looking for and to review the recording tool. Following the observations, the teachers being observed had lunch with the teachers who observed and received feedback from them on what the liked about the class they saw. Following lunch, the teachers who observed worked on a lesson incorporating strategies or activities based on what they observed. For this group we focused on literacy strategies. 


\section{Guiding Principles}

1. Observing is not evaluating.

2. We will reinforce and encourage strong instructional practices.

3. It will be a time to work on curriculum, lesson plans, and teaching skills.

4. It is a time to observe teachers at work and share observations.

5. It is a time to work together and collaborate.

6. We will work together with respect.

\section{Peer Mentoring Schedule}

\begin{tabular}{|c|c|c|c|c|}
\hline \multicolumn{2}{|c|}{ Period 1 - 8:15-9:45 A.M. } & \multicolumn{3}{|c|}{ Meet in staff room for orientation and to review protocol. } \\
Prep for observations.
\end{tabular}


Below is another example of a recording tool for peer observation. This document could be used as an exit slip for any $\mathrm{PD}$ activity.

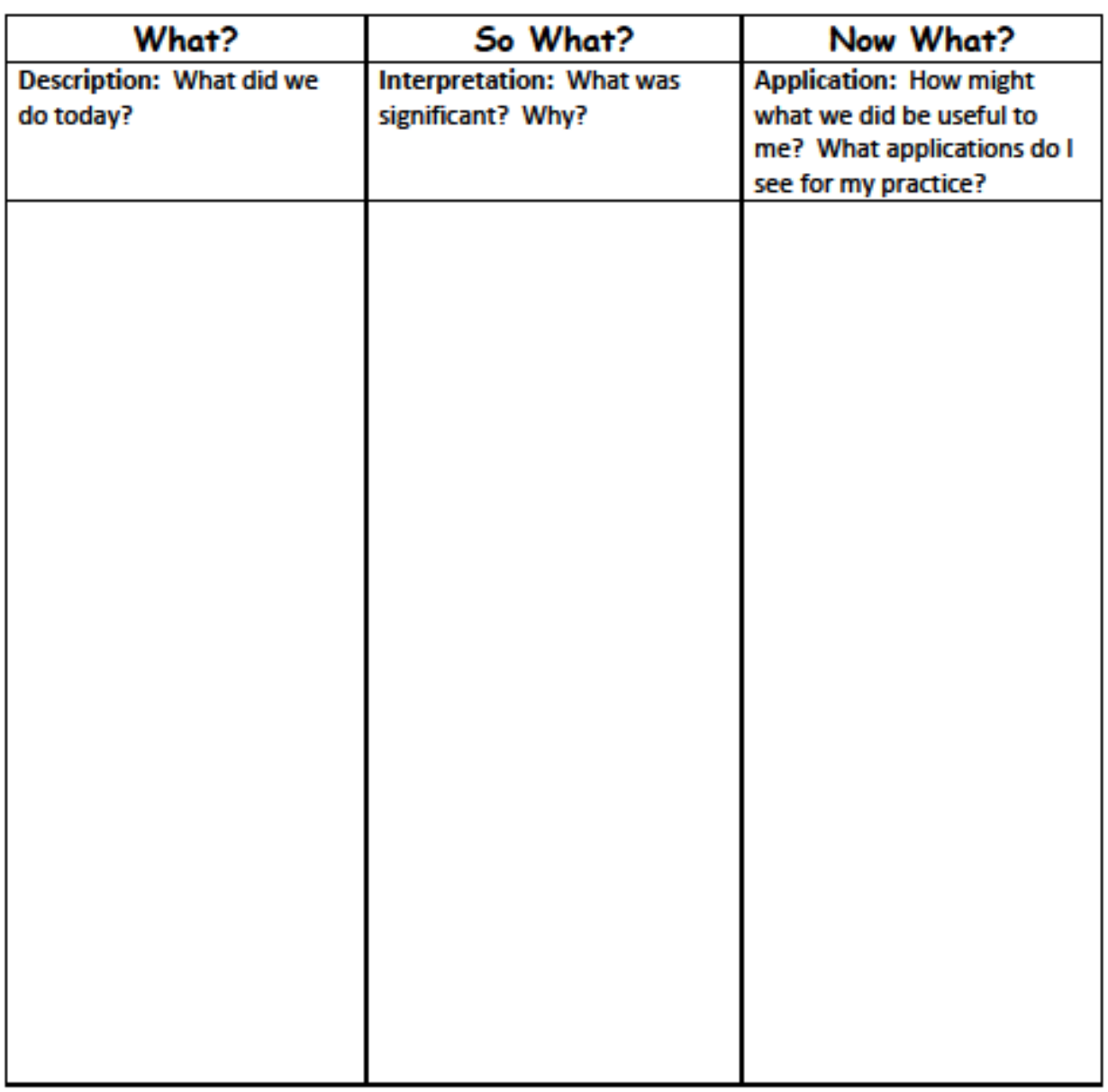

Peer observation can require some funding. In order for teachers to observe other teachers, the school may have to pay for substitutes. Some districts allow teachers to use their 
professional development funds for this type of activity. I usually ask teachers, in the beginning of the year survey, if they are willing to use their professional funds for the Peer Observation activity. In my experience, this has worked well and significantly reduces the cost. 


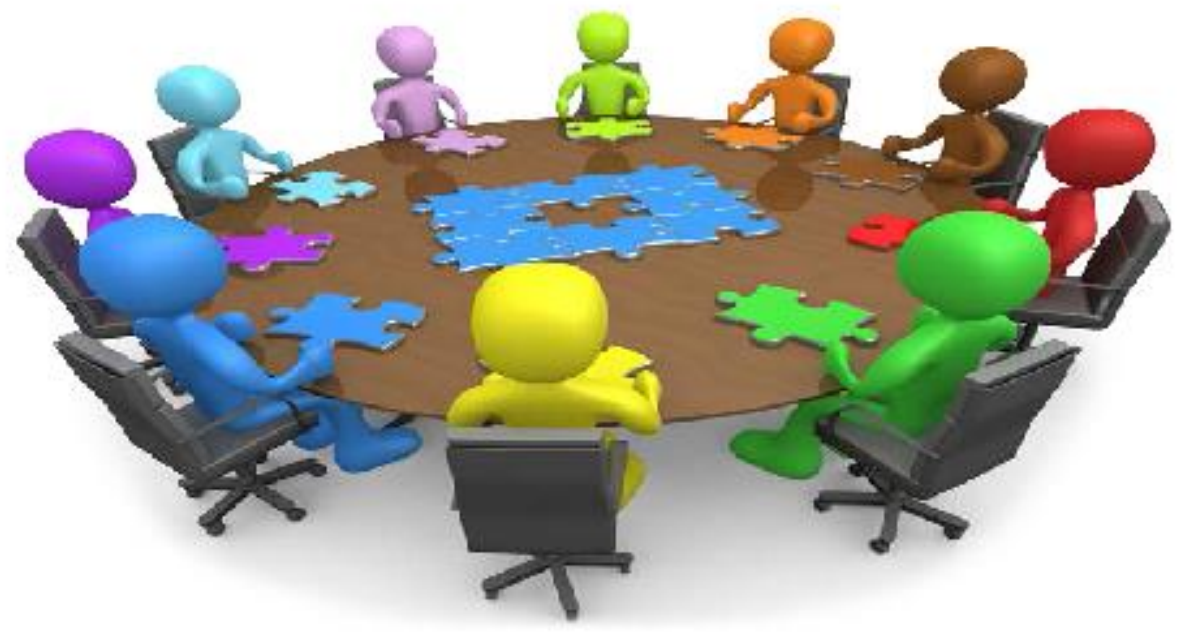

CHAPTER FIVE

\footnotetext{
"...learning always occurs in a context of taking action, and they value engagement and experience as the most effective strategies for deep learning."

Richard Dufour,
}

Professional Learning Communities

The term "professional learning community" was coined by Richard DuFour and Robert Eaker over 15 years ago. In 1998, DuFour and Eaker presented the idea that the most effective strategy for improving teaching and learning was to develop professional learning communities or PLC's (Eaker, DuFour \& DuFour, 2002). Several books and thousands of workshops later, 
they are considered to be two of the country's greatest practitioners. In the education world, a PLC is defined as a group of teachers who meet regularly as a team to identify goals for student learning, develop common formative assessments, analyze current achievement, set goals, share strategies and create lessons. During the regular meetings lessons are adjusted based on results. There is an expectation that this collaboration among teachers will produce ongoing improvement and gains in achievement (Schmoker, 2005).

According to DuFour and Mattos (2013) the PLC model provides the opportunity to focus on the collective analysis of student learning rather than the micromanagement of instruction thus creating a collaborative culture. Educators in schools that have established PLC's are more likely to experience the most useful and relevant professional development (Little, 2006). The table below (adapted from Lieberman and Mace, 2008) identifies community as being one of the most important aspects of learning.

Table 3 - Social Aspects of Learning (Adapted from Lieberman and Mace, 2008). 


\section{Social Aspects of Learning}

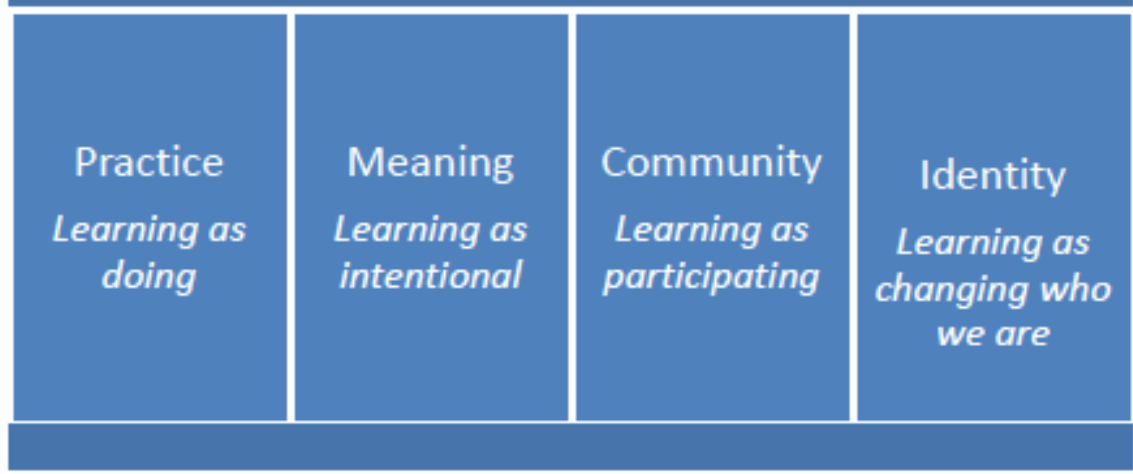

The professional leaming community model includes time for teachers to meet to examine student work and address problems of practice. These kinds of opportunities seem to appeal to teachers and engage them in a more effective way than top-down mandated professional development that gives little control to teachers. Teachers also discount the professional development that is seen as remediation for poor performance rather than a process for school wide improvement (Sawchuk, 2010).

The definition of professional community varies depending on the source, however, there seems to be a connection between high levels of school community and higher student achievement (Youngs, 2001). When staff members work together, teachers experience less isolation. When there are conversations about teaching and learning, participants often demonstrate a higher commitment to the goals, mission and vision of the school. The desired outcome of establishing a community of leamers structure is staff learning in order to increase student learning (Hord and Sommers, 2008). The following graphic demonstrates this relationship and identifies steps in a planning backwards model to reach desired student 
outcomes. In the PLC model, the staff is engaged in professional learning that identifies what they need to do to work more effectively with students. Other important aspects of the PLC process are availability of resources, leadership, policies and a school culture that supports continuous improvement.

Figure 5-Relationship Between Professional Learning and Student Leaming (adapted from Hord and Summers, 2008, p. 18)

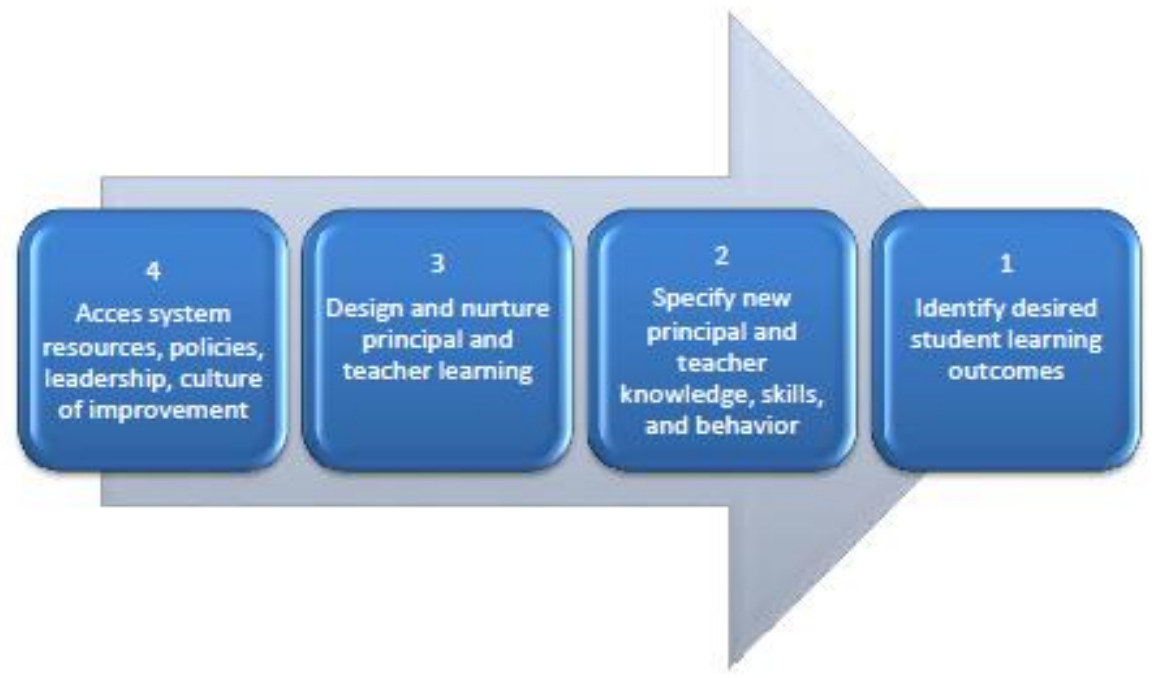

Professional leaming communities provide an opportunity for teachers to learn a new way of interacting with their peers, increasing their level of comfort in talking about their teaching practice and ultimately improving their teaching. Structured collaboration can replace uniformity or cookie-cutter teaching and put teacher knowledge and expertise at the center of curriculum development (Lieberman \& Mace, 2008)

The PLC structure can be the umbrella over all professional development activities. Professional Learning Communities can be structured with teachers in grade level teams, looking 
at data and discussing problems of practice in their common assignments. I have implemented PLC's for seven years using a slightly different approach.

What I have found to be successful is to use the PLC structure and philosophy to create learning groups working on areas of interest, common problems of practice and/or inquiry. For example, the PLC structure can be used for a group of teachers who are doing action research projects that may or may not be similar. The purpose of the PLC is to provide time for teachers to discuss intervention strategies, data collection and analysis. Even though the topic of the research may be different, the process is the same and teachers can learn from one another regarding the action research process. District initiatives can also be addressed in PLC groups. For example, a PLC composed of algebra teachers can work together on incorporating Common Core Standards in their unit and lesson planning or a PLC group composed of teachers from multiple content areas can discuss and implement proficiency grading practices. Another example is using the PLC structure for a group of teachers participating in peer observation. This PLC works together to review articles, define protocols and to set up observation opportunities. They participate in observations together and discuss what they leamed.

Regardless of the PLC structure, I have found some definite ways to maximize the experience for teachers.

- PLC groups should include between 4 and 10 participants.

- Meetings should be at least twice monthly

- Each meeting should be between 60 and 90 minutes in length

- Meetings should not be cancelled unless absolutely necessary 
- Include a mid-year and end-of-year sharing of practice and celebration (PLC

groups present their work to the whole staff)

Below is a list of PLC groups that teachers in a large urban high school created.

\section{$\underline{\text { PLC's }}$}

Care Team-related to district equity work

Peer Observation

Equity Team

Action Research

Technology Tools in Instruction

CTE/Content Integration

Freshmen Academy

Proficiency Grading

Differentiation in Instruction

Culturally Responsive Instructional Strategies

The PLC groups listed above were created in a PD session in which staff brainstormed on topics that they would like to investigate with their peers. At the end of the year, each group did a presentation for the entire staff on what they learned and next steps for their PLC. Most of the PLC's continued their work the following year. Below is a sample of teacher comments following two of the PLC presentations. 


\section{Comments after PLC Presentations}

1. Action research - Integrating math and science

- Really interesting way for students to see pattern

- Great work demonstrating how concepts are connected. Excellent way to maximize engagement and make the content relevant.

- Love the methodology of using the stacking overheads. Instant gratification

- You demonstrated for your peers how "do-able" this way.

- Loved the idea of integrating the subject areas

- Very helpful in giving an example of a project. Look forward to seeing if this improves student's scores.

- Showed how we can help other disciplines achieve a goal with innovative lessons.

- Nice combo of using cross curricular to enhance learning. Not an "add-on."

- Visuals really help with big picture.

- Really appreciate the math connection

- Great integration of two disciplines

- Nice work. Wish we had more opportunities for multiple disciplines merging.

- Good integration.

- Nicely organized activity.

- Finding common areas to co-teach, collaborate.

- Great cross-curricular tie in! Good outline of process.

2. Technology in the Classroom

- I didn't know you could scan and e-mail a pdf form that can be written on. Very helpful.

- Cool stuff. I need to take your classes.

- Prezi looks super useful. I will use this.

- Amazing what can be done on the computer. Great presentation. I would love to learn more.

- Edmodo website was interesting. I think this will be useful to manage make up work.

- Love the Edmodo technology. I was thinking maybe we could use it as a staff instead of as a class-for example unit plans, etc.

- The fillable forms is very cool. Where can I access the "how to video?"

- I like the idea of creating pdf files from one hard copy.

- Nice application! Nice presentation!

- Would love something like this for planner. Love the Prezi presentation!

- I liked learning about the technology. 
- I liked your use of technology and the talk about technology. I plan to use Edmodo to communicate with parents and students in the future.

- Edmodo idea and quick show seems really cool-modem with some great use.

- I like acknowledging that technology/apps, etc. are actually a good idea in the classroom.

- Good detailed communication to students and keeps things organized.

One of the most important things I learned during the PLC presentations was that teachers were more engaged in the professional development if they felt that change was happening because of them, rather than happening to them. The professional development activities became an opportunity for teachers to be active participants in developing school-wide instructional frameworks as well as an avenue for removing the isolation of traditional teaching practice. The PLC groups exhibited a high level of satisfaction with themselves and their projects when they presented their findings at the end of the year. They believed their projects yielded personal and professional benefits. I observed an increase in teacher's self-efficacy and self-esteem after the first year of required PLC's. In addition, the culture of the staff shifted from individualistic and self-centered to a shared, collaborative, goal-oriented leaming community.

Following are two examples of forms that can be used for PLC meeting notes. 
Date

GROUP NAME/PLC

MEMBERS PRESENT:

MEMBERS ABSENT:

Before starting on the ground rules make sure you pick someone in the group to fill the following roles:

Facilitator:

Recorder:

Time Keeper:

GROUND RULES FOR THE GROUP:

BRAINSTORMING QUESTIONS: (Facilitator: make sure you hear from everyone)

WHAT ARE SOME IDEAS THAT YOU WOULD LIKE TO PURSUE AND WORK ON AS A GROUP THIS YEAR? 
WHAT ARE SOME WAYS IN WHICH YOU CAN SUPPORT CCSS? IF YOU DON'T KNOW, WHAT SUPPORT DO YOU NEED TO KNOW MORE ABOUT THIS?

WHAT EXTRA SUPPORTS WOULD YOU LIKE THIS YEAR TO MAKE SURE THAT YOUR GROUP GETS THE MOST OUT OF THE EXPERIENCE? (Examples may include:

presentation from district TOSA on topic, articles for topic to get us started)

**** When you are finished turn into an administrator. Only ONE needed per group. 
Resource Sheet for PLC Meeting Notes

Meeting Date:

PLC Name:

\begin{tabular}{|l|l|}
\hline Facilitator: & \\
\hline Record keeper: & \\
\hline Time keeper: & \\
\hline Members present: & \\
\hline Members absent: & \\
\hline $\begin{array}{l}\text { Summary of } \\
\text { accomplishments: }\end{array}$ & \\
& \\
\hline Rext steps for group: & \\
\hline
\end{tabular}




\section{Summary}

The National Staff Development Council (NSDC) recommends a professional development system so that "every educator engages in effective professional learning every day so every student achieves" (2009). This premise includes regular opportunities for teachers to collaborate, regular and continuous feedback and time for teachers to share teaching strategies. This type of professional development translates into improved teaching and ultimately improved student achievement. To be successful, schools and districts should implement professional development that is sustainable and ongoing. Linda Darling Hammond et al (2009), also supports the idea of professional leaming focused on student achievement and opportunities for teachers to collaborate regarding curriculum planning and teaching practices. There is much that can be learned and applied when teachers collaborate in a teachers teaching teachers model. Administrators and school leaders (including teacher leaders) can provide the frameworks, tools, time and support for teachers to acquire a sense of professionalism, responsibility, efficacy and motivation to constantly reflect on teaching practice and their impact on student learning.

I have observed teachers become energized and excited about the shift in pedagogy when given the opportunity to conduct research in their classrooms, collaborate with colleagues, observe other teachers and reflect on how they might use this information to grow as professionals. Michael Fullan, (2007, p. 35) reported that professional development programs are rarely "powerful enough, specific enough, or sustained enough to alter the culture of the classroom and school." Regardless of years of experience, teacher-directed professional development that is ongoing and more personalized appears to have the most impact on classroom instruction. It is classroom instruction that has the most impact on student leaming Lotter, Hardwood and Bonner (2006) claim that the shift from shorter more formulaic 
professional development to long-term, reflective professional development can be complex and time-consuming. Admittedly, it is true that simply writing a check for an "expert" to present a workshop is easier and less time consuming that planning ongoing, collaborative opportunities for teachers. However, the benefits that can be derived from teachers working together to improve their instructional practice, at a much reduced financial burden on school districts, surely challenges administrators to devote the time and energy it will take to sustain high quality professional development that impacts classroom instruction.

The final tool in the handbook is an opportunity for teachers to evaluate their own professional growth and accomplishments following the implementation of a PD plan. This is modeled after the "Criteria Sheet" strategy introduced by Linda Christensen in her book, Teaching for Joy and Justice. Ideally this would be given to teachers at the beginning of the year as you would give a criteria sheet to students at the beginning of the unit so they know what they are expected to do and leam. 


\section{Teacher Professional Development 2012-13}

\section{Criteria Sheet for Instruction}

During the past few years our professional development has included working on reading and writing across the curriculum, SIOP strategies, unit/lesson plans, the implementation of the Common Core State Standards, instructional strategies that meet the needs of our diverse student body and practices that include high expectations for each student.

As we continue to focus on instruction in our professional development, it is important to assess where we are. This activity is designed for you to self-assess and highlight which areas you feel most proficient and which areas you need to work on. Please complete the criteria sheet and submit documents by the last day of school. We will use the information to help plan next year's instructional professional development.

Name

1. Unit plans

- Submit one for each unit of each subject currently teaching

- Common Core State Standards are present available here: $\mathrm{http} / / \mathrm{www}$.ode. .state.or.us/search/page/?id=2860

- Differentiation strategies are present

- Formative and summative assessments are identified

- Learning targets for the unit are identified

- Curriculum includes culturally relevant materials and information

*Teachers can choose to do daily lesson plans instead of unit plans.

2. Eight (8) writing tasks

- 2 per quarter per subject taught

- Submit a "criteria sheet" for each task with clear expectations for students

*This is NOT journaling, a learning log entry, an exit slip, a list, or a warm up...

3. Posted daily objective/leaming target for each subject taught

4. 1 reading work sample per semester (two total)

- Submit two formatted reading work samples

- Article should be of appropriate Lexile level (reading level)

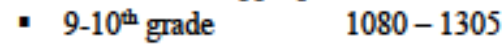

- $11^{\text {th }}-12^{\text {th }}$ grade $1215-1355$

Work sessions: March 21-Late start(one hour), April 23-ACT (one hour), April 24-Late start (one hour), May 16-Late start(one hour). 


\section{References}

Ainsworth, L. (2010). Rigorous curriculum design: How to create curricular units of study that align standards, instruction, and assessment. Colorado: The Leadership and Learning Center.

Bandura, A. (1989). Human agency in social cognitive theory. American Psychologist, Sept., Vol. 44(9), 1175-1184.

Bondy, E. \& Ross, D. (1998). Teaching teams: Creating the context for faculty action research. Innovative Higher Education, 22(3), 231-250.

Darling-Hammond, L. (1996). The right to learn and the advancement of teaching: Research, policy, and practice for democratic education. Educational Researcher, 25(6), 5-17.

Darling-Hammond. L. (2009). Teacher learning. What matters in teacher professional development. Education Leadership, 66(5), 46-53.

Dufour, R. \& Mattos, M. (2013). How do principals really improve schools. Educational Leadership, 70(7), 34-40.

Eaker, R., DuFour, R. \& DuFour, R. (2002). Getting started: Reculturing schools to become professional learning communities as work. Bloomington, IN: Solution Tree.

Fullan, M. (2007). Change the terms for teacher leaming. Journal of Staff Development 28(3): $35-36$.

Fullan, M. (1995). The school as a leaming organization: Distant dreams. Theory into Practice, 34(4), 230-235.

Gordon, S. (2008). Dialogic reflective inquiry. Integrative function of instructional supervision. Catalyst for Change, 35(2), 4-11. 
Hanson, S. (2010). What mentors learn about teaching. Educational Leadership, 67(8), 76-80.

Hardy, L. (2003). No child left behind? Show me the money! American School Board Journal, 190, 29-32.

Hendricks, C. (2006). Improving Schools Through Action Research: A comprehensive guide for educators. New Jersey: Pearson.

Hord, S.M. \& Sommers, W.A. (2008). Leading professional learning communities: Voices from research and practice. Califomia: Corwin Press.

Johnson, S. M. \& Fiarman, S.E. (2012). The potential of peer review. Educational Leadership, 70(3), 20-25.

Knight, J. (2007). Instructional Coaching: A Partmership Approach to Improving Instruction. California: Corwin Press.

Kozulin, A. \& Gindis, B. (2003). Vgotsky's educational theory in cultural context. UK: Cambridge University Press.

Lambert, L. (2000). Building leadership capacity in schools. APC Monographs. Retrieved from: http://research.acer.edu.au/apc monographs/2

Lambert, L. (2003). Leadership redefined: An evocative context for teacher leadership. School Leadership \& Management, 23(4), 421-430.

Lambert, L., Walker, D., Zimmerman, D. P., Cooper, J. E., Lambert, M. D., Gardner, M. E. \& Szabo. (2002). The constructivist leader, $2^{\text {nd }}$ edition. New York, NY: Teachers College Press.

Lieberman, A. \& Mace, D. H. (2008). Teacher learning: the key to educational reform. Journal of Teacher Education, 59(3), 226-234.

Lieberman, A. \& Wood, D. (2001). The work of the National Writing Project: Social 
practices in a network context. Palo Alto, CA: Camegie Foundation.

Lotter, C., Harwood, W.S., \& Bonner, J. José. (2006). Overcoming a learning

bottleneck: Inquiry professional development for secondary science teachers. Journal of Science Teacher Education, 17, 185-216.

Mertler, C. (2006). Action research: Teachers as researchers in the classroom. California: Sage Publications.

Mills, G.E. (2003). Action research: A guide for the teacher researcher. New Jersey: Pearson. Monroe County Township. (2014) Retrieved from:

htto://www.monroek12 ni.us/cms/lib07/NJ01000268/Centricity/Domain/1/professionaldevelopment/pdf/Action Research Example for In-service.pdf

National Staff Development Council. 2009. NSDC's definition of professional development. Retrieved from: www.nsdc.org/standfor/definition.cfm.

Sawchuk, S. (2010). Cost of teacher training lost in district budgets. Education week, 30(11), 14-16.

Schmoker, M. (2005). Here and now: Improving teaching and leaming. In R. Eaker, R. Dufour \& R. Dufour (Eds.), On Common Ground: The Power of Professional Learning Communities (pp. xi). Indiana: Solution Tree.

Schmoker, M. (2005). No turning back: The ironclad case for professional learning communities. In R. Eaker, R. Dufour \& R. Dufour (Eds.), On Common Ground: The power of professional learning Communities (pp. 135-154). Indiana: Solution Tree.

Warren, S., Doom, D. \& Green, J. (2008). Changes in vision: Teachers engaging in action research. The Educational Forum, 72(3), 260-270. 
Youngs, P. (2001). District and state policy influences on professional development and school capacity. Educational Policy, 15(2), 278-301. 
Appendix A

Sample PD Plans 
Sample PD Plan 1

Sample Professional Development Plan 


\section{MT. HOOD H. S.}

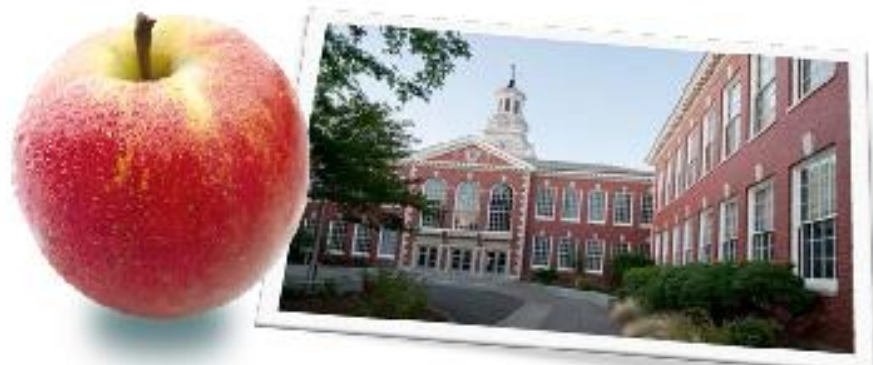

Continued focus on Equity in our practices

DESCRIPTION: (from Racial Equity Policy) will significantly change its practices in order to achieve and maintain racial equity in education. Educational equity means raising the achievement of all students while (1) narrowing the gaps between the lowest and highest performing

students and (2) eliminating the racial predictability and disproportionality of which student groups occupy the highest and lowest achievement categories.

\section{Equity (con't)} LOOKS LIKE:

- Continued work on understanding root issues around race, racism, and white privilege

- Develop and use common language specifically utilizing the

six conditions and four agreements

- Incorporate knowledge into polices, practices and discussions

- Use data to target areas of support and interruption

- Focus on priority students and subgroups 


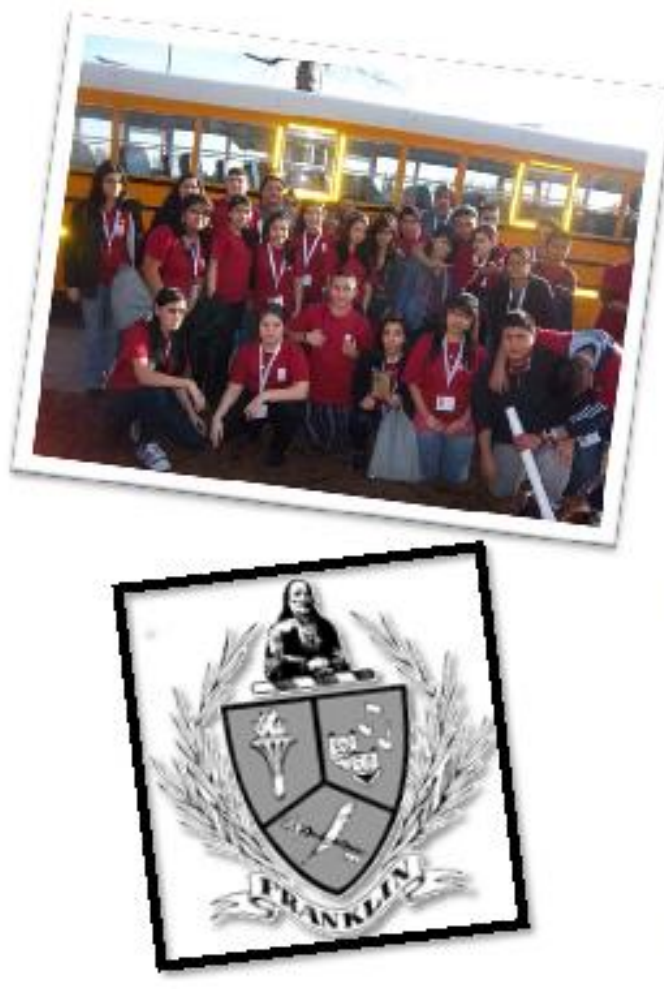

\section{Professional Learning}

The purpose of a PLC is to improve teacher practice and student learning through formal, ongoing interactions of small groups of staff that share aspects or their practice to receive feedback and support. Teachers can be a part of one (yearlong) or two PLC groups.

\section{College Readiness (YR)}

DESCRIPTION: Action research team that explores what it means and takes for each student to be college ready.

LOOKS LIKE: research strategies, individual student plans, survey voices that we may be missing. (All through a lens of equity)

\section{Proficiency Grading (YR)}

DESCRIPTION: The general goal of proficiency-based learning is to ensure that students acquire the knowledge and skills that are deemed to be essential to success in school, higher education, careers, and adult life. If students fail to meet

Implementing CCSS - English (YR)

\section{Implementing CCSS - Math (YR)} DESCRIPTION: Oregon is one of 45 states that have adopted the Common Core State Standards in order to provide a common core approach to integrated learning to prepare students for college and career success. The standards define the knowledge and skills students should have, emphasize learning goals, describe end of year expectations and focus on results, leaving room for teachers to determine how their learning goals should be achieved.

LOOKS LIKE: For the 2013-2014 school year, it is expected that these standards will be reflected in all unit and lesson plans in kids friendly language that's connected with outcome and aligned with assessments. There will be work in departments and professional development to support integration of CCSS into every classroom and subject area. minimum expected standards, they typically receive additional instruction, practice time, and academic support to help them achieve proficiency, but they do not progress in their education until expected standards are met. LOOKS LKKE: investigate and apply proficiency grading in your classroom. Strategize

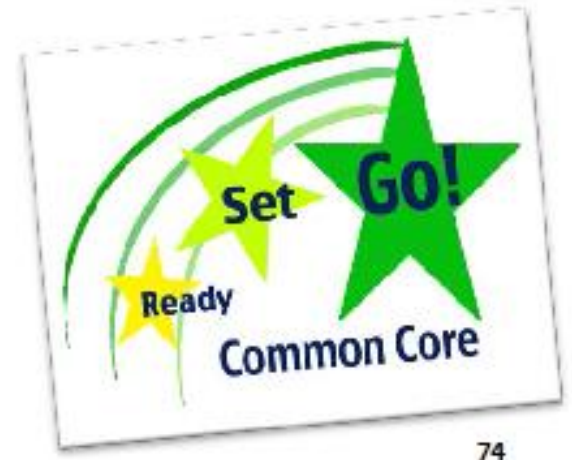



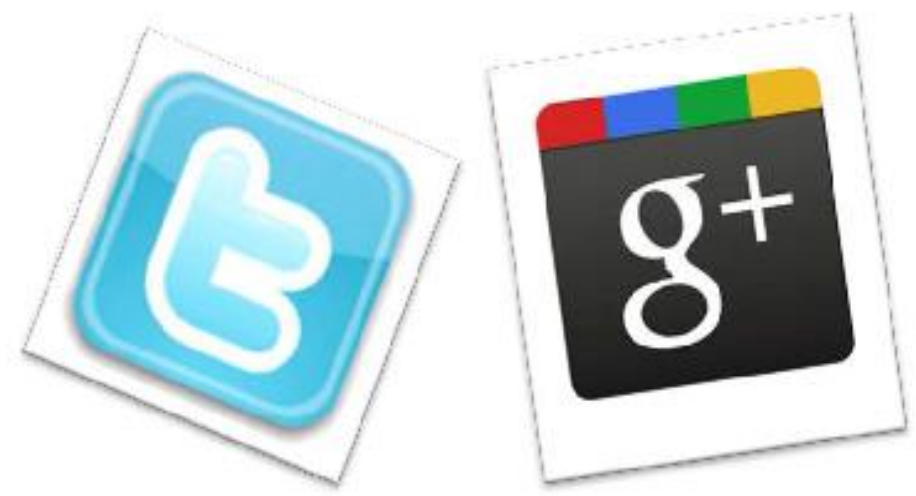

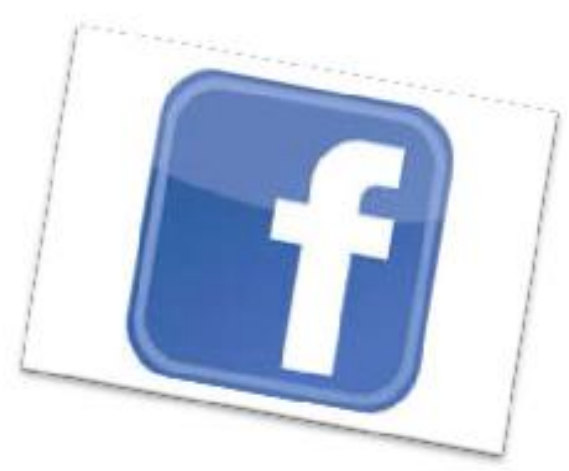

Implementing social media for communication

\section{Counseling and College DESCRIPTION: Our counseling office and Career} Coordinator often need ways in which we disseminate information quickly. In the age of social media, we would like to embrace these communication avenues.

LOOKS UIKE: What are other schools doing to embrace social media? What kind of communication and messages is done through this? How is it managed at different sites?

\section{Action Research (YR)}

DESCRIPTION: WIKI defines: Action research is a reflective process of progressive problem solving led by individuals working with others in teams or as part of a "community of practice" to improve the way they address issues and solve problems. ... http://en.wikipedia.org/wiki/Action research

LOOKS UKE: Each person designs, implements, and shares classroom based research to improve their practice.

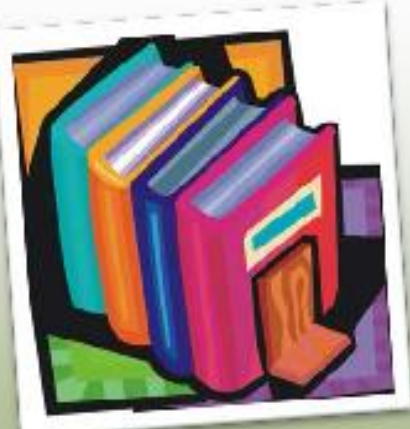

DESCRIPTION: Teachers can close the gap!!!

This book is geared towands first and second year teachers however anyone that wishes to reflect on their teaching is welcome. The focus of the book is on a vision of excellent teaching that correlates with dramatic student achievement in communities where the gap is most severe.

$$
\begin{aligned}
& \text { LOOKS LIKE: Six chanters } \\
& \text { answer the question "what } \\
& \text { distinguishes highiy effective }
\end{aligned}
$$


More PLC choices

other's classrooms to provide support and feedback.

LOOKS LIKE: group members will organize, reflect and

communicate powerful observed practices.

\section{CARE team (B)}

DESCRIPTION: More and more, essential skills become important as it holds the key to graduation. Our job is to make sure that we are providing work samples both for grading and for practice.

LOOKS UKE: PLC will work to create work samples that are embedded into the curriculum offered.

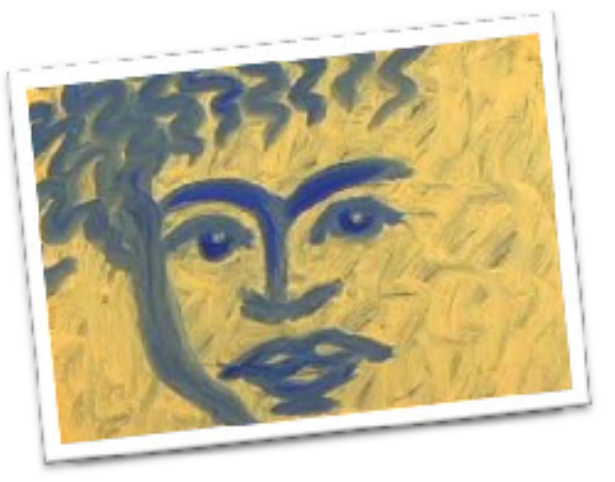

DESCRIPTION: CARE - Collaborative Action Research for Equity. No need for description here. CARE team members and staff that wish to join the CARE team - LOOKS LIKE: This will be your time to discuss your focus students, to discuss the peer observations and to plan future equity PD for all staff. DESCRIPTION: What is cultural relevance and how do l exhibit this in my class?

LOOKS LIKE: Research to create lesson plans that are culturally relevant. Reflect on current practice to see how current lessons could be culturally relevant - if they are not.

Integrating Tech: Teacher/student use

ARE YOU STILL NOT FINDING SOMETHING THAT FITS YOUR NEEDS AND/OR INTEREST? FEEL FREE TO ADD A FOCUS TO THE UST OF PLC'S AND WE CAN SEE IF WE CAN MAKE IT WORK!

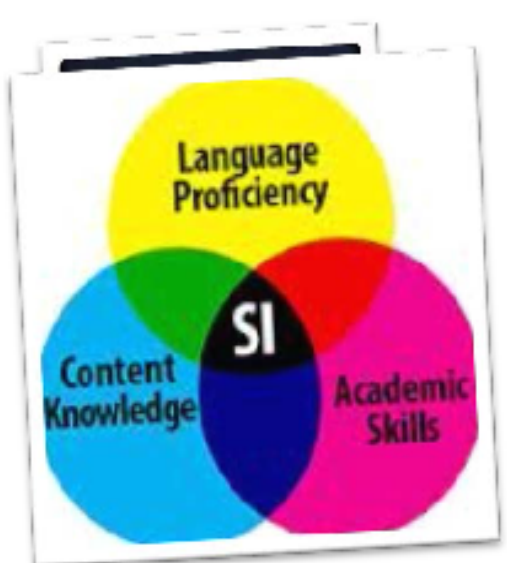

Freshmen Academies (A)

DESCRIPTION: Academy teachers wishing to explore all facets of academies.

LOOKS LIKE: Work on Freshman First Grant, common grading practices, common lessons, and practices that work with our Freshmen community. 


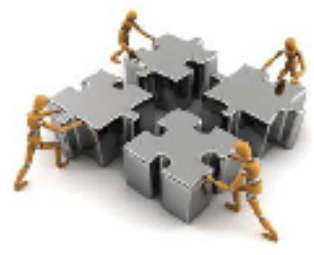

SAMPLE PROFESSIONAL

DEVELOPMENT PLAN 2

$\begin{array}{ll} & \text { PD Schedule } \\ \text { Mondays: } & 3: 30-5: 00 \\ \text { Third Wednesday(late start): } & 8: 15-10: 00 \\ \text { Third Thursday(late start): } & 8: 15-9: 00\end{array}$

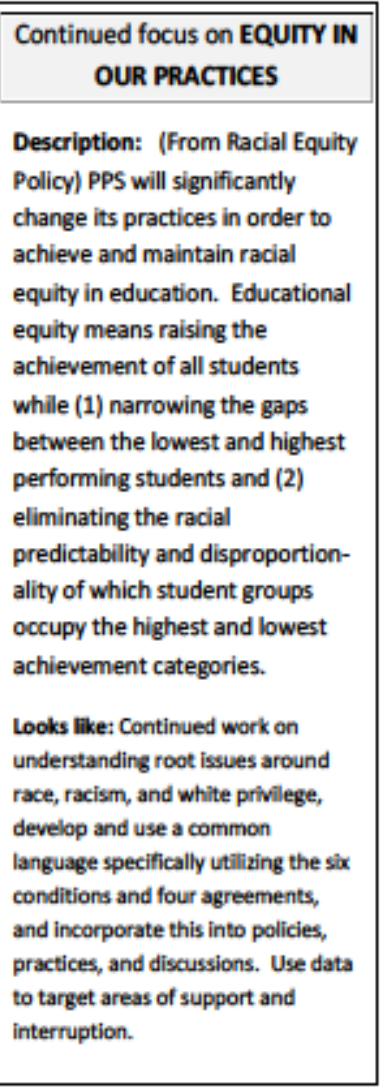

\section{Incorporating COMMON CORE \\ STANDARDS into our curriculum}

Description: Oregon is one of 45 states that have adopted the Common Core State Standards (CCSS) in order to provide a common approach to integrated learning to prepare students for college and career success. The standards define the knowledge and skills students should have, emphasize learning goals, describe end-of-year expectations, and focus on results, leaving room for teachers to determine how these learning goals should be achieved. This includes all of the essential skills work we've been doing in past years.

Looks like: For the 2012-13 school year, it is expected that these standards will be reflected in all unit and lesson plans in kid friendly language that's connected with outcomes and aligned with assessments. There will be work in departments and professional development to support integration of coss into every classroom and subject area.

\section{June 20-22 CURRICULUM CAMPIIIIIII}

Centered on what teachers identhed as necessary sapport to incorporate essential skils the reading and witing into your contest area. LOOKS UKE: Brief interactive workshop in momings followed by collaborathe work time on units and lessons that hoopporate workshop strategies. Work on lesson and enit plans, leam new strategles, embed work samples in your content arka. Share with other teachers, leave with classoom-ready products.

\section{Professional Learning} Communities (PLCs)

Description: The purpose of a PLC is to improve teacher practice and student learning through formal, ongoing interactions of small groups of staff that share aspects of their practice to receive feedback and support. Next year, everyone will work in PLCs, but we will expand the potential options for group foci.

Looks like: Some options include: CEG- similar to your group this year, taking turns sharing work to receive feedback.

Specific focus CFG-agree on a focus like writing, equity issues at Benson, proficiency based grading, freshman academy, and all work revolves around that topic.

Action Research-- each person designs, implements, and shares classroom-based research to improve their practice.

Peer Obsenvations-group members take turns visiting each other's classrooms to provide support and feedback. 
Sample PD Plan 3

\section{4-15 PLC Structure}

PLC teams will meet once a month on a Wednesday morning. Each teacher can choose his or her PLC method and topics for study. The objective is learning more about how to help students learn more and be successful. Here are sample methods:

- Action Research: You create a proposal to learn more about a pressing topic through study, surveys, collection and analysis of data.

- Equity CARE Team Work: With the assistance of PPS Equity Office staff, use CARE Team protocols to gather data on specific students and reflect on how school culture may or may not serve them best.

- Peer Observation: Commit to observing peers at our school or other schools each month and reflecting on and sharing your observations.

- Critical Friends Group-like-Ieam: Use CFG protocols with team members to examine student assessments, work through "sticky issues," and learn or refine instructional techniques.

\section{Surgested topics include:}

- Social-Emotional Curriculum (Discovery, etc.)

- Engaging Diverse Parents as Partners in Students' Success

- CTE-visiting peers' classrooms, sharing practice, integration with other content areas

- Common Core-aligning standards to courses, developing expertise with instructional shifts

- Integration of Technology

- Improving Math scores

- Elimination of our racial gap in test scores, attendance, dual credit, graduation rate

- Hands-on, Active Teaching in longer periods

- Inclusion techniques for students with disabilities

- Improving our Graduation or Completion Rate

- Proficiency Grading

\section{Accountability:}

1. Each staff needs to complete their PD plan for the year by September 15, 2014.

2. You will have a short update to complete each month and turn in to the principal.

3. Each staff member will participate in a sharing of their learning at the end of the year. 
Appendix B

Teacher Professional Development Survey 
Sample Survey (adapted from survey used in Portland Public Schools, 2008)

\section{High School Professional Development Survey}

Please take 10 minutes to complete the survey questions below. Your responses will be used to plan future professional development.

School:

Number of years teaching:

Content Area:

1. For any professional development you have taken in your teaching career, please

- Circle district or the sehool to show who presented the training.

- Check the bor if you took the professional development in the past two year:

- Use the scale below to mark the impact of the program in your classroom.

$1=$ No impact on student learning

2 = A little impact on student leaming

3 = some impact on student learning

4 = Considerable impact on student learning

5 = Large impact on student learning

\begin{tabular}{|c|c|c|c|c|c|c|c|}
\hline Professional Development & Circle Sponsor & $\begin{array}{c}\text { Check if taken in } \\
\text { last } 2 \text { years }\end{array}$ & \multicolumn{4}{|c|}{ Impact } & 5 \\
\hline \multicolumn{8}{|l|}{ Summer Workshops } \\
\hline Four-week Portland Writing Project & District School & $\square$ & & & & & \\
\hline 3 or 4 Day Curricuhum Camp & District School & $\square$ & & & & & \\
\hline Other & District School & $\square$ & & & & & \\
\hline \multicolumn{8}{|c|}{ Collaboration: Modeling/coaching practices } \\
\hline $\begin{array}{l}\text { Long range planning (exit criterix, } \\
\text { curriculum mapping) }\end{array}$ & District School & $\square$ & & & & & \\
\hline $\begin{array}{l}\text { Modeling literacy lessons in your chassroom } \\
\text { (Tosa, Instructional Specialist, Collengue) }\end{array}$ & District School & $\square$ & & & & & \\
\hline Unit planning & District School & $\square$ & & & & & \\
\hline Department planning & District School & $\square$ & & & & & \\
\hline Small School planning & District School & $\square$ & & & & & \\
\hline $\begin{array}{l}\text { Curriculum Guides (Where the Heart Is, } \\
\text { Slan, Fout Food Notion, ek) }\end{array}$ & District School & $\square$ & & & & & \\
\hline Peer Observations (in district) & & $\square$ & & & & & \\
\hline Peer Observations (out of distriet) & & $\square$ & & & & & \\
\hline Other & District School & $\square$ & & & & & \\
\hline
\end{tabular}

\begin{tabular}{|l|c|c|c|c|c|c|}
\hline \multicolumn{1}{|c|}{ Professional Development } & $\begin{array}{c}\text { Circle } \\
\text { Presenter }\end{array}$ & $\begin{array}{c}\text { Check if taken in } \\
\text { last 2 years }\end{array}$ & \multicolumn{4}{|c|}{$\begin{array}{c}\text { Impact } \\
\mathbf{2}\end{array}$} \\
\hline Strategy In-Service & & $\mathbf{4} 5$ \\
\hline SIOP Literacy Strategies & District School & $\square$ & & & & \\
\hline
\end{tabular}




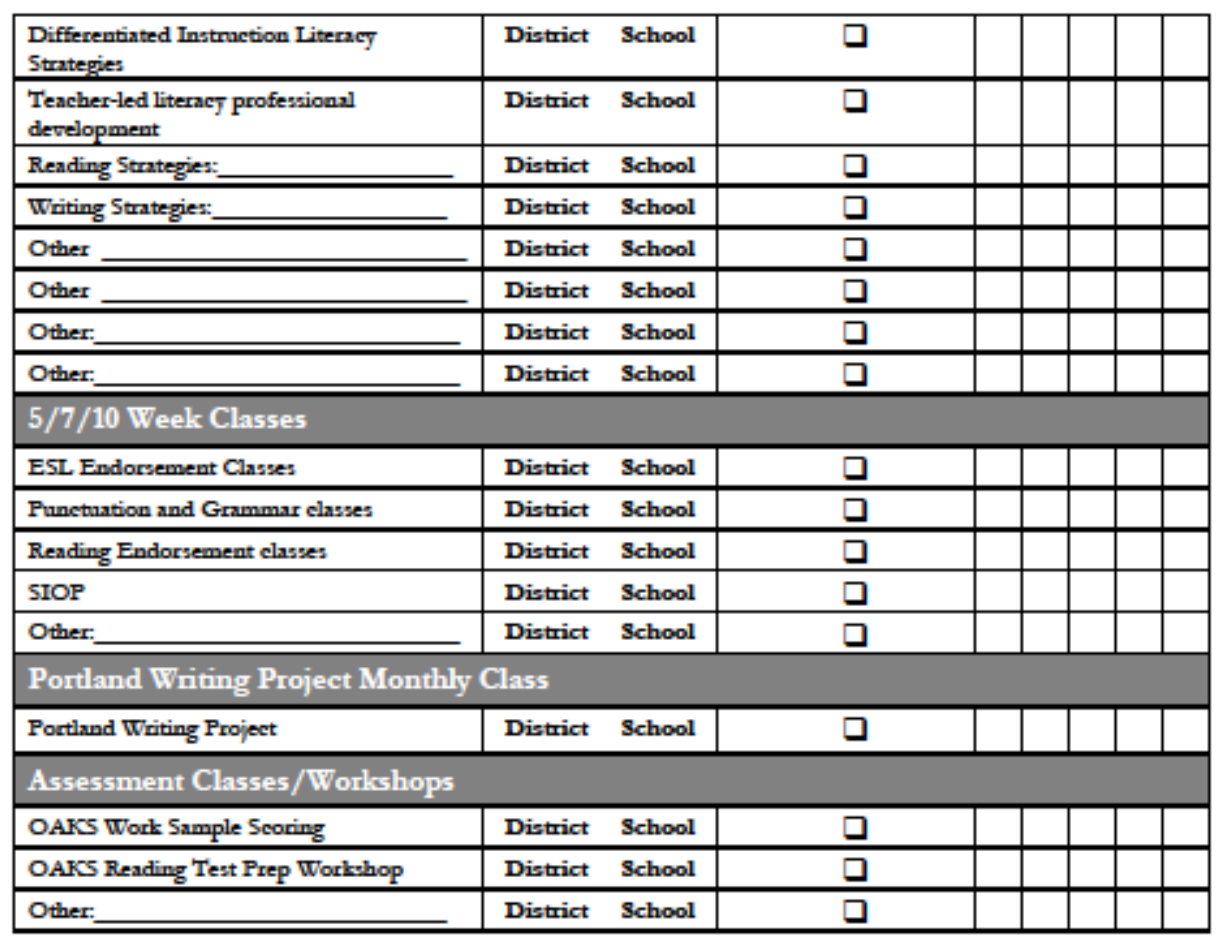

2. Please indicate other courses, seminars, workshops or other professional development you have taken outside the district.

\begin{tabular}{|c|c|c|c|c|c|c|c|}
\hline \multirow[t]{11}{*}{$\begin{array}{c}\text { University Courses/ } \\
\text { Conferences/Workshops } \\
\text { (Write in title or topic) }\end{array}$} & \multirow[t]{2}{*}{$\begin{array}{c}\text { Provider } \\
\text { (Write in name of } \\
\text { organization) } \\
\end{array}$} & $\begin{array}{l}\text { Check if } \\
\text { taken in } \\
\text { last } 2 \text { years }\end{array}$ & \multicolumn{5}{|c|}{$\begin{array}{c}\text { Impact on } \\
\text { student learning }\end{array}$} \\
\hline & & $\square$ & & & & & \\
\hline & & D & & & & & \\
\hline & & $\square$ & & & & & \\
\hline & & D & & & & & \\
\hline & & $\square$ & & & & & \\
\hline & & $\square$ & & & & & \\
\hline & & D & & & & & \\
\hline & & $\square$ & & & & & \\
\hline & & 口 & & & & & \\
\hline & & $\square$ & & & & & \\
\hline
\end{tabular}


3. What professional development had the greatest impact on your students' learning? Why? (Implementation time? Collaboration time? Format?')

4. What professional development had the least impact on your students' learning? (Lack of implementation time? Lack of follow through? Lack of materials? Didn't intersect with your needs?)

5. What current needs do you have for professional development? What would you like to see offered? When would you like it offered - late start, summer institutes, staff meetings, etc.?

6. Other comments: 
Appendix C

Sample Staff Surveys Following PD Activities 


\section{PLC Feedback (Staff Survey)}

Please use your PLC time to complete this form

* Required

Name: *

This is a required question

$\mathrm{PLC} / \mathrm{s}$ in which you participate? *

You may click all that pertain to you

Check all that apply.

- $\Gamma$ CCSS - Math

- $\Gamma$ CCSS - English

- $r$ cCSS - Social Studies

- $\ulcorner$ Proficiency Grading

- $\Gamma$ Art Integration

- $\Gamma$ College Readiness

- $\Gamma$ Brain/Research

- $r$ Dual Credit

- Peer Observation

- $\Gamma$ Frosh Academies

- $\Gamma$ Differentiation

- $\Gamma$ Technology

- C Culturally Relevant Classrooms

- $\Gamma$ Implementing Social Media

This is a required question

How have you contributed to your PLC? *

Please be specific - provide examples.

This is a required question 
What has been most difficult with your PLC? *

Please be specific - provide examples

This is a required question

What has been the most rewarding and/or positive experience? *

Please be specific - provide examples

This is a required question

What resources have you used in your PLC? *

Please be specific - provide examples

This is a required question

What findings, discoveries and/or strategies will you be presenting to the staff? *

This is a required question

What are some preliminary specifics of your presentation? *

examples include: agenda, time needed, materials etc?

This is a required question

As you think of next year, what advice do you have for PLCs? *

This is a required question 
Never submit passwords through Google Forms. 100\%: You made it.

\section{CCSS Math Presentation}

Please answer the following questions:

* Required

I felt that this presentation... *

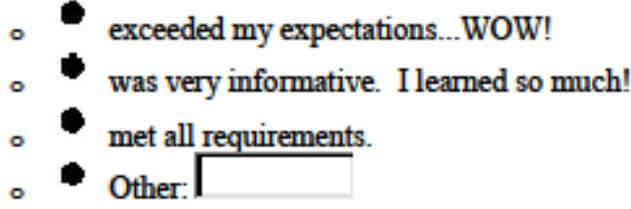

This is a required question

What did you like and/or learn from the presentation? *

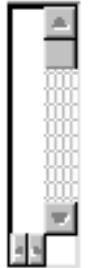

This is a required question

How could you use the information presented in your own classroom? *

슬

$\rightarrow$

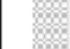

$\nabla$

This is a required question

When reflecting on what was presented, do you have any suggestions for further professional development? (NEXT YEAR) * 


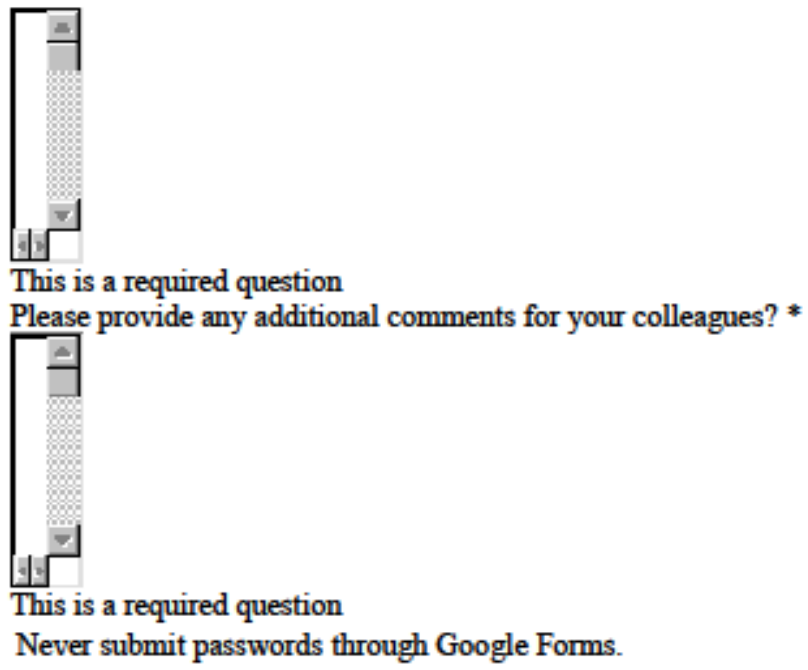

